\title{
Biochemical and structural characterization of spliceosomes purified at defined stages of assembly from the yeast $S$. cerevisiae
}

\author{
Dissertation \\ zur Erlangung des mathematisch-naturwissenschaftlichen Doktorgrades \\ "Doctor rerum naturalium" \\ der Georg-August-Universität zu Göttingen \\ im Promotionsprogramm Biologie \\ der Georg-August-University School of Science (GAUSS)
}

vorgelegt von

Julia Dannenberg

aus Braunschweig

Göttingen, 2013 


\section{Betreuungsausschuss}

Prof. R. Lührmann, Abteilung für Zelluläre Biochemie/MPI-bpc Göttingen

Prof. R. Ficner, Abteilung für Molekulare Strukturbiologie, GZMB Göttingen

\section{Mitglieder der Prüfungsfungskommission}

Referent: Prof. R. Lührmann, Abteilung für Zelluläre Biochemie/MPI-bpc Göttingen

Korreferent: Prof. R. Ficner, Abteilung für Molekulare Strukturbiologie, GZMB

Göttingen

\section{Weitere Mitglieder der Prüfungskommission:}

Prof. J. Enderlein, Abteilung für Biophysik, III. Physikalisches Institut der Universität Göttingen

Prof. H. Stark, Abteilung für Elektronenmikroskopie, MPI-bpc Göttingen

Prof. J. Wienands, Abteilung für Zelluläre und Molekulare Immunologie, Universität Göttingen

Prof. H. Krebber, Abteilung für Molekulare Genetik, Institut für Mikrobiologie und Genetik

Tag der mündlichen Prüfung: 8. April 2013 


\section{Table of content}

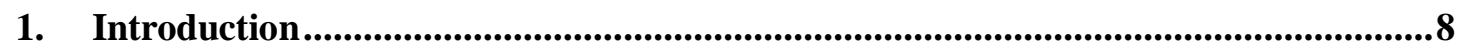

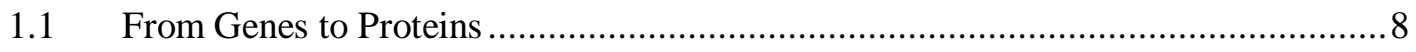

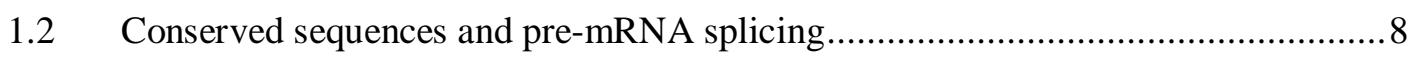

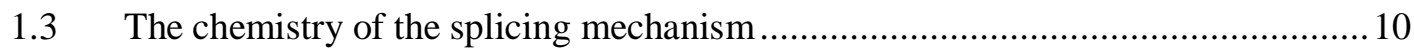

1.4 SnRNPs - the building blocks of the spliceosome ….........................................11

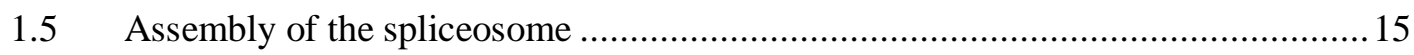

1.6 $\mathrm{DExD} / \mathrm{H}$ box proteins as the driving force for spliceosome remodeling ................17

1.7 Spliceosome associated non-snRNP factors - proteins of the NTC .......................19

1.8 Structural rearrangements of the Spliceosomal RNA-RNA network ......................19

1.9 Approaches for the isolation of native spliceosomal complexes .........................21

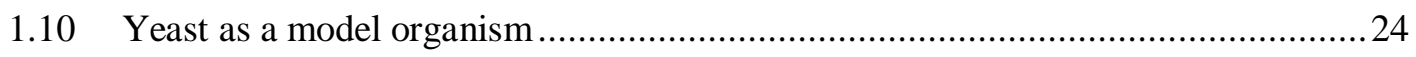

1.11 Investigation and characterization of yeast spliceosomal complexes via mass spectrometry and electron mircroscopy ...........................................................24

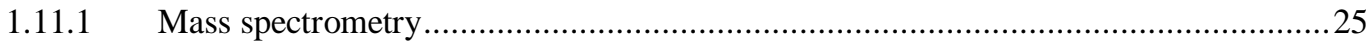

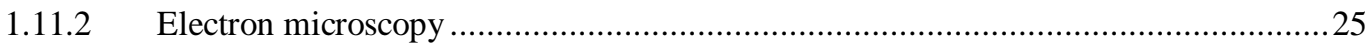

1.12 Dual Color Fluorescence Cross-Correlation Spectroscopy - an excellent technique to study protein dynamics within the spliceosome ...............................................26

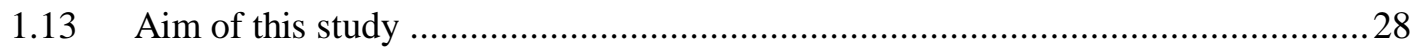

2. Materials and Methods...................................................................................................33

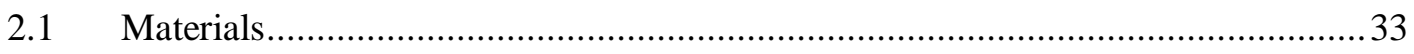

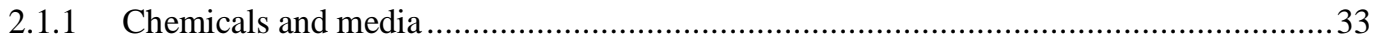

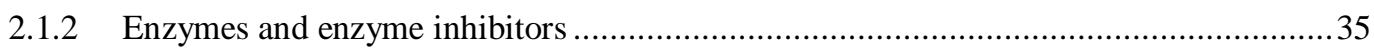

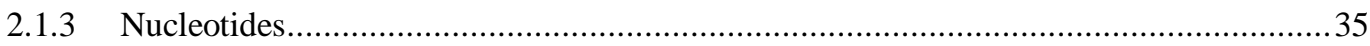

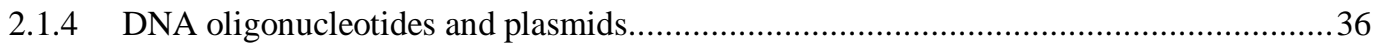

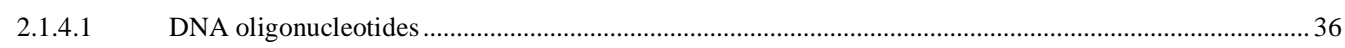

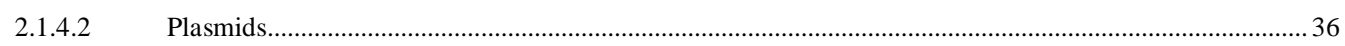

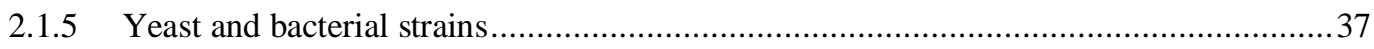

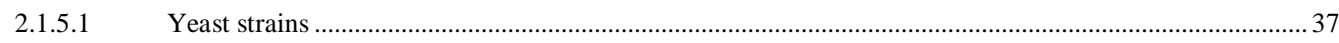

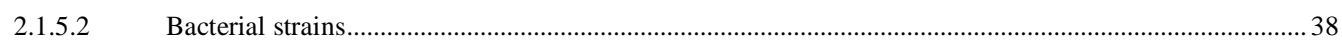




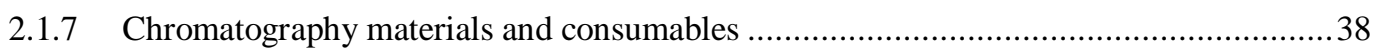

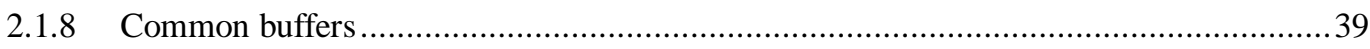

2.1.9 Machines and working equipment ............................................................... 40

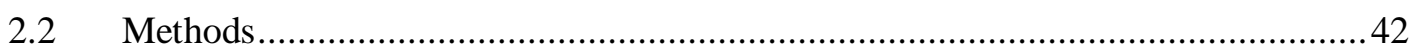

2.2.1 General molecular biology methods ................................................................ 42

2.2.1.1 Concentration determination of nucleic acids............................................................................ 42

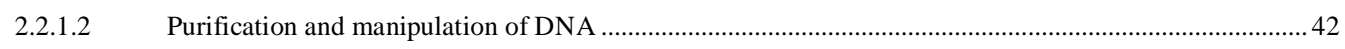

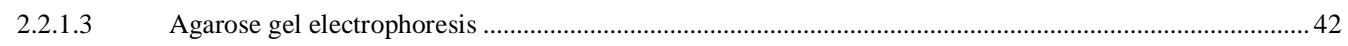

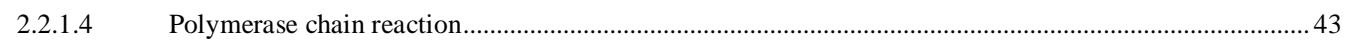

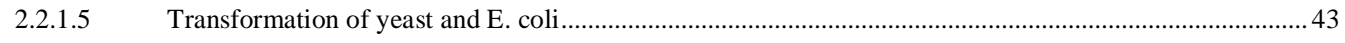

2.2.1.6 Phenol-chloroform-isoamylalcohol (PCI) extraction and ethanol precipitation.......................................... 44

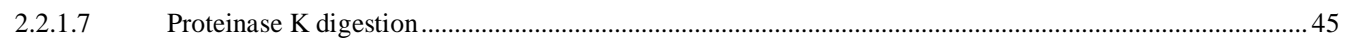

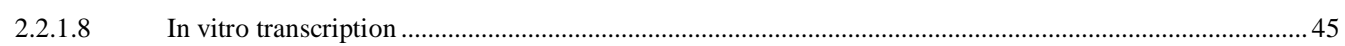

2.2.1.9 Denaturing polyacrylamide gel electrophoresis of RNA (splicing products) ……..................................... 47

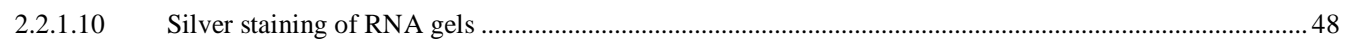

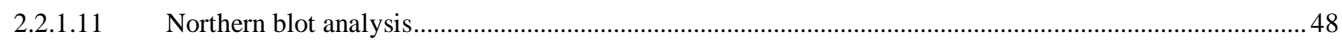

2.2.2 Protein-biochemistry standard methods ...................................................... 49

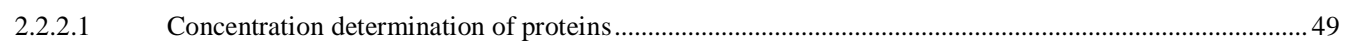

2.2.2.2 Ethanol precipitation of proteins for Mass Spectrometric analysis ........................................................... 49

2.2.2.3 Denaturing Polyacrylamide Gel Electrophoresis (PAGE) ...................................................................... 50

2.2.2.4 Coomassie staining of protein gels …………….......................................................................... 50

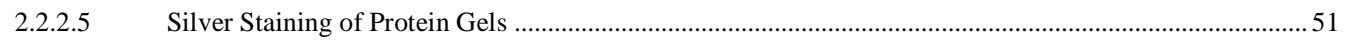

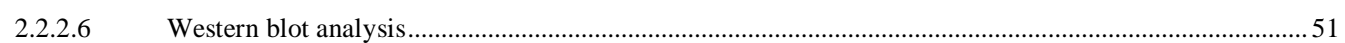

2.2.3 Purification of recombinant proteins............................................................... 52

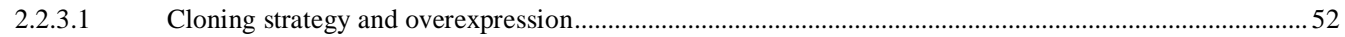

2.2.3.2 Purification of proteins .................................................................................................................. 53

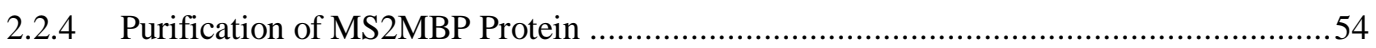

2.2.5 Cell culture and extract preparation ................................................................5

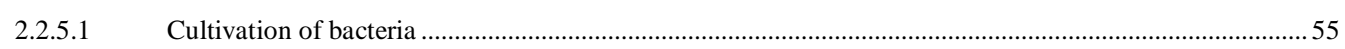

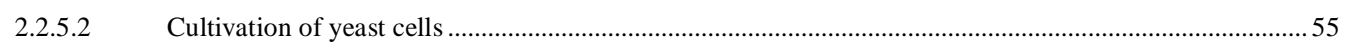

2.2.5.3 Preparation of yeast whole cell extracts and immunodepletion ............................................................... 56

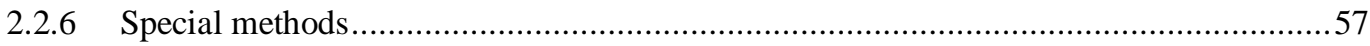

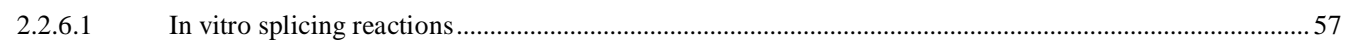


2.2.7 Reconstitution of functional spliceosomes for FCCS

2.2.7.1 Treatment of complexes for RNA PAGE ………….............................................................................. 59

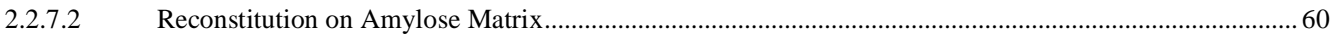

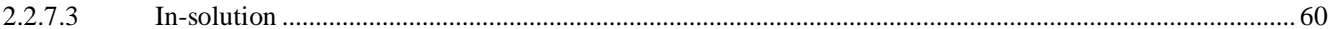

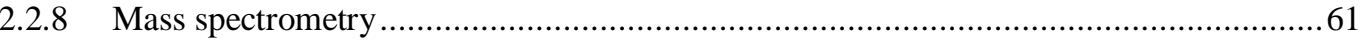

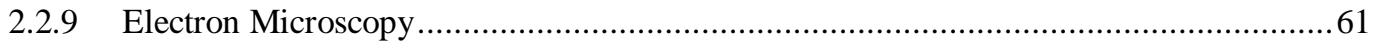

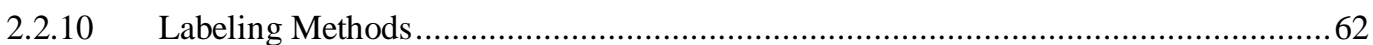

2.2.10.1 Preparation of yeast strains expressing EGFP-tagged proteins …………................................................ 62

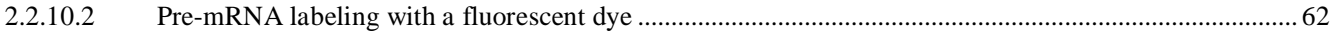

2.2.11 Fluorescence Cross Correlation Spectroscopy (FCCS) .......................................63

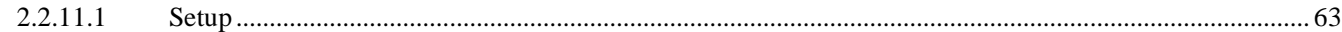

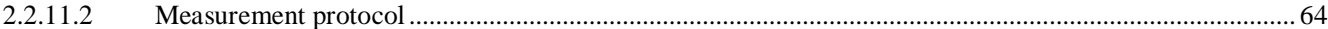

3.1 Pre-mRNA constructs and conditions used for the isolation of yeast spliceosomal complexes.

3.2 Preliminary work for stalling and isolating active spliceosomal complexes from

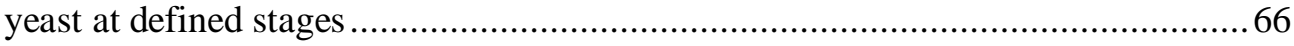

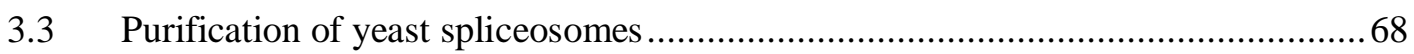

3.3.1 Purification of the pre-catalytic B complex 69

3.3.2 Affinity-purified complex B is functionally committed for subsequent activation and splicing catalysis

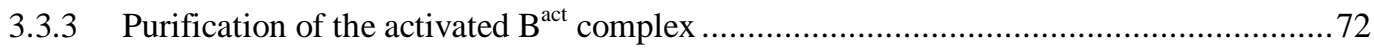

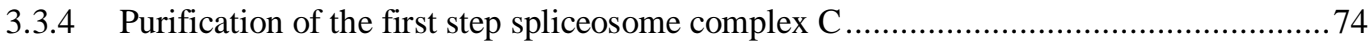

3.4 Protein composition of purified yeast spliceosomes ........................................ 77

3.4.1 The proteome of the pre-catalytic B complex …......................................... 78

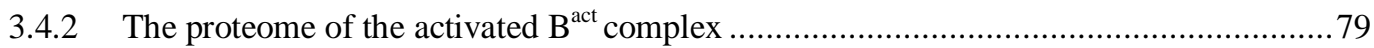

3.4.3 The proteome of the step1 spliceosome $\mathrm{C}$ complex .......................................... 81

Electron microscopy of Yeast spliceosomes .......................................... 85

3.5.1 Electron microscopy of yeast spliceosomal complexes Complex B, $\mathrm{B}^{\text {act }}$ and C...........86 
3.6 Isolation and characterization of early spliceosomal complexes isolated from the

Yeast S. cerevisiae

3.6.1 Inactivation or removal of Prp5 stalls the spliceosome assembly at the stage of the CC complex

3.7 Investigation of the protein rearrangements at the catalytic core of the spliceosome

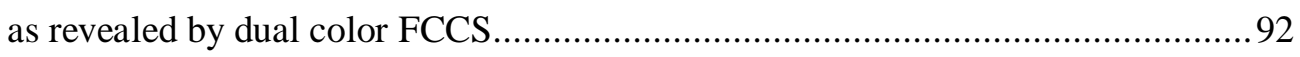

3.8 Generation of doubly labeled spliceosomes for dcFCCS measurements .94

3.8.1 Stability of the binding of EGFP fusion proteins to the $\mathrm{B}^{\text {act } \triangle \mathrm{Prp} 2}$ complex under dcFCCS conditions.

3.8.2 Cwc24 and Cwc27 leave the spliceosome during Prp2-mediated catalytic activation under near-physiological conditions .98

3.8.3 Cwc24 is essential for the first step of splicing in vitro but it is not required for catalysis of the splicing reaction per se

3.8.4 The U2-associated SF3a and SF3b proteins Prp11 and Cus1 remain bound to the B* complex under physiological conditions, but their affinity is weakened at high salt ..... 102

3.8.5 The binding of the RES complex protein Bud13 is weakened during catalytic activation... 103

3.8.6 Binding of Yju2 to the spliceosome is strengthened upon catalytic activation....... 105

3.8.7 Prp2-mediated catalytic activation of the spliceosome creates also a high affinity binding site for $\mathrm{Cwc} 25$ in the spliceosome 106

4. Discussion 110

4.1 The structural dynamics of the spliceosome are modulated by multiple $\mathrm{DExD} / \mathrm{H}$-box RNA helicases, the driving forces of the spliceosome

4.2 The protein composition of yeast spliceosomes is less complex than that of metazoan spliceosomes

4.3 Isolation and characterzation of early spliceosomal complexes from yeast......

4.4 Evolutionary conservation of yeast spliceosomes

4.5 Spliceosomal dynamics during catalytic activation

4.6 Compositional dynamics correlate with structural changes

4.7 Suitability of dual color Fluorescens Cross Correlation Spectroscopy (dcFCCS) for investigating spliceosomal protein dynamics 
4.8 Prp2-mediated transformation of the $\mathrm{B}^{\text {act }}$ into the $\mathrm{B}^{*}$ complex substantially alters the binding affinity of several proteins at the catalytic core of the spliceosome ... 124

4.9 Cwc24 functions in the generation of an active spliceosome but is not required for splicing catalysis per se.

4.10 Sf3a/b proteins remain bound to the $\mathrm{B}^{*}$ spliceosome under near-physiological conditions, but their binding is reduced at high salt.....

4.11 Prp2 action creates high-affinity binding sites for the step 1 factors Yju2 and Cwc25 in the catalytically activated spliceosome

4.12 Substantial Prp2-mediated remodeling during catalytic activation of the spliceosome

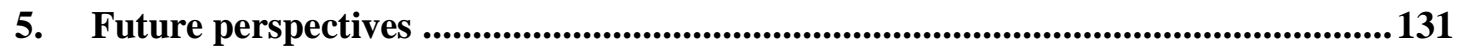

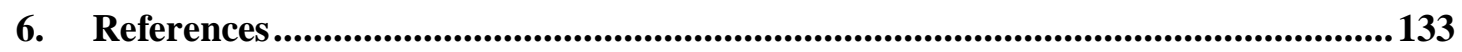

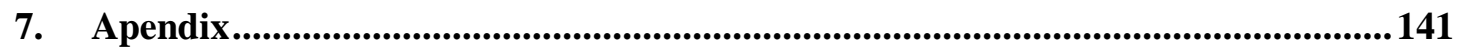

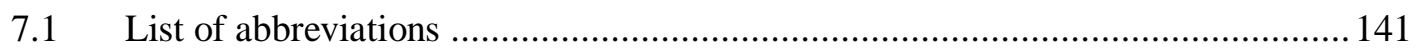

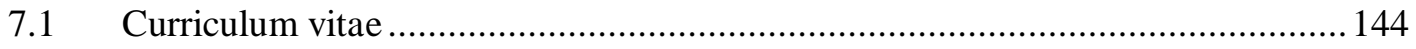

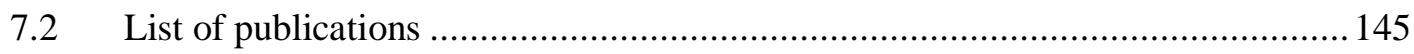

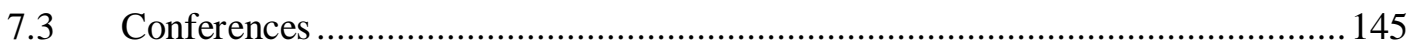

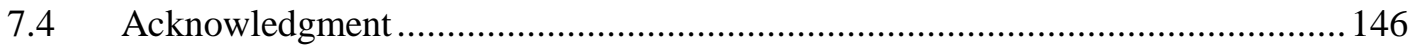

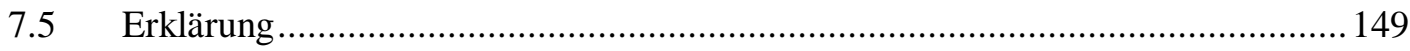




\section{Abstract}

Splicing of pre-messenger RNA (pre-mRNA) is catalyzed by the spliceosome, a multimegadalton ribonucleoprotein (RNP) comprising several small nuclear (sn) RNPs and numerous proteins. The spliceosome assembles on its pre-mRNA substrate in an ordered process that begins with recognition of the 5' end of the intron (5' splice site, 5'SS) by the U1 snRNP. Thereafter the U2 snRNP binds to the pre-mRNA's branch point sequence (BPS), forming complex A. Complex A then binds the preformed U4/U6.U5 tri-snRNP to form complex B, which contains a full set of snRNAs in a pre-catalytic state. Complex $\mathrm{B}$ is then activated for catalysis by a major rearrangement of its RNA network and its overall structure; this remodeling includes dissociation of the U1 and U4 snRNAs and the formation of the activated spliceosome $\mathrm{B}^{\text {act }}$. In the catalytically activated complex (termed $\mathrm{B}^{*}$ ) step 1 catalysis takes place: the adenosine at the BPS attacks the 5'SS, generating a cleaved 5' exon and intron-3' exon intermediate. The resulting complex $\mathrm{C}$ then catalyzes step 2 catalysis, in which the intron is cleaved at the 3 ' splice site (3'SS) with concomitant ligation of the 5 ' and 3' exons to form mature mRNA. Thus, the spliceosome is a particularly dynamic RNP machine that undergoes many changes in composition and conformation. The structural dynamics of the spliceosome are facilitated by the action of multiple DExD/H-box RNA helicases. Among these are Prp5 and Prp2, which are essential ATPase required prior to the first step of pre-mRNA splicing. Prp5 enables stable U2 snRNP association with the branch site and Prp2 promotes a structural rearrangement that transforms the $\mathrm{B}^{\text {act }}$ into the catalytically activated $\mathrm{B}^{*}$ complex.

The pathway of spliceosome assembly and the main features of its catalytic chemistry appear to be conserved between metazoans and yeast. Thus, I set out to study isolated spliceosomal complexes from the lower eukaryote Saccharomyces cerevisiae as it was already known to possess a basic (constitutive) spliceosomal machinery similar to that of primates. Each new round of splicing generates a catalytic centre de novo during the transitions from complex $\mathrm{B}$ to $\mathrm{B}^{\text {act }}$ to $\mathrm{B}^{*}$ and to the product of step 1 of splicing, complex C. Here, I focused on the isolation and characterization of complex $\mathrm{B}$, the activated complex $\mathrm{B}^{\text {act }}$ and complex $\mathrm{C}$. Each complex was stalled via truncation or modification of the actin pre-mRNA used during the splicing reaction or adjustment of the ATP concentration in the splicing reaction. Each complex was then 
isolated by centrifugation and affinity-selection, their proteomes determined by mass spectrometry (in collaboration with Prof. Henning Urlaub) and their structures examined by electron microscopy (in collaboration with Dr. Berthold Kastner and Prof. Holger Stark), for the first time. The analysis of the three stalled yeast spliceosomal "snapshots" isolated here has made it possible to pinpoint the window of function for important spliceosomal proteins. For instance, the number, characteristics and time of recruitment of evolutionarily conserved proteins involved in the formation and stabilization of the U2/U6/pre-mRNA network of the catalytic center in complex $\mathrm{B}^{\text {act }}$ remained so far elusive. The data revealed several evolutionarily conserved proteins recruited at the time of pre-catalytic activation (i.e. Cwc2, Cwc24, Yju2, Prp2 and Spp2) and also provided important hints for those proteins involved in promoting step 1 catalysis and the formation of complex C (i.e. Cwc25). Compared to metazoan spliceosomes the number of proteins associated with purified yeast spliceosomes at any stage is less than a half, yet more than $85 \%$ of these have evolutionarily conserved counterpart in humans. The less complex protein composition of yeast spliceosomes offers also a significant advantage for three-dimensional (3D) structure analyses. The EM analyses show for the first time images of S. cerevisiae spliceosomal complexes at well defined stages of function. These are at an unprecedented quality level, and they are well suited for 3D structure investigations, based on criteria such as their structural integrity and homogeneity.

In this work I have also applied dual-color fluorescence cross-correlation spectroscopy (dcFCCS, in collaboration with Prof. Jörg Enderlein, III. Institute of Physics, University of Göttingen), to measure the binding affinity of splicing factors which were detected in the first part of this work - to the yeast spliceosome and to follow their binding dynamics during the catalytic activation of the spliceosome promoted by the RNA helicase/ATPase Prp2 and its co-activator Spp2. dcFCCS is a sensitive and versatile optical technique that allows the direct analysis of the dynamic association and dissociation events among proteins and/or RNAs in complex systems in solution at low nanomolar concentrations and in equilibrium, without requiring biochemical or physical perturbation of the sample. For this purpose I have employed a recently described purified splicing system developed in our laboratory which recapitulate catalytic activation and step 1 of splicing in vitro and consists of $\mathrm{B}^{\text {act }}$ 
complexes assembled in extracts where Prp2 is thermo sensitive and can be heatinactivated. These $\mathrm{B}^{\text {act }}$ complexes lacking Prp2 are then purified to near homogeneity and complemented with recombinantly expressed Prp2 and Spp2 splicing factors. To perform dcFCCS, the $\mathrm{B}^{\text {act }}$ complexes were assembled on pre-mRNA labeled with a red fluorescent dye. In addition, spliceosomal proteins of interest were labeled in vivo by fusing them with the green fluorescent protein EGFP, by genetic modification in yeast. The purified doubly-labelled spliceosomes were then analyzed before and after catalytic activation by Prp2 and the weakening or strengthening of the binding of the EGFP-labeled protein to the spliceosome was analyzed by measuring the crosscorrelation between the green label and the red fluorescent dye. The analysis and evaluation of the dcFCCS data in this work was done in collaboration with Prof. Jörg Enderlein and Mira Prior (III. Institute of Physics, University of Göttingen).

The data revealed that the binding affinity of quite a number of proteins is significantly changed during the Prp2-mediated catalytic activation of the spliceosome. Specifically, the essential zinc finger protein Cwc24, was quantitatively displaced from the $\mathrm{B}^{*}$ complex. Consistent with this, we show that $\mathrm{Cwc} 24$ is required for step 1 but not for catalysis per se. Interestingly, the U2-associated SF3a and SF3b proteins Prp11 and Cus1 were destabilized during catalytic activation. Indeed, they remained bound to the $\mathrm{B}^{*}$ spliceosome under near-physiological conditions (i.e. 75 $\mathrm{mM}$ ), but their binding was reduced at higher salt. As the U2 SF3a/b proteins bind near the branch point sequence, this indicated that the branch site must be remodeled in complex $\mathrm{B}^{*}$ as a prerequisite for step 1 catalysis. On the other hand, high affinity binding sites were created for the step 1 factors Yju2 and Cwc25 during catalytic activation, consistent with their requirement for step 1 catalysis. In conclusion, These results shed light on the nature of the structural remodeling mediated by Prp2 in the spliceosome and suggest that during catalytic activation the spliceosome undergoes significant rearrangements. 
Introduction 


\section{Introduction}

\subsection{From genes to proteins}

The blueprint of cells is encoded in their DNA. The flow of information from genes to proteins requires two main steps, termed transcription and translation. Transcription is a DNA-controlled process where DNA is "transcribed" into RNA; translation is the RNA-controlled synthesis of proteins. In eukaryotic cells, genes are expressed as precursor messenger RNAs (pre-mRNAs) due to the fact that in higher eukaryotes the coding sequences of genes, the exons are interrupted by non-coding sequences, the introns. These mosaic structure or split genes, is only found in eukaryotes. First, the precursor is synthesized/transcribed by the polymerase II. After transcription and before the transport out of the nucleus into the cytoplasm, the precursor RNA has to undergo a maturation process or so-called RNA processing step. Due to the split gene character, the non-coding sequences have to be removed from the precursor messenger RNA by a mechanism called splicing. During this process, introns are removed from the precursor and the flanking sequences, the exons, are joined to build the functional mature RNA. RNA processing includes in addition to splicing, the modification of both ends of the pre-mRNA: capping of the 5' end and polyadenylation of the 3 ' end. Both modifications play an important role in mRNA export, stability and translation and occur co-transcriptionally. After RNA processing the mature RNA can be transported from the nucleus to the cytoplasm, where it is used by ribosomes as a template for the synthesis of the amino-acid sequence, leading to the formation of a protein.

\subsection{Conserved sequences and pre-mRNA splicing}

Splicing itself is catalyzed by a macromolecular machinery, the spliceosome and requires a set of specific sequences contained within the intron. The boundaries of exons and introns must be precisely identified by the spliceosome, because an error of only one nucleotide would result in a shift of the gene's reading frame and would lead to the translation of a non-functional protein. 
The process of pre-mRNA splicing is highly conserved from yeast to humans; however the degree to which it occurs is clearly different (Ast, 2004). Whereas nearly all human genes contain introns, the yeast Saccharomyces (S.) cerevisiae has introns in only $\sim 3-4 \%$ of its genes (Lopez and Seraphin 1999). Interestingly, about $70 \%$ of genes encoding for ribosomal proteins contains an intron. Introns vary in their length and sequences and exon-intron boundaries are only defined by very short sequence stretches, which makes the process of splicing challenging, but both organisms, humans and yeast are suitable models for in vitro studies and for understanding the highly conserved splicing process. In pre-mRNA transcripts three conserved sequences our found which are recognized by different factors during the splicing process. The sequences are the 5' splice site (5'SS), the branch point sequence (BPS) and the 3'splice site (3'SS).

In the yeast (S. cerevisiae) these elements are highly conserved (Fig. 1.1).

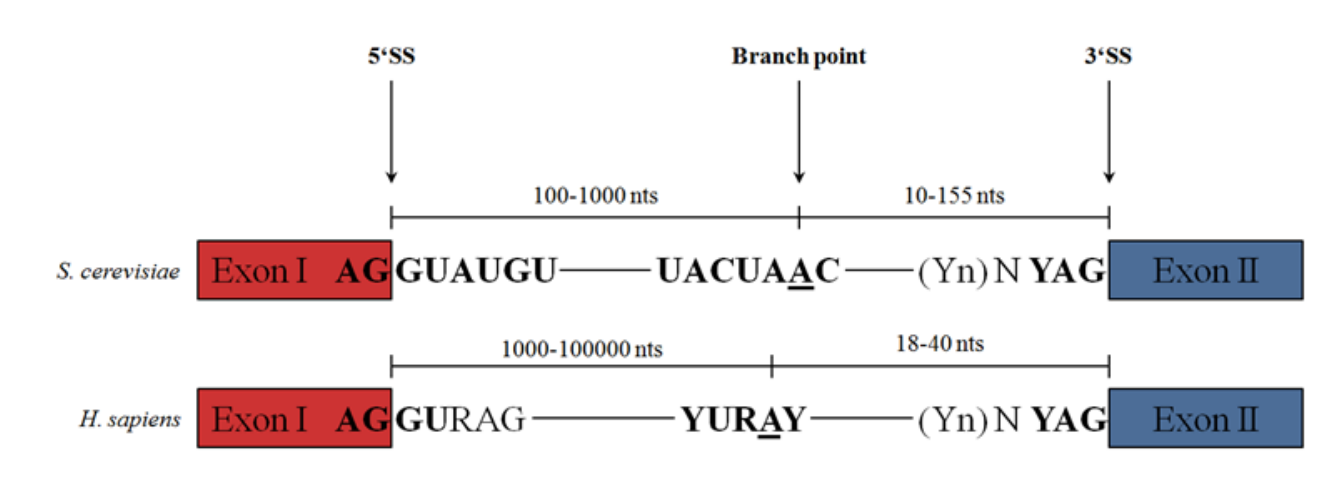

Figure 1.1: Conserved sequences in intron of S.cerevisiae and Homo sapiens

(kindly provided by Dr. Nicolas Rasche)

The (5'SS) sequence defines the boundary between an exon and a downstream intron and is composed of R/GUAUGU (' $R$ ' is a purine, '/' indicates the exon/intron boundary)(Lopez and Seraphin 1999). While in S. cerevisiae the 5'SS is $90 \%$ conserved, the human consensus sequence AG/GUAGU is rather degenerated.

The (3'SS) sequence defines the boundary between an intron and a downstream exon and is composed of YAG/ (' $\mathrm{Y}$ ' is a pyrimidine, '/' indicates the exon/intron boundary) in $S$. cerevisiae as well as in $H$. sapiens. In many introns the 3 'SS is preceded by a stretch of $8-12$ pyrimidines called the polypyrimidine tract, which 
usually ends one nucleotide upstream of the $3^{\prime} \mathrm{SS}$. The polypyrimidine tract seems to be more important for splicing of human than for splicing of yeast introns.

Another conserved sequence element surrounds the adenosine (branch adenosine, branch point, BP), - which forms a branched intermediate in the course of the first step of splicing. This sequence is therefore called branch point sequence (BPS). The consensus sequence is composed of UACUA스 and in yeast it is usually located 1060 nucleotides upstream of the 3'SS (Spingola, Grate et al. 1999).

\subsection{The chemistry of the splicing mechanism}

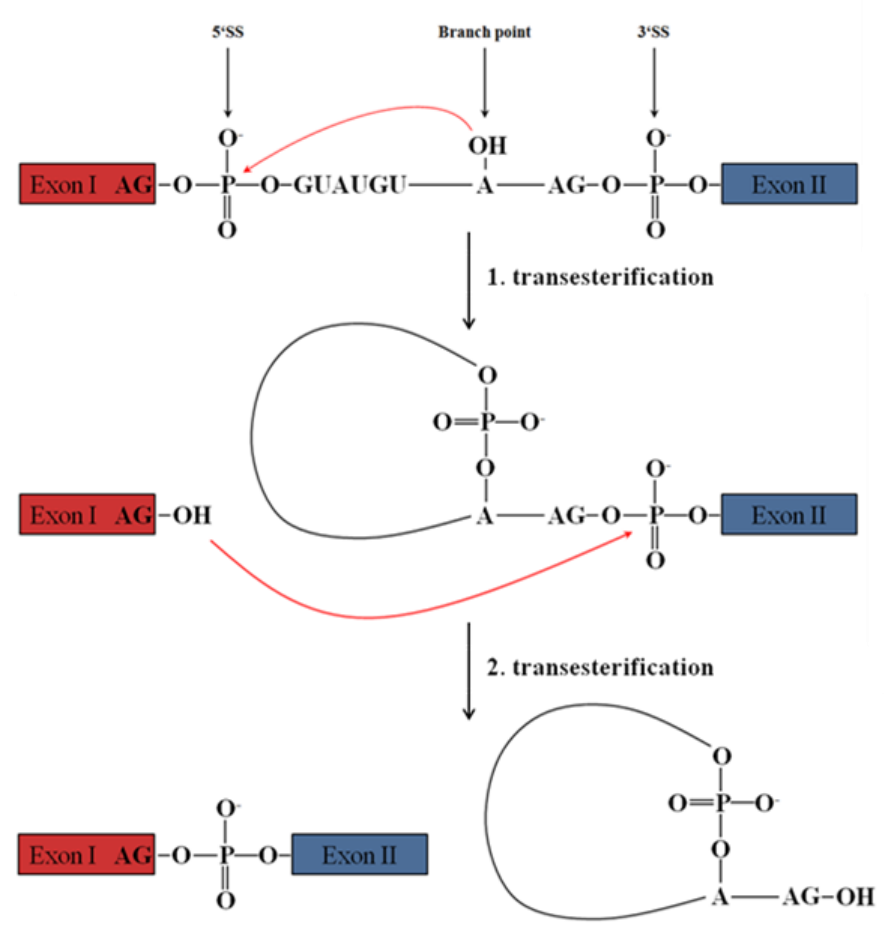

Figure 1.2: The chemistry of the pre-mRNA splicing reactions (Figure was kindly provided by Dr. Nicolas Rasche) Pre-mRNA splicing is carried out via a two transesterification step mechanism. Step 1 results in formation of a free 5' exon and a lariat-3' exon (lariat intermediate). Step 2 produces the ligated exons and an intron lariat structure. Nucleophilic attack by the reactive groups is shown as dashed lines in red. 
The process of pre-mRNA splicing consists of a two steps mechanism involving two consecutive transesterification reactions (Moore, Query et al. 1993; Moore and Sharp 1993). In the first step, the 2'-hydroxyl group $(\mathrm{OH})$ of the conserved branch point adenosine as a nucleophile attacks the phosphate at the 5'SS (5'exon/intron junction) resulting in a free 5' exon which contains a 3 ' terminal $\mathrm{OH}$ group and a branched lariat intermediate which contains an unusual 2'-5' phosphodieseter bond at the branchpoint adenosine (Fig. 1.2). In the second step, the 3' $\mathrm{OH}$ of the 5' exon attacks the phosphate at the intron/3' exon boundary (3'SS) followed by the ligation of the 5 ' and 3' exons and the release of the intron lariat. Subsequently, the mRNA is transported to the cytoplasm, whereas the intron lariat is degraded (Nilsen 1998); (Will and Luhrmann 2011). The splicing process is dependent on ATP.

\subsection{SnRNPs - the building blocks of the spliceosome}

The snRNPs are the main building blocks of the spliceosome. Each of these consists of a snRNA molecule (or two in the case of U4/U6), seven Sm proteins (B/B', D3, D2, D1, E, F, and G) that are shared by all of the spliceosomal snRNPs and several other, particle specific proteins (Brow 2002); (Will and Luhrmann 2011); (Wahl, Will et al. (2009); (Valadkhan and Jaladat (2011). More than 50 proteins are associated with the snRNPs and more than 100 non-snRNP proteins are in the spliceosome as revealed by mass spectrometry studies (Wahl, Will et al. 2009). In total five spliceosomal snRNAs are found in the yeast S.cerevisiae termed U1, U2, U4, U5 and U6. U5 exist in two isoforms: U5 long and U5 short, which originate from the same precursor transcript, but are differently cleaved at the 3'-stem loop by RNaseIII (Chanfreau, Elela et al. (1997). 
Introduction

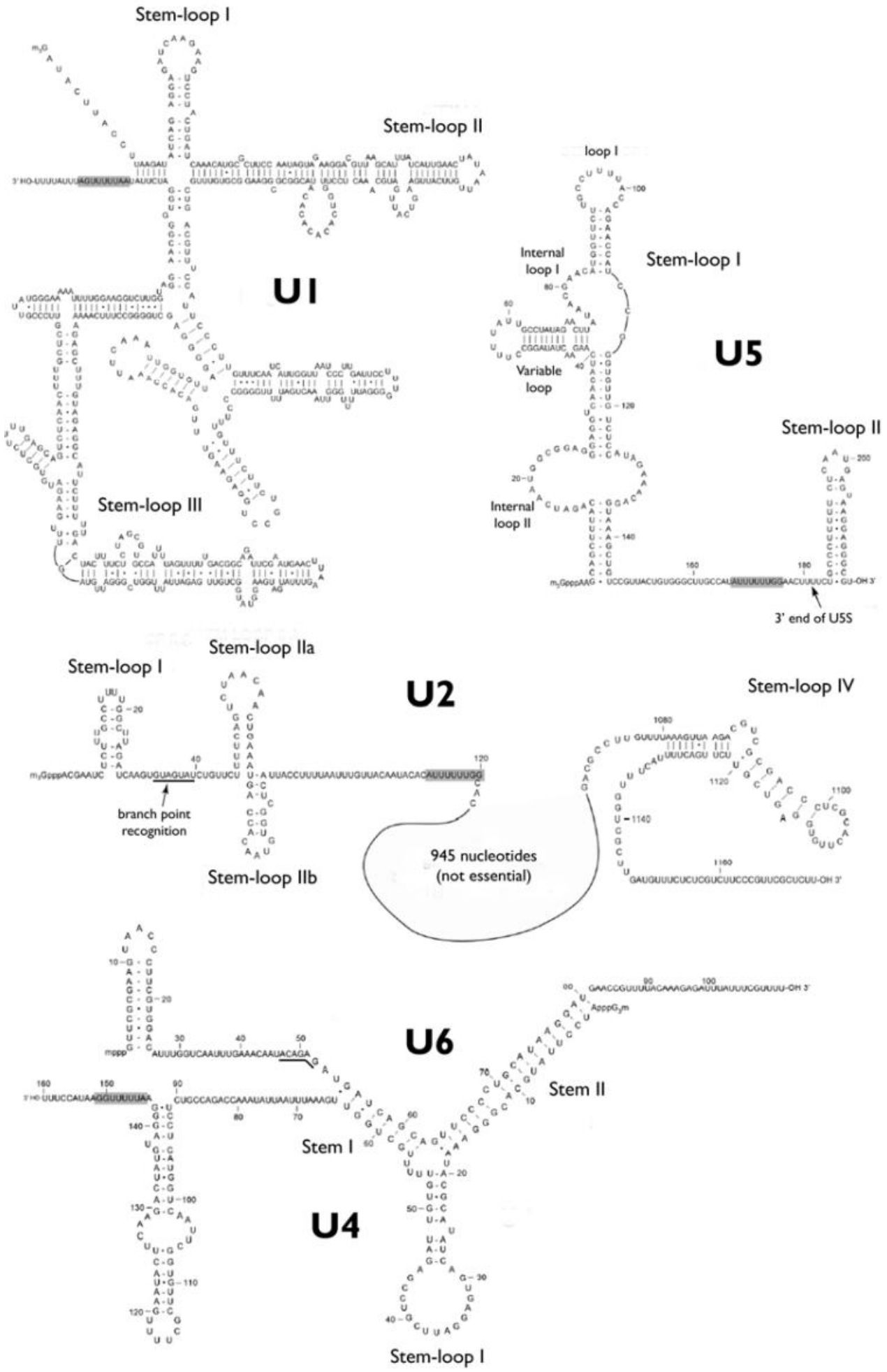

Figure 1.3: Secondary structures for the yeast U snRNAs

Schematic representation of proposed secondary structures of yeast snRNAs. The Sm binding site is indicated with a grey shadow. The conserved ACAGAGA box motif in U6 snRNA is underlined (adapted from Kretzner, Krol et al. (1990)(U1); (Shuster and Guthrie 1988)(U2); Frank, Roiha et al. (1994); (Will and Lührmann 2006)(U5); (Brow and Guthrie 1988)(U6, U4/U6)). 
The U snRNAs, except U6, are transcribed by the RNA polymerase II as snRNA precursors that acquire an $\mathrm{m}^{7} \mathrm{G}$ cap. U6 snRNA is transcribed by the polymerase III and bears a $\gamma$-monomethyl phosphate cap at its 5'-end (Singh and Reddy 1989). These pre-U snRNAs are subsequently exported to the cytoplasm where the snRNP assembly occurs (Kiss and Jady 2004);(Will and Lührmann 2001). In the cytoplasm, the seven Sm proteins bind to the Sm RNA site, a uridine rich consensus sequence, found in each of the snRNAs, except U6, and form a doughnut-shaped structure around the Sm binding site. In contrast, U6 bears a so-called Sm-like binding site (Lsm) at its 3' end, which also shows a high uridine content. To the Lsm site of U6, seven proteins, Lsm 2-8, are recruited during U6 snRNP biogenesis. These proteins are homologous to the Sm proteins. This binding process of Sm proteins with the snRNAs is an important step for later hypermethylation of the cap structure. In yeast this hypermethylation is catalyzed by a RNA-methyltransferase termed Tsg1, which is recruited by binding at the Sm site (Mouaikel, Verheggen et al. 2002). After assembly in the cytoplasm, the particle is transported back to the nucleus for assembly of the spliceosome.

As already mentioned above and illustrated in Fig. 1.4, each yeast U snRNP contains, beside the described seven Sm (Lsm) proteins, its particle-specific set of proteins. Both, common and particle specific proteins are evolutionarily conserved between organisms, outlining the importance of the protein composition for the mechanism of pre-mRNA splicing. If one compares for example the yeast U1 snRNP with the human U1 snRNP, one recognizes immediately that the yeast particle is more complex than the human one. While the human U1 snRNP is only composed of the Sm proteins and three snRNP specific proteins, U1A, 70K and U1C, the yeast U1 snRNP has ten specific proteins (Gottschalk, Tang et al. (1998); (Neubauer, Gottschalk et al. 1997). Three of these proteins are homologues of the human U1 proteins. Mud1 is the homologue of the human U1A protein, Snp1p of the human $70 \mathrm{~K}$ and Yhc1 of the human U1C protein. The function of the specific U1 proteins is to stabilize the binding of U1 snRNA to the 5'SS (Gottschalk, Tang et al. 1998); (Rosbash and Séraphin 1991). The U2 snRNP in yeast consists of twelve snRNP specific proteins; eleven of which are homologues to the human U2 snRNP proteins. The U2 associated proteins are Lea1 (homologue of U2A'), Ms11 (homologue of U2B' '), as well as the factors of the SF3a and SF3b complex: Prp9, Prp11 and Prp21 
(homologues of the human proteins of the SF3a complex: SF3a120, SF3a66, SF3a60), Cus1, Hsh49, Hsh155, Rse1 Rds3 and YSF3 (homologues of the human SF3b proteins) (Brow 2002); (Caspary and Séraphin 1998); (Wang and Rymond 2003). The snRNAs of the U4/U6 di-snRNP are base-paired with each other and in addition to the Sm and Lsm proteins, have five particle specific proteins, Snu13 (homologue of 15.5K), Prp3 (homologue of 90K), Prp4 (homologue of 60K), Prp31 (homologue of 61K) and Prp6 (homologue of 102K). In the human system, 102K/yeast Prp6 is associated with the U5 snRNA (Abovich, Legrain et al. 1990). The U5 particle contains six particle-specific proteins, Prp8 (homologue of 220K), Brr2 (homologue of 200K), Snu114 (homologue of 116K), Prp28 (homologue of 100K), Snu40 (has no homologue in human) and Dib1 (Stevens, Barta et al. 2001). Most of the yeast U5 proteins have highly conserved human homologues (Bach, Winkelmann et al. 1989; Bach and Lührmann 1991). The U5 specific protein Snu114 shows similarity to GTPases (Fabrizio, Laggerbauer et al. 1997), while Brr2 and Prp28 belongs to the family of the DExD/H-box proteins and are important driving forces during the splicing cycle (see chapter 1.6). The pre-assembled U4/U6.U5 tri-snRNP has, beside the particle specific proteins of U4, U5 and U6 also factors which only associates with the tri-snRNP, Snu66, Prp38, Snu23 and Spp381 (Gottschalk, Neubauer et al. 1999; Stevens, Barta et al. 2001). 


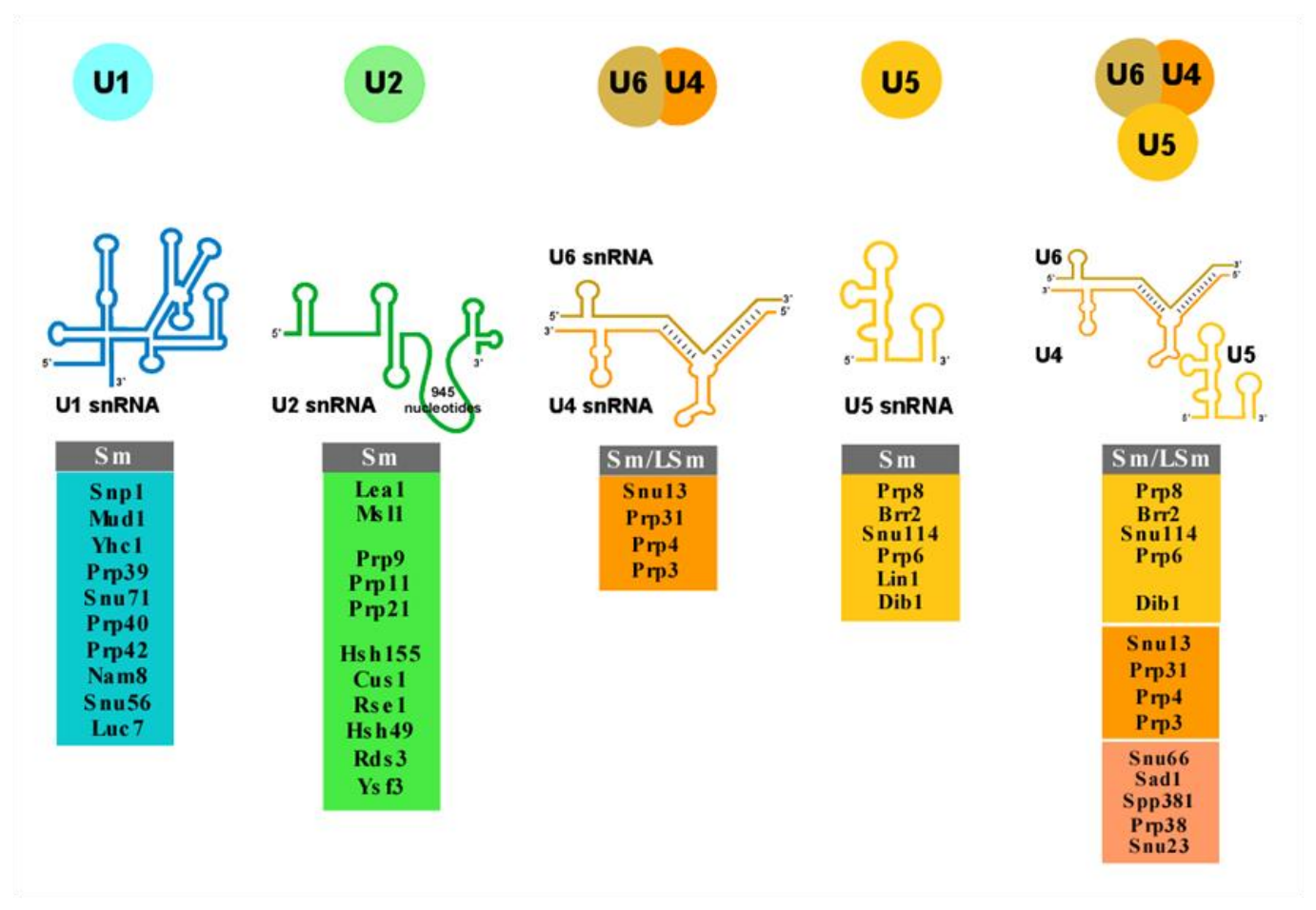

Figure 1.4: Composition of the yeast $U$ snRNPs. Each $U$ snRNP consist of a RNA molecule and the common Sm- or Sm.like proteins (Lsm) and several particle specific proteins. The common Sm proteins are grey boxed, the particle specific proteins are in the same color as the $\mathrm{U}$ snRNA of the particle which is shown above (scheme was kindly provided by Dr. Patrizia Fabrizio).

\subsection{Assembly of the spliceosome}

The assembly of the spliceosome in the course of the pre-mRNA splicing process occurs in a stepwise manner. The spliceosome is a highly dynamic protein-rich molecular machinery and is composed of the previously described five snRNPs. In vitro studies in humans and yeast showed that the spliceosome consists of several different complexes which are formed stepwise one after another termed as E, A, B, $\mathrm{B}^{\text {act }}, \mathrm{C}$ complex and postspliceosome (in this work yeast complexes are named after human spliceosomes). The assembly starts with the recognition of the 5'SS by U1 snRNP (see Figure 1.3) and the ATP-independent binding of U1 snRNA to the 5'SS in the early phase of spliceosome assembly leading to the early E complex (yeast Commitment complex; CC). After formation of the early complex, the BPS is recognized by the $\mathrm{U} 2$ snRNP, forming the spliceosomal A complex or prespliceosome in an ATP dependent manner (Das, Zhou et al. 2000). 


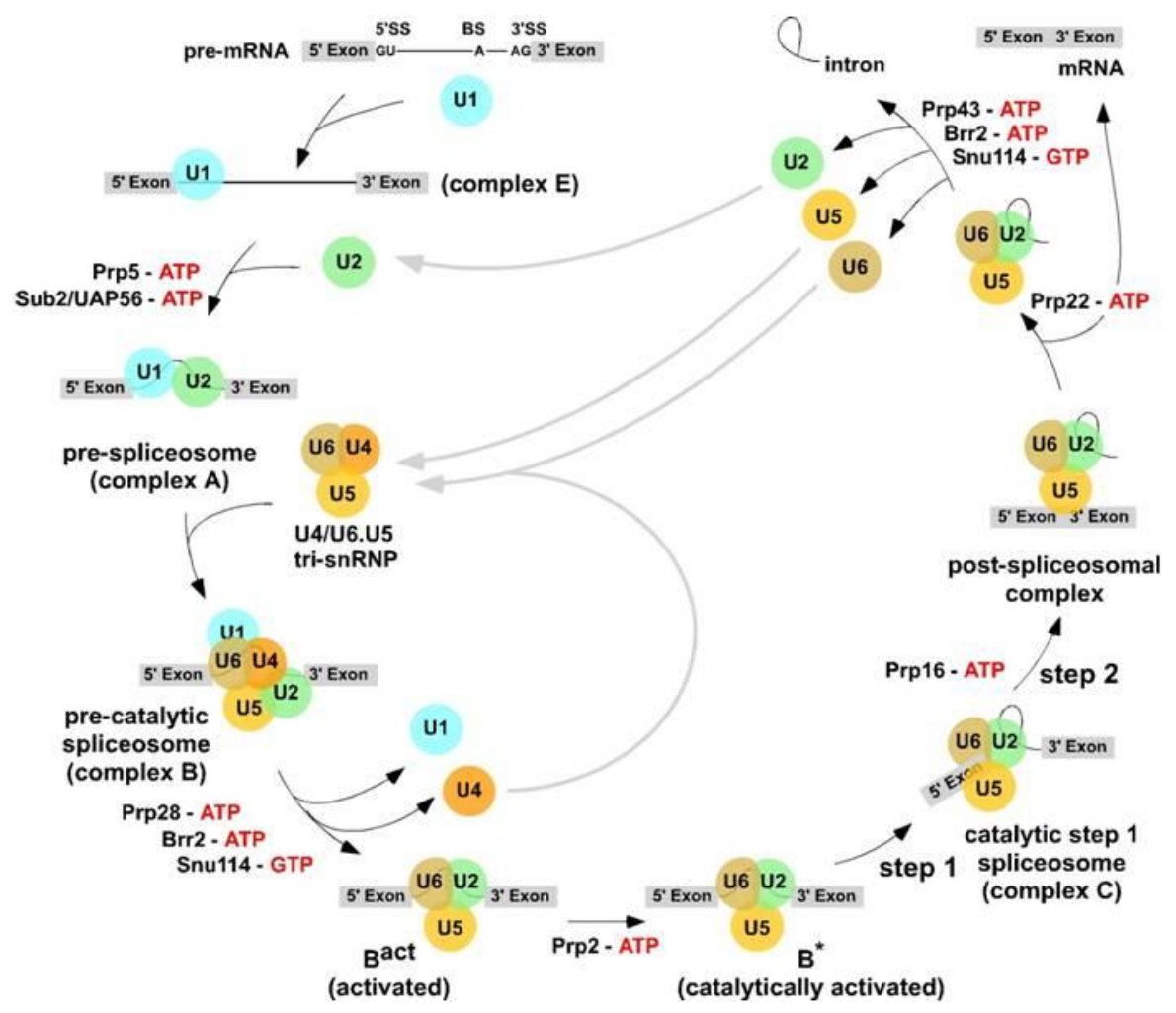

Figure 1.5: The assembly cycle of the spliceosome. The stepwise assembly of the spliceosome is initiated by the binding of U1 to the 5'SS in an ATP-independent manner, forming the early spliceosome or commitment complex. This early step is followed by the stable interaction of the U2 snRNP with the branch site generating the A-complex. After recruitment of the pre-formed trisnRNP U4/U6.U5 to the A-complex, complex B ist formed. The U1 and U4 snRNPs are released from the spliceosome and dramatic rearrangements of the RNA network lead to the activated $\mathrm{B}^{\text {act }}$ complex. After catalytic activation, step 1 occurs, forming the $\mathrm{C}$ complex. After step 2, the spliceosome disassembles and the mature RNA is released (Figure was kindly provided by Dr. Patrizia Fabrizio)

In this step the conserved sequence of U2 snRNA G $\psi$ AGUA ( $\psi$ is pseudouridine) allows the branch point adenosine to bulge out of the helix, which is essential for the first step of splicing (Query, Moore et al. 1994). The pre-catalytic spliceosomal Bcomplex is formed upon recruitment of the pre-assembled tri-snRNP U4/U6.U5 to the spliceosomal A-complex. Even if the spliceosome contains now a full set of $U$ snRNPs, it is still catalytically inactive. For the activation of the spliceosome a major rearrangement of the RNA network is required, including the release of the U1 snRNP and the U4 snRNP from the spliceosome. This step leads to the formation of 
the activated $\mathrm{B}$ complex, termed $\mathrm{B}^{\text {act }}$. At this stage, $\mathrm{U} 1$ is replaced by $\mathrm{U} 6$ at the 5'SS and U6 snRNA contacts also the U2 snRNA forming the catalytic centre, which is not catalytically active yet. The $\mathrm{B}^{\text {act }}$ complex is then catalytically activated to generate the $\mathrm{B}^{*}$ complex, which catalyzes the first step of splicing and thus generates the spliceosomal C complex. Prior to catalysis of the second step of splicing, the network undergoes another rearrangement (Konarska, Vilardell et al. 2006). In the second step, the lariat-3'exon intermediate is cleaved at the 3'SS and the 5'- and 3'-exon are ligated. The mature RNA is released from the spliceosome and the spliceosome dissociates, the intron is degraded and the U snRNPs are recycled for another round of splicing.

\section{6 $\mathrm{DExD} / \mathrm{H}$ box proteins as the driving force for spliceosome remodeling}

The dynamic interactions of the RNA network during spliceosome assembly described above require driving forces at distinct stages. Therefore, members of the protein family of DExD/H-box RNA dependent ATPases play an important role in the splicing mechanism. This group of enzymes plays a major role at the stage of disrupting RNA-RNA, RNA-protein and protein-protein interactions during rearrangement (Wahl, Will et al. 2009); (Staley and Guthrie 1998); (Valadkhan and Jaladat 2011), 2010); (Cordin, Hahn et al. 2012). At least eight of these proteins are conserved between human and yeast and function at various steps during the spliceosomal cycle (see table 1.1) 


\begin{tabular}{|c|c|c|}
\hline DExD/H-box ATPase & Human homologue & Stage in splicing cycle \\
\hline Sub2 & UAP56 & Pre-spliceosome \\
\hline Prp5 & hPrp5 & Pre-spliceosome \\
\hline Prp28 & U5-100 kD & Early activation \\
\hline Brr2 & U5-200 kD & Early activation \\
\hline Prp2 & hPrp2 & Late step-1 activation \\
\hline Prp16 & hPrp16 & Step-2 activation \\
\hline Prp22 & hPrp22 & mRNA release \\
\hline Prp43 & hPrp43 & Disassembly \\
\hline
\end{tabular}

Tabelle 1.1: Comparison of yeast and human ATPases and their involvement in

the splicing cycle. The function of each ATPase is described in the main text below (scheme was adapted from Brow, 2002)

At the early stage of spliceosome assembly, both helicases Sub2 and Prp5 promote the displacement of the spliceosomal factor SF1/BBP from the branchpoint region in an ATP-dependent manner to prepare the binding of U2 snRNA to the branchpoint (Kosowski, Keys et al. 2009); (Valadkhan and Jaladat 2011) 2010; (Wahl, Will et al. 2009). Prp5 is thought to play also a role in the remodeling of the U2 snRNA that is required for stable binding of U2 snRNP to the pre-mRNA branch site (Abu Dayyeh, Quan et al. 2002); (Staley and Guthrie 1998); (Wiest, O'Day et al. 1996); (Xu and Query 2007). The early binding of the U1 snRNA with the 5'SS has to be disrupted to free this position for binding of U6 snRNA with the 5'SS. This step is promoted by the protein Prp28 which is involved in the release of U1. Simultaneously, the U4/U6 snRNA duplex has to be unwound to release U4 from the spliceosome and to ensure the proper base-pairing of U6 snRNA with U2 snRNA. Responsible for this step is the helicase Brr2. Since Brr2 remains bound to the spliceosome during assembly, and seems to be required at a later step in the splicing cycle, has to be controlled very strictly (Small, Leggett et al. 2006). One of the major actors during catalysis is the helicase Prp2 and its co-activator Spp2. Prp2 acts immediately before the first step of splicing. ATP hydrolysis by Prp2 is the main driving force for catalytic activation of the spliceosome (transition from $\mathrm{B}^{\text {act }}$ complex to $\mathrm{B}^{*}$ complex), because its action leads to dramatic changes in the spliceosomal network (Kim and Lin 1996); (Fabrizio, Dannenberg et al. 2009); (Warkocki, Odenwalder et al. 2009) (Ohrt, Prior et al. 2012). It is interesting to note that the action of Prp2 leads to the destabilization of the U2 
proteins (SF3a and SF3b proteins), most probably in order to expose the branch point for catalysis (Lardelli, Thompson et al.); (Warkocki, Odenwalder et al. 2009). At the stage of the C complex, another helicase, Prp16 is needed. After the action of Prp16, the $\mathrm{C}$ complex catalyses the second step of splicing. The DExD/H-box helicase Prp22 acts subsequent to exon ligation and promotes the release of the mature mRNA from the spliceosome (Company, Arenas et al. 1991); (Schwer and Gross 1998). Finally, the spliceosome disassembles, the intron-lariat complex has to be degraded and the splicing components have to be recycled for another round of splicing. This process is triggered by the helicase Prp43 (Arenas and Abelson 1997). Hereby, the splicing factor Ntr2 is needed to recruit Prp43 to the spliceosome and Ntr1 is needed to activate the helicase activity of Prp43 (Tsai, Fu et al. 2005; Tsai, Tseng et al. 2007); (Boon, Auchynnikava et al. 2006); (Tanaka, Aronova et al. 2007);(Valadkhan and Jaladat 2011).

\subsection{Spliceosome associated non-snRNP factors - proteins of the NTC}

In the work of Tarn et al. in 1993, in vitro studies in yeast revealed the existence of a pre-assembled complex associated with the Prp19 protein, the NTC (nineteen complex). It was postulated that the NTC most likely plays a major role during the transition from the pre-catalytic B complex to the activated $\mathrm{B}^{\text {act }}$ complex (Tarn, Lee et al. 1993). It was also shown that the NTC enters the spliceosome subsequently after the dissociation of U1 and U4 and stabilizes the U5 and the U6 interaction with premRNA. The yeast NTC consists of eight proteins, Prp19, Ntc20, Ntc25, Isy1, Syf1, Syf2, Clf1 and Cef1. In human there are also eight proteins within the NTC which is named Prp19/CDC5 complex, among others the protein CDC25 which is the human orthologue to yeast Cef1 is found. The Prp19/CDC25 complex plays also an important role in human spliceosomes (Makarova, Makarov et al. 2004).

\subsection{Structural rearrangements of the Spliceosomal RNA-RNA network}

During the assembly of the spliceosome major rearrangements have to occur. The catalytical activation is hallmarked by a dramatic rearrangement at the RNA-RNA 
and the RNA-protein interactions (Staley and Guthrie 1998); (Brow 2002); (Wahl, Will et al. 2009); see Fig. 1.6).

At the early steps of spliceosome assembly, U1 snRNA contacts the 5'SS and basepairs with its complement sequence in the pre-mRNA in an ATP-independent manner. In the next step, the U2 snRNA base-pairs with the BPS in an ATPdependent manner to form the spliceosomal A complex. At the stage of the precatalytic B complex the pre-formed U4/U6.U5 tri-snRNP is recruited to the spliceosome. At this point the spliceosome consists of a full set of snRNPs but it is still in its pre-catalytic form, as long as the catalytically important regions of the U6 snRNA are still base-paired with the U4 snRNA. During activation, base-pairing between U4/U6 snRNA is disrupted and the U1 snRNP is replaced at the 5'SS by the U6 snRNP. U6 snRNA binds with its conserved ACAGAGA-box motif at the 5'SS of the pre-mRNA. This step is important to determine the 5'SS and to initiate the first step of catalysis (Fabrizio and Abelson 1990); (Lesser and Guthrie 1993). During this step, the U1 and U4 snRNPs are released from the spliceosome. U6 snRNA base-pairs with U2 snRNA in form of short helices (U6/U2 helices Ia, Ib and II). Another important role of U6 snRNA is the capacity to bind metal ions during catalysis by forming an intramolecular stem loops (U6-ISL) (Yean, Wuenschell et al. 2000); (Sontheimer 2001). After the recruitment of the tri-snRNP, U5 snRNA binds with its loop I to nucleotides of the exon upstream of the 5'SS. After the first step of splicing, U5 snRNA contacts also nucleotides of the exon downstream of the 3'SS. This mechanism is thought to juxtapose both exons of the pre-mRNA for the catalysis of the second step of the splicing reaction (Newman 1997). 

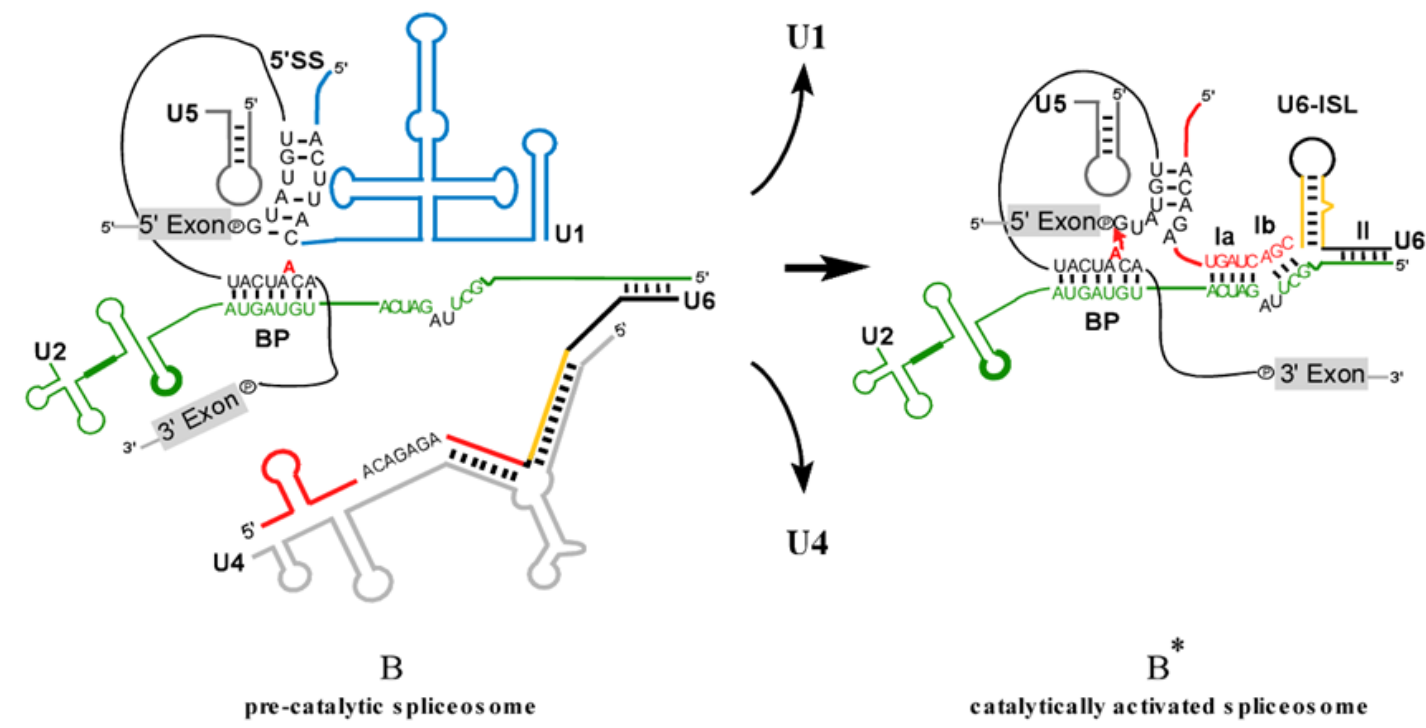

Figure 1.6: Structural dynamics during catalytic activation. On the left hand site the pre-catalytic form of the spliceosome, the pre-catalyic B complex is shown. After dramatic rearrangements of the RNA-RNA network and the subsequent release of the U1 and the U4 snRNPs, the catalytically activated spliceosome, the $\mathrm{B}^{*}$ complex is generated. Both exons are grey-boxed, the different snRNAs are shown in different colors. The branch point adenosine is highlighted in red (kindly provided by Dr. Patrizia Fabrizio)

\subsection{Approaches for the isolation of native spliceosomal complexes}

As mentioned above, spliceosomes are very dynamic molecular machines, thus, during their formation/catalytic activity, they go through many intermediate assembly/functional stages (i.e., E, A, B, B ${ }^{\text {act }}, \mathrm{B}^{*}$ and C complex) (Fig.1.5).

Two general methods have been employed to isolate native spliceosomal complexes. The first is to target a protein component of the spliceosome. To isolate a specific spliceosomal complex, ideally such a component should transiently interact with the spliceosome at a specific stage of its assembly/function. Anti-peptide antibodies raised against such a protein would allow immunoprecipitation and subsequent peptideinduced elution of only those spliceosomal complexes that contain the targeted protein. Using anti-peptide antibodies directed against spliceosomal proteins that are transiently, but stably associated with the spliceosome, activated spliceosomes from HeLa nuclear 
extract have been previously isolated (Makarov, Makarova et al. 2002), as well as spliceosomal complex B lacking the U1 snRNP (Makarova, Makarov et al. 2002).

A second approach for the isolation of spliceosomal complexes is targeting the premRNA by adding an aptamer sequence to its 5' or 3' end (e.g. the hairpin structures bound by tobramycin or the MS2 protein). Either prior to or after allowing spliceosomal complexes to form under splicing conditions in HeLa nuclear extract or in yeast $S$. cerevisiae whole cell extract (this work), the aptamer is bound by its ligand (e.g. tobramycin or MS2 protein fused to the maltose binding protein), which binds or is covalently attached to a solid support. After washing, complexes can then be eluted under native conditions by the addition of an excess of the aptamer or ligand. This approach has been successfully used to isolate a mixture of spliceosomal complexes (Zhou, Licklider et al. 2002), as well as spliceosomes at a more defined stage of assembly and function such as the $\mathrm{A}, \mathrm{B}, \mathrm{B}^{\text {act }}, \mathrm{B}^{*}$ or $\mathrm{C}$ complexes from human, Drosophila and yeast cells (this work, Fig. 1.7) under mild, physiological conditions (Jurica, Licklider et al. 2002); (Hartmuth, Urlaub et al. 2002); (Deckert, Hartmuth et al. 2006); (Bessonov, Anokhina et al. 2008); (Behzadnia, Golas et al. 2007); (Herold, Will et al. 2009); (Warkocki, Odenwalder et al. 2009), (Bessonov, Anokhina et al. 2010). A general problem of in vitro splicing is that spliceosome assembly is not synchronized; at a given incubation time point a heterogeneous population of spliceosomal complexes are assembled on the pre-mRNA. Thus, if a specific spliceosomal complex is to be isolated, additional measures must be undertaken to isolate a more homogeneous population. One approach is to stall spliceosome assembly at a given point. For example, an accumulation of human spliceosomal complex C can be achieved by removing the 3' splice site and the 3' exon of the premRNA (Bessonov, Anokhina et al. 2008). Affinity-purified C complexes formed on such a pre-mRNA substrate can even be chased through the catalytic steps of splicing and catalyze exon ligation in the absence of added factors. This provides a means to verify the functional integrity of the purified complexes (Bessonov, Anokhina et al. 2008). 


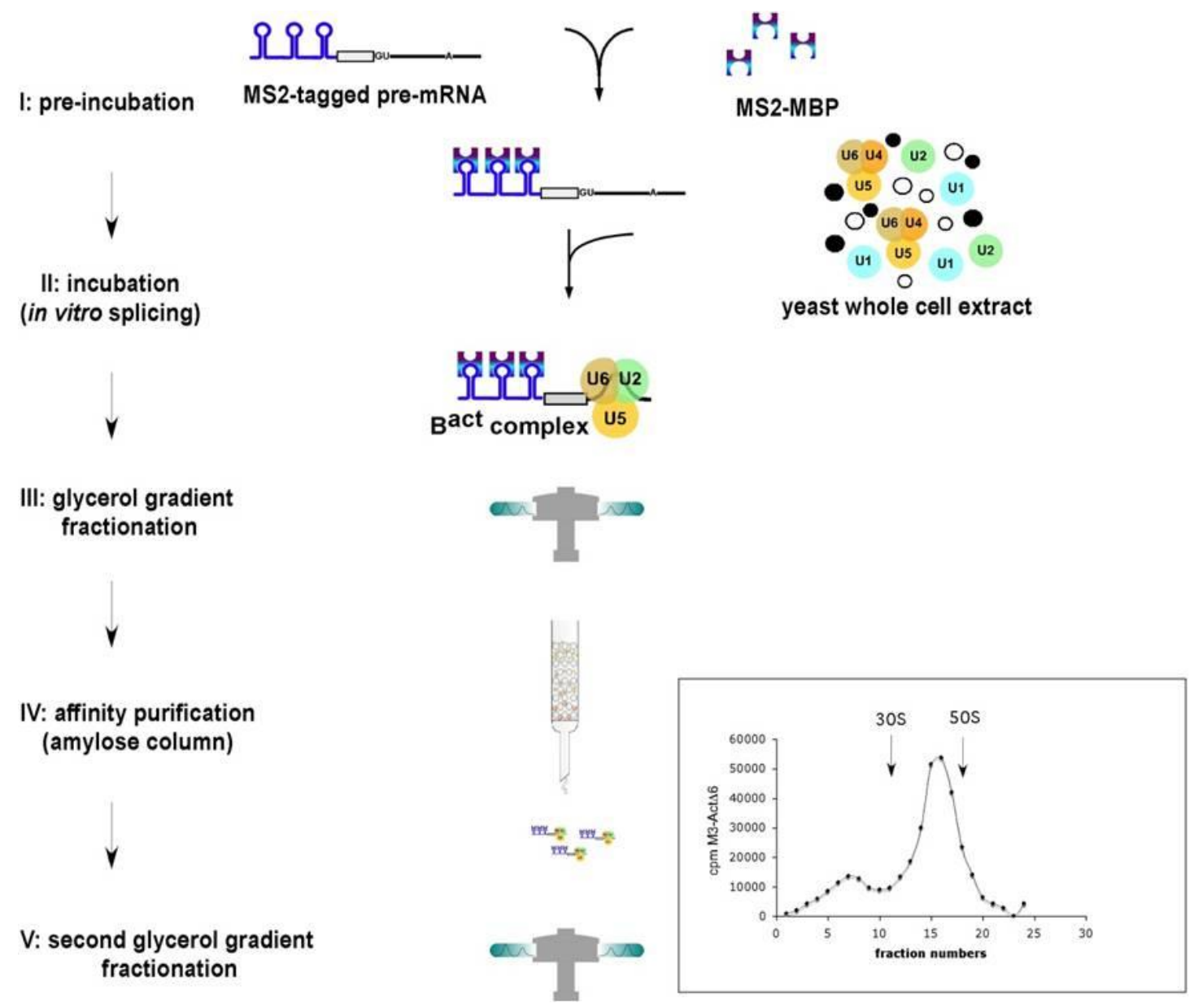

Figure 1.7: Schematic of the purification protocol for the isolation of yeast spliceosomes. Purification of the $\mathrm{B}^{\text {act }}$ spliceosome is depicted. In vitro splicing is carried out using yeast whole cell extract. The reactions are first separated via glycerol gradient centrifugation and subsequently purified on an amylose matrix. A second glycerol gradient centrifugation is carried out if very high purity is required. (This figure was kindly provided by Dr. Patrizia Fabrizio, department of cellular biochemistry, MPI-BPC).

Alternatively, splicing can be carried out for only very short periods of time, so that predominantly only early spliceosomal complexes such as E, A and B will have time to form (Hartmuth, Urlaub et al. 2002; Deckert, Hartmuth et al. 2006). Especially in yeast there is one distinctive feature, which provides another tool for stalling the spliceosomal assembly cycle at defined stages: the existence of temperature-sensitive strains for various spliceosomal factors, in particular for most of the essential DExD/H-box helicases. For example, it was shown in previous studies that the inactivation of Prp5, an essential DEAD-box helicase, known to function in A 
complex formation, leads to the accumulation of the early pre-spliceosomal Commitment complex in yeast (O'Day, Dalbadie-McFarland et al. 1996); (DalbadieMcFarland and Abelson 1990). To isolate and to purify yeast spliceosomes stalled at the commitment complex (CC) stage prior to the formation of pre-spliceosomal A complex, we used in this work, a temperature-sensitive yeast strain which carries a mutant of Prp5 and thus, can be heat-inactivated to accumulate Commitment complexes for subsequent biochemical and structural investigations.

\subsection{Yeast as a model organism}

Saccharomyces cerevisiae has been considered a model for molecular biology studies like pre-mRNA splicing. The benefit is the easy handling of this organism. Over the last few decades a set of well-established selection markers and protocols has been established which make genetic manipulation of this organism easy and rapid. Therefore, a number of different strains, recombinant spliceosomal factors or different RNA constructs, especially for studying the mechanism of pre-mRNA splicing, have accumulated. Screenings for synthetic lethality and genetic interactions have greatly widened our understanding of the complex mechanisms involved in pre-mRNA splicing. Moreover, one major aspect is the existence of temperature-sensitive strains for various spliceosomal factors in yeast as described above. This has provided a perfect device to block the spliceosomal cycle at distinct stages in yeast. Using wildtype pre-mRNAs that carry all sequences essential for pre-mRNA splicing, the purification of spliceosomal complexes that are functional intermediates can be perform. This feature and the accumulated knowledge of the last decades allow the stepwise reconstitution of the splicing machinery and its assembly in vitro in $S$. cerevisisae and will be described in more details in this work.

\subsection{Investigation and characterization of yeast spliceosomal complexes via mass spectrometry and electron mircroscopy}

In former biochemical and genetic studies, numerous proteins were found and characterized as spliceosomal factors, but their exact function is still partially 
unknown. To understand better their contribution and function in pre-mRNA splicing several special methods are required to investigate and characterize them.

\subsubsection{Mass spectrometry}

Mass spectrometry (MS) is one of the major analytical technologies for the identification of unknown protein factors and to determine the proteomic composition of highly complex samples like spliceosomal complexes. Large and complex biomolecules can be analyzed after ionization by either matrix-assisted laser desorption ionization (MALDI MS), electrospray ionization (ESI MS) or tandem MS (LC-MS/MS). The electrospray leads to formation of micrometer-sized droplets that accelerate in electric field with simultaneous evaporation of the solvent, so that only peptide ions enter the mass spectrometer (reviewed by (Fenn, Mann et al. 1989). In the mass spectrometer, the ions are separated according to their mass to charge ratio $(\mathrm{m} / \mathrm{z})$ and detected. For sequence information, one of the ions (peptides) is isolated and fragmented, typically by collision-induced dissociation and the fragments are detected. Finally, the set of masses obtained from MS analysis is used to search against a protein database to identify the peptides, and thus the proteins, contained in the sample. On the basis of peptide assignment quality, number of assigned total and unique peptides, and sequence coverage, a protein can be identified as a component of the spliceosome. MS gives fast and authentic identification of protein factors and it is an essential tool for studying protein dynamics (reviewed in (Mann, Hendrickson et al. 2001). MS analyses of the spliceosomes purified in our laboratory have been performed in collaboration with the MS facility and research group of Prof. Henning Urlaub at the MPI-bpc.

\subsubsection{Electron microscopy}

To gain insights into the structure and function of highly dynamic and complex structures like the splicing machinery, electron microscopy (EM) is another indispensable tool to obtain insights into the three-dimensional structure of the yeast splicing machinery. In addition, to learn more about the three-dimensional structure of macromolecular complexes in living cells can be considered an approach towards understanding better their function and mechanism. One of the major techniques to study EM structures is the single-particle-cryo-electron microscopy, which revealed 
promising results for the analysis of multiprotein complexes with a high resolution $(<$

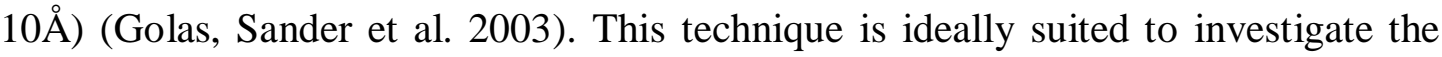
structure of spliceosomal complexes in the yeast S.cerevisiae. Previous work from our laboratory, Deckert et al. and Bessonov et al. have shown that when single-particle cryo electron microscopy was used, higher order structures at a resolution of $30-40 \AA$ were obtained for the human spliceosomal $\mathrm{B} \Delta \mathrm{U} 1$ and $\mathrm{C}$ complexes (Deckert, Hartmuth et al. 2006), (Bessonov, Anokhina et al. 2008).

The structural analysis of spliceosomal complexes isolated from yeast, done in this work, was performed according to the protocol of Kastner et al. with the Grafixmethod. Therefore, spliceosomal complexes were affinity purified under native conditions according to the protocol described in this work and in Fabrizio et al. and Dannenberg et al., and were then sedimented on a second glycerol gradient containing $0.1 \%$ Gluteraldehyd. Gluteraldehyd is a light chemical cross-linker which fixes the complexes under analysis during gradient centrifugation. The fixation step in this preparation allows longer absorption time of the particle on the grid for later analysis by the electron microscope (Kastner, Fischer et al. 2008) and Methods). For what concerns the 2D EM structure of spliceosomal complexes from the yeast S.cerevisiae nothing was known at the start of my work and it is one of the aims of this thesis.

EM analyses of the spliceosomes purified in our laboratory have been performed in collaboration with the EM facility and research group of Prof. Holger Stark at the MPI-bpc.

\subsection{Dual Color Fluorescence Cross-Correlation Spectroscopy - an excellent technique to study protein dynamics within the spliceosome}

Standard MS methods are only semi-quantative and can only give good indications about the relative abundance of a certain protein associated with various spliceosomal complexes. A feature of the spliceosome, however, is the ordered recruitment and subsequent release of spliceosomal factors. The spliceosome must therefore create binding sites for recruited partners at the correct phase of assembly cycle or existent binding sites are modulated to switch from low affinity to high affinity and vice versa. Therefore the elucidation of recruited partners, the definition of the exact time points 
of recruitment/release events and the assignment of dissociation constants for spliceosomal factors at different stages of the spliceosomal cycle is crucial in understanding molecular mechanism of the splicing process in depth.

A method that appears to meet the requirements for obtaining this much-needed information is dual-color fluorescence cross-correlation spectroscopy (dcFCCS). This is a sensitive and versatile optical technique that allows the direct analysis of the dynamics of the association and dissociation events among proteins and/or RNAs in complex systems in solution, at low nanomolar concentrations and in equilibrium without requiring a biochemical/physical perturbation of the sample (see Materials and Methods/Results). In brief, dcFCCS is based on the confocal microscope and requires particles labelled with two spectrally separated colours (e.g. green and red). The fluorescence of the labelled molecules is spectrally separated and detected in two channels. The signals are analysed by computing the auto-correlation of each channel and their cross-correlation. If molecules bearing different labels are not part of the same complex, then they will diffuse independently through the confocal volume. In that case, there will be no cross-correlation between both signals. However, if the molecules are part of the same complex, they will form doubly labeled entities. Codiffusion of the two labels will generate correlated signals in both detection channels and therefore a cross-correlation. The amplitude of the cross-correlation is proportional to the number of doubly labelled molecules and can therefore be used to monitor binding and release reactions (Fig.1.8) (Ricka and Binkert 1989; Schwille, Meyer-Almes et al. 1997; Földes-Papp 2005; Mütze, Ohrt et al. 2011). For a detailed mathematical description of the auto-correlation function refer to Schwille and Haustein, 2002 and to Sauer, Hofkens and Enderlein, 2011, as this is beyond the scope of this introduction. The computation and evaluation of the dcFCCS data in this work was done in collaboration with Prof. Jörg Enderlein and Mira Prior (III.Institute of Physics, University of Göttingen) (Kettling, Koltermann et al. 1998); (Foldes-Papp and Rigler 2001); (Ohrt, Staroske et al.). 


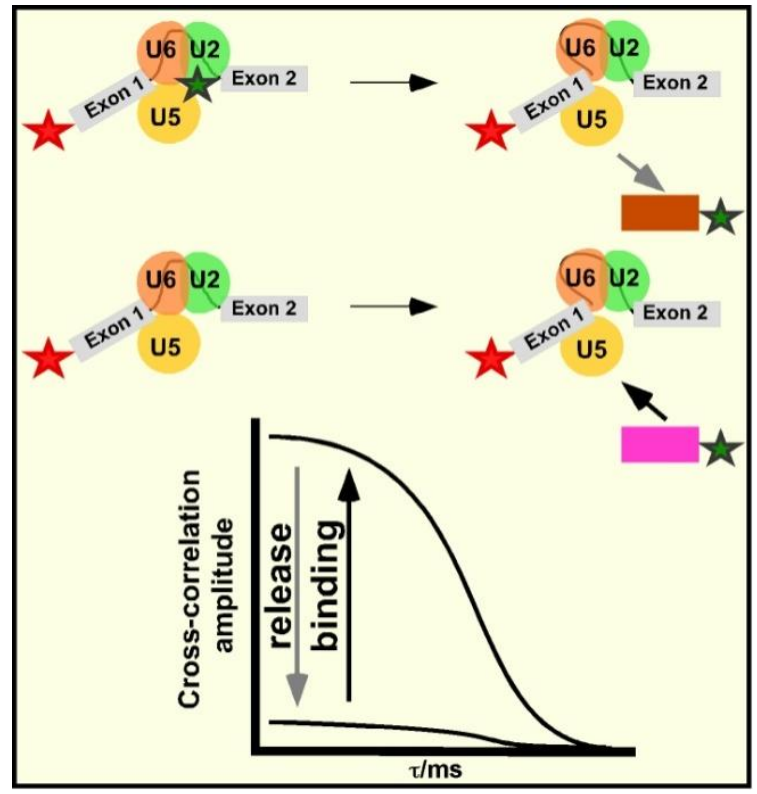

Figure 1.8: The cross-correlation amplitude is proportional to the amount of doubly labeled species

\begin{abstract}
Binding and release of a fluorescently labeled protein (brown or pink rectangles with a "green fluorophor") to a larger assembly of molecules (i.e.the spliceosome with a "red fluorophor") are shown schematically. The effects of the two events on the cross- correlation curves are indicated in the middle (adapted from (Ohrt, Prior et al. 2012)).
\end{abstract}

\title{
1.13 Aim of this study
}

The spliceosome is a protein-rich molecular machine that catalyzes the removal of a pre-mRNA intron. Proteomic studies of purified spliceosomes, assembled in vitro at defined stages of function, have primarily been carried out with splicing extracts from human HeLa cells. Human spliceosomes contain more than 50 proteins associated with snRNPs and more than 100 non-snRNP proteins as revealed by massspectrometric studies. Such studies showed that the spliceosome's protein complement varies substantially from one stage of the splicing cycle to another (Deckert, Hartmuth et al. 2006; Bessonov, Anokhina et al. 2008). One aim of this work was to expand these studies to the yeast Saccharomyces cerevisiae, since there is no alternative splicing in yeast cells and thus regulatory splicing factors such as SR and hnRNP proteins are absent. Nonetheless, the pathway of spliceosome assembly and the main 
features of its catalytic chemistry appear to be conserved between metazoans and yeast. The study of the extent of conservation is not only relevant for tracing evolutionary relationships, but it can also lead to conclusions about the mechanisms of conformational changes, such as those resulting in spliceosome activation or catalysis. Therefore, a comprehensive proteomic analysis of the yeast spliceosomes should reveal the minimum set of proteins required for driving the spliceosomal dynamics and for catalyzing the removal of a pre-mRNA intron.

Towards this goal we set up a strategy to purify and isolate spliceosomal complexes from yeast under native conditions for the first time, to learn more about the dynamics of protein recruitment and release during catalytic activation and step 1 of splicing. To isolate biochemically homogenous $\mathrm{B}, \mathrm{B}^{\text {act }}$ and $\mathrm{C}$ complexes, we used an actin premRNA and modifications thereof. For MS2 affinity-purification, three MS2 binding sites were fused to the 5' end of the various pre-mRNA constructs. Previous studies showed that truncation/modification of the actin pre-mRNA and adjustment of the ATP concentration in the splicing reaction can lead to stalling of the spliceosomal cycle (Rymond and Rosbash 1985; Cheng 1994). The intron in the actin pre-mRNA contains the yeast consensus branch point (BPS) sequence UACUAAC. The premRNA Act $\Delta 6$ and Act $\Delta 31$ were truncated 6 and 31 bases, respectively, after this sequence, and thus, lack the 3' SS and the 3' exon. These truncated precursors led to stalling at the stage of complex $\mathrm{B}^{\text {act }}$ and $\mathrm{C}$, respectively, when $2 \mathrm{mM}$ ATP was used. The inclusion of only $0.05 \mathrm{mM}$ ATP in the splicing reaction led to stalling at the stage of complex B. The various spliceosomal complexes were isolated by a three-step purification procedure developed in yeast during my $\mathrm{PhD}$ work and involves glycerol gradient centrifugations and affinity-selection of the MS2 tagged spliceosomal complexes with amylose beads. The protein composition of the $\mathrm{B}, \mathrm{B}^{\text {act }}$ and $\mathrm{C}$ complexes have been determined by mass spectrometry (MS), and the proteins that dissociate or are recruited during the transition from one complex to the next have been characterized for the first time. MS revealed a dramatic exchange of proteins during spliceosome assembly and activation. Specifically, we learned that in yeast, activation ( $\mathrm{B}$ to $\mathrm{B}^{\text {act }}$ transition) is accompanied by the stable recruitment of $\sim 20$ proteins, whereas $\sim 35$ proteins, including all $\mathrm{U} 1$ and U4/U6-associated proteins, are lost. Nine additional proteins are recruited during the transition from the $\mathrm{B}^{\text {act }}$ to the $\mathrm{C}$ 
complex. At the same time the DEAH-box helicase Prp2 and its co-activator Spp2, as well as the U2 SF3a and SF3b complexes, are also destabilised. However, it was not yet clear whether the U2 SF3a/SF3b proteins are subsequently lost from the spliceosome.

A fundamental outcome of this work is that it provides an inventory of the evolutionarily conserved splicing factors that are stably associated with three "snapshots" of spliceosome assembly, activation and catalysis and offer insights into the window of function of the proteins exchanged during the transition from one stage to the next. Another important outcome of this work is that it revealed that in yeast and human, the same homologous proteins dissociate and are recruited during the transition from the $\mathrm{B}$ to the $\mathrm{B}^{\text {act }}$, and from the $\mathrm{B}^{\text {act }}$ to the $\mathrm{C}$ complex, indicating that these compositional changes are an evolutionarily conserved design principle of the spliceosome.

The isolation of intact yeast spliceosomal complexes has already provided an important background not only for further biochemical, biophysical and functional studies (see below), but also for initial structural studies. Because of its dynamic and complex nature, obtaining structural information about the spliceosome represented a major challenge so far. Nevertheless in this work, electron microscopy (EM) of the three isolated "snapshots" of the yeast spliceosome revealed a quite homogenous general morphology of the $\mathrm{B}, \mathrm{B}^{\text {act }}$ and $\mathrm{C}$ complexes and also their significant differences in shape and structural details, consistent with their substantial compositional differences. Thus, these studies have paved the way to obtain a topographic map of the spliceosome, and will also provide novel insights into the structural remodeling events occurring during the spliceosome cycle.

Significantly, the moderate number of phylogenetically conserved proteins recruited to the yeast complexes $\mathrm{B}^{\text {act }}$ and $\mathrm{C}$ has made possible targeted investigations of the mechanism of activation and catalysis in a fully-defined biochemical reconstitution system in our laboratory (Warkocki, Odenwalder et al. 2009). In the latter studies was shown that the DEAH-box helicase Prp2 remodels substantially $\mathrm{B}^{\text {act }}$ into the catalytically activated $\mathrm{B}^{*}$ complex prior to the formation of the $\mathrm{C}$ complex. During this Prp2-mediated remodeling, the binding of several proteins to the spliceosome is 
weakened. Interestingly, these included the proteins of the U2 SF3a/SF3b subunits and further suggested that the ATPase Prp2 may facilitate the spliceosome's catalytic activation by inducing destabilisation of $\mathrm{U} 2 \mathrm{SF} 3 \mathrm{a} / \mathrm{SF} 3 \mathrm{~b}$ proteins. This rearrangement is important since it is believed to expose the BPS adenosine as a crucial preliminary to step 1. In addition, we observed that there were potentially several other proteins whose binding affinity to the spliceosome might have been changed by Prp2 action as revealed by the comparative MS analyses of purified spliceosomes described above. These included the RES (REtention and Splicing) complex proteins, the NTC-related proteins Cwc24 and Cwc27, and the essential catalytic step 1 factors Yju2 and Cwc25.

Thus, a second aim of this work was to study these events in a quantitative manner, toward this goal we established a dual color Fluorescens Cross Correlation Spectroscopy setup (in collaboration with Dr. Thomas Ohrt, Mira Prior and Prof. Jörg Enderlein). In this work, the technique of dcFCCS was applied for the first time to investigate the compositional dynamics of yeast spliceosomes in more details. Specifically, we have studied the modulation of the binding strength of various proteins to the yeast spliceosome during catalytic activation by Prp2 to finally shed some light on the nature of the release/loss of splicing factors during this crucial remodeling step. For this purpose, spliceosomes were stalled before step 1 by using the temperature-sensitive yeast mutant prp2-1 and affinity-purified to near homogeneity, yielding a $\mathrm{B}^{\text {act } \Delta \operatorname{Prp} 2}$ spliceosome. Highly purified $\mathrm{B}^{\text {act } \Delta \operatorname{Prp} 2}$ can be catalytically activated to form $\mathrm{B}^{*}$ when supplemented with recombinant Prp2 and Spp2 splicing factors (Warkocki, Odenwalder et al. 2009). We have used purified $\mathrm{B}^{\text {act } \Delta \mathrm{Prp} 2}$ complexes assembled on actin pre-mRNA labeled at its 5 ' end with the red fluorescent dye Atto647N. We labeled proteins by fusing the protein of interest with a fluorescent protein EGFP (enhanced green fluorescent protein) by genetic modification; the fluorescently labeled protein is uniquely produced in the modified yeast strain and is, therefore, quantitatively and selectively labeled in purified spliceosomes assembled in splicing extracts derived from such strains. The purified doubly-labeled spliceosomes were then analyzed before and after catalytic activation by Prp2 and the weakening or strengthening of the binding of the EGFP-labeled protein to the spliceosome was measured by dcFCCS. 
Using dcFCCS we show that the binding affinity of quite a number of proteins is significantly changed during the Prp2-mediated catalytic activation of the spliceosome. Finally, we convincingly demonstrate that the U2 SF3a/SF3b proteins Prp11 and Cus1 remain bound to the $\mathrm{B}^{*}$ spliceosome under near-physiological conditions, and that their binding is reduced only when high salt is included. Furthermore, high affinity binding sites are created for Yju2 and Cwc25 during catalytic activation, consistent with their requirement for step 1 catalysis. This work suggests that Prp2-mediated structural remodeling of the spliceosome leads to multiple rearrangements and show that dcFCCS is a powerful tool, ideally suited to investigate quantitatively the compositional dynamics of the spliceosome during its catalytic activation. In addition, this is the first example where purified, catalytically active spliceosomes were investigated directly in solution and in equilibrium. In conclusion, by combining biochemical, biophysical approaches and ultrastructural studies by EM, this work gives new insights and useful information about protein dynamics and structural changes occuring during spliceosome activation and catalysis. 


\section{Materials and Methods}

\subsection{Materials}

\subsubsection{Chemicals and media}

2-Mercaptoethanol

Acetic acid

Acetone

Agarose, electrophoresis grade

Ammoniumperoxodisulfate (APS)

Ampicillin

Bacto agar

Bacto yeast extract

Bacto peptone

Bradford-assay solution

Brilliant Blue G-Colloidal concentrate

Bromphenol blue

$\mathrm{D}(+)$-glucose monohydrate

Dipotassiumhydrogenphosphate

DNA-molecular weight marker

DTT (Dithiothreitol)

EDTA (Disodium salt dihydrate)

Formaldehyde

Formamide
Roth, Germany

Merck, Germany

Merck, Germany

Invitrogen,

Netherlands

Merck, Germany

Sigma-Aldrich,

Germany

BD, USA

BD, USA

BD, USA

Bio-Rad, Germany

Sigma-Aldrich,

Germany

Merck, Germany

Merck, Germany

Merck, Germany

Gibco, New

Zealand

Roth, Germany

Roth, Germany

Merck, Germany

Merck, Germany 
Glycerol

Glycoblue

HEPES (N-2-Hydroxyethylpiperazin-N-2-ethansulfonic acid)

Imidazole

Lithium acetate

Maltose

Methanol

Polyethylene glycol (PEG)

Ponceau S

Potassium Chloride

Potassiumdihydrogenphosphate

Pre-stained protein-molecular weight marker

Roti-Phenol-Chloroform-Isoamyl alcohol (PCI)

Rotiphorese Gel 30 solution

Rotiphorese Gel 40 solution

Rotiphorese Gel A and B solution

Silver nitrate

Sodiumdodecylsulfate (SDS)

Sodiumacetate

TEMED (N, N, N', N'-Tetramethylethylendiamine)

Tris-(hydroxymethyl)aminomethane (Tris)

Triton X-100

tRNA $E$. coli

Nonidet P-40 (Igepal CA-630)

Urea

Xylene cyanol FF
Merck, Germany

Ambion, USA

Calbiochem, USA

Merck, Germany

Sigma-Aldrich,

Germany

Merck, Germany

Merck, Germany

Sigma-Aldrich,

Germany

Serva, Germany

Merck, Germany

Merck, Germany

Bio-Rad, Germany

Roth, Germany

Roth, Germany

Roth, Germany

Roth, Germany

Merck, Germany

Serva, Germany

Merck, Germany

Sigma-Aldrich,

Germany

Roth, Germany

Merck, Germany

Boehringer,

Germany

Sigma-Aldrich,

Germany

Merck, Germany

Fluka, Switzerland 


\subsubsection{Enzymes and enzyme inhibitors}

Aprotinin

Benzamidine

Chymostatin

Complete $^{\mathrm{TM}}$ protease inhibitor tablets EDTA-free

Leupeptin

Pepstatin A

Phenylmethylsulfonylfluoride (PMSF)

Phusion ${ }^{\circledR}$ High-Fidelity DNA Polymerase

Proteinase K

Recombinant RNasin ${ }^{\circledR}$ Ribonuclease Inhibitor

Restriction Enzymes

RNasin (RNase inhibitor; $40 \mathrm{U} / \mu \mathrm{l}$ )

RQ DNase I (1 U/ $\mu \mathrm{l})$

SP6 RNA polymerase

T7 RNA polymerase

Taq DNA polymerase
Serva, Germany

Serva, Germany

Serva, Germany

Roche, Germany

Serva, Germany

Serva, Germany

Merck, Germany

New England Biolabs,

Germany

Sigma-Aldrich, Germany

Promega, USA

New England Biolabs,

Germany

Promega, USA

Promega, USA

New England Biolabs,

Germany

dept. Lührmann

Promega, USA

\subsubsection{Nucleotides}

Nucleoside-5'-triphosphate (ATP, CTP, GTP, UTP 100 mM each):

Pharmacia, Germany

Deoxynucleoside-5'-triphosphate Mix (dATP, dCTP, dGTP, dTTP $10 \mathrm{mM}$ each):

New England Biolabs, Germany

Radionucleotides: $\left[\alpha-{ }^{32} \mathrm{P}\right]-\mathrm{UTP},\left[\alpha-{ }^{32} \mathrm{P}\right]-\mathrm{dATP},\left[\alpha-{ }^{32} \mathrm{P}\right]$-ATP:

Perkin-Elmer, Germany 


\subsubsection{DNA oligonucleotides and plasmids}

\subsubsection{DNA oligonucleotides}

\begin{tabular}{|c|c|c|}
\hline Name & sequence ( $(5$ ' to 3 ') & description \\
\hline Sp6_for & ATTTAGGTGACACTATAG & $\begin{array}{l}\text { used for the generation of } \\
\text { template DNA for in vitro } \\
\text { transcription }\end{array}$ \\
\hline Act_rev & GGAATTCCCCTTCATCACCAA & $\begin{array}{l}\text { used for the generation of } \\
\text { template DNA for in vitro } \\
\text { transcription }\end{array}$ \\
\hline Act $+13+24$ & GATGGTGCAAGC & $\begin{array}{l}\text { used for RNase } \mathrm{H} \text { directed } \\
\text { cleavage of M3Act pre- } \\
\text { mRNA during C-complex } \\
\text { purification }\end{array}$ \\
\hline
\end{tabular}

\subsubsection{Plasmids}

Name

pUC18_T7_M3Act_wt

pUC18_T7_M3Act_ $\Delta 6$

pMal_MS2-MBP

pKT209 description

template for in vitro transcription, generated by Dr.

Thomas Ohrt

emplate for in vitro transcription, generated by Dr.

Thomas Ohrt

expression of MS2-MBP fusion protein, provided by

Robin Reed and Josep Vilardell

used for the amplicfication of the yEGFP cassette by PCR; Euroscarf, Frankfurt am Main 


\subsubsection{Yeast and bacterial strains}

\subsubsection{Yeast strains}

BJ2168

MATa, leu2, trp1, ura3, prb1-1122, pep4-3, prc1-407,gal2

This strain carries deletions in protease genes.

prp2-1 (3.2 AID) MATalpha, prp2-1, ade2, his3, lys2-801, ura3

kindly provided by R-JLin. This strain carries a G360D mutation in Prp2, rendering it heat labile.

prp5-1

MATa prp5-1,ade2-101, his3-1200 tyr1 ura3-52

(single base change in the PRP5 gene which lead to the substitution of glycine 293 with aspartate (G293D) in the protein. This substitution is 12 residues upstream of the glycine-lysine-threonine (GKT) triplet in the highly conserved, nucleotide-binding motif 1 within the putative helicase domain)

YTO13

Snu114-yEGFP MATalpha, prp2-1, ade2, his3, lys2-801, ura3; SNU114::yEGFP-CaURA3 C-terminus

YTO15

Cus1-yEGFP MATalpha, prp2-1, ade2, his3, lys2-801, ura3; CUS1::yEGFP-CaURA3 C-terminus

YTO17

Prp11-yEGFP MATalpha, prp2-1, ade2, his3, lys2-801, ura3; PRP11::yEGFP-CaURA3 C-terminus

YTO18

Cwc24-yEGFP MATalpha, prp2-1, ade2, his3, lys2-801, ura3; CWC24::yEGFP-CaURA3 C-terminus

YTO20

Cwc27-yEGFP MATalpha, prp2-1, ade2, his3, lys2-801, ura3; CWC27::yEGFP-CaURA3 C-terminus

YTO21

Yju2-yEGFP MATalpha, prp2-1, ade2, his3, lys2-801, ura3; YJU2::yEGFP-CaURA3 C-terminus 
YTO25

Bud13-yEGFP MATalpha, prp2-1, ade2, his3, lys2-801, ura3; BUD13::yEGFP-CaURA3 C-terminus

\subsubsection{Bacterial strains}

BL21-CodonPlus(DE3)-RIL cells, F- ompThsdSB ( $r \mathrm{~B}-m \mathrm{~B}-)$ gal dcm lacY1, pRARE22 (CMR) pAR5615 (APR) Novagen, USA

\subsubsection{Commercial kits}

ECL western blot detection kit

Prime It II random primer labeling kit

Qiagen gel extraction kit

Qiagen plasmid preparation kit
GE Healthcare, UK

Stratagene, USA

Qiagen, Germany

Qiagen, Germany

\subsubsection{Chromatography materials and consumables}

Amylose resin

Cassettes for film exposure

Concentrator

Dialyses membranes MWCO 6000-8000 Da

Heparin Sepharose $\mathrm{T}^{\mathrm{TM}} 6$ Fast Flow

HisTrap ${ }^{\text {TM }}$ FF crude columns

IgG Sepharose 6 Fast Flow

Nylon membrane Hybond XL

Parafilm

Poly-Prep columns

ProbeQuant ${ }^{\mathrm{TM}}$ G-50 micro columns

ProbeQuant ${ }^{\mathrm{TM}} \mathrm{G}-25$ micro columns

Protein A-Sepharose CL 4B
New England Biolabs, Germany

Kodak, USA

Millipore, USA

SpektraPor, USA

GE Healthcare, UK

GE Healthcare, UK

GE Healthcare, UK

GE Healthcare, UK

Roth, Germany

Bio-Rad, USA

GE Healthcare, UK

GE Healthcare, UK

GE Healthcare, UK 
Protran Nitrocellulose membrane

Slide-A-Lyzer dialysis units (MWCO 6 kDa)

Sterile filters $0.2 \mu \mathrm{m}$ or $0.45 \mu \mathrm{m}$

Superdex 75 16/60 column

Whatman 3MM Paper

X-ray films BioMax MR
Schleicher \& Schüll, Germany

Pierce, USA

Sarstedt, Germany

GE Healthcare, UK

Whatman Paper, UK

Kodak, USA

\subsubsection{Common buffers}

Media, buffers, and solutions were prepared with deionized water (Millipore) and autoclaved if necessary $\left(121{ }^{\circ} \mathrm{C}, 20 \mathrm{~min}, 1 \mathrm{bar}\right)$. Solutions with heat-labile components were filter sterilized $(0.22 \mu \mathrm{m})$.

5x DNA loading dye

4x Separating gel buffer

4x Stacking gel buffer

10x TBE

Protein loading dye
$30 \%$ glycerol

5 mM EDTA, $\mathrm{pH} 8.0$

$0.25 \%(w / v)$ bromophenol blue

$0.25 \%(\mathrm{w} / \mathrm{v})$ xylene cyanol

1.5 M Tris

$0.4 \%$ (w/v) SDS

adjust to $\mathrm{pH} 8.8$

$0.5 \mathrm{M}$ Tris

$0.4 \%(\mathrm{w} / \mathrm{v}) \mathrm{SDS}$

adjust $\mathrm{pH}$ to 6.8

$0.89 \mathrm{M}$ Tris

$0.89 \mathrm{M}$ boric acid

25 mM EDTA pH 8.0

75 mM Tris-HCl, pH 6.8

1.25 mM EDTA, pH 8.0

$20 \%$ (v/v) glycerol 
$2.5 \%(\mathrm{w} / \mathrm{v}) \mathrm{SDS}$

$0.125 \%$ (w/v) bromophenol blue

$50 \mathrm{mM}$ DTT

RNA loading dye

$80 \%$ formamide

1 mM EDTA pH 8.0

$0.05 \%$ (w/v) bromophenol blue

$0.05 \%(\mathrm{w} / \mathrm{v})$ xylene cyanol

Slab 4 Buffer

$50 \mathrm{mM}$ Tris

$105 \mathrm{mM}$ glycine

$0.1 \%(\mathrm{w} / \mathrm{v}) \mathrm{SDS}$

SDS-PAGE Running buffer

25 mM Tris-HCl, pH 6.8

$192 \mathrm{mM}$ glycine

$1 \%(\mathrm{w} / \mathrm{v}) \mathrm{SDS}$

10x TBS

$200 \mathrm{mM}$ Tris

$1.37 \mathrm{M} \mathrm{NaCl}$

adjust to $\mathrm{pH} 7.6$

Western blotting buffer

1.5 L Slab4 Buffer

$0.6 \mathrm{~L}$ methanol

$0.9 \mathrm{~L} \mathrm{ddH}_{2} \mathrm{O}$

\subsubsection{Machines and working equipment}

ÄKTA Prime

ÄKTA Explorer

Autoclaves

Biofuge fresco

Biofuge pico
GE Healthcare, UK

GE Healthcare, UK

$\mathrm{H}+\mathrm{P}$ Labortechnik, Germany

Kendro, USA

Kendro, USA 
DNA Thermal Cycler

Gel documentation unit

Gelelectrophoresis apparatus

Geldryer Model 583

Gradient Master

'head-over-tail'

Heating blocks

Hybridization oven

Megafuge 1.0R

Milli-Q-water supply apparatus

Nanodrop

pH-Meter

Phosphorimager Typhoon 8600

Power supply EPS 2A 2000

Power supply EPS 3501/XL

Liquid Scintillation Analyzer Tri-Carb 2100 T

Sorvall SLC-6000 rotor

Sorvall SS-34 Rotor

Sorvall TH660 Rotor

Sorvall T865 Rotor

Sorvall T647.5 Rotor

Speed Vac Concentrator 5301

Spectrophotometer Ultrospec 3000 pro

Surespin 630 rotor

Tabletop centrifuges

Trans-Blot Cell

Ultracentrifuge Evolution

UV lamps (254 nm)

Vortex

X-ray film developer X-Omat 2000

Liquid scintillation analyzer
Hybaid Omni Gene, UK

Bio-Rad, USA

in-house

Bio-Rad, USA

BioComp Instruments, Canada

Rotor Cole-Parmer, USA

Eppendorf, Germany

Hybaid Biometra, UK

Kendro, USA

Millipore, USA

Thermofisher, Germany

Mettler Toledo, Switzerland

Amersham Pharmacia, Germany

Hoefer Pharmacia Biotech, USA

Amersham Pharmacia, Germany

Packard, USA

Kendro, USA

Kendro, USA

Kendro, USA

Kendro, USA

Kendro, USA

Eppendorf, Germany

Amersham Pharmacia, Germany

Thermo Fisher Scientific, USA

Heraeus, Germany

Bio-Rad, USA

Kendro, USA

Bachofer, Reutlingen

Janke \& Kunkel, Germany

Kodak, USA

Packard, USA 


\subsection{Methods}

\subsubsection{General molecular biology methods}

Unless otherwise stated all described methods for standard molecular biology are essentially performed according to Sambrook et al., 1989. When a commercial reaction set was used, the manufacturer's instructions were followed.

\subsubsection{Concentration determination of nucleic acids}

The concentration determination of RNA or DNA is based on the absorption maximum of the aromatic ring system of nucleic acids at a wavelength of $260 \mathrm{~nm}$. The concentration and purity of nucleic acids was estimated using the empirical standard values shown below. The ratio between $\mathrm{OD}_{260}$ and $\mathrm{OD}_{280}$ allows to assess contaminations with proteins or phenol.

\subsubsection{Purification and manipulation of DNA}

Plasmid DNA was obtained from E. coli cells using QIAGEN Plasmid Purification Kits according to the manufacturer's instructions. QIAGEN plasmid purification protocols are based on a modified alkaline lysis procedure, followed by binding of plasmid DNA to QIAGEN Anion-Exchange Resin under appropriate low-salt and $\mathrm{pH}$ conditions. Restriction endonucleases were obtained from New England Biolabs (NEB) and the reactions were performed according to the manufacturer's instructions. Generally 1-10 units of enzyme were used to cut $1 \mu \mathrm{g}$ of DNA within $1 \mathrm{~h}$ under the recommended conditions. DNA fragments were analyzed and purified by agarose gel electrophoresis.

\subsubsection{Agarose gel electrophoresis}

DNA-fragments generated by PCR were analyzed by agarose gel electrophoresis. Gels contained $1-2 \%$ agarose $(\mathrm{w} / \mathrm{v})$ and $0.4 \mu \mathrm{g} / \mathrm{ml}$ ethidiumbromide in $0,5 \mathrm{x}$ TBE buffer. DNA samples were supplemented with DNA loading dye and separated 
together with a DNA ladder as size marker at 110 Volts (constant voltage), in $0.5 \mathrm{x}$ TBE. Nucleic acids were visualized with UV-light at $254 \mathrm{~nm}$.

\subsubsection{Polymerase chain reaction}

The polymerase chain reaction (PCR) was used to amplify DNA fragments either for analytic (e.g. "colony PCR") or preparative purposes (e.g. transcription templates). A typical reaction mixture contained $0.4 \mathrm{ng} / \mu \mathrm{l}$ of template, $0.2 \mathrm{mM}$ of each $\mathrm{dNTP}, 0.6$ $\mu \mathrm{M}$ of each primer, the appropriate reaction buffer and the enzyme. Different kinds of polymerases (Taq-, Pfu- or Phusion-polymerase) were used depending on the purpose of the application.

A typical setup for a PCR included the following steps:

$\begin{array}{llll}\text { 1. } & 94^{\circ} \mathrm{C} & 5 \mathrm{~min} & \text { initial denaturation } \\ \text { 2. } & 94^{\circ} \mathrm{C} & 1 \mathrm{~min} & \text { cycle denaturation } \\ \text { 3. } & 52^{\circ} \mathrm{C} & 1 \mathrm{~min} & \text { primer annealing } \\ \text { 4. } & 72^{\circ} \mathrm{C} & 1 \mathrm{~min} & \text { elongation } \\ \text { 5. } & 72^{\circ} \mathrm{C} & 10 \mathrm{~min} & \text { final elongation }\end{array}$

steps 2 to 4 were repeated 35 times

For purification of DNA fragments for subsequent in vitro transcriptions, PCR reactions were purified with the PCR-clean-up Kit provided by Macherey-Nagel. The manufacturer's instructions were followed and DNA fragments were eluted in TE buffer. 5'- and 3'-DNA fragments for subsequent site-overlap extension PCRs were separated by agarose gel electrophoresis, visualized by ethidiumbromide and UV light. The DNA band was cut out with a razor blade and transferred to a 2 ml-reaction tube. DNA was extracted from the agarose and purified with the PCR-clean-up Kit by Macherey-Nagel according to the manufacturer's instructions.

\subsubsection{Transformation of yeast and E. coli}

For transformations, chemically competent cells of S.cerevisiae and E. coli were used. $50 \mathrm{ml}$ cultures of E.coli were grown to an $\mathrm{OD}_{600}$ of 0.3-0.5 and the cell pellet was washed twice with an ice cold solution of $50 \mathrm{mM} \mathrm{CaCl}_{2}$. After the addition of glycerol to a final concentration of $10 \%$ the cells were frozen in liquid nitrogen and 
stored at $-80^{\circ} \mathrm{C}$. For transformation competent cells were mixed with $50 \mathrm{ng}$ plasmid DNA and incubated on ice for $30 \mathrm{~min}$, followed by a heat shock at $42^{\circ} \mathrm{C}$ for $1 \mathrm{~min}$. Subsequently, the cells were incubated for $1 \mathrm{~h}$ at $37^{\circ} \mathrm{C}$ in $\mathrm{LB}$ medium before being transferred to Petri dishes containing a selection medium.

$50 \mathrm{ml}$ cultures of $S$. cerevisiae were grown to an $\mathrm{OD}_{600}$ of $0.6-0.8$. The cells were sedimented by brief centrifugation at $2500 \mathrm{x}$ g and washed with buffer containing 10 $\mathrm{mM}$ Tris, $\mathrm{pH}$ 7.5. Subsequently, the pellet was resuspended in a buffer containing 10 $\mathrm{mM}$ Tris, $\mathrm{pH} 7.5$ and $100 \mathrm{mM}$ lithium acetate (LiT-buffer) and incubated shaking slowly at RT for $40 \mathrm{~min}$. After a brief centrifugation the cells were resuspended in $800 \mu \mathrm{l}$ LiT-buffer and the designated DNA construct (250 ng for plasmids, $40 \mu \mathrm{g}$ for PCR constructs) was mixed with $100 \mu$ of cell suspension. As a carrier, salmon sperm DNA (1 mg/ml final concentration) was used and a solution of PEG 3350 (0.5 g PEG/ml LiT final concentration) was added. A heat shock?) treatment was performed for $5 \mathrm{~min}$ at $42^{\circ} \mathrm{C}$ (except ts strains) before the cells were transferred to YPD medium and incubated at $37^{\circ} \mathrm{C}$ (or $25^{\circ} \mathrm{C}$ if the strain was temperature sensitive) for $1 \mathrm{~h}$. Petri dishes containing a selection medium were used to select for successful transformants. Positive clones were checked for the correct integration of the construct via colony PCR.

\subsubsection{Phenol-chloroform-isoamylalcohol (PCI) extraction and ethanol precipitation}

The PCI extraction is used to separate nucleic acids from proteins. Phenol and chloroform denature proteins and keep them in the organic phase, while nucleic acids stay in the aqueous phase. Samples were thoroughly mixed with an equal volume of PCI (phenol/ chloroform/ isoamylalcohol, $\mathrm{pH}$ 7.5-8.0 in the ratio 25:24:1, commercially available from Roth). Phase separation was accelerated by centrifugation at $16000 \mathrm{xg}$ for $5 \mathrm{~min}$. The aqueous phase was transferred into a new tube and nucleic acids were precipitated by adding 3 volumes of absolute ethanol, 0.1 volume of $3 \mathrm{M}$ sodium acetate $\mathrm{pH} 5.3$ and, in case of nucleic acid concentrations below $200 \mathrm{ng} / \mu \mathrm{l}, 10 \mu \mathrm{g} / \mathrm{ml}$ Glycoblue (Ambion) was added as a carrier. Proteins were precipitated from the organic phase by adding 5 volumes of absolute ethanol or acetone. Both, RNA and protein samples were kept at $-20^{\circ} \mathrm{C}$ for at least $30 \mathrm{~min}$. The 
precipitates were sedimented by centrifugation at $16000 \mathrm{x}$ g for $20 \mathrm{~min}$. The pellet was washed with $70 \%$ ethanol $(\mathrm{v} / \mathrm{v})$, subsequently dried and resuspended in the desired solution.

\subsubsection{Proteinase $\mathrm{K}$ digestion}

Proteinase K digestion of (reconstitution) reactions were performed to obtain proteinfree RNA samples. All proteinase K digestions were done at a final concentration of $0.2 \%(\mathrm{w} / \mathrm{v})$ SDS, $10 \mathrm{mM}$ EDTA and $0.3 \mathrm{mg} / \mathrm{ml}$ proteinase K. Reactions were mixed thoroughly and incubated for $30 \mathrm{~min}$ at $37^{\circ} \mathrm{C}$. Subsequently, reactions were filled up to $200 \mu \mathrm{l}$ with "stop- splicing" buffer and RNAs were extracted by PCI and precipitated with ethanol.

\section{"stop-splicing" buffer}

$50 \mathrm{mM} \mathrm{NaOAc}(\mathrm{pH} 5,3)$

0,27 mM EDTA

$0,1 \%(\mathrm{w} / \mathrm{v}) \mathrm{SDS}$

\subsubsection{In vitro transcription}

In vitro transcriptions of RNA were carried out using different DNA templates derived from PCR reactions or linearized plasmid DNA (plasmid was restricted with Acc651 and then purified via PCI and ethanol precipitation). Depending on the type of the promoter of DNA templates, either Sp6 or T7 were used as DNA-dependant RNA polymerases. The synthesis of radioactively labeled pre-mRNA was performed using $[\alpha-32 P]$ UTP in a small reaction whereas the transcription of "cold" pre-mRNA was carried out in a preparative scale. For subsequent labeling of pre-mRNAs with a fluorescent dye, $\alpha$-GMPS was used in a 10:1 ratio over $\alpha$-GTP to be used as a starter nucleotide (for details see "pre-mRNA labeling"). The transcription reactions were incubated for $2,5 \mathrm{~h}$ at $37^{\circ} \mathrm{C}$ or $40{ }^{\circ} \mathrm{C}$ (for $\mathrm{T} 7$ and Sp6 polymerases, respectively). The reaction mixture was then loaded on a $5 \%$ denaturing polyacrylamide RNA gel containing $8 \mathrm{M}$ urea. In the case of radioactively labeled RNA, the transcript was detected by autoradiography whereas cold transcript was visualized by UV- 
shadowing at $312 \mathrm{~nm}$. The RNA bands were cut out from the gel and transferred to a $2 \mathrm{ml}$ reaction tube, $1,8 \mathrm{ml}$ of RNA elution buffer was added to the tube and the elution of the pre-mRNA from the gel piece was carried out by shaking at $4{ }^{\circ} \mathrm{C}$ over night. The next day, the supernatant without gel pieces was transferred to a chromatography column and filtered followed by ethanol precipitation as described above. The resulting pellet was resuspended in $\mathrm{ddH}_{2} \mathrm{O}$ and stored at $-20{ }^{\circ} \mathrm{C}$. The concentration of the cold RNA was determined as described above. From the radioactively labeled premRNA, $1 \mu$ l was counted in a scintillation counter and the specific activity of the transcript was calculated with the formula:

$$
R N A(\text { pmol })=\frac{\text { total cpm }}{2.2 \times 10^{6} \mathrm{cpm}} \times \frac{2+(\text { age of } 32 P)}{2 \times \operatorname{SA32P}\left(\mu \frac{\mathrm{Ci}}{\text { pmol }}\right)} \times \frac{[U T P(\mu M)]}{[32 P U T P(\mu M)] \times(\# \text { of Us })}
$$

where age of $32 \mathrm{P}$ is in weeks; SA $32 \mathrm{P}=$ specific activity of $32 \mathrm{P}$, usually $3 \mu \mathrm{Ci} / \mathrm{pmol}$; \# of $\mathrm{Us}=$ number of $\mathrm{U}$ residues per transcript.

\section{Radioactivly Labeled Transcription}

$\begin{array}{ll}\text { Template } & 0.1 \mu \mathrm{g} / \mu \mathrm{l} \\ \text { RNA polymerase buffer (NEB) } & 1 \mathrm{x} \\ \text { rNTPs } & \mathrm{A}, \mathrm{C}+\mathrm{G}[0.5 \mathrm{mM}] ; \mathrm{U}[0.1 \mathrm{mM}] \\ \text { RNasin (Promega) } & 2 \mathrm{U} / \mu \mathrm{l} \\ \left.\alpha-{ }_{-}^{32} \mathrm{P}\right] \mathrm{UTP}(3000 \mathrm{Ci} / \mathrm{mmol}) & 1 \mu \mathrm{l} / 4 \mu \mathrm{l} \text { reaction }\end{array}$

\section{Unlabeled Transcription}

Template

Selfmade transcription buffer

rNTPs

RNasin (Promega)

Pyrophosphatase (NEB)

RNA polymerase (Sp6/T7)

5x selfmade transcription buffer

$0.05-0.1 \mu \mathrm{g} / \mu \mathrm{l}$

$1 \mathrm{x}$

$2.5 \mathrm{mM}$ each

$2 \mathrm{U} / \mu \mathrm{l}$

$0.02 \mathrm{U} / \mu \mathrm{l}$

$2 \mathrm{U} / \mu \mathrm{l}$
$200 \mathrm{mM}$

Tris $\mathrm{pH} 8.0$

$150 \mathrm{mM}$

$\mathrm{MgCl}_{2}$

$10 \mathrm{mM}$

Spermidine

$50 \mathrm{mM}$

DTT 


\subsubsection{Denaturing polyacrylamide gel electrophoresis of RNA (splicing products)}

Denaturing polyacrylamide gel electrophoresis was mainly used to separate RNA species up to $1500 \mathrm{bp}$ in size. The gels contained $8 \mathrm{M}$ urea as denaturing agent and were used with acrylamide concentrations between 5\% and 10\%. The acrylamide polymerization was initiated by adding ammonium persulfate and TEMED. RNA samples were resuspended in RNA loading dye and denatured at $70^{\circ} \mathrm{C}$ for 3 min prior to gel loading. The electrophoresis was performed in $1 \mathrm{x}$ TBE buffer at a constant voltage. To allow a better separation of the splicing products and intermediates, an optimized ratio of acrylamide to bisacrylamide (29:1) was used. RNAs were visualized either by silver staining or autoradiography. In case of preparative separations e.g. electrophoresis of in vitro transcriptions, UV highlighting was sufficient to visualize the RNA fragments.

\section{RNA Gel solutions (per $20 \mathrm{ml})$ :}

$8 \mathrm{M}(\mathrm{w} / \mathrm{v})$ Urea

$5 \%$ to $10 \%$ acrylamide (either Rotiphorese Gel 40 solution or a 29:1 mixture of Rotiphorese Gel A and B)

$2 \mathrm{ml} 10 \times \mathrm{TBE}$

$100 \mu 110 \%(\mathrm{w} / \mathrm{v})$ APS \& $10 \mu \mathrm{l}$ TEMED

\begin{tabular}{|c|c|c|}
\hline $\begin{array}{c}\text { Xylene } \\
\text { percentage of } \\
\text { acrylamide } \\
{[\%]}\end{array}$ & $\begin{array}{c}\text { Cyanol } \\
\text { FF } \\
\text { [bases] }\end{array}$ & $\begin{array}{c}\text { Bromophenol } \\
\text { blue } \\
\text { [bases] }\end{array}$ \\
\hline
\end{tabular}

\begin{tabular}{|c|c|c|}
\hline 5 & 130 & 35 \\
\hline 6 & 106 & 29 \\
\hline 8 & 76 & 26 \\
\hline 10 & 55 & 12 \\
\hline 20 & 28 & 8 \\
\hline
\end{tabular}




\subsubsection{Silver staining of RNA gels}

Silver staining of RNA gels was essentially performed as described by (Merril, Goldman et al. 1981). First, the gel was fixed in a solution of $40 \%$ methanol and $10 \%$ acetic acid for at least 30 min or overnight. The gel was then washed twice with a solution of $10 \%$ ethanol and $5 \%$ acetic acid for $15 \mathrm{~min}$. Afterwards, it was briefly rinsed with $\mathrm{ddH}_{2} \mathrm{O}$ and subsequently stained with a solution of $12 \mathrm{mM} \mathrm{AgNO}$ for 30 min. The stained gel was briefly rinsed with $\mathrm{ddH}_{2} \mathrm{O}$ again and then incubated with the developing solution (0.28 $\mathrm{M} \mathrm{Na}_{2} \mathrm{CO}_{3}, 0.0185 \%$ formaldehyde) until RNA bands became visible. The developing reaction was stopped by the addition of 5\% acetic acid.

\subsubsection{Northern blot analysis}

Northern blotting was used to detect specific RNAs, using radioactively labeled DNA probes complementary to the respective RNA.

RNA samples were separated using denaturing polyacrylamide gel electrophoresis (see 2.2.1.9) and subsequently transferred to a nylon membrane via a semidry blotting procedure. The transfer was carried out in $0.5 \mathrm{x}$ TBE at $3 \mathrm{~mA} / \mathrm{cm}^{2}$ of gel surface for $2 \mathrm{~h}$. After blotting, the RNAs were crosslinked to the membrane via UV irradiation with $1200 \mu$ Joule x100. Before adding the probes, the membrane was incubated with prehybridization buffer (see Table 2.1 ) at $42^{\circ} \mathrm{C}$ for $2 \mathrm{~h}$. The pre-hybridization buffer was exchanged with fresh hybridization buffer containing the radioactive probes, and the hybridization was carried out for $24-48 \mathrm{~h}$ at $42^{\circ} \mathrm{C}$.

\section{Pre-/ Hybridization Buffer}

$25 \mathrm{mM} \mathrm{Na}_{3} \mathrm{PO}_{4} \mathrm{pH} 6.5$

6 x SSC

$5 \times$ Deinhardt's solution

$0.5 \%(w / v)$ SDS

$50 \%(\mathrm{v} / \mathrm{v})$ Deionized formamide

$0.1 \mathrm{mg} / \mathrm{ml}$ Salmon sperm DNA (5 min denat.)

\section{$\underline{20 \times S S C}$}

$300 \mathrm{mM}$ Na-Citrate

$3 \mathrm{M} \mathrm{NaCl}$

$100 \times$ Deinhardt's solution

$2 \%$ (w/v) Polyvenylpyrolodase

$2 \%(w / v)$ BSA

$2 \%(w / v)$ Ficoll 400 
Wash Buffer 1

$2 \times \mathrm{SSC}$

$0.5 \%(\mathrm{w} / \mathrm{v}) \operatorname{SDS}$
Wash Buffer 2

$2 \times \mathrm{SSC}$

$0.1 \%(w / v)$ SDS

Table 2.1: Solutions for Northern blotting

After hybridization, the membrane was washed twice at RT for 5 min with wash buffer 1 and twice with wash buffer 2 . A third wash step with wash buffer 2 was performed for $30 \mathrm{~min}$ at $50^{\circ} \mathrm{C}$. The radioactive probes were visualized via autoradiography.

The radioactive probes were generated using the Prime It II random primer labeling kit according to the manufacturer's instructions.

\subsubsection{Protein-biochemistry standard methods}

\subsubsection{Concentration determination of proteins}

To determine the concentration of proteins mainly the Bradford protein assay was used. This method involves the binding of Coomassie Brilliant Blue G-250 dye to proteins (Valadkhan and Jaladat 2010). The dye exists in three forms: cationic (red), neutral (green), and anionic (blue). Under acidic conditions, the dye is predominantly in the cationic form with an absorption maximum at $470 \mathrm{~nm}$. When the dye binds to protein, it is converted to the blue form and the absorption maximum shifts to $595 \mathrm{~nm}$. Using a protein standard, it is possible to determine the concentration of a protein solution. During this work the Bradford protein assay kit from Biorad was used, according to the manufacturer's instructions.

\subsubsection{Ethanol precipitation of proteins for Mass Spectrometric analysis}

For mass spectrometry analyses of proteins associated with spliceosomal complexes, the peak fractions of the respective second glycerol gradient were combined in lowprotein binding $1.5 \mathrm{ml}$ reaction tubes (Eppendorf). $350 \mu \mathrm{l}$ of combined fractions (in case it was more, dried down to $\sim 300 \mu \mathrm{l}$ ) were supplemented with $40 \mu \mathrm{g}$ glycoblue, 35 
$\mu 1$ of $3 \mathrm{M} \mathrm{NaOAc}(\mathrm{pH} 5.2)$ and $1100 \mu \mathrm{l}$ of ethanol. After thorough mixing the solution was stored at least over night at $-20{ }^{\circ} \mathrm{C}$ and then centrifuged for $30 \mathrm{~min}$ at $13.000 \mathrm{rpm}$ and $4^{\circ} \mathrm{C}$ in a table top centrifuge. Subsequently, the pellet was washed with $70 \%$ ethanol, dried in a vacuum dryer and resuspended in 1x SDS PAGE loading buffer from invitrogen.

\subsubsection{Denaturing Polyacrylamide Gel Electrophoresis (PAGE)}

To analyze proteins via denaturing PAGE either pre-casted NuPAGE® Bis-Tris gels (4-12\%) or self-casted polyacrylamide gels which were use for mass spec only were prepared according to the procedure established by Laemmli (1970). Commercial gels were used according to the manufacturer's instructions. For self-casted gels typical gel compositions are listed below:

\section{stacking gel}

4x stacking gel buffer

Rotiphorese Gel 30

$\mathrm{H}_{2} \mathrm{O}$

APS

TEMED

\section{$8 \%$ separating gel}

$\begin{array}{rlr}375.0 \mu \mathrm{l} & \text { 4x separating gel buffer } & 1250.0 \mu \mathrm{l} \\ 250.5 \mu \mathrm{l} & \text { Rotiphorese Gel 30 } & 1332.5 \mu \mathrm{l} \\ 874.5 \mu \mathrm{l} & \mathrm{H}_{2} \mathrm{O} & 2417.5 \mu \mathrm{l} \\ 10.0 \mu \mathrm{l} & \text { APS } & 16.75 \mu \mathrm{l} \\ 1.0 \mu \mathrm{l} & \text { TEMED } & 16.75 \mu \mathrm{l}\end{array}$

Protein samples were dissolved in protein loading dye and heated up to $95^{\circ} \mathrm{C}$ for 5 min prior to loading. Electrophoresis was typically performed at $150-200 \mathrm{~V}$ for $45 \mathrm{~min}$ using Biorad mini gel systems. The gels were stained either with Coomassie Brilliant Blue or with silver.

\subsubsection{Coomassie staining of protein gels}

Coomassie Brilliant Blue G-250 is a triphenylmethane dye forming strong non covalent complexes with proteins. Coomassie staining of protein gels was essentially performed as described in (Sambrook, Russell et al. 1989). For preparing a staining solution, $80 \mathrm{mg}$ Coomassie Brillant Blue G-250 were dissolved in $11 \mathrm{ddH} 2 \mathrm{O}$ and stirred for at least $2 \mathrm{~h}$. Subsequently, $3.5 \mathrm{ml}$ of $37.5 \% \mathrm{HCl}$ was added to the solution and the solution was stored in an amber glass bottle at room temperature. For 
Coomassie staining of proteins, gels were first fixed for 30 min with $40 \%$ methanol/10\% acetic acid at room temperature on a shaker. After rehydration of the gel in $\mathrm{ddH}_{2} \mathrm{O}$ pre-heated, staining solution was added to the gel. After incubation for at least $1 \mathrm{~h}$ at room temperature under gentle shaking the gel was destained over night with water. Finally, the gel was scanned and lanes were cut into 23 slices and analyzed by mass spectrometry in Prof. Urlaub's department.

\section{Coomassie staining solution:}

$50 \%(\mathrm{v} / \mathrm{v})$ Methanol

$10 \%(\mathrm{v} / \mathrm{v})$ Acetic acid

$0.25 \%$ (w/v) Coomasie Brillant Blue G-250

\section{Destaining solution:}

$50 \%(\mathrm{v} / \mathrm{v})$ Methanol

$10 \%(\mathrm{v} / \mathrm{v})$ Acetic acid

\subsubsection{Silver Staining of Protein Gels}

Silver staining of protein gels was performed according to Blum (1987). First, the gel was fixed in a solution of 50\% (v/v) Methanol/ 12\% (v/v) acetic acid for at least 30 min or overnight. Subsequently, the gel was washed twice with $50 \%(\mathrm{v} / \mathrm{v})$ ethanol and once with $30 \%$ (v/v) ethanol for 20 min each. The gel was then treated with a solution of $0.8 \mathrm{mM} \mathrm{Na}_{2} \mathrm{~S}_{2} \mathrm{O}_{3}$ for $60 \mathrm{~s}$ and briefly rinsed with water. Afterwards, the gel was stained with a solution of $12 \mathrm{mM} \mathrm{AgNO}_{3} / 0.026 \%$ formaldehyde for $20 \mathrm{~min}$. The staining solution was removed and the gel was rinsed with water, before adding the developing solution (56 mM Na $2 \mathrm{CO}_{3}, 0.0185 \%$ formaldehyde, $16 \mu \mathrm{M} \mathrm{Na}_{2} \mathrm{~S}_{2} \mathrm{O}_{3}$ ). To stop developing, the gel was transferred in a solution of $50 \%(\mathrm{v} / \mathrm{v})$ Methanol/ $12 \%$ $(\mathrm{v} / \mathrm{v})$ acetic acid.

\subsubsection{Western blot analysis}

For western blot analysis, proteins were transferred to a nitrocellulose membrane (Protan BA83 nitrocellulose, $0.2 \mu \mathrm{m}$ by Schleicher \& Schuell) by a wet blot procedure. A Biorad Mini Trans-Blot cell was used according to the manufacturer's instructions. The transfer usually was performed at $250 \mathrm{~mA}$ for $2 \mathrm{~h}$ and a Slab4, methanol, $\mathrm{H}_{2} \mathrm{O}$ mixture (in a ratio of 5:2:3) was used as transfer buffer. After the blot, the membrane was stained with Ponceau $S$ to check for a proper transfer. The stain 
was removed by washing with a TBS-Tween solution (1x TBS, 0.1\% Tween) 2-3 times for $5 \mathrm{~min}$ each. Next, the membrane was incubated for $1 \mathrm{~h}$ at RT in a TBSTween solution containing 5\% fat free milk powder, to block unspecific interactions between the antibody and the membrane. The antibody was then added to the blocking solution in the designated dilution and incubated at RT for 1h. Afterwards, the membrane was briefly rinsed with TBS-Tween twice, and then 2 times with TBSTween for 20 min each. If a second antibody was needed, it was added after this step and the previous steps were repeated.

\subsubsection{Purification of recombinant proteins}

Cloning of the genes and purification of the recombinant proteins described in this work was performed by Dr. Jana Schmitzová, Group of Dr. Pena, MPI-BPC Göttingen.

\subsubsection{Cloning strategy and overexpression}

Genes, coding for the proteins used in this study, were cloned as described in Warkocki et al., 2009: full length PRP5, PRP2 and CWC25 genes (genes are always in italics) and the N-terminally truncated form of SPP2 (aa 36-185) were amplified by standard PCR and ligated into the following vectors: PRP2, SPP2 into pET21a (Novagen). This resulted in fusion proteins with a C-terminal hexahistidine tag. $C W C 2$ was ligated into $p E T M 11$, resulting in $\mathrm{N}$-terminal hexahistidine tagged fusion proteins. Here the tag was cleavable with a tobacco etch virus (TEV) protease. For subsequent labeling of $\mathrm{Cwc} 25$, an N-terminal or C-terminal Cysteine tag was introduced by standard PCR and the resulting DNA was cloned as done for the wildtype $C W C 25$. After verification of the constructs by sequencing, the plasmids were transformed into the E.coli strain Rosetta II (Novagen) and cultures were grown in 2XYT medium or in autoinducing medium containing antibiotics for selection of the plasmids (Studier, 2005). In the case of 2xYT medium, cultures were induced by adding 0.6 mM IPTG for His-tagged proteins and by $0.1 \mathrm{mM}$ IPTG for GST-tagged 
proteins. After $20 \mathrm{~h}$ (or $48 \mathrm{~h}$ in the case of auto-inducing medium) at $17^{\circ} \mathrm{C}$, the cells were harvested, the pellets were washed and stored at $-80^{\circ} \mathrm{C}$.

\subsubsection{Purification of proteins}

All purification steps were performed at $4^{\circ} \mathrm{C}$. First, the cell pellets were resuspended in $5 \mathrm{ml}$ lysis buffer per $1 \mathrm{~g}$ of cells and lysed with a microfluidiser at 80 psi for six times (Microfluidics). After pelleting insoluble material by centrifugation for $40 \mathrm{~min}$ at $10,000 \mathrm{rpm}$ in a Sorval SS34 rotor, the supernatant was applied to HisTrap HP FF crude or GSTrap HP columns (GE Healthcare) which were equilibrated with the respective lysis buffer using the Äkta Prime system (GE Healthcare). For His-tagged proteins the column was first washed with 10 column volumes (CV) of Hislysis buffer, then with $2 \mathrm{CV}$ of washing buffer, again with $2 \mathrm{CV}$ of lysis buffer and finally with $3 \mathrm{CV}$ of $5 \%$ elution buffer in lysis buffer. After additional washing with $2 \mathrm{CV}$ each of 10, 15 and $20 \%$ elution buffer, proteins were eluted in a $20 \mathrm{CV}$ gradient of 20-100\% elutionbuffer.For GST-tagged proteins the columns were washed with 10 CV of GST-lysis buffer, then with2 CV of washing buffer followed by $2 \mathrm{CV}$ of GSTlysis buffer. The proteins were eluted with $2 \mathrm{CV}$ of $30 \mathrm{mM}$ reduced glutathione containing lysis buffer. Eluted proteins were dialyzed against His-lysis buffer containing $20 \mathrm{mM}$ imidazol for Histagged proteins and against GST-lysis buffer for GST-tagged protein versions. The tags were cleaved by the addition of TEV (Cwc25) proteases. The proteases were removed by affinity chromatography, retaining the proteases on the matrix, while purified proteins were eluted in the flow-through. Proteins were finally concentrated using Centricon concentrators (Millipore) and underwent further purification by gel filtration chromatography in buffers containing $20 \mathrm{mM}$ HEPES-NaOH pH7.5, with salt concentrations between 100 and $300 \mathrm{mM}$ $\mathrm{NaCl}$ (depending on the protein), $2 \mathrm{mM}$ DTT and $5 \%$ glycerol. Fractions of the gel filtration step were analyzed by SDS-PAGE and Coomassie staining. Fractions with $97 \%$ or higher purity were aliquoted, deep-frozen in liquid nitrogen and stored at $80^{\circ} \mathrm{C}$. Concentration was determined as described above using BCA protein assay standard kit.

\section{His-tag Lysis buffer}

50 mM HEPES $\mathrm{pH} 7.5$

$600 \mathrm{mM} \mathrm{NaCl}$

\section{His-tag Elution buffer}

50 mM HEPES pH 7.5

$600 \mathrm{mM} \mathrm{NaCl}$ 
2 mM $\square$-Mercaptoethanol

$10 \%$ glycerol

$20 \mathrm{mM}$ Imidazole
2 mM $\square$-Mercaptoethanol

$10 \%$ glycerol

$250 \mathrm{mM}$ Imidazole

\section{His-tag Wash buffer}

20 mM HEPES-NaOH pH 7.5

$2 \mathrm{M} \mathrm{LiCl}$

$5 \%$ glycerol

\section{Buffer for gelfiltration of His-tagged proteins}

20 mM HEPES pH 7.5

$200 \mathrm{mM} \mathrm{NaCl}$

2 mM DTT

$5 \%$ glycerol

\subsubsection{Purification of MS2MBP Protein}

The MS2-MBP fusion protein used for the purification of spliceosomal complexes was expressed and subsequently purified from electrocompetent BL21 DE pLysS cells. Cells containing the plasmid encoding the MS2-MBP protein were grown to an $\mathrm{OD}_{600}=0.3-0.6$ at $37^{\circ} \mathrm{C}$ in $\mathrm{LB}$ medium supplemented with the respective antibiotics. To induce the expression, IPTG was added to a final concentration of $0.1 \mathrm{mM}$ and the cells were incubated further until they reached an $\mathrm{OD}_{600}=2-2.5$. The cultures were harvested by centrifugation and the cell pellets were subsequently washed with $\mathrm{ddH}_{2} \mathrm{O}$. For cell lysis, the pellet was resuspended in $5 \mathrm{ml}$ lysis buffer $(20 \mathrm{mM}$ Tris$\mathrm{HCl}, \mathrm{pH}$ 7.6, $200 \mathrm{mM} \mathrm{NaCl}$, complete EDTA-free protease inhibitors from Roche according to the manufactures instructions) per gram of cells and processed with a microfluidiser (Microfluidics) at 80 psi for 2-3 times. The lysate was separated from cell debris by centrifugation $\left(12000 \mathrm{xg}, 4^{\circ} \mathrm{C}, 40 \mathrm{~min}\right)$ and incubated head-over-tail with $500 \mu \mathrm{l}$ of amylose resin per $10 \mathrm{ml}$ of lysate for $2 \mathrm{~h}$. Afterwards, the suspension was transferred into a Bio-Spin chromatography column (Biorad) and the resin was washed with 10 column volumes (CV) of wash buffer (20 mM HEPES, pH 7.9, 150 $\mathrm{mM} \mathrm{NaCl}, 0.05 \% \mathrm{NP}-40$ ). To decrease the salt concentration in view of the next 
purification step the amylose resin was washed with $5 \mathrm{CV}$ of $5 \mathrm{mM} \mathrm{Na}_{2} \mathrm{HPO}_{4}, \mathrm{pH} 7.0$ before the protein was eluted with $5 \mathrm{mM} \mathrm{Na}_{2} \mathrm{HPO}_{4}$ containing $20 \mathrm{mM}$ maltose. The eluate was loaded onto a heparin agarose column equilibrated with $5 \mathrm{mM} \mathrm{Na} \mathrm{HPO}_{4}$, pH7.0. After washing with $10 \mathrm{CV}$ of $5 \mathrm{mM} \mathrm{Na}_{2} \mathrm{HPO}_{4}, \mathrm{pH} 7.0$, the MS2-MBP protein was eluted using a higher salt concentration within the elution buffer $(20 \mathrm{mM}$ HEPES/KOH, pH 7.9, $100 \mathrm{mM} \mathrm{KCl,} \mathrm{15 \%} \mathrm{Glycerol,} 0.5 \mathrm{mM}$ DTT). The protein was shock frozen in liquid nitrogen and stored at $-80^{\circ} \mathrm{C}$.

\subsubsection{Cell culture and extract preparation}

\subsubsection{Cultivation of bacteria}

E. coli cells were grown in lysogeny broth (LB) medium (Sambrook, Russell et al. 1989), 2xYT medium or in autoinducing medium (Studier 2005). The medium was autoclaved for $15 \mathrm{~min}$ at $121^{\circ} \mathrm{C}$. For the selection of antibiotic resistances the medium contained Ampicillin $(100 \mu \mathrm{g} / \mathrm{ml})$, Chloramphenicol $(30 \mu \mathrm{g} / \mathrm{ml})$ or Kanamycin (30 $\mu \mathrm{g} / \mathrm{ml})$. Cells were stored for long term at $-80^{\circ} \mathrm{C}$ by adding $15 \%$ glycerol as a cryopreservative.

\subsubsection{Cultivation of yeast cells}

S. cerevisiae yeast cells were cultivated according to standard methods in YPD medium or on YPD-plates. To prepare YPD plates, first YP-medium including agar was autoclaved for $15 \mathrm{~min}$ at $121^{\circ} \mathrm{C}$ and cooled down to $60{ }^{\circ} \mathrm{C}$. Subsequently, $40 \mathrm{ml}$ of sterile $50 \%$ glucose was added per liter of YP medium (final concentration of 2 $\%)$. Subsequently, about $20-25 \mathrm{ml}$ of this medium was poured into Petri dishes. Plates were cooled down for ca. $1 \mathrm{~h}$ at roomtemperature and kept at room temperature for long-term storage. To start cultivation of a yeast strain, yeast cells were picked from a glycerol stock and streaked on a YPD-plate. The plate was then incubated for 2-3 days at $25^{\circ} \mathrm{C}$ or $30^{\circ} \mathrm{C}$ depending on the phenotype of the cells $\left(\mathrm{BJ} 2168\right.$ at $30^{\circ} \mathrm{C}$, prp21 and prp5- 1 at $25^{\circ} \mathrm{C}$ ). In the case of a replica-assay (named also frog-assay), a serial dilution of the yeast strain of interest was spotted on four different YPD-plates which 
were then incubated at $16^{\circ} \mathrm{C}, 25^{\circ} \mathrm{C}, 30^{\circ} \mathrm{C}$ and $37^{\circ} \mathrm{C}$. Cell growth was checked after 13 days and documented. For a long-term storage of the cells, the plates were sealed with parafilm and kept at $4^{\circ} \mathrm{C}$ up to 2 months. For subsequent extract preparation, a single colony of yeast cells from the YPD-plate was transferred to $50 \mathrm{ml}$ YPDmedium in a $250 \mathrm{ml}$ Erlenmeyer flask and incubated under shaking at the optimal temperature $\left(25^{\circ} \mathrm{C}-30{ }^{\circ} \mathrm{C}\right)$ depending on the yeast strain. OD600 of the cells in the pre-culture was determined and usually 20 OD of cells was inoculated into 2 liters of YPD medium in a $5 \mathrm{~L}$ Erlenmeyer flask. Alternatively, $100 \mathrm{~L}$ of YPD medium in a fermenter were inoculated with 1000 - 2500 OD 600 of yeast cells (depending on the strain) and supplemented with 4 L 50\% glucose and tetracycline and ampicillin (10 $\mu \mathrm{g} / \mathrm{ml}$ final concentration each) and incubated at the optimal temperature. Usually after 18-22 hours, cells reached an OD600 of 3-5 / $\mathrm{ml}$ and were harvested. For a longer storage in YPD medium, $800 \mu$ l of yeast cells were mixed with $400 \mu$ l of sterile $50 \%$ glycerol and kept at $-80^{\circ} \mathrm{C}$.

\section{YPD-medium}

$2 \%(\mathrm{w} / \mathrm{v})$ Bacto pepton

$1 \%(\mathrm{w} / \mathrm{v})$ Yeast extract $2 \%(\mathrm{w} / \mathrm{v})$ Glucose (sterile filtered)

$1 \%(\mathrm{w} / \mathrm{v})$ Bacto agar in the case of YPD-plates

\subsubsection{Preparation of yeast whole cell extracts and immunodepletion}

The preparation of yeast whole cell extracts for subsequent use during in vitro splicing reactions was performed essentially as described by Gottschalk, Neubauer et al. (1999). Yeast cells from the strains BJ2168, prp5-1 or prp2-1 (and its tagged derivatives), were grown overnight at $30^{\circ} \mathrm{C}$ (or $25^{\circ} \mathrm{C}$ for temperature sensitive strains) up to an OD600 of 3.5-4.5/ml in $5 \mathrm{~L}$ flasks or $10 \mathrm{~L}$ up to $100 \mathrm{~L}$ fermenter. Cells were pelleted for $10 \mathrm{~min}$ at $5000 \mathrm{rpm}$ in an SLC-6000 rotor. The pellet was washed twice with cold $\mathrm{H}_{2} \mathrm{O}$ and subsequently resuspended in cold AGK buffer (20 mM HEPES/KOH pH 7.9, $200 \mathrm{mM} \mathrm{KCl,} 1.5 \mathrm{mM} \mathrm{MgCl} 2,8 \%$ (v/v) glycerol) supplemented with $0.5 \mathrm{mM}$ DTT, $0.5 \mathrm{mM}$ PMSF, $2 \mathrm{mM}$ benzamidine, $1 \mu \mathrm{M}$ leupeptin, $2 \mu \mathrm{M}$ pepstatin A, $4 \mu \mathrm{M}$ chymostatin, and $2.6 \mu \mathrm{M}$ aprotinin. Alternatively, AGK buffer was supplemented with $0.5 \mathrm{mM}$ DTT, $0.5 \mathrm{mM}$ PMSF, $2 \mathrm{mM}$ benzamidine and one EDTAfree complete protease inhibitor tablet from Roche per $50 \mathrm{ml}$ of AGK buffer. The 
volume of the suspension was measured and the concentration of KCL was adjusted to $200 \mathrm{mM}$ again. To obtain yeast beads $2-5 \mathrm{~mm}$ in diameter, the cell suspension was dripped into liquid nitrogen, using a separating funnel. For cell lysis, these beads were ground in liquid nitrogen at $18000 \mathrm{rpm}$ using a centrifugal mill (Retsch). The powder formed during the grinding process was slowly thawed at RT, and the cell debris were separated from the extract by centrifugation $\left(25000 \times \mathrm{g}, 4^{\circ} \mathrm{C}, 30 \mathrm{~min}\right)$. A second centrifugation step at high speed was used in order to clarify the extract (100000 x g, $\left.4^{\circ} \mathrm{C}, 1 \mathrm{~h}\right)$. During the centrifugation the extract was separated into three phases. The upper phase contained lipids and liposomes, the middle phase was clear and the pellet contained ribosomes, DNA and fine cell debris. The middle phase was recovered and dialyzed twice against 50-100 volumes of buffer D (20 mM HEPES/KOH pH 7.9, 50 $\mathrm{mM} \mathrm{KCl}, 0.2 \mathrm{mM}$ EDTA, $0.4 \mathrm{mM} \mathrm{MgCl}$, 20\% (v/v) glycerol, $0.5 \mathrm{mM}$ DTT, $0.5 \mathrm{mM}$ PMSF, $2 \mathrm{mM}$ benzamidine) for $1.5 \mathrm{~h}$ each. After dialysis, the extract was centrifuged at $17000 \mathrm{x} \mathrm{g}$ for $5 \mathrm{~min}$ and subsequently frozen in liquid nitrogen. The extract was stored for long term at $-80^{\circ} \mathrm{C}$.

\subsubsection{Special methods}

\subsubsection{In vitro splicing reactions}

In vitro splicing reactions were performed essentially as described by Fabrizio, McPheeters et al. (1989). A splicing reaction usually contained 40\% total yeast extract, 1x splice cocktail (see below) and $40.000 \mathrm{cpm}(0.4 \mathrm{nM})$ of radioactively labeled Actin WT pre-mRNA. The reactions were incubated at $23^{\circ} \mathrm{C}$ for $0-60 \mathrm{~min}$ and aliquots were taken at several time points. The reactions were stopped by storing them on ice. Afterwards, Proteinase $\mathrm{K}$ digestion was used to strip off completely the proteins of the RNA. A typical Proteinase K reaction included the sample to be digested, $0.2 \%$ SDS (w/v), $10 \mathrm{mM}$ EDTA and $0.3 \mathrm{mg} / \mathrm{ml}$ proteinase $\mathrm{K}$. The reactions were incubated at $37^{\circ} \mathrm{C}$ for $30 \mathrm{~min}$. Subsequently, $200 \mu \mathrm{l}$ of "Stop-splicing" buffer were added, PCI extraction was performed followed by ethanol precipitation (2.2.1.6). The RNAs were separated by denaturing PAGE and the gels were analyzed by autoradiography.

\section{$\underline{5 x \text { splicing cocktail: }}$}

„stop splicing“ buffer

$50 \mathrm{mM} \mathrm{NaOAc}$ (pH 5.3)

$0.27 \mathrm{mM}$ EDTA

$0.1 \%(w / v)$ SDS 
$300 \mathrm{mM}$ phosphate buffer, $\mathrm{pH} 7.3^{*}$

$15 \%(\mathrm{w} / \mathrm{v})$ PEG 8000

$10 \mathrm{mM}$ ATP

$12.5 \mathrm{mM} \mathrm{MgCl}_{2}$

$10 \mathrm{mM}$ spermidine

*phosphate buffer at $\mathrm{pH} 7.3$ was prepared by mixing solutions of $\mathrm{K}_{2} \mathrm{HPO}_{4}$ and $\mathrm{KH}_{2} \mathrm{PO}_{4}$ according to Sambrook, Russell et al. (1989).

\subsubsection{Purification of spliceosomal complexes}

To isolate spliceosomal complexes under native conditions according to the protocol of Fabrizio, Dannenberg et al. (2009); (Dannenberg, Fabrizio et al. 2012) the M3-Act pre-mRNA wild type or truncated substrate was bound to the MS2-MBP fusion protein by incubating a 30-35 times molar excess of MS2-MBP with the designated pre-mRNA and $20 \mathrm{mM}$ HEPES-KOH, pH 7.9 on ice for $30 \mathrm{~min}$.

Depending on the required amount of spliceosomal complexes, a 6-72 ml splicing reaction containing $1.8-2.5 \mathrm{nM}$ of 32P-labeled M3-Act pre-mRNA (specific activity 20-300 cpm/fmol) was performed in $60 \mathrm{mM} \mathrm{K-PO4} \mathrm{(pH} \mathrm{7.4),} \mathrm{3 \%} \mathrm{PEG} \mathrm{8000,} 2.5 \mathrm{mM}$ $\mathrm{MgCl} 2,2.0 \mathrm{mM}$ ATP, $2.0 \mathrm{mM}$ spermidine, and 40\% yeast extract in buffer D (20 mM HEPES-KOH, pH 7.9, 50 mM KCl, 0.2 mM EDTA pH 8.0, 20\% (v/v) glycerol, 0.5 mM DTT, and $0.5 \mathrm{mM}$ PMSF). The complexes were assembled by incubating at $23^{\circ} \mathrm{C}$ for 50 min. Complex $\mathrm{C}$ was treated additionally with a 125 -fold molar excess of a DNA oligonucleotide complementary to $n t+13$ to +24 of the actin intron and the reaction was incubated for $10 \mathrm{~min}$ at $30{ }^{\circ} \mathrm{C}$ to allow cleavage by $\mathrm{RNaseH}$ present in the extract (Fabrizio, Dannenberg et al. 2009); (Bessonov, Anokhina et al. 2008) During this procedure, the endogenous RNase $\mathrm{H}$ present in the extract digests the RNA intron of early spliceosomal complexes whose presence would complicate the purification.

After this procedure, six ml aliquots of the splicing reaction were loaded onto 36-ml linear 10-30\% (w/w) glycerol gradients containing GK150 buffer (20 mM HEPES$\mathrm{KOH} \mathrm{pH} \mathrm{7.9,} 1.5 \mathrm{mM} \mathrm{MgCl} 2,150 \mathrm{mM} \mathrm{KCl})$. Gradients were centrifuged for $14 \mathrm{~h}$ at $23.000 \mathrm{rpm}$ in a SureSpin 630 rotor (Thermo Scientific) and harvested manually in $1500-\mu$ fractions from the top. Fractions were analyzed by Cherenkov counting in a 
scintillation counter and peak fractions containing complexes were pooled and loaded onto columns containing 250-300 $\mu \mathrm{l}$ of amylose matrix euilibrated with GK150 buffer. The matrix was washed two times with $10 \mathrm{ml}$ GK150 buffer and two times with GK75 buffer supplemented with 5\% glycerol and 0.01\% NP40, and spliceosomal complexes were eluted dropwise with $750 \mu$ l elution buffer (GK75 buffer containing $12 \mathrm{mM}$ maltose, $5 \%$ glycerol and $0.01 \% \mathrm{NP} 40$ ). The elution fractions were either used directly for reconstitution assays or for FCCS.

\subsubsection{Non-denaturing Complex gels}

First, a standard splicing assay is performed. After the incubation time of the splicing reaction (10 $\mu \mathrm{l}$ sample volume) $2 \mu \mathrm{l}$ Stop Heparin Mix* has to be added to each sample. Keep on ice, treat the sample gently. Do NOT vortex. Then, $3.0 \mu 1$ of teach sample has to be loaded on a complex gel* $4 \%(80: 1)$. The gel should be poured one day before and wrapped with foil. Keep at $4{ }^{\circ} \mathrm{C}$. Run the gel at $300 \mathrm{~V}$ for $30 \mathrm{~min}$ and then at $230 \mathrm{~V}$ for $5 \mathrm{~h}$ at $4^{\circ} \mathrm{C}$. Change the T.E. running buffer every hour. For analysis of the splicing intermediates on denaturing PAGE, PK-digestion has to be performed. Therefore, $40 \mu \mathrm{l}$ of PK-mix has to be added to the rest of each sample (see PKdigestion of proteins)

\section{“Stop Heparin" Mix:}

Complex gel solution $4 \% /(80: 1$; Acrylamide/Bis-Acrylamide):

In T.E 1x (20 mM Tris-HCl, pH 8.0, 1 mM EDTA, pH 8.0)

\subsubsection{Reconstitution of functional spliceosomes for FCCS}

\subsubsection{Treatment of complexes for RNA PAGE}

$10 \mathrm{fmol}$ of $\mathrm{B}^{\mathrm{act}}{ }_{-} \mathrm{Prp} 2$ complexes from the elution of the amylose matrix were supplemented with $100 \mathrm{fmol}$ (10x molar excess) of recombinant proteins in a $40 \mu 1$ reaction. After incubating the reconstitution reaction for $10 \mathrm{~min}$ on ice, a 10x "rescue" solution was added to the reaction. After thorough mixing the reactions were incubated at $23{ }^{\circ} \mathrm{C}$ for 40 to $50 \mathrm{~min}$. After Proteinase $\mathrm{K}$ digestion the RNAs were 
extracted by PCI and ethanol precipitation and analyzed by an $8 \%$ denaturing PAGE followed by autoradiography.

\subsubsection{Reconstitution on Amylose Matrix}

For reconstitution assays on the amylose matrix, complexes were kept on the matrix and transferred to a $1.5 \mathrm{ml}$ reaction tube. Complex concentration was determined by Cherenkov counting and recombinant proteins were added in 10x molar excess. A typical reconstitution reaction was performed with $250 \mu 1-300 \mu 1$ amylose beads in a final volume of $600 \mu \mathrm{l}$ (in GK 75 buffer) containing $60 \mu \mathrm{l}$ "rescue" solution. Reactions were incubated at $23^{\circ} \mathrm{C}$ for 45 min and transferred back to a plastic column (one per each reaction). If ATP had to be depleted, the reaction was supplemented with $2 \mathrm{mM}$ glucose and 2 Units recombinant hexokinase and incubated for $10 \mathrm{~min}$ at $23{ }^{\circ} \mathrm{C}$ before the matrix was transferred back to the column. The reaction was then washed thoroughly with $10 \mathrm{ml}$ of GK75 buffer and the complexes were eluted with 20 $\mathrm{mM}$ maltose as described above. If several reactions were to be reconstituted on the amylose matrix, the peak of the SureSpin gradient was divided equally to the appropriate number of chromatography columns containing $250 \mu 1$ amylose beads. Reactions were then carried out like described above, but in a final volume of $500 \mu$.

\subsubsection{In-solution}

For real-time FCCS measurements, i.e. from reactions carried out in solution, reactions were carried out in a final volume of $60 \mu$ with a final complex concentration of $0.8 \mathrm{nM}-1.1 \mathrm{nM}$. Recombinant proteins were added in 10 fold excess. Instead of the 10x rescue mix, however, the reaction conditions were only adjusted to final concentrations of $2.5 \mathrm{mM} \mathrm{MgCl} 2$ and $2 \mathrm{mM} \mathrm{ATP} \mathrm{(or} \mathrm{other} \mathrm{analogues),} \mathrm{as}$ PEG8000 increased the background of the FCCS measurements.

\section{$\underline{10 x \text { "rescue" solution }}$}

$200 \mathrm{mM}$ phosphate buffer, $\mathrm{pH} 7.3$

$10 \mathrm{mM} \mathrm{MgCl} 2$

$20 \mathrm{mM}$ ATP 
$14 \%$ PEG 8000

\subsubsection{Mass spectrometry}

For Mass spectrometry, proteins recovered from purified spliceosomal complexes (usually between 100-400 fmol), were separated by SDS-PAGE using a 4-12\% BisTris-HCL (pH 7.0) NUPAGE polyacrylamide gel (Invitrogen) and stained with Coomassie. Entire lanes were cut into 23 slices and proteins were digested in-gel with trypsin and extracted as described by described Shevchenko, Wilm et al. (1996). Resulting peptides were analyzed in an LC-coupled ESI Q-ToF (QToF Ultima, Waters) and/or OrbitrapXL (ThermoFisher Scientific) mass spectrometer under standard conditions. Proteins were identified by searching fragment spectra against the NCBI nonredundant (nr) database using Mascot as search engine.

\subsubsection{Electron Microscopy}

Eluted complexes were fixed by loading onto a $3.8 \mathrm{ml}$ linear $10 \%-30 \%$ glycerol gradient containing $0.1 \%$ gluteraldehyde in the $30 \%$ gradient solution and centrifuged for $107 \mathrm{~min}$ at 490,000 g (Kastner, Fischer et al. 2008). Gradients were fractionated from the bottom using a fraction collector. Particles were negatively stained by the double-carbon film method (Golas, Sander et al. 2003). Images were taken at $160 \mathrm{kV}$ and a magnification of 88,000 or 115,000 in eucentric height at a defocus of $1.5 \mathrm{~mm}$ in a CM200FEG microscope (FEI, Eindhoven, The Netherlands) at RT on a $4 \mathrm{k} 34 \mathrm{k}$ CCD camera (TVIPS GmbH, Gauting, Germany) using 2-fold pixel binning. About 10,000 particle images were collected for each data set and were subjected to singleparticle image processing at the level of $2 \mathrm{D}$ projection images using the IMAGIC-V software package (Image Science $\mathrm{GmbH}$, Berlin, Germany). Good-quality class averages were obtained after several iterations of alignment, multivariate statistical analysis (MSA), and classification. 


\subsubsection{Labeling Methods}

\subsubsection{Preparation of yeast strains expressing EGFP-tagged proteins}

To construct yeast strains with the yEGFP tag at the $\mathrm{C}$ terminus of selected proteins, the yEGFP cassette was amplified by PCR from the plasmid pKT209 (purchased from Euroscarf, Frankfurt am Main). We used this PCR product to transform haploid yeast cells from strain 3.2.AID/CRL2101 (Yean and Lin 1991), and transformants were selected on synthetic dextrose dropout medium lacking uracil. The correct integration of the tag in the genome was confirmed by PCR, and on the protein level by western blotting. The resulting strains carry a single chromosomal copy of the gene of interest, containing the yEGFP tag, the Candida albicans URA3 marker at their $\mathrm{C}$ terminus and in addition a temperature-sensitive Prp2 ATPase (prp2-1).

\subsubsection{Pre-mRNA labeling with a fluorescent dye}

Guanosine-5'-O-monophosphorothioate (59-GMPS) can be incorporated as the first nucleotide by T7 or Sp6 RNA polymerase (dependent of the used promoter) in vitro. 5'-GMPS-containing mature actin pre-mRNA was prepared by in vitro transcription of Acc65I digested pUC18-Actin-wt plasmid DNA with T7(Sp6) RNA polymerase (40 mM Tris- $\mathrm{HCl}, \mathrm{pH} 8.0,30 \mathrm{mM} \mathrm{MgCI} 2,10 \mathrm{mM}$ DTT, $2 \mathrm{mM}$ spermidine, $0.1 \mathrm{U}$ yeast inorganic pyrophosphatase (NEB), $0.5 \mathrm{U}$ RNasin (Promega), $4 \mathrm{mM}$ ATP, $4 \mathrm{mM}$ CTP, 4 mM UTP, $1 \mathrm{mM} \mathrm{GTP,} 10 \mathrm{mM} \mathrm{5'-GMPS} \mathrm{(Biolog);} 37^{\circ} \mathrm{C}, 3 \mathrm{~h}$ ). Transcripts were purified by electrophoresis through $5 \%$ polyacrylamide, $8 \mathrm{M}$ urea gels and passively eluted into $0.5 \mathrm{M} \mathrm{NaOAc}$, pH 5.3, 1 mM EDTA, pH 8.0, 2.5\% phenolchloroform-isoamyl alcohol. To link the 5'-GMPS-modified pre-mRNA covalently to the fluorescent dye Atto647N, Atto647N-maleimide was incubated with the premRNA in the presence of $100 \mathrm{mM} \mathrm{NaPO} 4$ (pH 7.2) at RT for $4 \mathrm{~h}$. The Atto647Nlabeled pre-mRNA was prepurified by $4 \mathrm{x}$ ethanol precipitation and several washing steps to remove unreacted dye, resulting in nearly $100 \%$ labeled pre-mRNA. The dye:RNA stoichiometry was calculated according to the manufacturer's protocol (Molecular Probes).

The thiol group of the pre-mRNA and the maleimide group of the dye form a thioether linkage and are therefore covalently attached to each other. The labelling 
efficiency was determined by measuring the absorption of the RNA molecules at 260 $\mathrm{nm}$ and the absorption of the attached dye at $647 \mathrm{~nm}$. Efficiency in $\%$ is then calculated with the formula:

$$
\text { labeling efficiency } \%=\frac{A(\text { dye })}{A(R N A)} \times \frac{\varepsilon(R N A)}{\varepsilon(\text { dye })} \times \# \text { of } n t
$$

where $\varepsilon$ is the molar extinction coefficient, \# is the number of nucleotides of the respective pre-mRNA and $\mathrm{A}$ is the absorption. Usually a labeling efficiency of more than $98 \%$ was obtained.

\subsubsection{Fluorescence Cross Correlation Spectroscopy (FCCS)}

\subsubsection{Setup}

The two-color-dual-focus setup is based on an inverse epi-fluorescence microscope (MicroTime 200, PicoQuant GmbH, Berlin, Germany).The system is equipped with two identical pulsed $470 \mathrm{~nm}$ diode lasers (LDH-P-C-470 B, PicoQuant GmbH, Berlin, Germany) and two identical pulsed $635 \mathrm{~nm}$ diode lasers (LDH-P-635, PicoQuant $\mathrm{GmbH}$, Berlin, Germany) with linear polarization and a pulse duration of $50 \mathrm{ps}$ (FWHM). The lasers are pulsed alternately with an overall repetition rate of $10 \mathrm{MHz}$ (PIE mode) corresponding to a delay between pulses of 25 ns (PDL 828 "Sepia II", PicoQuant GmbH, Berlin, Germany). The light of each of the two pairs of identical wavelength lasers is combined by two polarizing beam splitters (Ealing Catalogue, St. Asaph, UK) into single beams. These beams are combined by a dichroic mirror (490 dcxr, Chroma Technology, Rockingham, VT, USA) resulting in a single beam containing both wavelengths. The beam is coupled into a polarization-preserving single mode fiber. At the fiber output, the light is collimated and reflected up by a dichroic mirror (Q660LP, Chroma Technology, Rockingham, VT, USA). Before entering the objective, the light is passed through a Nomarski prism (U-DICTHC, 
Olympus Europa, Hamburg, Germany) which splits the beam deflects into two slightly different directions depending on their polarization. Then the light is focused into the microscope's objective (UPLAPO 60x W, 1.2 N.A., Olympus Europa, Hamburg, Germany) and one thus obtains two overlapping foci with a fixed lateral distance determined by the properties of the Nomarski prism. Fluorescence is collected by the same objective (epi-fluorescence setup), passed through the Nomarski prism and the dichroic mirror, and focused by a tube lens through a single circular aperture (diameter $150 \mathrm{~mm}$ ). After the pinhole, the light is re-collimated, split by a polarizing beam splitter cube and a dichroic mirror (640 dcxr, Chroma Technology, Rockingham, VT, USA), and focused onto two single photon avalanche diodes (SPAD, AQR13, Perkin Elmer, Wellesley, MA, USA), respectively for the red and the blue excitation. Emission bandpass filters HC692/40 and HC520/35 (Semrock, USA) for red and blue excitation, respectively, positioned directly in front of each detector, discriminate fluorescence against scattered light. A single-photon counting electronics (HydraHarp 400, PicoQuant GmbH, Berlin, Germany) independently records the detected photons of all detectors with an absolute temporal resolution of 4 ps on a common time frame.

\subsubsection{Measurement protocol}

Spliceosomal complexes were assembled on fluorescently labeled pre-mRNAs (bearing Atto647 as a fluorescent label at the 5'-end) and purified as described above. On the amylose matrix complexes were supplemented with recombinant proteins as described. Complexes were kept on ice until measured by FCCS. Complexes were measured in a volume of $25 \mu \mathrm{l}$ at a concentration of $1.1 \mathrm{nM}$ in a reaction chamber consisting of two glass slides connected through a $1 \mathrm{~mm}$ spacer. Measurement was then performed for $10 \mathrm{~min}$ at room temperature. 


\section{Results}

Spliceosome dynamics comprise a complex, but regulated interplay of several snRNPs and factors that interact sequentially with the pre-mRNA. The purification of spliceosomal complexes at distinct stages is very helpful to learn more about the composition, structur and function of the yeast spliceosome. In the last years, a number of purification strategies have been employed to purify human spliceosomes at different time points in vitro. To isolate and characterize biochemically homogeneous $\mathrm{B}, \mathrm{B}^{\text {act }}$ and $\mathrm{C}$ complexes from the yeast $S$. cerevisiae, we first had to establish a system which is suitable for stalling the spliceosome assembly at distinct stages of the splicing cycle and allows purifying these complexes under native conditions. To purify the stalled complexes, we made use of an affinity selection method by using pre-mRNAs, modified at their $3^{\prime}$ or $5^{\prime}$ end, which were fused to three MS2-binding sites (M3) to their 5' end. Each stalled complex was isolated by a three step affinity selection method including centrifugation and affinity-selection (Deckert, Hartmuth et al. 2006); (Jurica and Moore 2002).Their proteomes was determined by mass spectrometry (MS), and their structures were examined by electron microscopy (EM).

\subsection{Pre-mRNA constructs and conditions used for the isolation of yeast spliceosomal complexes}

To isolate biochemically homogeneous $\mathrm{B}, \mathrm{B}^{\text {act }}$ and $\mathrm{C}$ complexes actin pre-mRNA and its modifications were employed. For the later affinity purification, three MS2 binding sites were fused to the $5^{\prime}$ end of the various pre-mRNA constructs; the resulting constructs were termed "M3-Act". Previous studies have shown that truncation/modification or mutation of the actin pre-mRNA and adjustment of the ATP concentration in the splicing reaction lead to stalling of the spliceosomal cycle (Cheng 1994);(Vijayraghavan, Parker et al. 1986); (Rymond and Rosbash 1985). The intron in the actin pre-mRNA contains the yeast consensus branch point sequence (BPS) UACUAAC. M3-Act $\Delta 6$ and M3-Act $\Delta 31$ were truncated 6 and 31 bases after 
this sequence. Both of these, thus, lacked the 3'SS and the 3' exon. The variant M3ActACAC contained a mutation in the introns' 3'SS (AGAG to ACAC), which was followed by an unmutated but shortened 3' exon. The inclusion of only $0.05 \mathrm{mM}$ ATP in the splicing reaction led to stalling of the spliceosomal cycle at the stage of the precatalytic B complex for the wild-type and for the M3-Act $\Delta 6$ construct, as already observed in previews studies (Tarn, Lee et al. 1993).

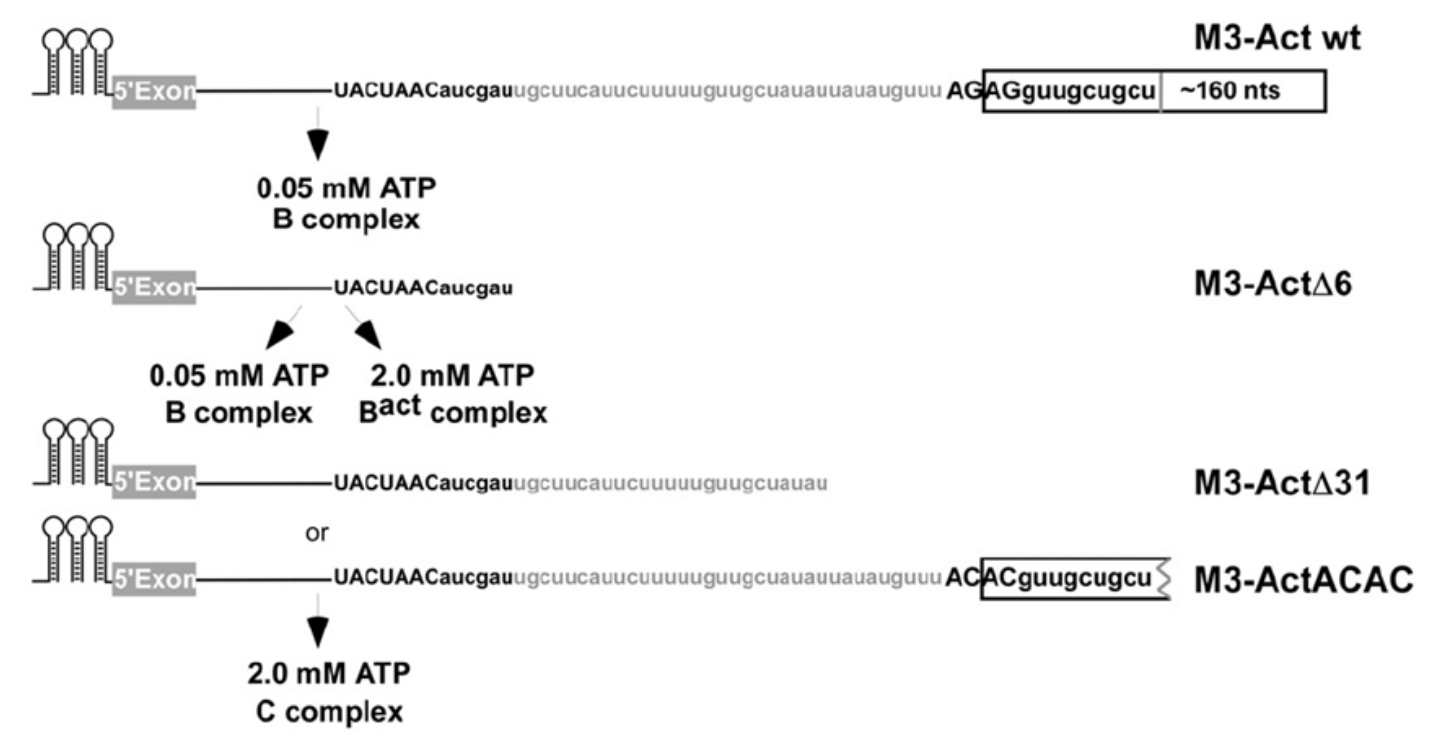

Figure 3.1: Pre-mRNA constructs used for the purification of spliceosomes

(adapted from (Fabrizio, Dannenberg et al. 2009)

M3-Act wt is used to assemble either complex B under low ATP concentrations while M3-Act $\Delta 6$ is used to stall $\mathrm{B}^{\text {act }}$ complexes. M3-Act $\Delta 6$ is truncated six nucleotides downstream of the BPS, M3-Act $\Delta 31$ is truncated 31 nucleotides after the BPS and stalls spliceosome assembly at the stage of complex C. M3Act ACAC has a mutation in its 3'SS (AGAG to ACAC) and stalls the cycle prior to the second step.

\subsection{Preliminary work for stalling and isolating active spliceosomal complexes from yeast at defined stages}

Our first goal was to test if our "set up" worked for the isolation of spliceosomal complexes from the yeast S.cerevisiae thus, we verified that the presence of the three MS2 hairpins did not interfere with the splicing cycle and that the constructs were able to undergo spliceosome assembly. 
For the in vitro assembly of yeast spliceosomal complexes we made use of whole cell extract made from the S.cerevisiae strain BJ-2168 (a protease deficient strain) and the various M3-Act pre-mRNA constructs mentioned above. The extracts were made according to the protocol (see methods; (Fabrizio, Dannenberg et al. 2009); (Dannenberg, Fabrizio et al. (2012). A prerequisite for this was to in vitro transcribe the pre-mRNA constructs via SP6 or T7 polymerase For detection of the RNA by autoradiography, the pre-mRNA was radioactively labeled with $\left[{ }^{32} \mathrm{P}\right]-\mathrm{UTP}$ during transcription. The inclusion of only $0.05 \mathrm{mM}$ ATP in the splicing reaction led to stalling of the splicing cycle at the stage of complex B, both for M3-Act and M3Act $\Delta 6$ (Fig. 3.2 A lanes 6-8, 14-16). Raising the ATP concentration to $2.0 \mathrm{mM}$ ATP led the splicing reaction to proceed to completion for the M3-act wt construct while the pre-catalytic $\mathrm{B}$ complex was converted into the activated $\mathrm{B}^{\text {act }}$ complex, showing neither splicing intermediates nor mature RNA, which identifies these complexes as pre-catalytic splicing intermediates (Figs. $3.2 \mathrm{~A}$ and B lanes 2-4, 10-12). When we applied the same conditions to the M3-Act $\Delta 31$ construct, we observed a different behavior compared to the M3-Act $\Delta 6$ version of pre-mRNA truncation. In this case, the spliceosome assembly could proceed up to the stage of the C complex (Fig. $3.2 \mathrm{~A}$ lanes 18-20). The presence of the cleaved 5' exon and intron-3'SS intermediates without products formation (i.e. mRNA and intron-lariat), identified this complex as a C complex which performed the first but not the second step of splicing (Fig. $3.2 \mathrm{~B}$ lanes 18-20). The characteristics of splicing using the M3-ActACAC construct was similar to the M3-Act $\Delta 31$ construct, but if one compares the intensities of the band signals on the gels, the yield of C complex was higher (Fig. 3.2 C lanes 2-4). 
A

A
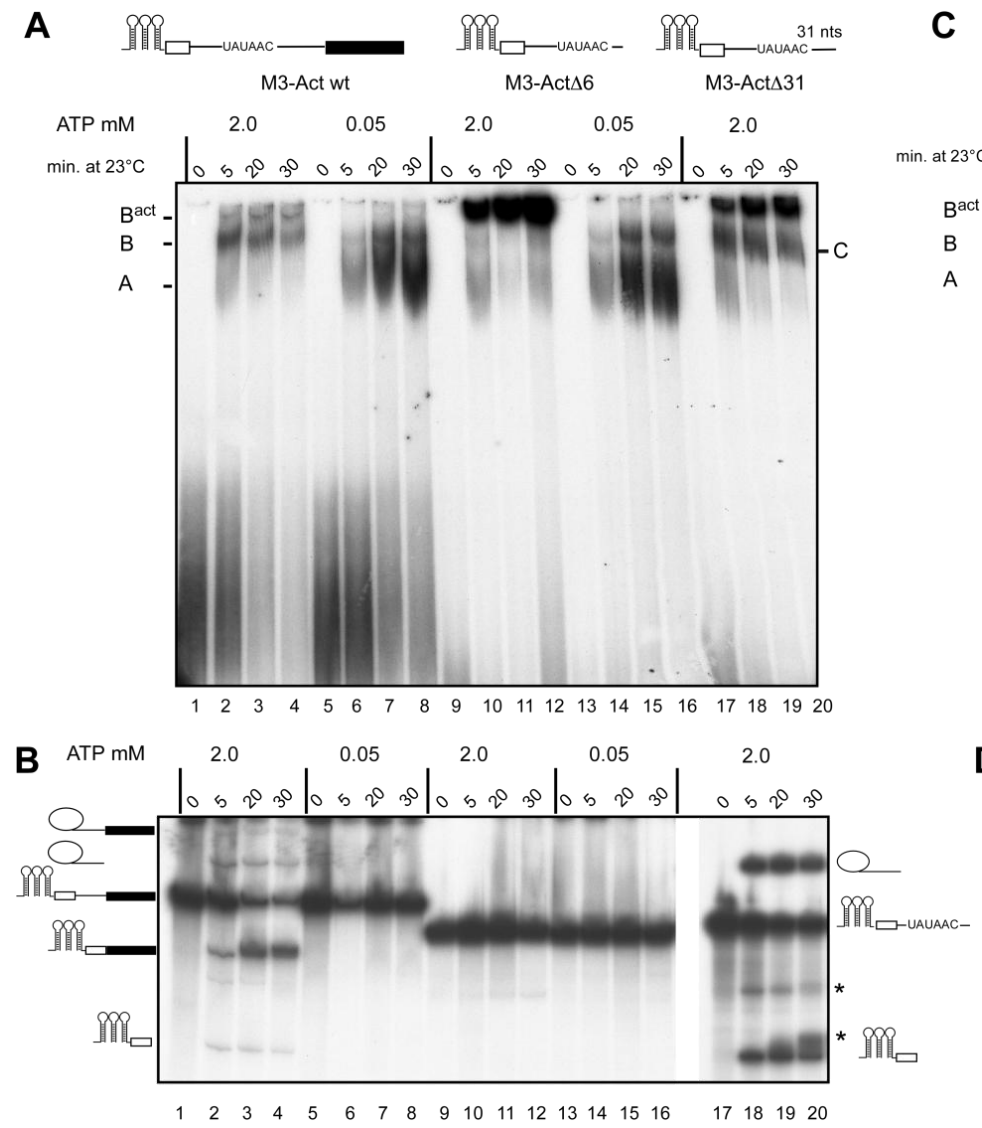
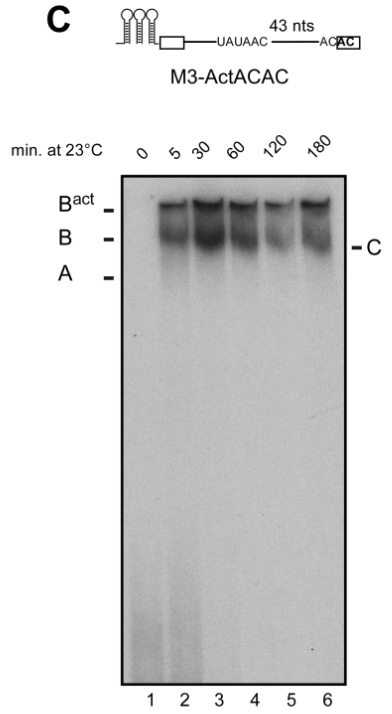

D

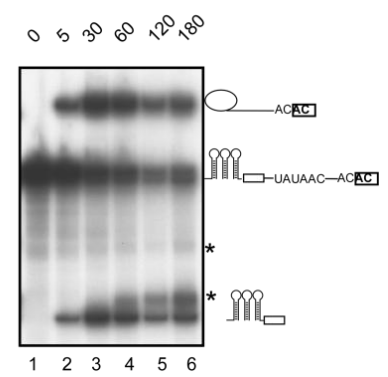

Figure 3.2: Kinetics of splicing and splicing complex formation. Panel A shows the kinetics of in vitro splicing complex formation and in panel B splicing is depicted. In lanes 1-8 of both panels M3-Act wt was used; in lanes 9-16, M3-Act $\Delta 6$ and in lanes 17-20, M3 Act $\Delta 31$ was used. The constructs are shown as a scheme above panel A. The panels $\mathrm{C}$ and $\mathrm{D}$ shows the kinetics of spliceosomal complex formation using the 3'SS mutant construct M3-ActACAC. Splicing was performed under the same conditions using $2.0 \mathrm{mM}$ ATP in yeast whole-cell extract for 0-180 min. In the panels $\mathrm{A}$ and $\mathrm{C}$ the splicing complexes were analyzed on non-denaturing RNA-PAGE. In the panels $\mathrm{B}$ and D, the RNA substrates were analyzed by denaturing RNA-PAGE. The position of the complexes, the pre-mRNA and the splicing intermediates are indicated as a scheme on the left and right. The asterisks indicate unknown RNA derivates.

\subsection{Purification of yeast spliceosomes}

To obtain preparative amounts for the isolation of spliceosomal complexes and for later analysis by mass spectrometry and electron microscopy we performed upscale experiments. Therefore we incubated first each of the different $\left[{ }^{32} \mathrm{P}\right]$-labeled M3-Act substrates with the MS2-MBP fusion protein to allow the binding of the MS2-MBP to the three MS2 hairpins at the 5'End of the pre-mRNA for later affinity-purification on 
amylose beads. Yeast whole-cell extracts prepared from the protease-deficient strain $\mathrm{BJ} 2168$ were used in these experiments and the reactions were incubated at $23^{\circ} \mathrm{C}$ for 50-60 min to allow formation of spliceosomal complexes. Mainly, the time point of $50 \mathrm{~min}$ was chosen, since after $50 \mathrm{~min}$ of incubation, the majority of spliceosomal complexes have formed. In case of low ATP, only pre-catalytic B complexes could be formed, with high ATP but with the M3-Act $\Delta 6$ substrate, spliceosomal assembly stopped at the stage of the activated $\mathrm{B}^{\text {act }}$ complex. After incubation under splicing conditions, the reaction was placed on ice and subsequently loaded on six linear 10\%$30 \%$ glycerol gradients in the presence of $150 \mathrm{mM} \mathrm{KCl}$ and was centrifuged in a Sorvall SureSpin rotor 630 at $22.100 \mathrm{rpm}$ for $18 \mathrm{~h}$ at $4{ }^{\circ} \mathrm{C}$. This step serves as a first isolation step to enrich the $\mathrm{B}, \mathrm{B}^{\text {act }}$ or $\mathrm{C}$ complexes and separate them from the majority of other spliceosomal complexes and also to remove unbound MS2-MBP fusion protein. After centrifugation, 23 fractions of $1.5 \mathrm{ml}$ were collected by hand from the top of the gradient and the peak fractions were determined by Cherenkovcounting of all fractions. The peak fractions were located in the 40S-45S region of the gradient, containing the major amount of complex $\mathrm{B}, \mathrm{B}^{\text {act }}$, or $\mathrm{C}$. These fractions were pooled and bound on an amylose column, pre-equilibrated with wash buffer G-150 (containing $150 \mathrm{mM} \mathrm{KCl}$ ) at $4^{\circ} \mathrm{C}$. The complexes were bound to the matrix by gravity flow and afterward washed two times with $~ 10 \mathrm{ml}$ of G-150 buffer, two times with $10 \mathrm{ml}$ of buffer G-75 (containing $75 \mathrm{mM} \mathrm{KCl}$ ) and then eluted with a buffer containing $12 \mathrm{mM}$ Maltose, $0.01 \%$ NP40 and 5\% glycerol in G-75. The purification was carried out under stringent conditions so that only stably bound proteins would be present. For mass spectrometry or electron microscopy, the eluted complexes underwent a second centrifugation step, this time on a 10\%-30\% glycerol gradient containing $75 \mathrm{mM} \mathrm{KCl}$ for $1 \mathrm{~h}$ and $47 \mathrm{~min}$ at 60,000 rpm in a Sorvall TH660 rotor at $4^{\circ} \mathrm{C}$ (see methods). Their distribution in the gradient was determined again by Cherenkov-counting and their RNA and protein content were analyzed by denaturing PAGE.

\subsubsection{Purification of the pre-catalytic B complex}

Spliceosomal B complexes were assembled on M3-Act $\Delta 6$ pre-mRNA substrate under splicing conditions with only $0.05 \mathrm{mM}$ ATP in the reaction. The purification was 
carried as described above. The verified sedimentation coefficient known as Svedberg constant $(\mathrm{S})$ is $\sim 40 \mathrm{~S}$ for the B complex.
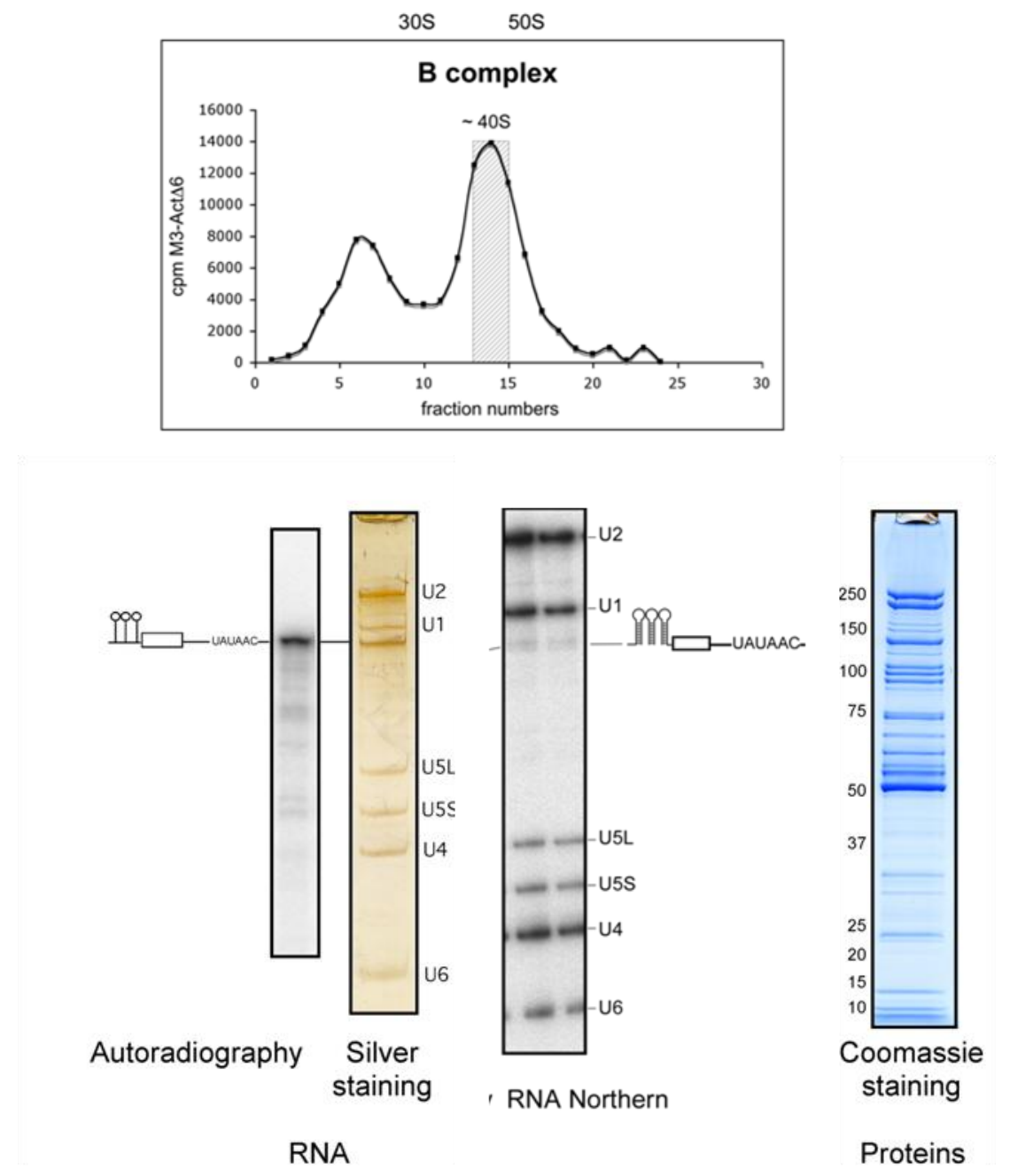

Figure 3.3: Characterization of the pre-catalytic B complex. Upper panel: Profile of purified B complex (specific activity of $100 \mathrm{cpm} / \mathrm{fmol}$ ) separated on a glycerol gradient. The radioactivity contained in each gradient fraction was determined by Cherenkov counting. Sedimentation was determined by analyzing the UV absorbance of a reference gradient containing prokaryotic ribosomal subunits. Lower panel: RNA from gradient fractions (\# 13-14) was recovered, analyzed by denaturing PAGE, and visualized by silver staining, autoradiography, and Northern analysis. RNA identities are indicated on the right. Proteins were separated by SDS-PAGE and Coomassie stained. 
The distribution of the main population of the spliceosomal B complexes is shown schematically in Fig. 3.3 A as a graph which corresponds to the gradient profile. After pooling the fractions of the main peak of the gradient, they were analyzed by RNA PAGE and Northern Blot. The autoradiography of the RNA PAGE revealed the premRNA. Silverstaining of the RNA gels afterwards revealed a full set of snRNPs, U2, U4, U5 and U6, in equimolar amounts, whereas U1 was slightly underrepresented. The snRNAs were additionally analyzed by Northern Blot (Fig. 3.3 B). No splicing intermediates were detected by denaturing PAGE, but only unspliced pre-mRNA.

\subsubsection{Affinity-purified complex $B$ is functionally committed for subsequent activation and splicing catalysis}

To examine whether the affinity-purified B complexes stalled by using $0.05 \mathrm{mM}$ ATP are functionally committed to splicing, we performed "chasing experiments". Therefore, we assembled them on M3-Act wt pre-mRNA but with $0.05 \mathrm{mM}$ ATP. The complexes isolated as described above were then incubated with a mixture of 2.0 $\mathrm{mM}$ ATP and MN-digested extract, where all endogenous snRNAs have been digested by treating with microccocal nuclease (MN).

In the presence of $2.0 \mathrm{mM}$ ATP and MN-digested extract, the purified B complexes were able to catalyze both steps of splicing (Fig. 3.4, lanes 1 and 2), whereas no splicing was observed when an equimolar amount of only naked [32P]-labeled M3Actin pre-mRNA was used under the same conditions (Fig. 3.4, lanes 9 and 10). As expected, neither affinity purified B complex nor the naked M3-Actin pre-mRNA underwent splicing in the $\mathrm{MN}$-treated extract when treated with only $0.05 \mathrm{mM}$ ATP (Fig. 3.4, lanes 5-6 and 11-12). Taken together, these experiments demonstrate that our isolated B complexes do not require complementation with any of the spliceosomal U snRNAs for their activity. Thus, we could demonstrate that the B complexes, isolated from the yeast S.cereviesiae, were no "dead-end" complexes and were able to perform the subsequent steps of splicing, on the other hand, the incubation of purified B complexes under splicing conditions, but in the absence of MN-extract, did not result in splicing (Fig. 3.4, lanes 3-4 and 7-8). This suggested that likely, these purified complexes lacked one or more factors required for subsequent spliceosome activation and/or catalysis. 
Results

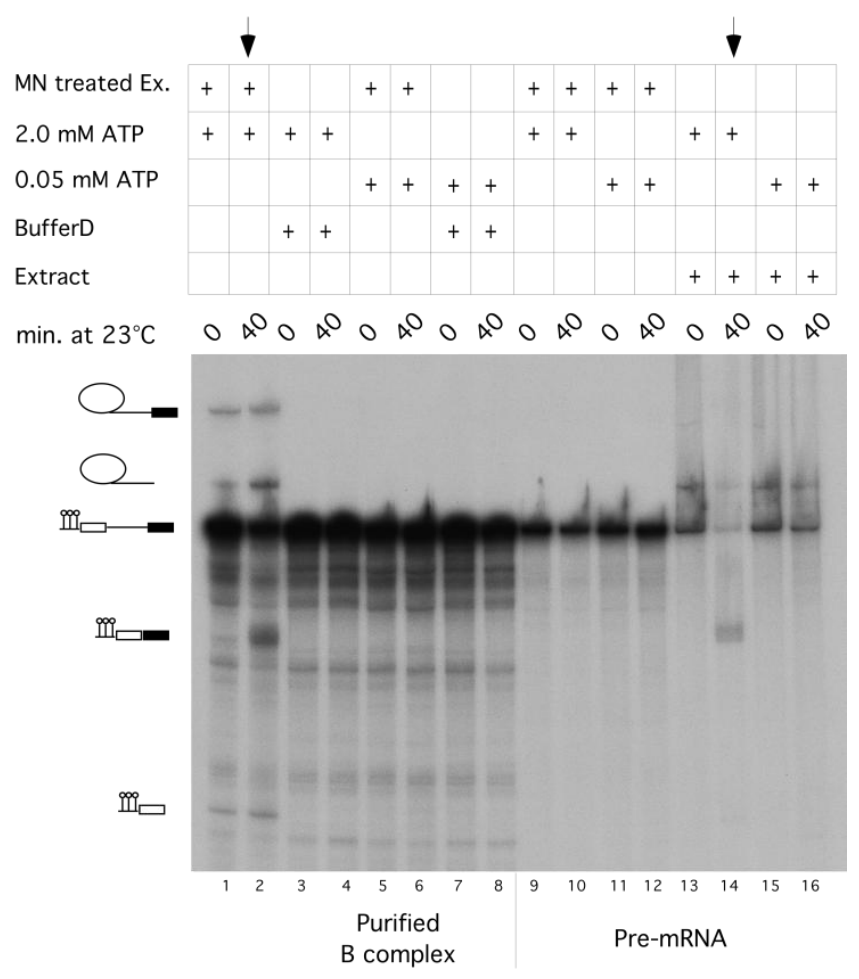

Figure 3.4: Affinity-purified complex $B$ is functionally committed for subsequent activation and splicing catalysis. Affinity-purified B complexes were incubated ( 0 and 40 minutes) with $2.0 \mathrm{mM}$ ATP and micrococcal nuclease (MN) digested extract under splicing conditions (lanes 1-2), $2.0 \mathrm{mM}$ ATP and Buffers D (lanes 2-3), (MN) digested extract and 0.05 mM ATP (lanes 5-6) and $0.05 \mathrm{mM}$ ATP and Buffer D. An equimolar amount of naked, [32P]-labeled wt M3-Actin pre-mRNA was analyzed under the same conditions (lanes 9-12), or with whole cell extract and $2.0 \mathrm{mM}$ or $0.05 \mathrm{mM}$ ATP (lanes 13-16).

\subsubsection{Purification of the activated $\mathrm{B}^{\text {act }}$ complex}

For the activated, but not catalytically active spliceosomal complex $\mathrm{B}^{\text {act }}$ the purification procedure was the same except the concentration of ATP during the splicing reaction. Complex $\mathrm{B}^{\text {act }}$ was prepared by using M3-Act $\Delta 6$ as splicing substrate and $2.0 \mathrm{mM}$ ATP. The $\mathrm{B}^{\text {act }}$ complex has a slightly higher $\mathrm{S}$ value than the $\mathrm{B}$ complex. The $S$ value changes from $40 \mathrm{~S}$ to $45 \mathrm{~S}$ due to the activation of the spliceosome which is accompanied by conformational changes of the RNA network (Fig. 3.5 A). 

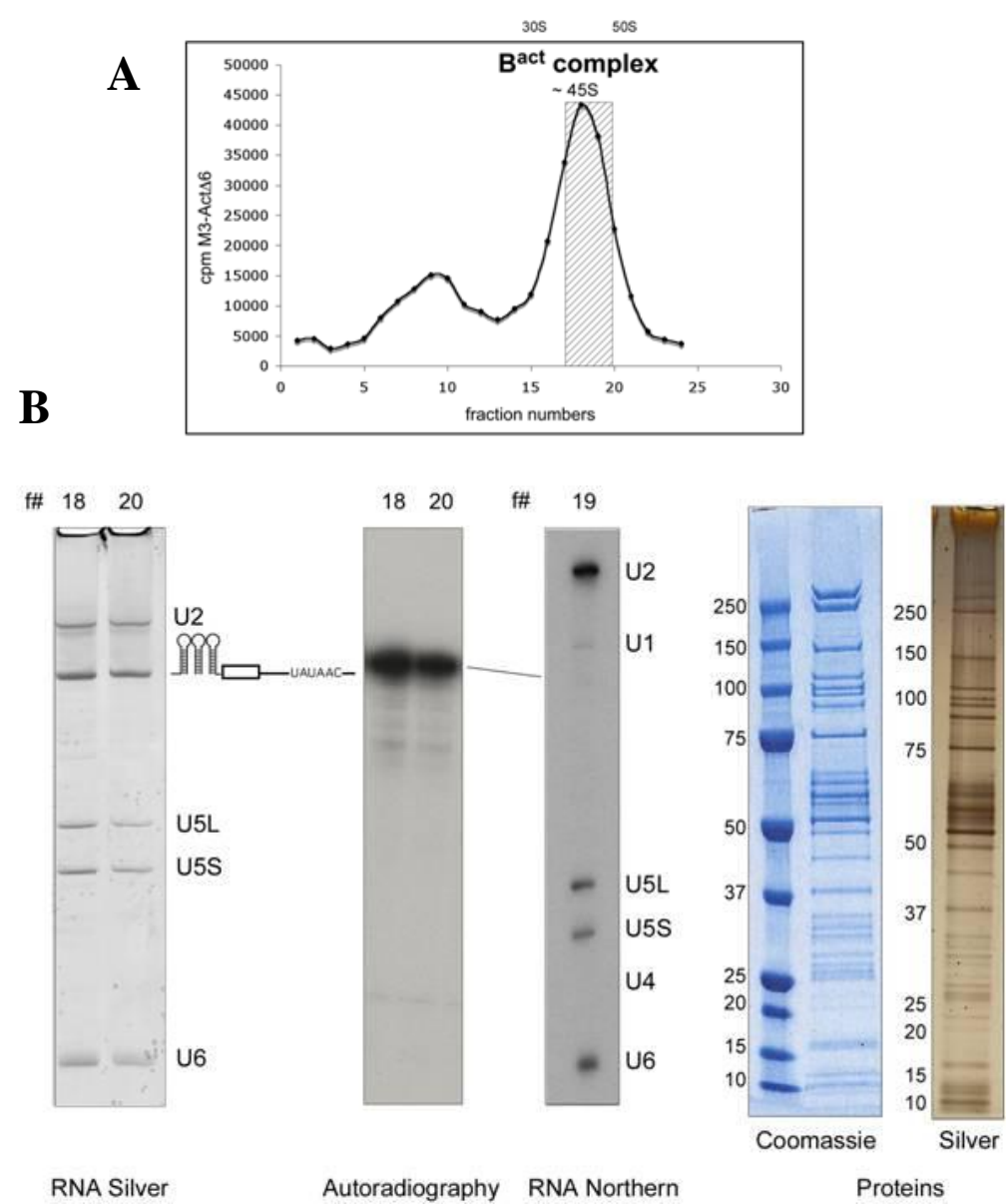

Figure 3.5: Characterization of the purified $\mathbf{B}^{\text {act }}$ complex. Upper (A): Profile of affinity-purified complex $\mathrm{B}^{\text {act }}$ (specific activity of $185 \mathrm{cpm} / \mathrm{fmole}$ ) separated on a glycerol gradient centrifuged for 15 hours at 20.700 r.p.m. $(58,257 \mathrm{~g})$ in a Sorvall TH660 rotor. The radioactivity contained in each gradient fraction was determined by Cherenkov counting. Sedimentation coefficients were determined by analyzing the UV absorbance of fractions of a reference gradient containing prokaryotic ribosomal subunits. Lower (B): RNA from gradient fractions (\#18-20), were separated by denaturing PAGE and visualized by silver staining, autoradiography and Northern analysis (fraction \# 19). RNA identities are indicated on the right. Protein composition of purified complex $B^{\text {act }}$. Proteins were separated by SDS-PAGE and visualized by staining with Coomassie or with Silver, depending on the preparation.

Nearly stochiometric quantity of unspliced pre-mRNA and U2, U5 and U6 snRNAs were detected by silverstaining, whereas U1 and U4 snRNAs were absent from this complex which is an indication that the isolated complex was the activated $\mathrm{B}^{\text {act }}$ complex and not the pre-catalytic B complex (Fig. 3.5 B). 


\subsubsection{Purification of the first step spliceosome complex $\mathrm{C}$}

Complex $\mathrm{C}$ was assembled on either M3-Act $\Delta 31$ or M3-ActACAC pre-mRNA. The use of the two different constructs was done to determine whether additional factors were recruited to M3-ActACAC as compared to the shorter M3-Act $\triangle 31$ pre-mRNA. To remove earlier pre-catalytic spliceosomal complexes like A, B and $\mathrm{B}^{\text {act }}$ complexes, we performed oligo-directed RNaseH cleavage immediately after the splicing reaction. RNasH was not added since the yeast whole cell extract already contains this enzyme. The cleaving procedure was proofed in preliminary experiments with numerous oligos which covered the whole length of our actin pre-mRNA construct to optimize the cleavage; simultaneously, we obtained additional information about the accessibility of the pre-mRNA at the stage of the first step spliceosome (Fig.3.6 A). To control that our pre-catalytic complexes underwent digestion of their pre-mRNAs, we treated also our $\mathrm{B}$ and $\mathrm{B}^{\text {act }}$ complexes with the oligo for RNAse $\mathrm{H}$ cleavage that we used for our $\mathrm{C}$ complex. We demonstrated by non-denaturing PAGE that the $\mathrm{C}$ complex was not affected by RNase $\mathrm{H}$ cleavage and that only the free pre-mRNA or pre-catalytic complexes were cleaved (Fig.3.7).

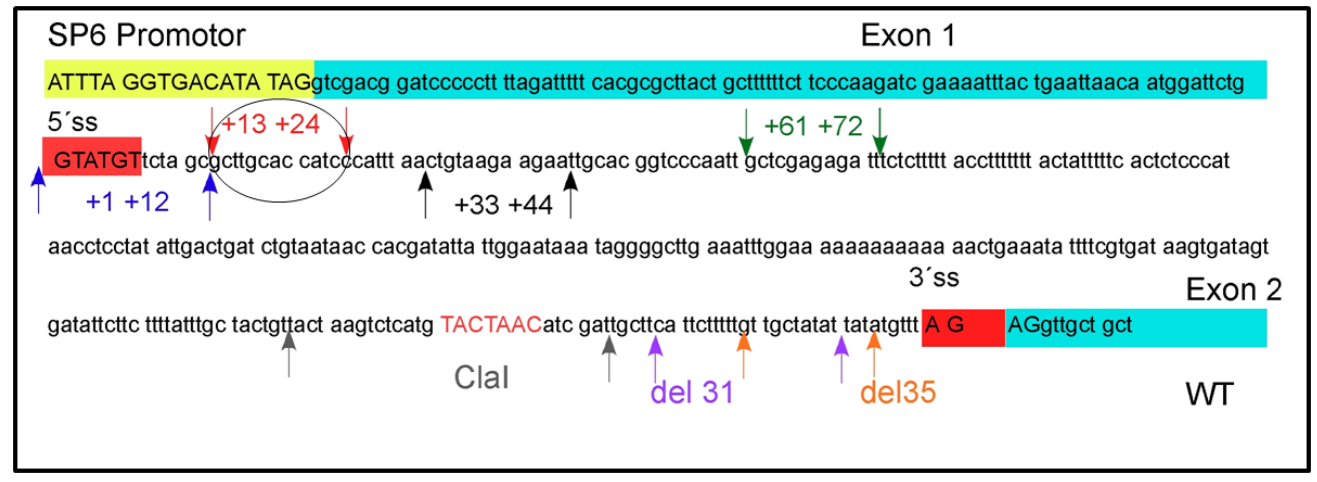

Fig. 3.6 A: Sequence of the actin wt pre-mRNA. The promoter sequence is indicated as a yellow box; both exons are shown in turquoise and the 5' and 3' SS are indicated as red boxes. The numbers stand for the region on the pre-mRNA complementary to the individual oligo. The black circle indicates the oligo used for the oligo-directed RNAseH digestion of actin wt pre-mRNA. 
Results

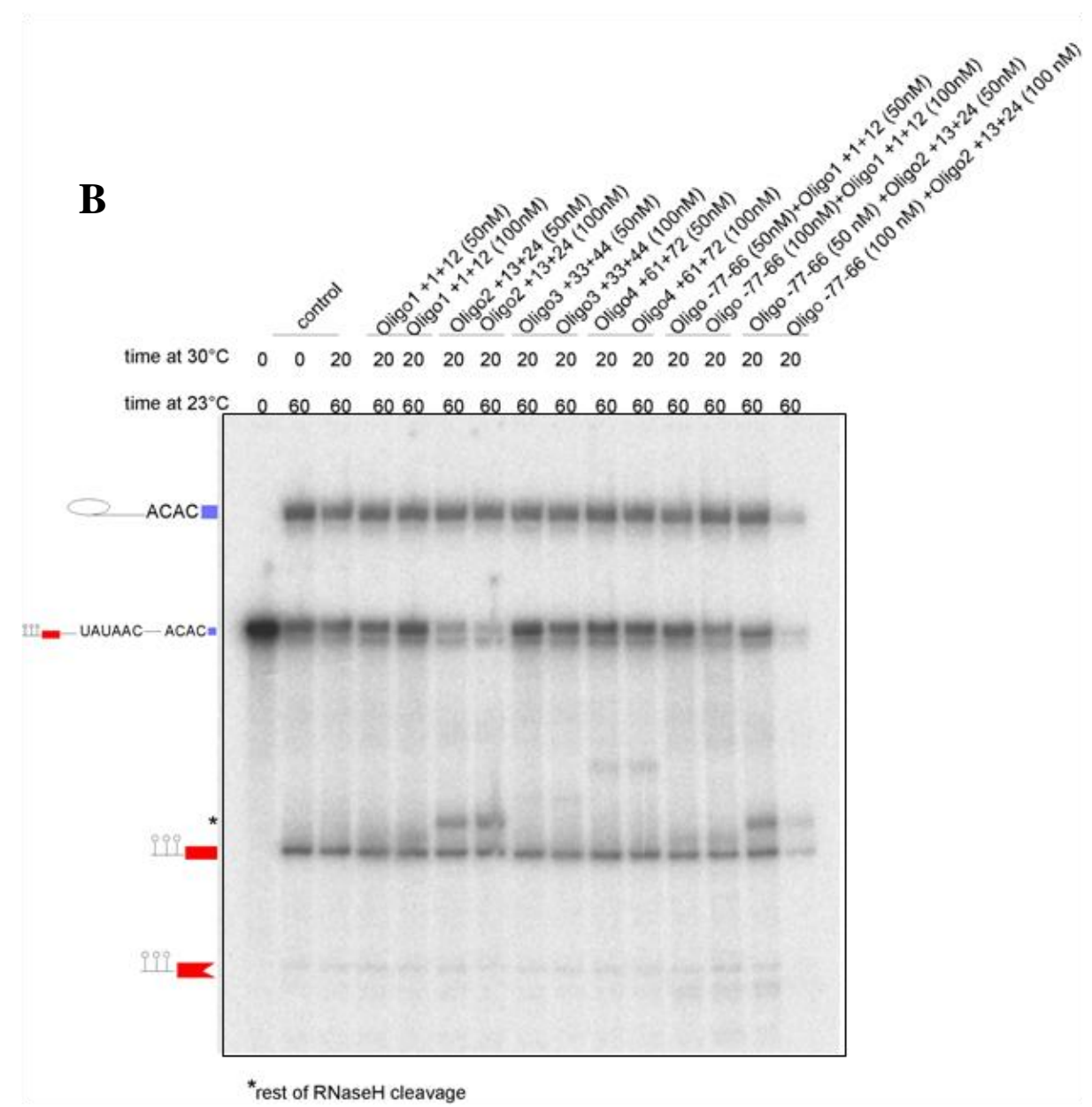

Figure 3.6 B: Test of various oligos for the oligo-directed RNAseH digestion of Actin wt pre-mRNA.RNA-PAGE of actin pre-mRNA after treatment with different oligos for directed RNase $\mathrm{H}$ cleavage. Sequence of the individual oligo is indicated above each lane, splicing intermediates are indicated schematically on the left. For details see text. 
Results

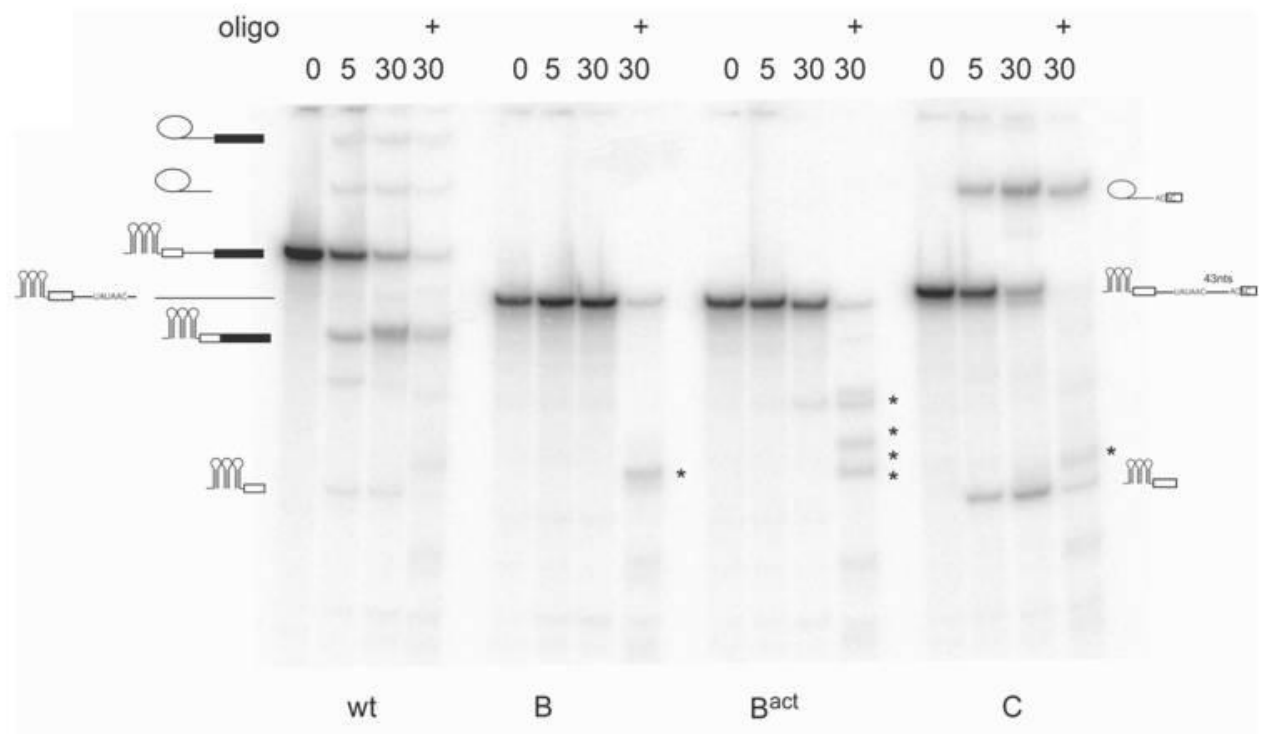

Figure 3.7: Oligo-directed RNaseH digestion of yeast $B, B^{\text {act }}$ and $C$ complexes.

Kinetics of in vitro splicing with M3-Actin wt, M3-Act $\Delta 6$ and mutated at the 3'ss (see text for details). Splicing was performed at 2.0 or $0.05 \mathrm{mM} \mathrm{ATP,} \mathrm{in} \mathrm{yeast} \mathrm{whole} \mathrm{cell} \mathrm{extract} \mathrm{for} \mathrm{0-30} \mathrm{min}$ followed by oligo-directed $\mathrm{RNaseH}$ digestion for an additional $20 \mathrm{~min}$ at $30 \mathrm{C}^{\circ}$ (+oligo). RNA was analyzed by denaturing PAGE. Asterisks: RNaseH digestion products.

The cleaving procedure was carried out for 20 min at $30{ }^{\circ} \mathrm{C}$ with an oligo complementary to the downstream region of the 5'ss +13+24 (Fig.3.6; Methods).

The purification strategy for complex $\mathrm{C}$ was as described for the other complexes. Irrespective of which pre-mRNA was used (M3-Act $\triangle 31$ or M3-ActACAC), complex $\mathrm{C}$ exhibited an $\mathrm{S}$ value of $\sim 40 \mathrm{~S}$ and contained similar amounts of U2, U5 and U6 snRNA (see Fig.3.8). Denaturing PAGE revealed an excised 5' exon and intron3'exon, which confirmed the isolation of the step 1 spliceosome. Quantitative analysis of the radioactive bands as revealed by RNA PAGE, silver staining and Northern blotting showed that only $5 \%-10 \%$ of unspliced pre-mRNA remained in the purified C complex after oligo-directed RNase H cleavage (Fig.3.8). 
Results
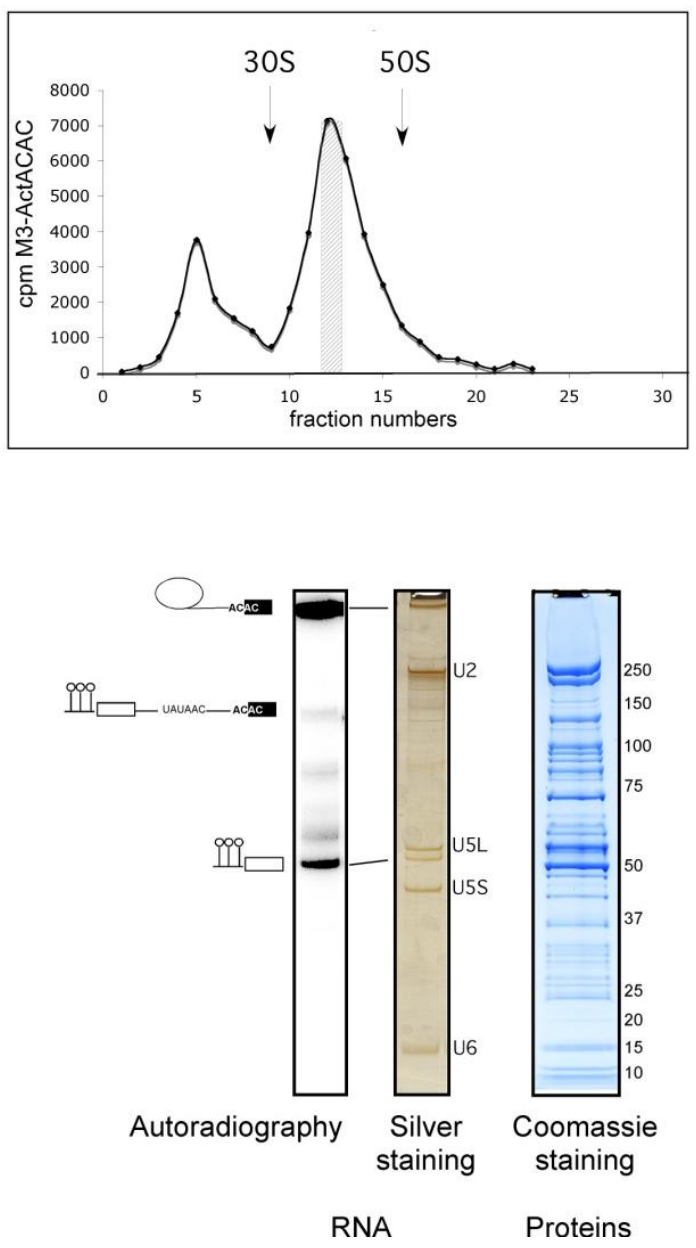

Figure 3.8: Characterization of affinity-purified C complex. Profiles of affinity-purified complex C (specific activity 200, 160 and $180 \mathrm{cpm} / \mathrm{fmole}$, respectively) assembled on M3-Actin pre-mRNAs mutated at the 3' SS, respectively and separated on glycerol gradients. The radioactivity contained in each gradient fraction was determined by Cherenkov counting. Sedimentation coefficients were determined by analyzing the UV absorbance of fractions of a reference gradient containing prokaryotic ribosomal subunits. Splicing was performed in yeast whole cell extract for $60 \mathrm{~min}$ at $23 \mathrm{C}^{\circ}$, followed by oligo-directed $\mathrm{RNaseH}$ digestion for an additional $20 \mathrm{~min}$ at $30 \mathrm{C}^{\circ}$ to allow $\mathrm{RNaseH}$ digestion of early spliceosomal complexes. RNA from gradient fractions 12-15 was separated by denaturing PAGE and visualised by silver staining and autoradiography. Splicing substrates intermediates and products as well as snRNAs identity are indicated on the right and left.

\subsection{Protein composition of purified yeast spliceosomes}

To determine the protein composition of the complexes isolated from the yeast S.cerevisiae via the three steps method described above, the peak fractions of the glycerol gradients of each complex derived from the TH660 centrifugation step were 
prepared for denaturing SDS-PAGE and the proteins were visualized by Coomassie or silver staining. The Coomassie stained protein gels were subsequently identified by liquid chromatography-coupled tandem mass spectrometry (LC-MS/MS) and scored by the absolute number of peptides found in each preparation. MS analyses were repeated several times, with a minimum of two times for each complex. Proteins which we found only in one out of two or more preparations were considered as contaminants, while the majority of the proteins found in our preparations were reproducibly detected.

\subsubsection{The proteome of the pre-catalytic B complex}

The pre-catalytic B complex was isolated as described above. After the second centrifugation step in a Sorvall TH660 rotor, the peak fractions of the gradient were pooled and the sample volume was concentrated down to a volume of $500 \mu 1-350 \mu 1$ by drying under vacuum. Samples were precipitated with 2-4 volumes of ethanol $100 \%$, washed with ethanol $70 \%$ and the pellet was resuspended in MS sample buffer. The protein sample was separated in $4-12 \%$ Bis-Tris- $\mathrm{HCl}$ ( $\mathrm{pH}$ 7.0) NuPage polyacrylamide gels (Invitrogen) and stained with G-colloidal Coomassie Brilliant Blue. An entire lane of the Coomassie-stained gel was cut into 23 slices and proteins were digested in-gel with trypsin and extracted according to (Shevchenko, Wilm et al. 1996). The peptides extracted from the samples were analyzed in an LC-coupled ESI Q-ToF (Q-ToF Ultima, Waters) mass spectrometer under standard conditions. Proteins were identified by searching fragment spectra of sequenced peptides against the NCBI non-redundant database by using the search engine Mascot.

The proteins we found associated with the yeast pre-catalytic B complex revealed a set of $\sim 60$ proteins and is shown in Table 1. This set was comprised of all known U1and U2 snRNP specific proteins (U1 snRNP: Prp39, Snu71, Prp40, Prp42, Nam8, Snu56, Snp1/U1-70k, Mud1/U1-A, Luc7Luc7B1 and Yhc/U1-C; U2 snRNP: Rse1/SF3b130, Hsh155/SF3b155, Prp9/SF3a60, Cus1/SF3b145, Prp21/SF3a120, Prp11/SF3a66, Lea1/U2-A', Hsh49/SF3b49, Ms11/U2-B', Rds3/SF3b14b and Ysf3/SF3b10). For the U5 snRNP we could detect the U5 specific proteins Prp8, Brr2, Snu114, Prp6 and Dib1. Lin 1 was not detected, because Lin1 is thought to associate only with free U5 snRNP and not together with the tri-snRNP that is 
integrated into the B complex. Also all U4/U6 particle specific proteins were found in the B complex as well as the tri-snRNP specific proteins Snu66, Spp381 and Snu23. The RNA helicase Prp28 which is known to displace the U1 snRNA from the 5'SS to allow the formation of a duplex between the 5'SS and U6 snRNA was found in any of our preparations. By RNA-PAGE and Northern blotting we could also observe a slightly underrepresentation of the U1 snRNA (see Fig. 3.3 above). These observations led to the assumption that we isolated a B complex at the stage shortly after Prp28 has acted and from which U1 snRNA is already destabilized from the 5'SS.

In all of our B complex preparations we detected each of the three candidates of the retention and splicing complex (RES complex): Bud13, Pml1 and Ist/Snu17 which is consistent with previous studies showing that these proteins associate with the yeast spliceosome before the first step. Another group consisting of eight proteins already known to contribute to splicing is the NTC (Nineteen-complex, proteins associated with Prp19). All eight proteins were found in our purified B complexes. Former experiments indicated that the NTC is required for the catalytic activation of the spliceosome and is recruited after U4 release. Our data show that the NTC is already bound to the spliceosome at the stage of the pre-catalytic B complex, but is underrepresented compared to our Bact and C complexes (see below). Most of the NTC proteins found in yeast have human counterparts, which were also found associated with the human B complex (Deckert et al., 2006). The full set of the 60 proteins together with all the miscellaneous proteins found in the yeast B complex was already described in my Diploma thesis and will not be one of the main focuses of this work. The description of the yeast B complex should only give a brief insight into spliceosome assembly to understand better the transition from the pre-catalytic spliceosome to the activated $\mathrm{B}^{\text {act }}$ complex and the first step spliceosome, the $\mathrm{C}$ complex.

\subsubsection{The proteome of the activated $B^{\text {act }}$ complex}

The method for analyzing the protein content of the purified yeast $\mathrm{B}^{\text {act }}$ complex was the same as for the B complex and the first step spliceosome. In comparison to the B complex, the proteome of the activated $\mathrm{B}^{\text {act }}$ complex shows dramatic differences in its 
composition (Table 1). The changes in the organization of the proteome included mainly the loss of all U1- and U4/U6 snRNP specific proteins and also the U6 associated Lsm2-8 proteins. This observation is consistent with the published data which showed the destabilization of the Lsm2-8 proteins during activation of the spliceosome (Chan, Kao et al. 2003). The U5 proteins Prp6 and Dib1, all proteins specific for the tri-snRNP, plus Prp5 and Urn1 are slightly underrepresented but likewise present in $\mathrm{B}$ complex but not in $\mathrm{B}^{\text {act }}$. In conclusion, $\sim 35$ proteins, more than half of the $\sim 60$ proteins found in complex $\mathrm{B}$, are released or destabilized and then lost during purification. Proteins recruited to $\mathrm{B}^{\text {act }}$ which were not present in $\mathrm{B}$ complex included $\sim 12$ proteins, several of which are well-established splicing factors or were previously detected in the endogenous Cef1-associated complex (Ohi and Gould 2002). Among these are the NTC-related proteins, which are homologous to human proteins that either physically interact with Prp19 or CDCL5 in humans or are present in the human $35 \mathrm{~S}$ U5 snRNP. Two of these proteins are also part of the human Prp19/CDCL5 complex - Cwc15/AD002 and Prp46/PRL1 - and are already integrated into human B complex (Deckert, Hartmuth et al. 2006). Two additional proteins of the NTC, termed Bud31 and Ecm2, are homologous to the human Prp19related proteins G10 and RBM22 (Makarova, Makarov et al. 2004). Another important result of the MS analysis of the protein content of the activated $B^{\text {act }}$ complex was the remarkable number of peptides which was sequenced for the RNA helicase Prp2 and its binding partner Spp2. It is already known that both proteins are required prior to step 1 . Both of them are recruited during $\mathrm{B}^{\text {act }}$ formation and their quantity is consistent with $\mathrm{B}^{\text {act }}$ being pre-catalytic. Indeed, Prp2 action is needed for catalytic activation of the spliceosome, which leads to its release. Other studies showed that another protein factor found in complex $\mathrm{B}^{\text {act }}$, Yju2, is also needed for step 1 and is known to promote step 1 after Prp2 function (Liu, Chen et al. 2007). All of the step 2 factors were absent in complex B ${ }^{\text {act }}$, except Prp17, a step 2 factor known to play an important role in step 1 of the splicing reaction (Sapra, Khandelia et al. 2008). In contrast, several well-established spliceosomal proteins known to act during step 2 of splicing were not found in $\mathrm{B}^{\text {act }}$, as for example Prp22, Prp16, Slu7 and Prp18, suggesting that $\mathrm{B}^{\text {act }}$ is very pure. Indeed, this group of proteins is recruited at a later stage. In summary, the transition from the pre-catalytic $B$ to the activated $B^{\text {act }}$ complex involves a dramatic change in composition, in which more than 30 proteins 
dissociate from the spliceosome, 12 new ones associate and eight, the NTC-complex, are stably bound. Thus, $\mathrm{B}^{\text {act }}$ is composed of $\sim 40$ proteins.

\subsubsection{The proteome of the step1 spliceosome $C$ complex}

For the assembly of complex $\mathrm{C}$, we used the M3-Act $\Delta 31$ or the M3-ActACAC substrate. Both complexes have exactly the same protein composition (compare Table 1) and for both complexes we applied the three steps affinity-purification method. The evaluation of complex $\mathrm{B}^{\text {act }}$ and $\mathrm{C}$ reveals nearly the same protein content, only the number of peptides changes if one compares individual proteins. One prominent example is the RNA helicase Prp2 and its counterpart Spp2. Both show reproducibly a reduced number of peptides in complex $\mathrm{C}$ as compared to $\mathrm{B}^{\text {act }}$. This observation is consistent with the findings of previous studies, Prp2 binds at the stage of the $\mathrm{B}^{\text {act }}$ complex and dissociates from the spliceosome concomitant with the first step of splicing (Kim and Lin 1996). Surprisingly, this dissociation was also observed for some of the members of the U2-associated, heteromeric SF3a complex and also for parts of the SF3b, like for example Rse1, Hsh155, Prp11 or Cus1, for which the peptide number decreased more than half. In comparison to Prp2 and the U2 associated proteins, the proteins of the U5 snRNP are present in equal amounts in $\mathrm{B}^{\text {act }}$ and in C complexes. The proteins associated with Prp19 exhibit a higher number of peptides in complex $\mathrm{C}$ which indicates a more stable integration in the spliceosome.

Proteins which are really characteristic for $\mathrm{C}$ complex and never found in complex $\mathrm{B}^{\text {act }}$ or $\mathrm{B}$, are a set of nine proteins, Slu7, Prp18, Prp22, Prp16, Cwc23 and Cwc25, Ntr1 and Ntr2 and Prp43. The most prominent factors are the step 2 factors Prp22, Slu7 and Prp18. Prp17 was already mentioned to be present in the $\mathrm{B}^{\text {act }}$ complex, while Prp16 could only be detected by one peptide but only in complex C. For Prp16 we have hypothesized that it is only transiently associated with the spliceosome, so it might be that we stalled complex C after Prp16 action. Another possibility is that we purified an intermediate spliceosome stalled after step 1 and before step 2. We found two additional proteins in our $\mathrm{C}$ complex preparation, $\mathrm{Cwc} 23$ and $\mathrm{Cwc} 25$. At least Cwc25 is known to be essential for growth, but the precise function of both proteins was still unknown when I started my PhD work (Ohi and Gould 2002). The helicase Prp43 together with Spp382/Ntr1 and Ntr2 are also recruited at the stage of complex 
C (Table 1). This is consistent with earlier observations that Spp382 and Ntr2 associate with Prp43 (forming the NTR complex) and thereby modulate its helicase activity (Tsai, Tseng et al. 2007). The NTR complex is associated with the spliceosome before step 2, but it acts later during the disassembly of the postspliceosomal complex (Tanaka, Aronova et al. 2007). In summary, the biochemical composition of the spliceosome changes not only during early assembly steps, but also during the transition from $\mathrm{B}^{\text {act }}$ to $\mathrm{C}$; although this compositional change is not as dramatic as that during the transition from $\mathrm{B}$ to $\mathrm{B}^{\text {act }}$.

\begin{tabular}{|c|c|c|c|c|c|c|c|c|c|c|c|}
\hline \multirow[t]{3}{*}{$\begin{array}{c}\text { Yeast } \\
\text { Protein } \\
\text { name }\end{array}$} & \multirow[t]{3}{*}{$\begin{array}{l}\text { Systematic } \\
\text { Gene name }\end{array}$} & \multirow[t]{3}{*}{$\begin{array}{l}\text { MW } \\
\text { (kD) }\end{array}$} & \multicolumn{6}{|c|}{$\begin{array}{l}\text { Number of peptides sequenced in } B \text {, } \\
B^{\text {act }} \text { and } C \text { complex preparations }\end{array}$} & \multirow{3}{*}{$\begin{array}{l}\text { Penta- } \\
\text { snRNP }\end{array}$} & \multirow{3}{*}{$\begin{array}{l}\text { Cef1 } \\
\text { TAP }\end{array}$} & \multirow{3}{*}{$\begin{array}{c}\text { Human } \\
\text { Protein name }\end{array}$} \\
\hline & & & \multicolumn{2}{|c|}{$\begin{array}{c}\text { M3-Actin } \\
\Delta 6\end{array}$} & \multicolumn{2}{|c|}{$\begin{array}{l}\text { M3-Actin } \\
\Delta 6\end{array}$} & \multirow{2}{*}{$\begin{array}{c}\text { M3 } \\
\text { Actin } \\
\mathbf{\Delta 3 1} \\
\text { C } \\
\# 1\end{array}$} & \multirow{2}{*}{$\begin{array}{c}\text { M3 } \\
\text { Actin } \\
\text { ACAC } \\
\text { C } \\
\# 2 \\
\end{array}$} & & & \\
\hline & & & $\begin{array}{l}\text { B } \\
\# 1\end{array}$ & $\begin{array}{c}\text { B } \\
\# 2\end{array}$ & $\begin{array}{l}\text { B }^{\text {act }} \\
\# 1\end{array}$ & $\begin{array}{l}\mathbf{B}^{\text {act }} \\
\# 2\end{array}$ & & & & & \\
\hline \multicolumn{12}{|c|}{ Sm proteins } \\
\hline B & YER029C & 22.4 & 31 & 3 & 49 & 8 & 9 & 33 & 14 & 5 & $\underline{B}$ \\
\hline D1 & YGR074W & 16.3 & 22 & 4 & 3 & 5 & 5 & 10 & 8 & 1 & $\underline{\mathrm{D} 1}$ \\
\hline D2 & YLR275W & 12.8 & 26 & 9 & 27 & 7 & 10 & 6 & 5 & 3 & $\underline{\mathrm{D} 2}$ \\
\hline D3 & YLR147C & 11.2 & 14 & 4 & 3 & 10 & 6 & 8 & 5 & 2 & $\underline{\mathrm{D} 3}$ \\
\hline $\mathrm{E}$ & YOR159C & 10.4 & 2 & 1 & 6 & 5 & 7 & 1 & 1 & & $\underline{E}$ \\
\hline $\mathrm{F}$ & YPR182W & 9.6 & 20 & 2 & 9 & 4 & 4 & 1 & 2 & 2 & $\underline{F}$ \\
\hline G & YFL017W-A & 8.5 & 3 & 2 & 4 & 1 & 1 & 1 & 2 & 2 & G \\
\hline \multicolumn{12}{|c|}{ U1 snRNP proteins } \\
\hline Prp39 & YML046W & 74.7 & 27 & 8 & & 1 & & & 3 & & \\
\hline Snu71 & YGR013W & 71.4 & 26 & 8 & 1 & 1 & & & 3 & & S164 \\
\hline Prp40 & YKL012W & 69.0 & 19 & 12 & 1 & 4 & & & 7 & & FBP11 \\
\hline Prp42 & YDR235W & 65.0 & 17 & 7 & & & & & 2 & & \\
\hline Nam8 & YHR086W & 56.9 & 5 & 3 & 1 & 3 & & & 2 & & TIA1/TIAR \\
\hline Snu56 & YDR240C & 56.5 & 6 & 2 & & & & & 4 & & \\
\hline Snp1 & YIL061C & 34.4 & 18 & 1 & & & & & 5 & & $\underline{\mathrm{U} 1-70 \mathrm{~K}}$ \\
\hline Mud1 & YBR119W & 34.4 & 14 & 5 & 1 & & & 1 & 3 & & $\underline{\mathrm{U} 1-\mathrm{A}}$ \\
\hline Luc7 & YDL087C & 30.0 & 1 & & 2 & & & & 2 & & LUC7B1 \\
\hline Yhc1 & YLR298C & 27.0 & 5 & & & & & & 2 & & $\underline{\mathrm{U} 1-\mathrm{C}}$ \\
\hline \multicolumn{12}{|c|}{ U2 snRNP proteins } \\
\hline Rse1 & YML049C & 153.8 & 91 & 63 & 111 & 61 & 32 & 52 & 6 & 1 & $\underline{\text { SF3b130 }}$ \\
\hline Hsh155 & YMR288W & 110.0 & 93 & 24 & 83 & 23 & 22 & 16 & 9 & 1 & $\underline{\text { SF3b155 }}$ \\
\hline Prp9 & YDL030W & 63.0 & 70 & 25 & 66 & 45 & 14 & 12 & 7 & 2 & $\underline{\text { SF3a60 }}$ \\
\hline Cus1 & YMR240C & 50.2 & 42 & 10 & 71 & 17 & 4 & 8 & 3 & & $\underline{\text { SF3b145 }}$ \\
\hline
\end{tabular}


Results

\begin{tabular}{|c|c|c|c|c|c|c|c|c|c|c|c|}
\hline Prp21 & YJL203W & 33.0 & 50 & 4 & 35 & 16 & 5 & 14 & 13 & 2 & $\underline{\text { SF3a120 }}$ \\
\hline Prp11 & YDL043C & 29.9 & 30 & 5 & 25 & 22 & 2 & 9 & 11 & 1 & $\underline{\text { SF3a66 }}$ \\
\hline Lea1 & YPL213W & 27.2 & 28 & 3 & 47 & 11 & 22 & 17 & 10 & 6 & $\underline{\mathrm{U}_{2}-\mathrm{A}^{\prime}}$ \\
\hline Hsh49 & YOR319W & 24.5 & 4 & 2 & 41 & 2 & 6 & 2 & 9 & & $\underline{\text { SF3b49 }}$ \\
\hline Msl1 & YIR009W & 12.8 & 8 & & 10 & 4 & 2 & 7 & 7 & 2 & $\underline{\mathrm{U} 2-\mathrm{B} "}$ \\
\hline Ysf3 & YNL138W-A & 10.0 & 3 & 1 & 9 & 2 & 1 & 1 & & & SF3b10 \\
\hline \multicolumn{12}{|c|}{ U5 snRNP proteins } \\
\hline Prp8 & YHR165C & 279.5 & 233 & 81 & 166 & 125 & 176 & 306 & 22 & 38 & $\underline{220 \mathrm{~K}}$ \\
\hline Brr2 & YER172C & 246.2 & 197 & 90 & 237 & 197 & 110 & 126 & 30 & 17 & $\underline{200 \mathrm{~K}}$ \\
\hline Prp28 & YDR243C & 66.6 & & & & & & & & & $\underline{100 \mathrm{~K}}$ \\
\hline Lin1 & YHR156C & 40.4 & & & & & & & & & $52 \mathrm{~K}$ \\
\hline Dib1 & YPR082C & 16.7 & 10 & 1 & & & & & 5 & & $\underline{15 \mathrm{~K}}$ \\
\hline \multicolumn{12}{|c|}{ U4/U6 snRNP proteins } \\
\hline Prp31 & YGR091W & 56.3 & 27 & 11 & & & & & 12 & & $\underline{61 \mathrm{~K}}$ \\
\hline Prp3 & YDR473C & 56.0 & 27 & 11 & & & & & 29 & & $\underline{90 \mathrm{~K}}$ \\
\hline Prp4 & YPR178W & 52.4 & 27 & 14 & & 1 & & 2 & 12 & & $\underline{60 \mathrm{~K}}$ \\
\hline Spp381 & YBR152W & 34.0 & 26 & 6 & & & & & 3 & & \\
\hline $\operatorname{Prp} 38$ & YGR075C & 28.0 & 21 & 8 & 1 & 1 & 2 & 3 & 7 & & $\underline{\text { hPRP38 }}$ \\
\hline Snu23 & YDL098C & 23.0 & 33 & 8 & & & & & 13 & & hSNU23/ZMAT \\
\hline & & & & & & & & & & & $\underline{2}$ \\
\hline \multicolumn{12}{|c|}{ Lsm proteins } \\
\hline$\underline{\mathrm{LSm} 4}$ & YER112W & 21.3 & 16 & 3 & & 1 & & & 5 & & $\underline{\mathrm{LSm} 4}$ \\
\hline LSm7 & YNL147W & 13.0 & 3 & 1 & & & & & 2 & & LSm7 \\
\hline LSm8 & YJR022W & 12.4 & 3 & 1 & & & & & 4 & & LSm8 \\
\hline$\underline{\mathrm{LSm} 2}$ & YBL026W & 11.2 & 8 & 4 & & & 2 & & 2 & & $\underline{\mathrm{LSm} 2}$ \\
\hline$\underline{\mathrm{LSm} 5}$ & YER146W & 10.4 & 2 & 1 & & & & & & & LSm5 \\
\hline$\underline{\mathrm{LSm} 3}$ & YLR438C & 10.0 & 1 & & & & & & 2 & & $\underline{\mathrm{LSm} 3}$ \\
\hline LSm6 & YDR378C & 9.4 & 5 & 1 & 1 & & & & 2 & & LSm6 \\
\hline $\begin{array}{c}\text { Yeast } \\
\text { Protein } \\
\text { name }\end{array}$ & $\begin{array}{l}\text { Systematic } \\
\text { Gene name }\end{array}$ & $\begin{array}{l}\text { MW } \\
\text { (kD) }\end{array}$ & Nun & r of $p$ & omple & quenc & $\begin{array}{l}\text { in } B, B \\
\text { ons }\end{array}$ & t and $\mathrm{C}$ & & & \\
\hline
\end{tabular}


Results

\begin{tabular}{|c|c|c|c|c|c|c|c|c|c|c|c|}
\hline & & & & & $\# 1$ & $\# 2$ & $\# 1$ & $\# 2$ & & & \\
\hline \multicolumn{12}{|c|}{ RES complex } \\
\hline Bud13 & YGL174W & 30.5 & 23 & 4 & 81 & 26 & 11 & 30 & & 1 & MGC13125 \\
\hline Pml1 & YLR016C & 23.6 & 6 & & 14 & 5 & 1 & 3 & 5 & & $\underline{\text { SNIP1 }}{ }^{a}$ \\
\hline $\begin{array}{l}\text { Ist3/Snu1 } \\
7\end{array}$ & YIR005W & 17.0 & 3 & & 12 & 2 & 3 & 1 & 7 & 1 & CGI-79 ? ${ }^{\mathrm{a}}$ \\
\hline \multicolumn{12}{|c|}{ NTC/Prp19 complex } \\
\hline Syf1 & YDR416W & 100.0 & 28 & 19 & 124 & 67 & 52 & 69 & 8 & 18 & $\underline{\text { hSYF1/XAB2 }}$ \\
\hline Clf1 & YLR117C & 82.4 & 16 & 6 & 40 & 18 & 44 & 33 & 12 & 16 & $\underline{\text { CRNKL1 }}$ \\
\hline Cef1 & YMR213W & 68.0 & 21 & 18 & 87 & 24 & 72 & 69 & 7 & 11 & $\underline{\text { CDC5L }}$ \\
\hline Prp19 & YLL036C & 56.6 & 49 & 31 & 235 & 50 & 195 & 150 & 13 & 17 & $\underline{\mathrm{hPRP} 19}$ \\
\hline Isy1 & YJR050W & 28.0 & 8 & 1 & 37 & 11 & 14 & 17 & 8 & 2 & $\underline{\text { KIAA1160 }}$ \\
\hline Syf2 & YGR129W & 25.0 & 11 & 2 & 43 & 16 & 14 & 37 & 2 & 2 & GCIP p29 \\
\hline Snt309 & YPR101W & 21.0 & 2 & 1 & 21 & 11 & 17 & 10 & 6 & 9 & $\underline{\text { SPF27 }}$ \\
\hline Ntc20 & YBR188C & 16.0 & 11 & 2 & 8 & 1 & 2 & 11 & 3 & 4 & \\
\hline \multicolumn{12}{|c|}{ NTC related proteins } \\
\hline Prp46 & YPL151C & 51.0 & 20 & 9 & 97 & 35 & 20 & 28 & 7 & 20 & $\underline{\text { PRL1 }}$ \\
\hline Prp45 & YAL032C & 42.5 & 19 & 5 & 70 & 15 & 13 & 37 & 18 & 16 & $\underline{\text { SKIP1 }}$ \\
\hline Ecm2 & YBR065C & 41.0 & & & 35 & 5 & 26 & 32 & 1 & 8 & RBM22？ \\
\hline Cwc2 & YDL209C & 38.4 & & & 43 & 19 & 9 & 45 & 11 & 5 & RBM22？ \\
\hline Cwc15 & YDR163W & 20.0 & & & 38 & 10 & 16 & 22 & & 3 & $\frac{\text { AD- }}{\underline{002 / \mathrm{HSPC} 148}}$ \\
\hline Bud31 & YCR063W & 18.4 & & & 12 & 1 & 4 & 11 & 10 & 2 & G10 \\
\hline \multicolumn{12}{|c|}{ Early splicing factors } \\
\hline $\operatorname{Prp}^{\mathrm{b}}$ & YBR237W & 96.4 & 10 & 5 & & & & & & & hPRP5 \\
\hline $\mathrm{Urn}^{\mathrm{b}}{ }^{\mathrm{b}}$ & YPR152C & 54.0 & 8 & 5 & & & & & & & TCERG $^{\mathrm{d}}$ \\
\hline \multicolumn{12}{|c|}{ Known splicing factors } \\
\hline Prp2 & YNR011C & 100.0 & & & 116 & 64 & 24 & 19 & & & DDX16 \\
\hline Spp2 & YOR148C & 20.6 & & & 15 & 6 & 1 & 1 & & $5 *$ & GPKOW/T54 \\
\hline Yju2 & YKL095W & 32.0 & & & 27 & 8 & 10 & 16 & & 5 & $\mathrm{CCDC} 130$ \\
\hline Cwc21 & YDR482C & 15.7 & & & 14 & 8 & 5 & 6 & & 2 & Srm300 \\
\hline Cwc22 & YGR278W & 67.3 & & & 48 & 17 & 33 & 67 & & 2 & KIAA1604 \\
\hline Cwc24 & YLR323C & 28.0 & & & 40 & 20 & 2 & 9 & & $4 *$ & RNF113A \\
\hline Cwc27 & YPL064C & 35.0 & & & 29 & 11 & 2 & 6 & & 1 & NY-CO-10 \\
\hline Cwc23 & YGL128C & 33.2 & & & & & 2 & 3 & & 2 & DNAJ A1 ? ${ }^{\mathrm{c}}$ \\
\hline Cwc25 & YNL245C & 20.4 & & & & & 2 & 3 & & 1 & CCDC49 \\
\hline \multicolumn{12}{|c|}{ Step 2 proteins } \\
\hline Prp17 & YDR364C & 52.0 & & & 24 & 10 & 14 & 36 & & 5 & hPRP17 \\
\hline $\operatorname{Prp} 22$ & YER013W & 130.0 & & & & & 24 & 68 & & 2 & hPRP22 \\
\hline Prp16 & YKR086W & 121.6 & & & & & & 1 & & & hPRP16 \\
\hline Slu7 & YDR088C & 44.6 & & & & & 2 & 17 & & 1 & $\underline{\text { hSLU7 }}$ \\
\hline Prp18 & YGR006W & 28.4 & & & & & 7 & 12 & & & hPRP18 \\
\hline
\end{tabular}




\begin{tabular}{|c|c|c|c|c|c|c|}
\hline \multicolumn{7}{|c|}{ Disassembly proteins ${ }^{b}$} \\
\hline Prp43 & YGL120C & 87.6 & & 9 & 2 & hPRP43 \\
\hline Ntr2 & YKR022C & 36.6 & & 2 & & \\
\hline \multicolumn{7}{|c|}{ CBP proteins } \\
\hline $\mathrm{Cbc} 2$ & YPL178W & 24.0 & 1 & 1 & & $\mathrm{CBP} 20^{d}$ \\
\hline
\end{tabular}

Table 3.1: The table shows the protein content of spliceosomal complexes isolated from the yeast S.cerevisiae. Proteins were identified by LC-MS/MS after three steps purification and separation by PAGE. Proteins identified in two out of two preparations are shown. Numbers represent the absolute number of peptides sequenced for a protein found in a particular preparation (i.e., \#1 or \#2). The table contains information about the S.cerevisiae protein, the systematic gene name, the calculated molecular weight in $\mathrm{kDa}$, and the concentration in pmols of each complex are also included (Ohi and Gould 2002);(Stevens, Ryan et al. 2002). The last column contains the name of the human protein to aid comparison with previous studies of human spliceosomal complexes. Proteins are grouped in organizational and/or functional subgroups. Prp28, Lin1 and Sad1 were not detected by MS and are included for completeness.

${ }^{\mathrm{a}}$ Homologs could not be assigned unambiguously on the basis of BLAST data.

${ }^{\mathrm{b}}$ Never detected in yeast spliceosomal complexes.

${ }^{c}$ Extensiv homology between protein family members prevents assignement of S.cerevisiae homologs on the basis of BLAST data.

${ }^{\mathrm{d}}$ Human homolog previously detected in one or more human spliceosomal complex.

(Table adapted from Molecular cell Paper,(Fabrizio, Dannenberg et al. 2009)

\subsection{Electron microscopy of Yeast spliceosomes}

To obtain the insights into the structure and the rearrangements of yeast spliceosomes during the transition from $\mathrm{B}$ to $\mathrm{B}^{\text {act }}$ to $\mathrm{C}$ complexes, we purified complexes as described above. After two steps purification we loaded the isolated complexes onto a second glycerol gradient containing glutaraldehyde to fix the particles (Kastner, Fischer et al. 2008). The gradient was collected from the bottom with a gradient collector (see Methods). Particles from the peak fractions were then negatively stained and analyzed by EM. To obtain a better resolution, the single-particle images were classified, and members of each class were averaged. Results are summarized in Figure 3.9, which shows for each particle a typical EM field (left), a gallery of class 
averages (middle) and interpretative sketches (right). All three complexes showed monodisperse distributions with a particle size of approximately $40 \mathrm{~nm}$.

\subsubsection{Electron microscopy of yeast spliceosomal complexes Complex B, $\mathbf{B}^{\text {act }}$ and $\mathbf{C}$}

The B complex shows in most projection classes a triangular or rhombic shape (uppermost block). The most noticeable structural feature of the predominant classes (Fig. 3.9, columns 1 and 2) is an almost straight element, $\sim 30 \AA$ long and 7-10 wide; in the orientation shown, this element runs from the bottom of the image (foot) to the upper left (stump). Classes looking approximately like mirror images of the main form are also found but rarely (Fig. 3.9, column 3). Other more frequently seen forms include those shown in columns 4-6. These forms could be attributed to sideon views of complex B.

Complex $\mathbf{B}^{\text {act }}$. The images analyzed from the $\mathrm{B}^{\text {act }}$ complex were very different from those of B. Most classes show a protruding domain resembling that of the foot of complex B (shown pointing downwards in the representations of $\mathrm{B}^{\text {act}}$ ) (Figure 3.9). However, the main body appears more compact. The most frequent images of $\mathrm{B}^{\text {act }}$ (Fig. 3.9, middle block, columns 1 and 2) display a slightly asymmetrical main body with outlines running left and right at different angles, such that the left appears steeper than the right. A more elongated accumulation of stain is found parallel to the left flank, while on the right there is a point-like accumulation of stain. $\mathrm{B}^{\text {act }}$ also shows relatively frequent symmetric (Fig. 3.9 column 3) and asymmetric (Fig. 3.9, column 4) variants of the main form. Further typical images of $\mathrm{B}^{\text {act }}$ are shown in columns 5 and 6 (Fig. 3.9). On the left-hand side, these show a pronounced axis while the right-hand side appears as a wing (Fig. 3.9, column 6). 

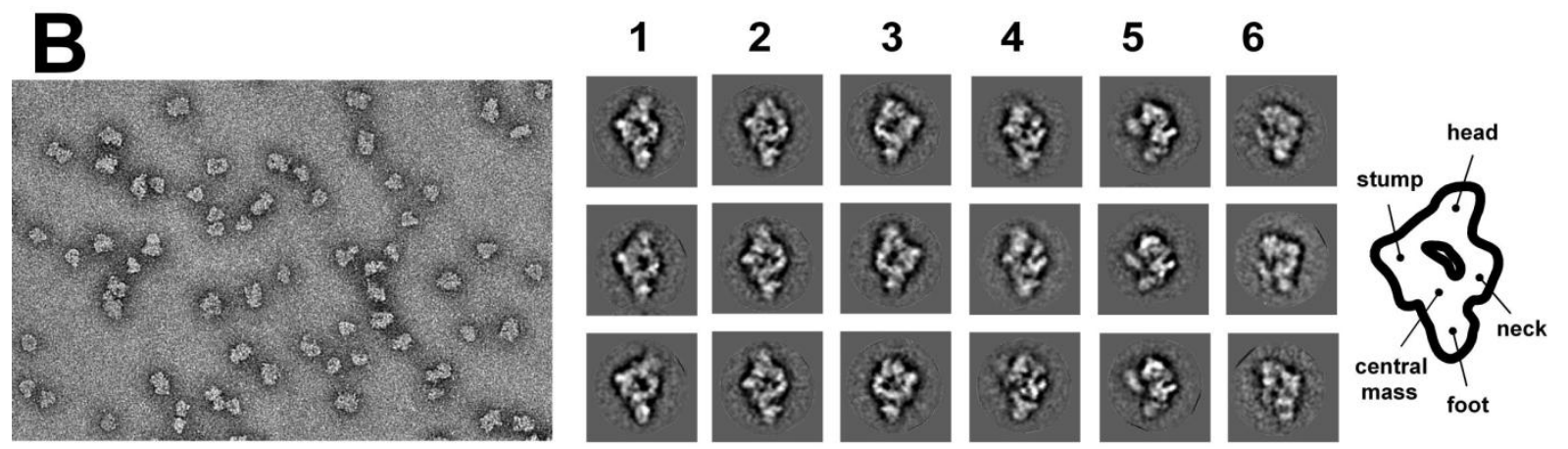

\section{Bact $^{\text {act }}$}
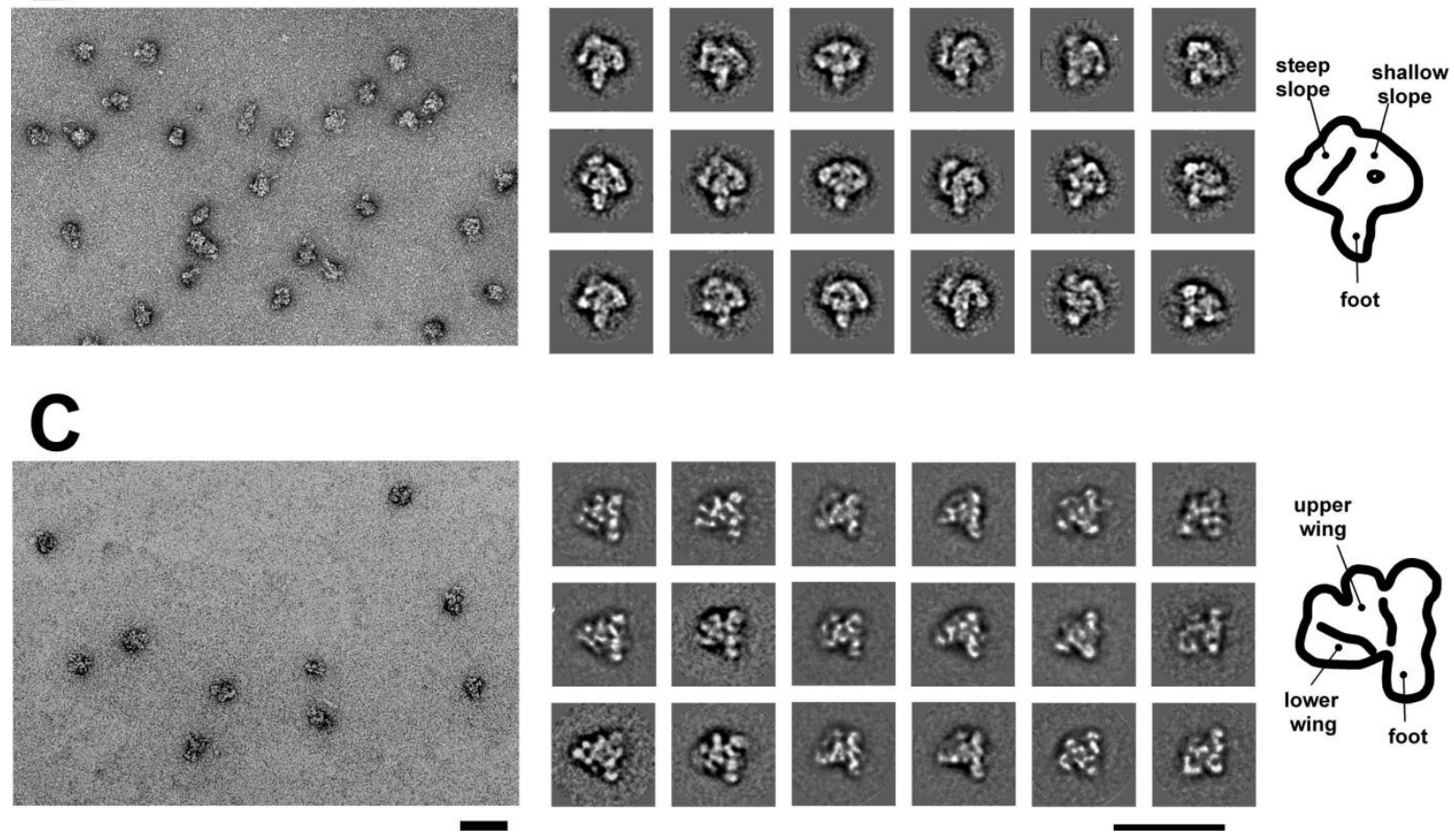

Figure 3.9: Negative stain Electron Microscopy of yeast spliceosomes. Overview of negatively stained samples is shown in the left panels. Representative class averages are shown in the galleries in the middle (numbered 1 to 6), starting with the most frequently observed class, for which a schematic drawing is shown on the right. All three particles display a short protuberance that in the class averages is shown pointing downward (foot). Some structural features are labeled. Names introduced by Boehringer (Boehringer, Makarov et al. 2004) for the human B complex are used also for the yeast B complex. A small fraction of images typical of the most frequent classes of complex $\mathrm{B}^{\text {act }}$ was also detected in the $\mathrm{C}$ complex preparation. Scale bars, $50 \mathrm{~nm}$ (Fabrizio, Dannenberg et al. 2009)

Complex C. The C complex was assembled on M3-ActACAC and exhibits also in most image classes an approximately straight element (Fig. 3.9, lowest block). Here, the axis is always on the right-hand side of the particle in the "foot-down" orientation (Fig. 3.9, columns 1-4). Less frequent forms include those shown in columns 5 and 6 
(Fig.3.9). In summary, the image classes of complex $\mathrm{C}$ appear less compact than those of $\mathrm{B}^{\text {act}}$. Thus, the analysis of the EM images of the three purified complexes reveals structures of about the same size but with quite different morphology. The most pronounced structural differences are seen between $\mathrm{B}$ and $\mathrm{B}^{\text {act }}$. Complex $\mathrm{B}^{\text {act }}$ and $\mathrm{C}$ also exhibit differences, but some views possess similar main features.

\subsection{Isolation and characterization of early spliceosomal complexes isolated from the Yeast $\mathrm{S}$. cerevisiae}

As described above, we have purified in vitro assembled spliceosomal complexes B, $\mathrm{B}^{\text {act }}$ and $\mathrm{C}$ from yeast and revealed that yeast spliceosomes contain fewer proteins than metazoans and that each functional stage is very homogeneous and well suited for three dimensional structure analyses. Next, we wanted to obtain more insights into the very early steps of spliceosomal assembly. Little is known about the compositional organization of early spliceosomal complexes harboring the U1 and U2 snRNPs, which together with several non-snRNP proteins are involved in juxtaposing the functional sites of the pre-mRNA. Here, we have stalled yeast spliceosomes at the commitment complex (CC) stage prior to pre-spliceosome (A complex) formation. Therefore we used the temperature-sensitive (ts) yeast strain carrying the mutant of the Prp5 helicase, termed prp5-1, where the helicase Prp5 can be heat-inactivated (Ruby, Chang et al. 1993) (see Introduction/Helicases). Previous studies have shown that Prp5 is thought to play an important role for the stable association of the U2 snRNP to form the pre-spliceosome. The stable integration of U2 is the first ATPdependent step in the splicing cycle and requires the helicase Prp5 (O'Day, DalbadieMcFarland et al. 1996)

Recognition and pairing of the correct 5', 3' splice sites (SS) and branch point sequence (BPS) of a pre-mRNA are critical events that occur early during spliceosome assembly in metazoans as well as in yeast. Our aim was to investigate in more detail the early events and to obtain more knowledge about the transition from commitment complex to complex A. In addition, it would be interesting to determine how the Prp5-mediated hydrolysis of ATP, promotes the stable association of the U2 snRNP in the pre-spliceosome. Therefore we used our well-established in vitro assembly and three steps purification system. 


\subsubsection{Inactivation or removal of Prp5 stalls the spliceosome assembly at the stage of the CC complex}

To stall the spliceosomal assembly at a very early stage of the assembly pathway and prior to the pre-spliceosomal A complex we used extracts made from the yeast temperature-sensitive (ts) mutant strains of Prp5 (prp5-1).

After testing the prp5-1 ts-mutant strains (kindly provided by the lab of John Abelson) for temperature sensitivity, yeast whole cell extract was made according to the protocol (Dannenberg, Fabrizio et al. 2012); see Methods). For the assembly of early complexes we used our wt M3-Act pre-mRNA substrate, ${ }^{32} \mathrm{P}$-labeled, and whole cell extract made from the ts-strain prp5-1 and a concentration of ATP of $2.0 \mathrm{mM}$. After heat-inactivation of the extract at $35^{\circ} \mathrm{C}$, we incubated the reaction with the premRNA substrate at $23^{\circ} \mathrm{C}$ for $50^{\prime}$ and incubated the sample under standard splicing conditions. Subsequently, we up scaled the experiments and purified the complexes obtained. The purification strategy was the same as for the $\mathrm{B}, \mathrm{B}^{\text {act }}$ and $\mathrm{C}$ complexes.

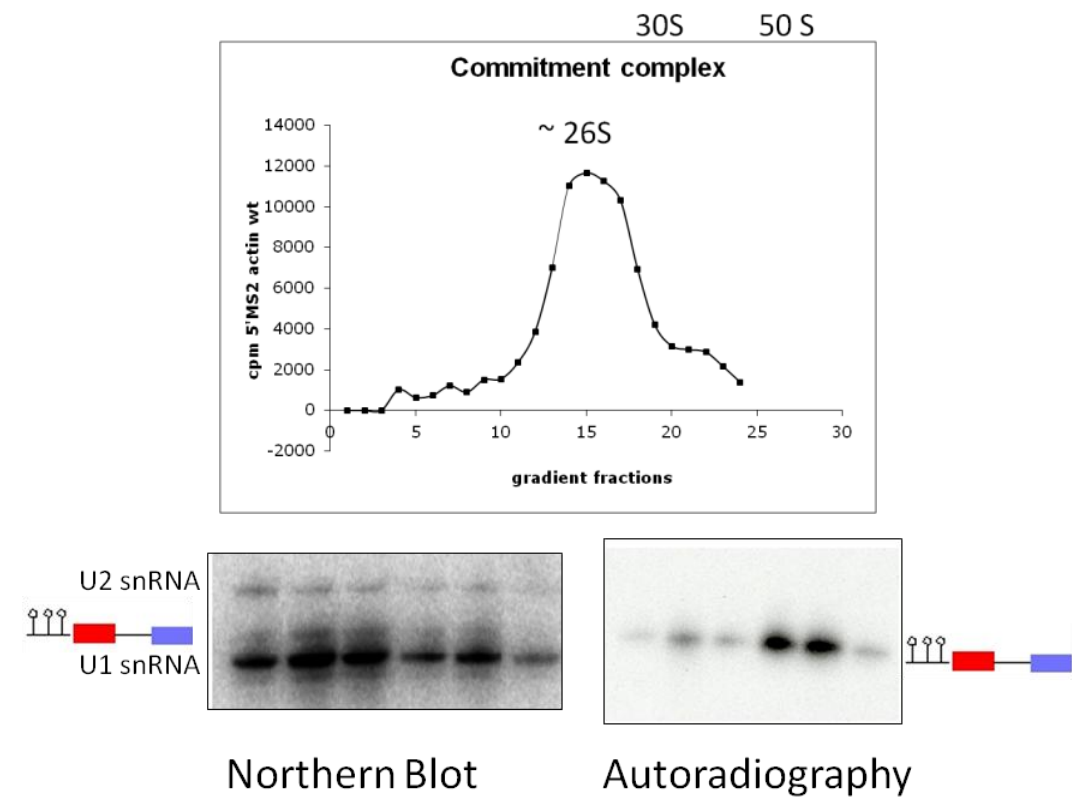

Figure 3.10: Northern Blot and autoradiography of the RNA-PAGE of the commitment complex. Profile of affinity-purified Commitment complex separated on a glycerol gradient centrifuged for 3 hours at 60.000 r.p.m. in a Sorvall TH660 rotor. The radioactivity contained in each gradient fraction was determined by Cherenkov counting. Sedimentation coefficients were determined by analyzing the UV absorbance of fractions of a reference gradient containing prokaryotic ribosomal subunits. Lower (B): RNA from gradient fractions (\#14-18), were separated by denaturing PAGE and visualized by autoradiography and Northern Blot analysis. RNA identities are indicated on the right. 
The gradient profile of the distribution of the radioactive labeled pre-mRNA in the complex, compared to co-sedimentation of $30 \mathrm{~S}$ and $50 \mathrm{~S}$ ribosomal subunits, revealed a sedimentation coefficient of $\sim 26 \mathrm{~S}$ for our stalled complex. RNA PAGE and Northern blot analysis of the purified complex showed that it contained exclusively pre-mRNA and U1 snRNPs, thus this complex had the characteristics of a CC (Fig. 3.10).

Following these preliminary studies, the protein composition of the isolated complexes has been determined by mass spectrometry. The mass spectrometry data revealed a full set of U1 snRNP proteins, all Sm proteins and the early protein factors Ms15 and Mud2, which indicated that our complex was a commitment complex 2 (CC2) (Fig. 3.11). Thus, our complexes stalled at the stage of the early commitment complex, were stable for mass spectrometry analysis. These complexes might be well suited for further studies, i.e. reconstitution of the pre-spliceosomal A complex or for further investigations concerning the role of the ATP-driven stable association of the U2 snRNP with the spliceosome.

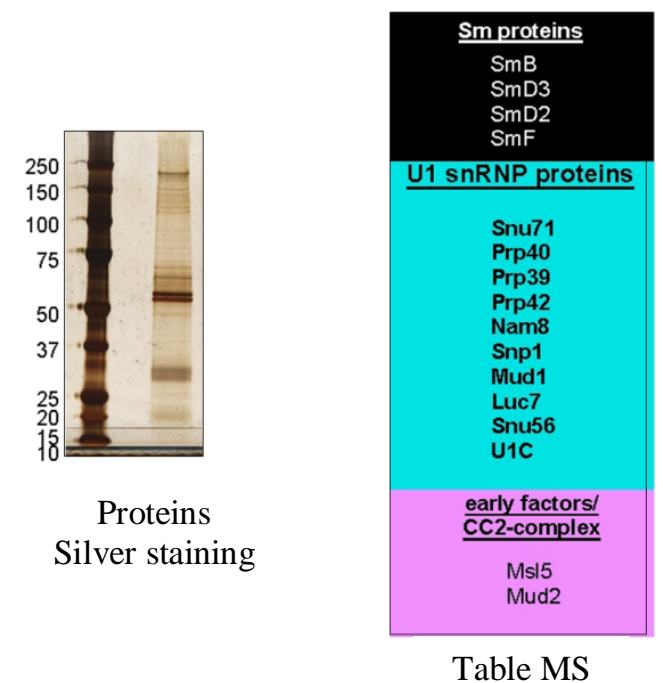

Figure 3.11: Proteins of the Commitment complex. On the left: Proteins of affinitypurified commitment complexes were analyzed by PAGE and silver staining. On the right: Table of Proteins found in our preparations of commitment complexes isolated from yeast as revealed by MS.

If one compares the protein content analyzed by silver or coomassie stained gels of the early $\mathrm{CC}$ complex with the one of $\mathrm{B}$ and $\mathrm{B}^{\text {act }}$ complexes (see Figures 3.3 and 3.5 
above), one can observe a dramatic difference in the number of proteins which are associated with each individual complex.

\begin{tabular}{|c|c|c|c|c|c|c|}
\hline \multirow[t]{2}{*}{$\begin{array}{c}\text { Yeast } \\
\text { Protein } \\
\text { name }^{a}\end{array}$} & \multirow[t]{2}{*}{$\begin{array}{l}\text { Systemati } \\
\text { c Gene } \\
\text { name }\end{array}$} & \multirow[t]{2}{*}{$\begin{array}{l}\text { MW } \\
(\mathbf{k D})\end{array}$} & \multicolumn{3}{|c|}{$\begin{array}{c}\text { Number of peptides sequenced in Prp5- } \\
1 \text { inact and ATP depleted complex } \\
\text { preparations }\end{array}$} & \multirow[b]{2}{*}{$\begin{array}{l}\text { Human proteir } \\
\text { name }\end{array}$} \\
\hline & & & $\begin{array}{l}\text { Prp5- } \\
1 \\
\text { inact. } \\
\# 1\end{array}$ & $\begin{array}{c}\text { Prp5- } \\
1 \\
\text { ATP } \\
\text { depl. } \\
\# 1\end{array}$ & Description & \\
\hline \multicolumn{7}{|c|}{ U1snRNP proteins } \\
\hline \multirow{4}{*}{$\begin{array}{l}\text { Snu71 } \\
\text { Prp40 } \\
\text { Prp39 } \\
\text { Prp42 }\end{array}$} & YGR013W & 71.4 & 8 & & & S164 \\
\hline & YKL012W & 69.0 & 6 & & & PRP40B \\
\hline & YML046W & 74.7 & 5 & & & PRPF39 \\
\hline & YDR235W & $\begin{array}{r}155 . \\
0\end{array}$ & 5 & & & PRPF39 \\
\hline \multirow{2}{*}{$\begin{array}{l}\text { Nam8 } \\
\text { Snp1 }\end{array}$} & YHR086W & 57.0 & 1 & & & TIA1/TIAR \\
\hline & YIL061C & 34.4 & 2 & & & U1-70K \\
\hline \multirow{2}{*}{$\begin{array}{l}\text { Mud1 } \\
\text { Luc7 }\end{array}$} & YBR119W & 34.8 & 3 & & & U1-A \\
\hline & YDL087C & 30.2 & 3 & & & LUC7B \\
\hline \multirow{2}{*}{$\begin{array}{l}\text { Snu56 } \\
\text { Yhc1 }\end{array}$} & YDR240C & 56.4 & 2 & & & \\
\hline & YLR298C & & - & & & U1-C \\
\hline \multicolumn{7}{|c|}{ Sm proteins } \\
\hline $\mathrm{SmB}$ & YER029C & 22.4 & & & & B \\
\hline \multirow{2}{*}{$\begin{array}{l}\text { SmD2 } \\
\text { SmD3 }\end{array}$} & YLR275W & 12.8 & 1 & & & D2 \\
\hline & YLR147C & 11.2 & & & & D3 \\
\hline $\mathrm{SmF}$ & YPR182W & 9.7 & & & & $\mathrm{~F}$ \\
\hline \multicolumn{7}{|c|}{ Commitment complex associated proteins } \\
\hline \multirow{2}{*}{$\begin{array}{l}\text { Msl5 } \\
\text { Mud2 }\end{array}$} & & 53.0 & 21 & & & BBP1 \\
\hline & YKL074C & 60.0 & 17 & & & U2AF65 \\
\hline \multicolumn{7}{|c|}{$\begin{array}{l}\text { Poly (A+) RNA-binding protein, involved in mRNA export from the nucleus to the } \\
\text { cytoplasm }\end{array}$} \\
\hline $\begin{array}{l}\text { Hrb1/To } \\
\text { m34 }\end{array}$ & YNL004W & 49.1 & 2 & 2 & export of mRNAs & PABPC4L \\
\hline \multirow{2}{*}{$\begin{array}{l}\mathrm{Np13} \\
\mathrm{Cft} 1\end{array}$} & YDR432W & 45.4 & 2 & & export of mRNAs & SFRS4 \\
\hline & & 15.3 & 3 & 4 & $\begin{array}{l}\text { involved in poly }(\mathrm{A}) \text { site } \\
\text { recognition and required for } \\
\text { both pre-mRNA cleavage and } \\
\text { polyadenylation }\end{array}$ & \\
\hline Pab1 & & 64.5 & 3 & 30 & $\begin{array}{l}\text { Poly(A) polymerase, one of } \\
\text { three factors required for } \\
\text { mRNA 3 - end polyadenylation }\end{array}$ & \\
\hline Pta1 & & 27.6 & 1 & & & \\
\hline Fip1 & & 35.8 & 3 & & Polyadenylation factor & \\
\hline Pat1 & YCR077C & 88.5 & 9 & 25 & Polyadenylation factor & PATL1 \\
\hline
\end{tabular}

\section{Table 3.2}

Peptides sequenced in the CC preparations obtained from yeast extracts heat-inactivated for Prp5-1 (inact) and additionally ATP depleted. Proteins were identified by LC-MS/MS after three steps purification and separation by PAGE. Numbers represent the absolute numbers of peptides sequenced for a protein found in each preparation. The table contains information about the S.cerevisiae protein, the systematic gene name, and the calculated molecular weight in $\mathrm{kDa}$. The last column contains the name of the human protein to aid comparison with previous studies of human spliceosomal complexes. Proteins are grouped in organizational and/or functional subgroups. 
Additionally, to investigate the role of ATP at the early steps of spliceosomal assembly and to see whether there is a difference in the recruitment of spliceosomal factors to the early complex, we repeated the experiments with ATP-depleted whole cell extracts made from functional, not heat-inactivated prp5-1 strains. As revealed by MS, no changes in peptide numbers sequenced for proteins recruited to early spliceosomes were detected when the extract was ATP-depleted (Table 2).

\subsection{Investigation of the protein rearrangements at the catalytic core of the spliceosome as revealed by dual color FCCS}

In the first part of our work we isolated spliceosomal complexes from the yeast S.cerevisiae and obtained important information of the proteome and the three dimensional structure of spliceosomal $\mathrm{B}, \mathrm{B}^{\text {act }}$ and $\mathrm{C}$ complexes. Such a characterization of the protein content of spliceosomal complexes was done for the first time and gave important insights of the protein dynamics at the core of the spliceosome during assembly and step 1 catalysis. To identify the factors recruited at distinct stages of spliceosome assembly, has helped us to understand better the mechanistic aspects of the catalytic activation and the process of pre-mRNA splicing in general. Our MS analysis showed a dramatic change of the protein factors which were recruited and released during catalytic activation and spliceosome assembly.

While the studies summarized above provide initial indications of the dynamics of the spliceosome's protein composition during its catalytic activation, they provide only little information about the degree of weakening or stabilization of the binding affinity of individual proteins or about the order in which proteins are bound to the spliceosome or dissociate from it. For example, there is disagreement in the literature as to the binding behavior of the $\mathrm{U} 2 \mathrm{SF} 3 \mathrm{a} / \mathrm{b}$ proteins during the catalytic phase of the yeast spliceosome. Depending on the conditions under which the catalytically active spliceosomes are isolated, these proteins are reported to be "completely absent" to "stoichiometrically present". In view of our observation of the reduced peptide numbers sequenced for the U2 proteins in our affinity-purified first step spliceosomes, as compared to the $\mathrm{B}^{\text {act }}$ and $\mathrm{B}$ complexes, we wanted to learn more about their binding behavior during catalytic activation and first step of splicing. Indeed, our previous results led to the question whether the $\mathrm{U} 2 \mathrm{SF} 3 \mathrm{a} / \mathrm{b}$ proteins are just 
destabilized or even released from the spliceosome during the catalysis of the first step of the splicing reaction. To address this and additional questions, we applied the technique of dual color Fluorescence-cross correlation spectroscopy (dcFCCS) to study the dynamics of protein factors during the catalytic activation of the spliceosome mediated by Prp2 helicase. DcFCCS had to fulfill some important properties, for example it should allow us to measure the dynamics of the spliceosome in solution, i.e. in thermodynamic equilibrium and it should deliver quantitative data about the protein factors of interest.

The dcFCCS technique is an optimal method to study the dynamics of spliceosomal protein recruitment and dissociation, because i) it is a versatile and very sensitive method and requires sample concentrations in the low nM range, ii) it allows real time measurements in solution and in thermodynamic equilibrium and iii) provides quantitative data and is suitable for the elucidation of dissociation constants. The biochemical set up for using dcFCCS (reviewed in (Haustein and Schwille 2007) was already well established in our laboratory by Dr. Peter Odenwälder and Dr. Thomas Ohrt and the technical setup for dcFCCS was done in collaboration with Prof. Jörg Enderlein and Mira Prior, from the III. Institute of Physics, University of Göttingen.

First we applied a strategy to stall the spliceosome assembly at the $\mathrm{B}^{\text {act }}$ complex using the prp2-1 strain. As demonstrated by the work of Kim and Lin (Kim and Lin 1996) the Prp2 helicase functions before the first step of splicing and can be heat inactivated in the temperature sensitive strain prp2-1. As a result, the spliceosome assembly can be stalled at the stage of an activated, but not yet catalytically active complex. In the work of Warkocki et al., 2009 an in vitro reconstitution system was established in our laboratory using this temperature-sensitive mutant of the RNA helicase Prp2 and the M3-Act wt substrate, to investigate the role of Prp2 in catalytic activation (Warkocki, Odenwalder et al. 2009). It could be demonstrated that $\mathrm{B}^{\text {act }}$ spliceosomes stalled prior to the first step by inactivating Prp2 could be purified. The protein composition of these complexes, termed $\mathrm{B}^{\text {act } \Delta \mathrm{Prp} 2}$, was characteristic for spliceosomes which have not yet undergone first step and are thus pre-catalytic. Importantly, it was shown that the complexes were able to catalyze efficient step 1 when supplemented with recombinant Prp2, Spp2 and first step factor Cwc25 and step 2 when supplemented with Prp16, Slu7/Prp18 and Prp22 in the presence of ATP (Warkocki, Odenwalder et al. 2009). 
Second, we chose proteins of interest, which were suitable for the investigation of the compositional dynamics of the spliceosome during conversion from the $\mathrm{B}^{\text {act }}$ to the $\mathrm{B}^{*}$ complex (adapted from Warkocki et al, 2009), i.e. the proteins Cwc24, Cwc27, Yju2, Bud 13, a factor of the RES complex and the U2 snRNP-associated SF3a factor Prp11 and SF3b factor Cus1. The majority of these factors are recruited to the spliceosome during its activation (see Table 1).

\subsection{Generation of doubly labeled spliceosomes for dcFCCS measurements}

Our experimental strategy is outlined in Figure 3.12. The (stable) core spliceosome was tagged with the red fluorescent dye Atto647N at the 5' end of actin pre-mRNA. For this purpose, a wild-type actin pre-mRNA that included three binding sites for MS2 phage coat protein upstream of the first exon (M3Act) was prepared by transcription in vitro with T7 RNA polymerase in the presence of a 10-fold molar excess of guanosine-5'-O-monophosphorothioate (5'-GMPS) over unmodified GTP. The gel-purified pre-mRNA was then allowed to react with a 100-fold excess of Atto$647 \mathrm{~N}$ malemide, whereby the 5'-terminal phosphorothioate group of the M3Act reacted with the $\mathrm{C}=\mathrm{C}$-double bond of the maleimide group of the dye, forming, almost quantitatively, the stable thioether product Atto647N -M3Act (see Methods; (Ohrt, Prior et al. 2012). We confirmed that Atto647N-M3Act was as active in a splicing assay in vitro as unmodified M3Act pre-mRNA (data not shown, experiment done by Dr. Peter Odenwälder from our laboratory).

The individual proteins were genetically fluorescently labeled by constructing yeast strains (in collaboration with Dr. Thomas Ohrt and Dr. Patrizia Fabrizio; see Methods; (Ohrt, Prior et al. 2012) that expressed the protein of interest with a Cterminal EGFP (enhanced green fluorescent protein) fusion domain on the basis of the temperature-sensitive Prp2-1 strain, containing the mutated ATPase Prp2 which is needed to stall the spliceosome assembly at the stage of $B^{\text {act }}$ (i.e., $B^{\text {act } \Delta \operatorname{Prp} 2}$ ) (Fig. 3.12). The following spliceosomal proteins were expressed stably as EGFP fusion proteins: Cus1, Prp11, and Bud13 (members of the SF3b, SF3a, and RES protein complexes, respectively), and $\mathrm{Cwc} 24, \mathrm{Cwc} 27$ and Yju2. All constructed strains grew like the unmodified strain prp2-1. Next we checked whether the tagged proteins and the labeled RNA substrate were able to assemble spliceosomal complexes in our in vitro 


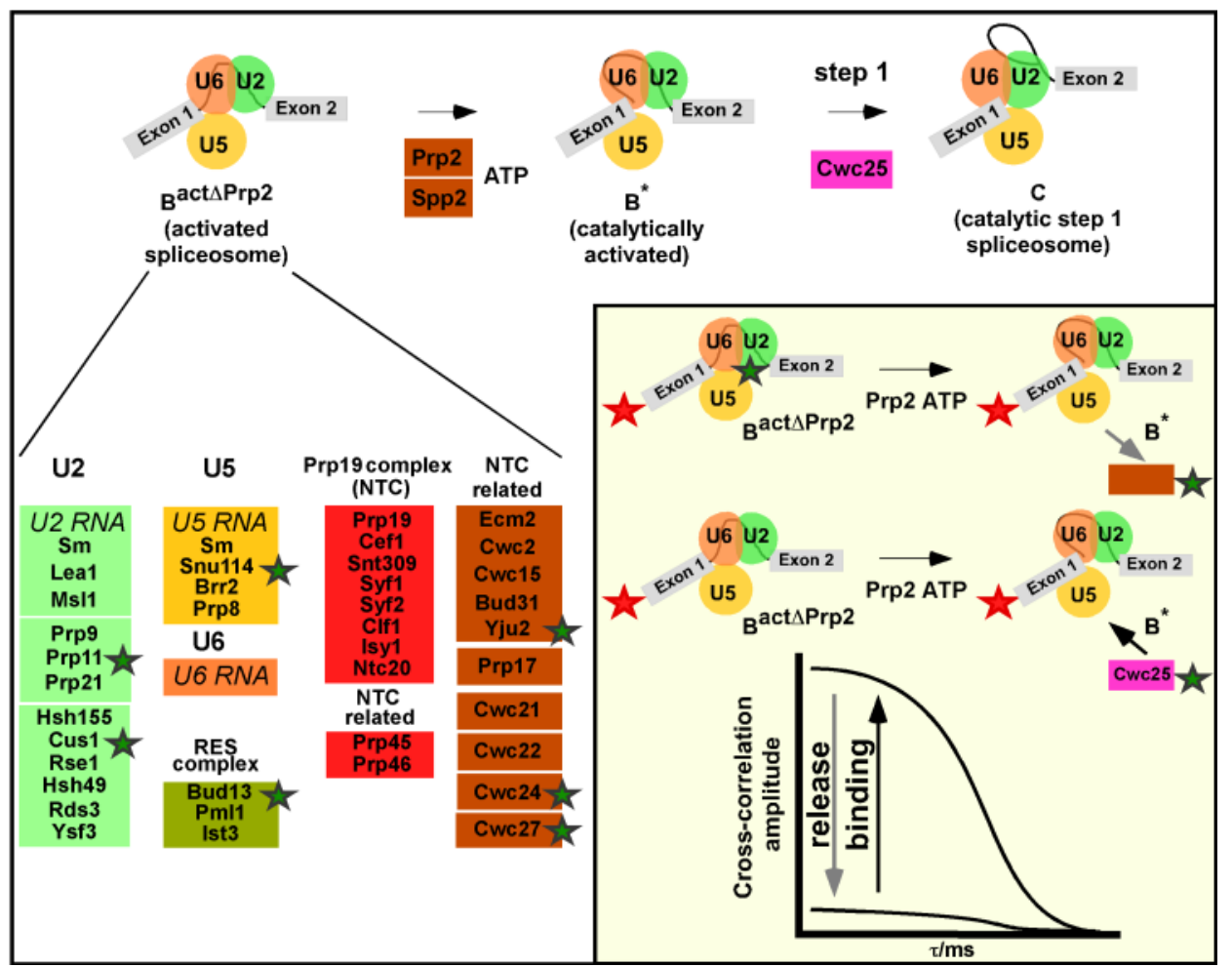

Figure 3.12: Experimental design and example of data. The Prp2-deficient spliceosomal complex $\mathrm{B}^{\text {act } \triangle \mathrm{Prp} 2}$ (stalled through the inactivation of Prp2) is catalytically activated by the addition of Prp2 together with Spp2 and ATP. This leads to complex B*, which on binding the step1 factor Cwc25, catalyses the the first step of splicing and forms the $\mathrm{C}$ complex. U2/5/6 snRNPs are shown as circles. The composition of the activated spliceosome is shown underneath; green stars indicate the spliceosomal proteins that were tagged with EGFP. (Inset) Release or recruitment of an EGFP-labeled protein (green star) from/to the spliceosome (carrying Atto647N, red star). The cross-correlation amplitude at short correlation time $t$ is proportional to the amount of doubly labeled spliceosomes (adapted from (Ohrt, Prior et al. 2012)).

reconstitution system. Therefore we used the labeled RNA substrate Atto647N-M3Act wt together with the different yeast whole cell extracts made from the constructed EGFP strains in comparison with unlabeled substrate or prp2-1 extracts. After assembly and separation of the $\mathrm{B}^{\text {act } \Delta \operatorname{Prp} 2}$ complexes by glycerol gradient centrifugation, the pooled peak fractions from the gradient were loaded on an affinityselection column containing amylose beads. The bound complexes were washed one time with G-150 buffer (containing $150 \mathrm{mM} \mathrm{KCl}$ ) and two times with G-75 (containing $75 \mathrm{mM} \mathrm{KCl}$ ) and were subsequently eluted with $20 \mathrm{mM}$ Maltose. For real-time dcFCCS measurements, reactions were carried out in a final volume of $60 \mu 1$ 
with a final complex concentration of $1.1 \mathrm{nM}$. The eluted fractions were supplemented with ten times excess of recombinant proteins and instead of the 10x rescue mix (used for reconstitution on beads), the reaction conditions were only adjusted to final concentrations of $2.5 \mathrm{mM} \mathrm{MgCl} 2$ and $2 \mathrm{mM}$ ATP (or other analogues) in buffer G-75 in a final volume of $60 \mu 1$. The reactions were incubated at $23^{\circ} \mathrm{C}$ for $45 \mathrm{~min}$ and subjected subsequently to dcFCCS measurement. Indeed, all EGFP-tagged extracts and substrates were able to form $\mathrm{B}^{\text {act } \Delta \operatorname{Prp} 2}$ spliceosomes and all tested preparations led to equal amounts of spliceosomal particles stalled prior to first step of splicing. Even all purified complexes were able to perform first step when supplemented with recombinant proteins required for the activation and for the first step of splicing.

\subsubsection{Stability of the binding of EGFP fusion proteins to the $B^{\text {act } \Delta \text { Prp2 }}$ complex under dcFCCS conditions}

First we performed some preliminary experiments to set up our dcFCCS conditions. For dcFCCS measurement our complexes had to fulfill two important requirements (i) they had to be stable at least for $\sim 3 \mathrm{~h}$ and (ii) we had to avoid the aggregation of our complexes during dcFCCS measurement. Toward this goal, we used the well-known protein Snu114. Snu114 is a GTPase that remains stably bound to the spliceosome during the whole splicing cycle (Bartels, Urlaub et al. 2003). We found that the $\mathrm{B}^{\text {act } \triangle \mathrm{Prp} 2}$ complexes which contained the Snu114-EGFP fusion protein showed constant high cross-correlation between the green label (protein) and the red label (RNA), Fig. 3.13, column 1, indicating that the $\mathrm{B}^{\text {act } \triangle \operatorname{Prp} 2}$ complexes do not dissociate under the conditions used for dcFCCS. When we induced the catalytic activation of our Snu114-EGFP-B ${ }^{\text {act } \Delta \text { Prp2 }}$ complexes by incubating them with recombinant Prp2/Spp2 proteins plus $2.0 \mathrm{mM}$ ATP for $45 \mathrm{~min}$ at $23^{\circ} \mathrm{C}$, we observed an almost quantitative conversion ( $>90 \%$ ) of the $45 \mathrm{~S} \mathrm{~B}^{\text {act } \Delta \operatorname{Prp} 2}$ complex to the slower migrating 40 S B* complex (see Cwc24-EGFP experiments; Fig.3.17, shown for Cwc24-EGFP complexes and also demonstrated for unlabeled spliceosomes in (Warkocki, Odenwalder et al. 2009). 


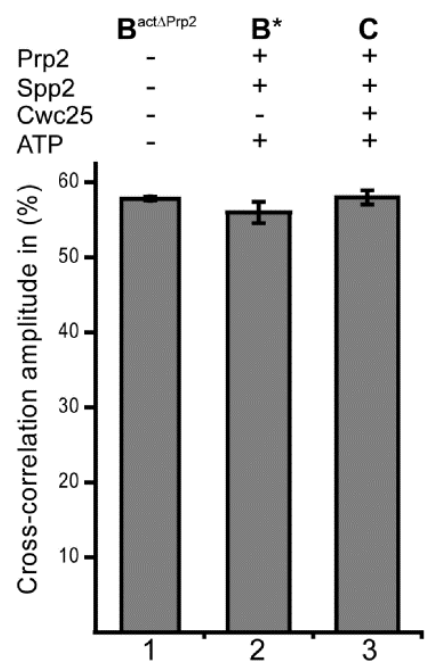

Figure 3.13: Binding behavior of Snu114-EGFP fusion protein to the spliceosome analyzed by dcFCCS. Affinity-purified $\mathrm{B}^{\text {act } \triangle \operatorname{Prp} 2}$ complexes assembled on Atto647N-M3Act, carrying Snu114-EGFP (column 1), were complemented with Prp2, Spp2, and ATP (column 2) and Cwc25 (column 3). After incubation $\left(45 \mathrm{~min}\right.$ at $23^{\circ} \mathrm{C}$; see Methods), dcFCCS measurements were then performed at complex concentrations of $1.0 \mathrm{nM}$. Cross-correlation amplitudes derived from two independent preparations are shown for each complex. Error bars indicate the standard deviation from two independent measurements.

As also shown in Fig. 3.13, column 2 the activation of the spliceosome and the conversion from the $\mathrm{B}^{\text {act } \Delta \mathrm{Prp} 2}$ complex to the $\mathrm{B}^{*}$ complex had no effect on the binding behavior of Snu114-EGFP to the spliceosome. Even addition of Cwc25, which results in the first step spliceosome showed no alteration of the association of Snu114-EGFP with pre-mRNA (Fig. 3.13, column 3) and we observed still a high level of cross correlation between the green label and the red Atto 647N labeled pre-mRNA. The results indicate that Snu114-EGFP remains stably bound in the $\mathrm{B}^{*}$ and $\mathrm{C}$ complex under non-stringent conditions, i.e. low salt ( $75 \mathrm{mM} \mathrm{KCl})$.

To determine the boundary of the stability Snu114-EGFP with the spliceosomal complexes we performed additional salt treatment experiments by increasing the $\mathrm{KCl}$ concentration in our experiments for both, $\mathrm{B}^{\text {act } \Delta \mathrm{Prp} 2}$ and for $\mathrm{B}^{*}$ complexes. Fig. 3.14 shows that up to a concentration of $300 \mathrm{mM} \mathrm{KCl}$ we observed high cross correlation and Snu114-EGFP still remained bound to the complexes. By increasing the salt concentration up to $500 \mathrm{mM} \mathrm{KCl}$, dcFCCS measurement was no longer possible 
because of precipitation and aggregation of the complexes on the cover slide used for dcFCCS measurement (data not shown, demonstrated by the work of Dr. Peter Odenwälder from our laboratory).

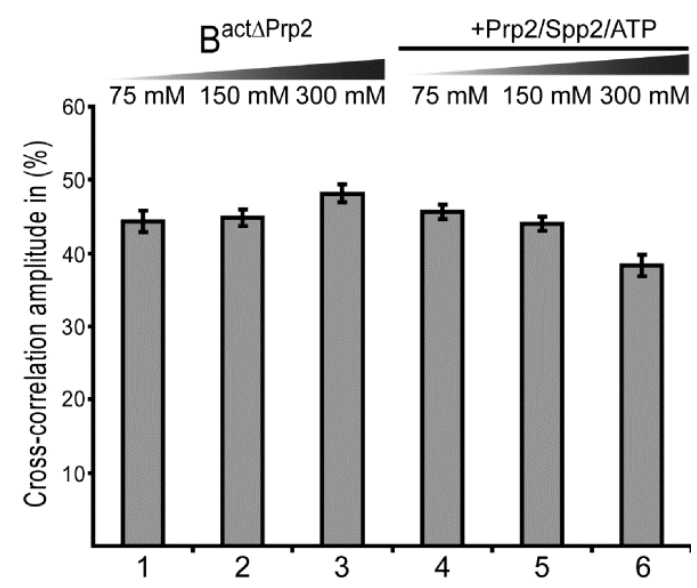

Figure 3.14: Salt-resistance of Snu114-EGFP binding to the spliceosome during catalytic activation. Affinity-purified $B^{\text {act } \triangle P r p 2}$ complexes assembled on Atto647N-M3Act, carrying Snu114-EGFP (columns 1-3), were complemented with Prp2, Spp2, and ATP (columns 4-6). After the standard incubation, increasing concentrations of $\mathrm{KCl}$ were added to the samples, which were then subjected to dcFCCS measurements.

Our experiments demonstrated that Snu114-EGFP remained stably associated to the spliceosome even after catalytic activation and high salt conditions as also postulated for native Snu114 (Bartels, Urlaub et al. 2003). In summary, we demonstrated that our complexes were stable enough for dcFCCS measurements after Prp2-mediated activation of purified complexes.

\subsubsection{Cwc24 and Cwc27 leave the spliceosome during Prp2-mediated catalytic activation under near-physiological conditions}

After the pilot experiments done with our Snu114-EGFP-B ${ }^{\text {act } \Delta \operatorname{Prp} 2}$ complexes, we investigated the changes in the binding behavior of Cwc24 upon Prp2-mediated activation. Therefore we first isolated the Cwc24-EGFP-B ${ }^{\text {act } \Delta \operatorname{Prp} 2}$ complexes by two steps purification via glycerol gradient centrifugation $(10 \%-30 \%, 75 \mathrm{mM} \mathrm{KCl}$, in Sorvall SureSpin630 rotor) and affinity chromatography on amylose beads. After elution from the amylose beads (in $75 \mathrm{mM} / 20 \mathrm{mM}$ Maltose), we induced the catalytic 
activation by incubating our complexes with recombinant Prp2 and Spp2 proteins and $2.0 \mathrm{mM}$ ATP under non-stringent condition $(75 \mathrm{mM} \mathrm{KCl})$. After the incubation for 45 $\min$ at $23^{\circ} \mathrm{C}$, the activated spliceosomes were directly transferred on the cover slide for dcFCCS analysis. In the Cwc24-EGFP-B ${ }^{\text {act } \triangle P r p 2}$ complex we observed a cross correlation between the green Cwc24 and the red pre-mRNA of $\sim 60 \%$. After the Prp2-mediated activation of the spliceosome, the cross correlation between the green and the red label was reduced to less than $5 \%$ in the $\mathrm{B}^{*}$ complex as shown in Fig. 3.15 column 2.

A

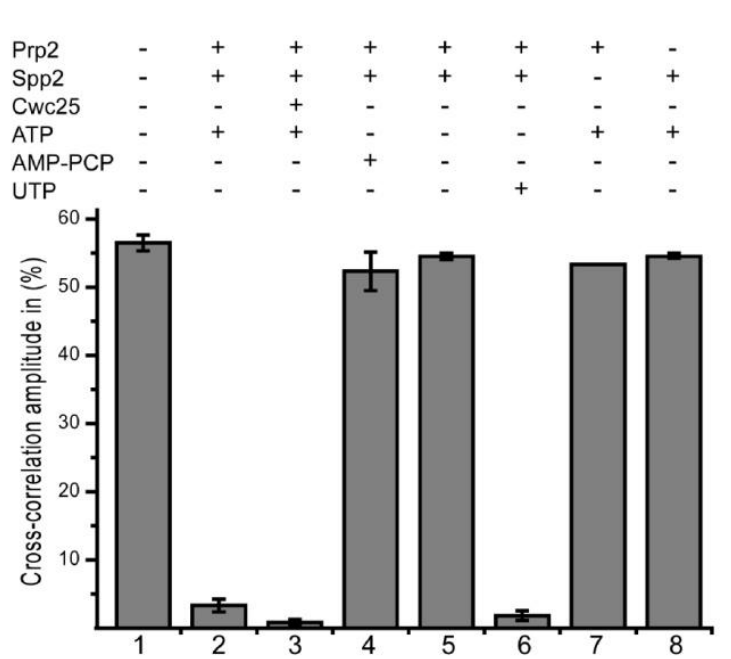

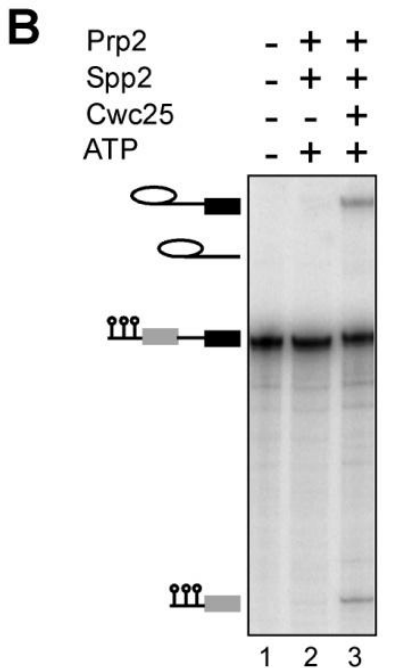

Figure 3.15: Displacement of Cwc24 from the spliceosome during Prp2-mediated catalytic activation, implying its non-involvement in the catalytic step 1 of splicing.

(A) Affinity-purified B ${ }^{\text {act } \triangle P r p 2}$ complexes assembled on Atto647N-M3Act carrying Cwc24-EGFP (column 1) were complemented as indicated above each bar or (B) Affinity-purified $\mathrm{B}^{\text {act } \Delta \mathrm{Prp} 2}$ complexes assembled on ${ }^{32}$ P-labelled M3Act, carrying Cwc24-EGFP (lane 1) were complemented with Prp2, Spp2 and ATP (lane 2), plus the addition of Cwc25 (lane 3). The positions of the pre-mRNAs, the splicing intermediates and products are indicated on the right.

This observation indicates almost quantitative dissociation of Cwc24-EGFP from the complex during activation. The addition of $\mathrm{Cwc} 25$ to form $\mathrm{C}$ complex revealed a complete loss of the binding affinity of $\mathrm{Cwc} 24$ with the complex as demonstrated in Fig. 3.15, column 3. The cross correlation amplitude went down near to background noise $(<3 \%)$ which implies that Cwc24, although essential for pre-mRNA splicing, is not a factor essential for the first step of splicing which occurs in the C complex. In 
the presence of non-hydrolysable AMP-PCP or without ATP (columns 4-5), or without Prp2 or Spp2 (columns 7-8), the cross-correlation of $\sim 60 \%$ remained unchanged. These results show that the dissociation of Cwc24-EGFP from the spliceosome accompanies the Prp2-mediated transformation of the $\mathrm{B}^{\text {act } \Delta \operatorname{Prp} 2}$ complex into $\mathrm{B}^{*}$. The almost complete loss of Cwc24-EGFP from the activated spliceosome is all the more notable, as this protein is very stably bound to the Cwc24-EGFP-B ${ }^{\text {act } \Delta \text { Prp2 }}$ complex, as indicated by its presence at $300 \mathrm{mM}$ salt (Figure 3.16, column 3). The dissociation of Cwc24-EGFP during the $\mathrm{B}^{\text {act } \Delta \operatorname{Prp} 2}$ to $\mathrm{B}^{*}$ complex transition also occurred efficiently in the presence of UTP (Fig. 3.15, column 6), consistent with the fact that Prp2 has a broad rNTP specificity (Kim, Smith et al. 1992). As yeast Brr2 is strictly ATP-specific, it is very unlikely that Brr2 ATPase activity is involved in the displacement of Cwc24 from the spliceosome, suggesting that this dissociation is solely due to the action of Prp2.

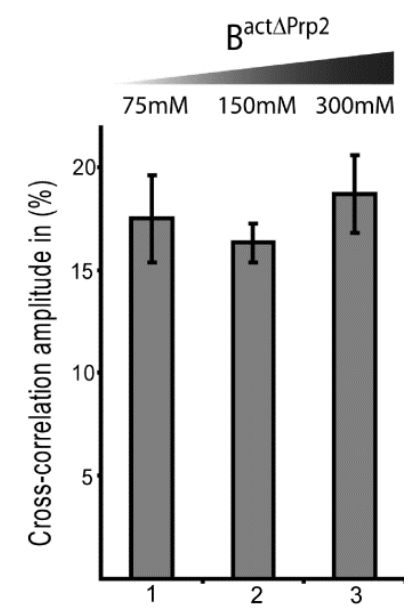

Figure 3.16: Salt resistance of Cwc24-EGFP binding to the spliceosome during Prp2-mediated activation. Affinity-purified $B^{\text {act } \triangle P \text { rp2 }}$ complexes assembled on Atto674N-M3Act wt pre-mRNA carrying the Cwc24-EGFP protein were eluted from the amylose matrix and were treated with increasing salt concentration $(75-300 \mathrm{mM} \mathrm{KCl})$ and then incubated on ice for $30 \mathrm{~min}$ before dcFCCS measurement.

Cwc27, although not essential for the growth of yeast under normal physiological conditions (Winzeler, Shoemaker et al. 1999; Giaever, Chu et al. 2002), behaved in a manner similar to Cwc24 (Ohrt, Prior et al. 2012). As with Cwc24, the drop in cross- 
correlation was seen after incubation with Prp2, Spp2 and ATP, but not when any of these components was absent from the reaction mixture; in addition, ATP could be replaced by UTP but not by AMP-PCP. We conclude that both Cwc24 and Cwc27 lose their affinity for - or are displaced from - the spliceosome upon catalytic activation of the $\mathrm{B}^{\text {act } \Delta \operatorname{Pr} 2}$ complex.

\subsubsection{Cwc24 is essential for the first step of splicing in vitro but it is not required for catalysis of the splicing reaction per se}

The above results indicate that $\mathrm{Cwc} 24$ dissociates almost quantitatively from the spliceosome during or after its catalytic activation, thus suggesting that it is not required for the actual first step of splicing. To determine whether the essential protein $\mathrm{Cwc} 24$ is required for the actual catalytic step, affinity-purified $\mathrm{B}^{\text {act } \Delta \operatorname{Prp} 2}$ complexes assembled on ${ }^{32}$ P-labelled M3Act pre-mRNA (Fig. 3.15 B, lane 1) were complemented with Prp2, Spp2 and ATP to allow the dissociation of Cwc24 (lane 2). Cwc25 was then added (lane 3). The spliceosomes from which Cwc24 had dissociated (Fig. 3.15 A, column 3), were capable of carrying out catalytic step 1 of splicing (Fig. $3.15 \mathrm{~B}$, lane 3), supporting the idea that $\mathrm{Cwc} 24$ is required before the action of Prp2 and not for catalytic step 1 per se.

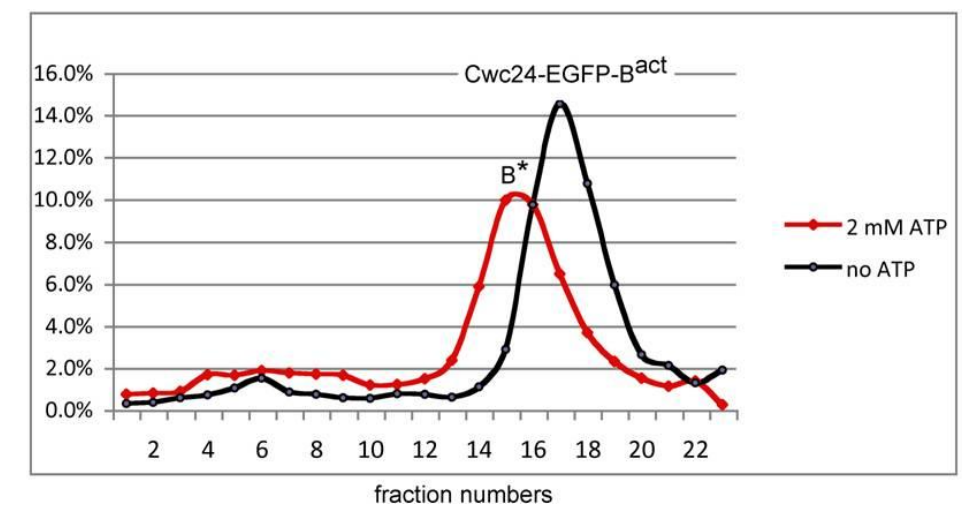

Figure 3.17: Catalytic activation of the Cwc24-EGFP-B ${ }^{\text {act } \Delta \operatorname{Prp} 2}$ complex by Prp2.

Profile of affinity-purified Cwc24-EGFP-B ${ }^{\text {act } \Delta \text { Prp2 }}$ spliceosomes separated on a glycerol gradient containing $75 \mathrm{mM} \mathrm{KCl}$ after incubation with Prp2/Spp2 without the addition of ATP (45S; black line) or with the addition of $2 \mathrm{mM}$ ATP (40S, B* complex; red line). The radioactivity contained in each gradient fraction was measured by Cerenkov counting. Sedimentation coefficients were determined by analyzing the UV absorbance of fractions of a reference gradient containing prokaryotic ribosomal subunits. The y axis shows the percentage of radioactively labeled RNA found in each fraction relative to the amount found in all fractions. 


\subsubsection{The U2-associated SF3a and SF3b proteins Prp11 and Cus1 remain} bound to the $B^{*}$ complex under physiological conditions, but their affinity is weakened at high salt

We observed a reduction of the U2 snRNP associated proteins as revealed by Mass spectrometry analysis (First part of this work; (Fabrizio, Dannenberg et al. 2009). For this reason we chose the U2 snRNP-associated SF3a protein Prp11 and the SF3b associated protein Cus1 to examine the binding behavior of these individual proteins by dcFCCS as representatives for the $\mathrm{U} 2$ snRNP proteins. We therefore constructed Prp11-EGFP and Cus1-EGFP strains and used the whole cell extract made from these strains for our experiments. The experimental procedure was the same as for Cwc24EGFP and Snu114-EGFP. We purified our $\mathrm{B}^{\text {act } \Delta \operatorname{Prp} 2}$ complexes assembled on Atto674N-M3Act wt pre-mRNA carrying the Prp11-EGFP or Cus1-EGFP protein. After reconstitution with recombinant proteins Spp2, Prp2 and $2.0 \mathrm{mM}$ ATP they were analyzed by dcFCCS. For investigation of the salt stability of these complexes, the samples were treated with different salt concentrations by adding $\mathrm{KCl}$ to a final concentration of $150 \mathrm{mM}$ or $300 \mathrm{mM}$ to the samples and incubated for $30 \mathrm{~min}$ on ice before measurement. The results, shown in Fig. 3.18., revealed that both proteins, Prp11-EGFP and Cus1-EGFP remained stably bound to the $\mathrm{B}^{\text {act } \Delta \operatorname{Prp} 2}$ complex even at high salt concentrations with a cross correlation of $\sim 45 \%$ (Fig. $3.18 \mathrm{~A}$ and B, column 1-3). As well after the addition of Prp2, Spp2 and $2.0 \mathrm{mM}$ ATP at a salt concentration of $75 \mathrm{mM} \mathrm{KCl}$, the Prp11-EGFP and Cus1-EGFP stayed associated with the $\mathrm{B}^{*}$ complex (Fig. 3.18 A and B, columns 4). Only after increasing the salt concentration from $75 \mathrm{mM} \mathrm{KCl}$ up to $300 \mathrm{mM} \mathrm{KCl}$ we could observe a dramatic decrease of cross correlation and a weakening of the binding of Prp11-EGFP and Cus1-EGFP from the $\mathrm{B}^{*}$ complex (Fig.3.18 $\mathrm{A}$ and $\mathrm{B}$, columns 5-6). At $150 \mathrm{mM} \mathrm{KCl}$ (column 5) a reduction of $20 \%$ of cross correlation could be observed, whereas at $300 \mathrm{mM} \mathrm{KCl}$ (column 6 ) the majority of the proteins, more than $70 \%$, had dissociated from the $\mathrm{B}^{*}$ complex. In contrast to the observations of the binding behavior of Snu114-EGFP, which remained stably bound even under high salt conditions, we demonstrated that the U2-SF3a/b proteins were tightly bound to the pre-catalytic spliceosome, but their binding is weakened after Prp2 action and the catalytically activation of the spliceosome, becoming salt-sensitive. However, their affinity to the $\mathrm{B}^{*}$ complex is 
higher than that of Cwc24-EGFP or Cwc27-EGFP. Even after addition of recombinant $\mathrm{Cwc} 25$, i.e. upon $\mathrm{C}$ complex formation, Cus1 and Prp11 remained bound to the spliceosome at a salt concentration of $75 \mathrm{mM} \mathrm{KCl} \mathrm{(data} \mathrm{not} \mathrm{shown).}$

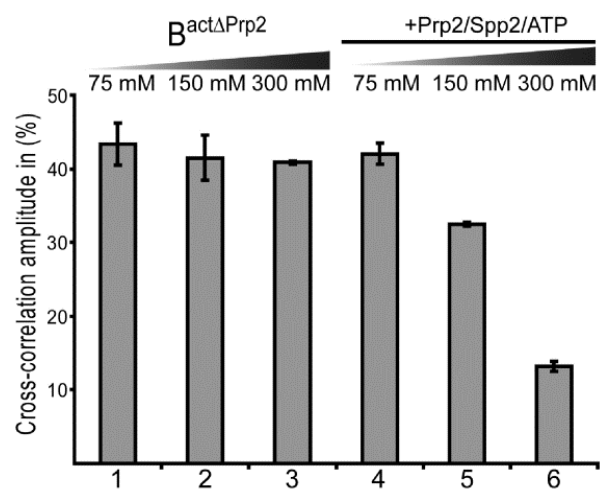

Prp11-EGFP

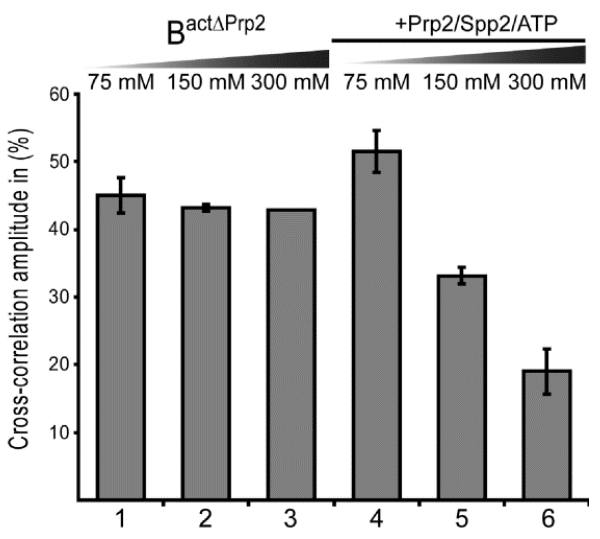

Cus1-EGFP

Figure 3.18: Binding of U2 SF3a/b proteins Prp11-EGFP and Cus1-EGFP to the spliceosome is made salt-sensitive by the Prp2-mediated catalytic activation. Affinity-purified Bact $\Delta$ Prp2 complexes were assembled on Atto674N-M3Act wt, carrying Prp11-EGFP (A) or Cus1-EGFP (B). The complexes were incubated with increasing salt concentrations before (columns1-3) and after addition of Prp2, Spp2 and ATP (columns 4-6).

\subsubsection{The binding of the RES complex protein Bud13 is weakened during catalytic activation}

The pre-mRNA Retention and Splicing (RES) complex plays an important role in nuclear retention of un-spliced pre-mRNAs. The yeast RES complex consists at least of three proteins: Ist/Snu17, Pml1 and Bud13. Our previous results confirmed the data from the literature that the RES complex associates with the spliceosome before step 1 of splicing, as we showed for the yeast spliceosomal B complex (Dziembowski, Ventura et al. 2004);(Fabrizio, Dannenberg et al. 2009). For investigating the binding behavior of the RES complex to the spliceosome, we chose the protein Bud13 as a representative for the RES complex and we applied the same experimental strategy using dcFCCS described above. The cross correlation intensity of the Bud13-EGFP$\mathrm{B}^{\text {act } \triangle \mathrm{Prp} 2}$ under non-stringent conditions $(75 \mathrm{mM} \mathrm{KCl})$ was at $\sim 28 \%$ between the green 
labeled protein Bud13-EGFP and the red labeled pre-mRNA (Fig. 3.19, column 1), but was reduced by almost $50 \%$ (down to $~ 15 \%$ ) when treated with high salt concentrations (300 mM KCl; Fig. 3.19, column 3) in the Bud13-EGFP-B ${ }^{\text {act } \Delta \operatorname{Prp} 2}$ complex.

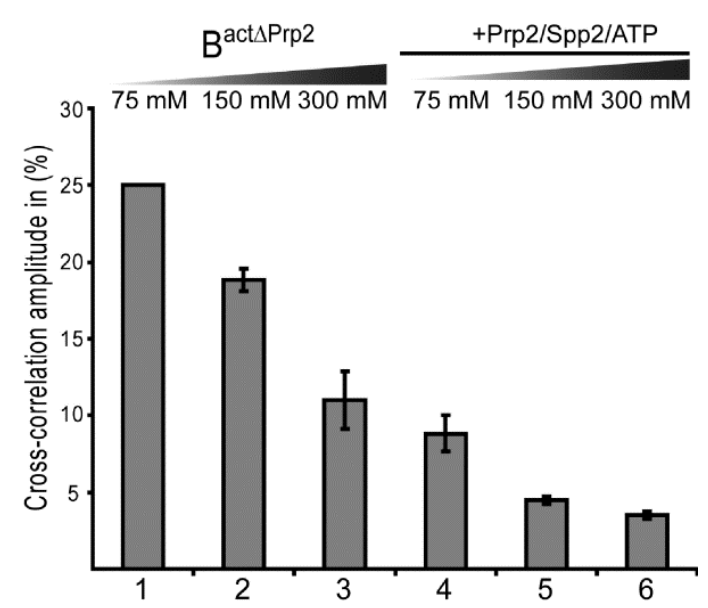

\section{Bud13-EGFP}

\section{Figure 3.19: Displacement of Bud13-EGFP from the spliceosome during Prp2-}

mediated catalytic activation. Affinity-purified $B^{\text {act } \triangle \mathrm{Pr} p 2}$ complexes assembled on Atto647NM3Act, carrying Bud13-EGFP (columns 1-3), were complemented with Prp2, Spp2, and ATP (columns 4-6). After incubation, increasing concentrations of $\mathrm{KCl}$ were added and dcFCCS was performed as above.

In comparison to the binding strength of Cwc24-EGFP and Snu114-EGFP, we observed a weaker association of Bud13-EGFP with the spliceosomal $\mathrm{B}^{\text {act } \Delta \mathrm{Prp} 2}$ complex. Even more significant was the dramatically reduced affinity of Bud13EGFP for the $\mathrm{B}^{*}$ complex after Prp2-mediated activation of the Bud13-EGFP-B ${ }^{\text {act } \triangle \mathrm{Prp} 2}$ complex under high salt conditions (300 mM KCl, Fig. 3.19, column 6). At these stringent conditions Bud13-EGFP was almost displaced from the spliceosome after catalytic activation (Fig. 3.19, column 5 and 6). This observation is congruent with the idea that the members of the RES complex remain bound to the spliceosome until the Prp2-mediated catalytic activation of the spliceosome takes place, to avoid the premature release of unspliced pre-mRNA from the nucleus. It was demonstrated by Dziembowski et al. that inactivation of these proteins causes leakage of unspliced premRNA from the nucleus (Dziembowski, Ventura et al. 2004). 


\subsubsection{Binding of Yju2 to the spliceosome is strengthened upon catalytic activation}

Yju2 is a novel splicing factor known to be associated with components of the NTC and to play a role in pre-mRNA splicing, both in vivo and in vitro. Yju2 is recruited to the spliceosome prior the action of Prp2 and the first step of splicing at the stage of the $\mathrm{B}^{\text {act }}$ complex. Its role is in promoting step 1 of splicing after Prp2-mediated structural rearrangement of the spliceosome (Liu, Chen et al. 2007).

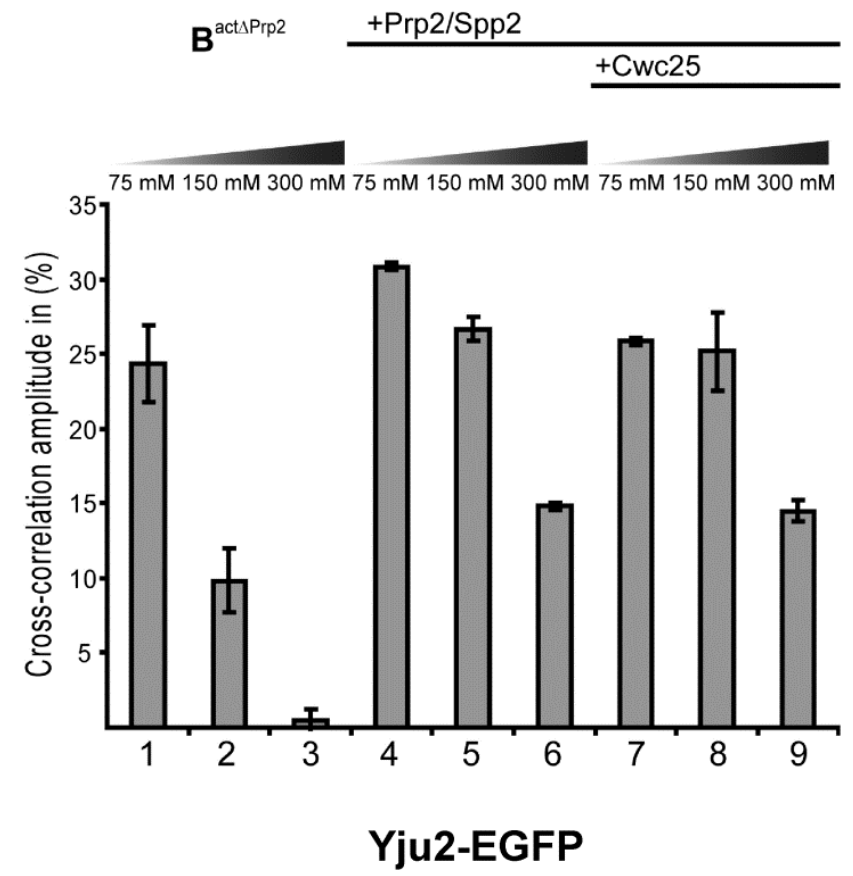

Figure 3.20: Strengthening of binding of Yju2-EGFP to the spliceosome upon catalytic activation. Affinity-purified $\mathrm{B}^{\text {act } \triangle \mathrm{Prp2}}$ complexes assembled on Atto647N-M3Act, carrying Yju2-EGFP (columns 1-3), were complemented with Prp2, Spp2, and ATP (columns 4-6), or with Prp2, Spp2, ATP, and Cwc25 (columns 7-9). After standard incubation, increasing concentrations of $\mathrm{KCl}$ were added.

The investigation of the binding affinity of Yju2-EGFP to purified spliceosomal complexes revealed that Yju2-EGFP has a lower affinity for the $\mathrm{B}^{\text {act } \Delta \operatorname{Prp} 2}$ complex than for $\mathrm{B}^{*}$ complex as demonstrated by dcFCCS data. Under non-stringent condition, Yju2-EGFP seemed to be associated with the $\mathrm{B}^{\text {act } \triangle \operatorname{Pr} 2}$ complex, but already at a concentration of $150 \mathrm{mM} \mathrm{KCl}$ more than $50 \%$ of the Yju2-EGFP was dissociated 
from the complex and at $300 \mathrm{mM} \mathrm{KCl}$ the dissociation was complete (Fig. 3.20, column 1-3). Interestingly, after the Prp2-mediated activation of the spliceosome, the binding affinity of Yju2-EGFP protein was higher for the $\mathrm{B}^{*}$ complex than for the corresponding $\mathrm{B}^{\mathrm{act} \Delta \operatorname{Prp} 2}$ (Fig. 3.20, column 4). The higher binding affinity was more prominent at $150 \mathrm{mM}$ and $300 \mathrm{mM} \mathrm{KCl}$ (Fig. 3.20, column 5 and 6). We concluded that the Prp2-dependent rearrangement of the spliceosome changes the binding affinity of Yju2 for the spliceosome from low to high. The addition of Cwc25, leading to the first step spliceosome had no additional effect on the binding strength of Yju2EGFP to the $\mathrm{C}$ complex. Moreover, the affinity of Yju2 was minimally affected by the first step of splicing (Fig. 3.20, column 7-9).

\subsubsection{Prp2-mediated catalytic activation of the spliceosome creates also a high affinity binding site for Cwc25 in the spliceosome}

We showed in our experiments described above, that the Prp2-mediated rearrangement of the spliceosome is accompanied by changes of the binding affinity of many proteins. Some were only destabilized during activation like the U2 snRNP associated SF3a/b proteins, other were displaced completely, i.e. Cwc24, Cwc27 or Bud13 or their binding was even enhanced like the factor Yju2. The essential factor for promoting the first step of splicing is Cwc25 as shown in Warkocki et al., 2009. To investigate the role and the binding affinity of Cwc25 during pre-mRNA splicing we conjugated the green fluorescent dye Alexa488N-maleimide to Cwc25 via cyteines which were linked to the protein at the $\mathrm{C}$ or $\mathrm{N}$ terminus of the protein. After labeling the overexpressed and purified protein (in collaboration with Dr. Jana Schmitzova and Dr. Thomas Ohrt) a second step of purification was performed to remove unbound Alexa488N-maleimide. Fluorescently labeled protein was obtained with a label efficiency of $\sim 70 \%$ (see Methods).

Next steps were to test whether fluorescently labeled Cwc25 was functional or whether Alexa488N-maleimide interferes with spliceosome assembly. Therefore, we purified $\mathrm{B}^{\text {act } \Delta \text { Prp2 }}$ complexes assembled on Atto647N-M3Act pre-mRNA as already described, and complemented them with Prp2, Spp2, ATP, and either unlabeled recombinant $\mathrm{Cwc} 25$ or its $\mathrm{N}$ or $\mathrm{C}$ terminus labeled versions. As shown in Figure 3.21, 
all Cwc25 preparations we have tested led to the identical step 1 efficiencies (done by Dr. Peter Odenwälder from our laboratory).

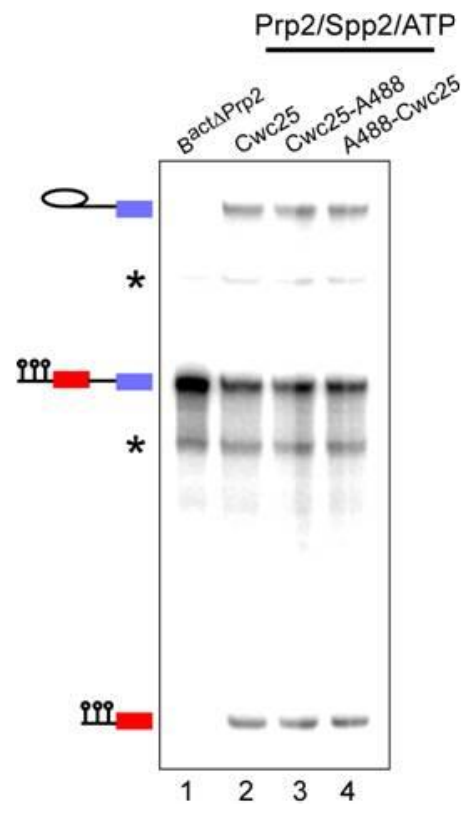

Figures 3.21: Functional assay using Cwc25-Alexa488N-maleimide. Complexes assembled on Atto647N-M3Act undergo the first step of splicing when complemented with Prp2, Spp2, ATP and Cwc25 labelled with the fluorescent dye Alexa488. $\mathrm{B}^{\text {act } \Delta \mathrm{Prp} 2}$ complexes assembled on Atto647N-M3Act (lane 1) were purified, eluted from the amylose matrix and complemented with Prp2, Spp2, ATP and Cwc25 (lane 2), or fluorescently labelled Cwc25 (lanes 3 and 4). Two preparations of Cwc25, C-terminally (lane 3) and N-terminally labelled (lane 4) were used. RNA was analysed on an $8 \%$ polyacrylamide-urea gel and visualised by autoradiography. The positions of the pre-mRNAs and the splicing intermediates are indicated on the left. Asterisks: uncharacterised pre-mRNA bands (Assay done by Dr. Peter Odenwälder, Figure kindly provided by Dr. Peter Odenwälder).

Next, we studied the recruitment of Cwc25 to the spliceosome in more detail.

Therefore, using extracts from the prp2-1 strain, $\mathrm{B}^{\text {act } \Delta \operatorname{Prp} 2}$ complexes were assembled on Atto647N-M3Act. After gradient separation and affinity-purification, the bound complexes were transferred into a new 1,5 ml Eppendorf tube and complemented with Prp2, Spp2, Cwc25-Alexa488 (C-terminally labeled) and ATP or only with Cwc25Alexa488. Reaction mixtures were incubated for $45 \mathrm{~min}$ at $23^{\circ} \mathrm{C}$ and transferred back into the chromatography columns for washing. After washing the reconstituted 
complexes twice with G-75 buffer to remove unbound Cwc25-Alexa488, the complexes were analyzed by dcFCCS (Fig. 3.22).

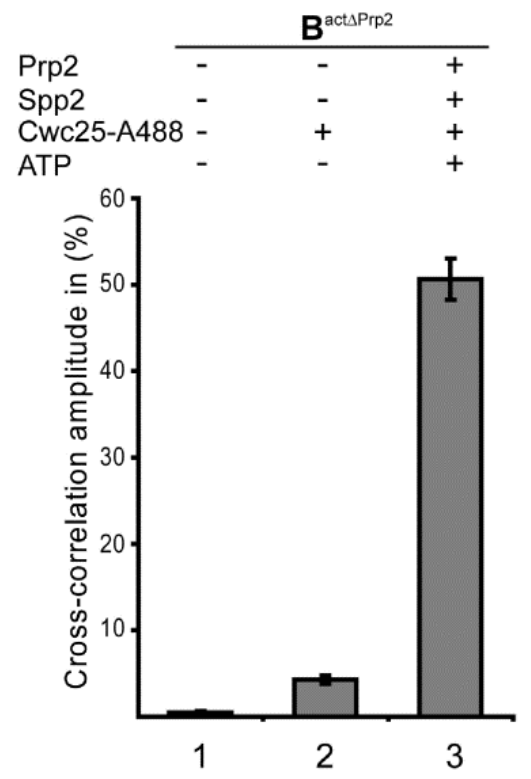

Figure 3.22: Catalytic activation by Prp2 creates a high-affinity binding site for

Cwc25 in the spliceosome. $\mathrm{B}^{\text {act } \triangle \mathrm{Prp} 2}$ complexes assembled on Atto647N-M3Act (column 1) were complemented on the amylose matrix with C-terminally labeled Cwc25-Alexa488 (column 2) or Cwc25-Alexa488 together with Prp2, Spp2 plus ATP (column 3). After incubation, the complexes were washed and eluted with maltose, and dcFCCS measurements were performed (this experiment was repeated for this work according to the protocol of Dr. Peter Odenwälder).

$\mathrm{B}^{\text {act } \Delta \operatorname{Prp} 2}$ complexes complemented with Cwc25-Alexa488 displayed only a background cross-correlation of $<5 \%$ (column 2). On the other hand, when the $\mathrm{B}^{\text {act } \Delta \mathrm{Prp} 2}$ complex was supplemented with Prp2, Spp2, ATP, and Cwc25-Alexa488, it showed a cross correlation amplitude of $\sim 50 \%$ (Fig. 3.22, column 3). Accordingly, Cwc25 binds efficiently to the spliceosome only after ATP-hydrolysis by Prp2 and rearrangement of the structure of the spliceosome, i.e. only after the release or destabilization of several proteins. This suggests that the remodeling of the spliceosome by Prp2 helicase generates a binding site for Cwc25 in the spliceosome. To study how the affinity of Cwc25 changes during catalytic activation of the spliceosome, we determined quantitatively the binding constants for Cwc25 at the $\mathrm{B}^{\mathrm{act} \Delta \mathrm{Prp} 2}$ and $\mathrm{B}^{*}$ stages, i.e., immediately before and after catalytic activation by Prp2 
done in parallel experiments by Dr. Peter Odenwälder (Computational analysis of the data was done by Mira Prior, III. Institute of Physics, University of Göttingen; data not shown) (Ohrt, Prior et al. 2012). The results of these additional experiments were in line with our results, thus, we conclude that the Prp2-dependent rearrangement of the spliceosome generates a high-affinity binding site for Cwc25. In conclusion dcFCCS is a high resolution and quantitative technique for the investigation of highly dynamic complexes like the spliceosome and we have obtained important insights about protein dynamics at the catalytic core of the spliceosome during pre-mRNA splicing in yeast. 


\section{Discussion}

In this work we established a method to isolate and to purify spliceosomal complexes from the yeast $S$. cerevisiae stalled at defined stages of spliceosome assembly for the first time (Dannenberg, Fabrizio et al. 2012); (Fabrizio, Dannenberg et al. 2009) We characterized the proteome of the $\mathrm{B}, \mathrm{B}^{\text {act }}$ and $\mathrm{C}$ complexes and could give first insights into the protein dynamics and the two-dimensional (2D) structural changes during transition from $\mathrm{B}$ to $\mathrm{B}^{\text {act }}$ and from $\mathrm{B}^{\text {act }}$ to $\mathrm{C}$ complexes during pre-mRNA splicing as revealed by Mass spectrometry (MS) and Electron microscopy (EM) analyses. During the conversion from $\mathrm{B}$ to $\mathrm{B}^{\text {act }}$ to $\mathrm{C}$, the compositional changes are accompanied by structural remodeling of the spliceosome which results in changes of the $\mathrm{S}$ values of the individual complexes, $40 \mathrm{~S}$ for $\mathrm{B}$ complex, $45 \mathrm{~S}$ for $\mathrm{B}^{\text {act }}$ and $40 \mathrm{~S}$ for $\mathrm{C}$ complexes. EM studies revealed that these compositional changes correlate with structural changes during both transitions, $\mathrm{B}$ to $\mathrm{B}^{\text {act }}$ and $\mathrm{B}^{\text {act }}$ to $\mathrm{C}$. Our results give insights into the highly dynamic RNP machine that undergoes many changes in composition and conformation.

\subsection{The structural dynamics of the spliceosome are modulated by multiple DExD/H-box RNA helicases, the driving forces of the spliceosome}

Among these helicases are Prp5 and Prp2, which are essential ATPase required prior to the first step of pre-mRNA splicing. The DEAD-box ATPase Prp5 enables stable U2 snRNP association with the branch point sequence (BPS). We showed here that the use of temperature-sensitive mutants of Prp5 (prp5-1) led to accumulation of early, pre-spliceosomal complexes, identified by MS as commitment complex 2 (CC2). Another important helicase, the DEAH-box ATPase Prp2, is known to promote a structural rearrangement that transforms the $\mathrm{B}^{\text {act }}$ into the catalytically activated $\mathrm{B}^{*}$ complex. Our MS results already revealed that a number of proteins are affected by the Prp2-mediated catalytic activation. Consequently, a second approach of this work was to deepen our previous results by studying the modulation of the binding strength of individual proteins to the yeast spliceosome during catalytic 
activation by Prp2 in a quantitative manner. Therefore, we applied the technique of dual color Fluorescens Cross Correlation Spectroscopy (dcFCCS) which was established during this work in collaboration with Dr. Thomas Ohrt, Dr. Peter Odenwälder, Mira Prior and Prof. Jörg Enderlein. The combination of our established three-step purification strategy (Fabrizio, Dannenberg et al. 2009); (Dannenberg, Fabrizio et al. 2012) together with in vitro reconstitution of functional spliceosomes (Warkocki, Odenwalder et al. 2009) and with the dcFCCS technique made it possible to shed some light on the nature of the release/loss of splicing factors during the crucial remodeling step of catalytic activation. This is the first example where purified, catalytically active spliceosomes were investigated directly in solution and in equilibrium. By dcFCCS we showed that the U2 SF3a/SF3b proteins Prp11 and Cus1 are destabilized and $\mathrm{Cwc} 24$, Bud13 and $\mathrm{Cwc} 27$ are released from the spliceosome after Prp2-mediated catalytic activation. Furthermore, we demonstrated that high affinity binding sites are created for the step 1 factors Yju2 and Cwc25 during catalytic activation, consistent with their requirement for step 1 catalysis. This work demonstrates that Prp2 has a major role in the structural remodeling and in the multiple rearrangements at the core of the spliceosome.

\subsection{The protein composition of yeast spliceosomes is less complex than that of metazoan spliceosomes}

If one compares the proteome of the yeast $\mathrm{B}, \mathrm{B}^{\text {act }}$ and $\mathrm{C}$ complexes with spliceosomal complexes isolated from other species, i.e. Drosophila or human spliceosomes, it is obvious that the yeast spliceosome has significantly less proteins than metazoan spliceosomes. The human and the Drosophila B complex isolated under similar nonstringent conditions contain 110 proteins (Deckert, Hartmuth et al. (2006); (Herold, Will et al. 2009), whereas the yeast B complex comprises $\sim 60$ proteins. The most drastic difference was shown for the purified Bact complexes from human with more than $\sim 140$ proteins compared to the yeast Bact complex with only $\sim 40$ proteins (Bessonov, Anokhina et al. (2010). A similar minimal protein composition like for the yeast $\mathrm{B}^{\text {act }}$ complex was revealed for the yeast $\mathrm{C}$ complex, which is composed of only $\sim 50$ proteins in yeast versus $\sim 110$ proteins in human (Bessonov, Anokhina et al. 
(2008). As a result we can conclude that the number of proteins of each yeast complex is less than half compared to human spliceosomal complexes (Fig 4.1.). We identified in total, $\sim 90$ proteins in the three isolated yeast complexes.

The proteins identified here include the majority of proteins which were found to be associated with previously isolated yeast complexes such as the purified penta-snRNP and the Cef1-associated complex (Ohi and Gould (2002); Stevens, Ryan et al. (2002)). Established splicing factors that were known to contribute to pre-mRNA splicing as revealed by genetics or other techniques, which were not found in our three complexes, include those that were only loosely associated and lost during purification, such as Prp28 and Sad1 or those that act even earlier in pre-mRNA splicing, e.g. Npl3 or Mud2 and Ms15 which were however found associated with the early pre-spliceosomal Commitment Complex that we have also isolated, purified and characterized in this work (Table 3.2 and Figure 4.1).

\subsection{Isolation and characterzation of early spliceosomal complexes from yeast}

Here, we have also purified yeast spliceosomes stalled at the commitment complex (CC) stage prior to prespliceosome (A complex) formation using a temperature sensitive yeast strain, which carries the mutant Prp5 protein (named prp5-1). The DEAD-box Prp5 is an essential, RNA dependent ATPase present in the CC that functions in subsequent A complex formation containing both the $\mathrm{U} 1$ and $\mathrm{U} 2$ snRNPs. Our stalled 26S complex contained exclusively pre-mRNA and U1 snRNPs. The protein composition of this complex has been determined by MS and contained in addition to all known U1 proteins, three additional splicing factors: Mud2, Msl5 and $\mathrm{Npl3}$, thus has all the characteristics of a CC2. In yeast two kinds of commitment complexes have been identified, termed $\mathrm{CC} 1$ and $\mathrm{CC} 2$. The $\mathrm{CC} 1$ is characterized by a faster mobility and is dependent on the presence of the 5'SS and the U1 snRNP, which binds to the 5'SS in an ATP-independent manner. CC2 has a lower mobility and needs the 5'SS and a functional BPS for proper formation.

The presence of Mud2, Ms15 and Npl3 in our MS analyses suggests that our isolated early complex is $\mathrm{CC} 2 . \mathrm{Npl3}$ is a SR-like protein in S. cerevisiae that was recently shown to be required for efficient co-transcriptional recruitment of the splicing 
machinery. It is involved in the recruitment of splicing factors to chromatinassociated transcripts. Npl3 was shown to promote efficient splicing of a large subset of genes via co-transcriptional recruitment of U1 and U2 snRNPs (Kress, Krogan et al. 2008); (Moehle, Ryan et al. 2012). SR and hnRNP proteins in metazoans are best understood for their role in alternative and constitutive splicing, although they have also been implicated in additional steps in gene expression, including mRNA export, translation, and even transcription itself (Singh and Valcarcel 2005); (Long and Caceres 2009); (Dreyfuss, Kim et al. 2002). The yeast S. cerevisiae, contains at least three genes with a canonical SR protein domain structure: one or more RNA recognition motifs and a domain enriched in arginine-serine-di-peptides (Long and Caceres 2009); (Manley and Krainer 2010). It was shown that deletion of Npl3 causes splicing defects. The affected genes were exclusively those encoding ribosomal proteins which represent the major class of intron containing genes in budding yeast, in other respects alternative splicing is extremely rare in yeast (Kress, Krogan et al. 2008; Long and Caceres 2009); (Moehle, Ryan et al. 2012). Recent experiments demonstrated that Npl3 remains associated with mRNA after splicing is completed (Moehle, Ryan et al. 2012). The fact that we found Npl3 only associated with our CC2 might be due to our purification strategy. Likely, Npl3 might be tightly associated with early spliceosomal complexes consistent with its suggested role of cotranscriptional recruitment of the splicing machinery.

Mud2 is a splicing factor known to be involved in early pre-mRNA splicing events and it has been shown to interact with the highly conserved BPS in yeast and with the U1 snRNP (Krämer et al., 1996). Ms15/BBP (homologue to SF1) is a branch point binding protein and recognizes the intron BPS UACUAAC in the pre-mRNA transcripts during spliceosome assembly. Ms15 is recruited to the spliceosome at a very early stage of assembly. Mud2 has been identified as the yeast homolog of U2AF65, the large subunit of U2AF that interacts with the polypyrimidine tract 3 ' to the mammalian BPS (Kistler and Guthrie 2001). In previous studies it was shown that Mud2 interacts with Ms15/BBP splicing factor and Sub2.

Sub2 was completely absent from our purified complexes (i.e. CC, B, Bact and C). Sub2 is a DEAD-box helicase, which acts very early in pre-mRNA splicing. Sub2 belongs to the DExD/H-box ATPase family, like Prp5 and Prp2, and is one of the helicases which play a role in both pre-mRNA splicing and mRNA export. Like the 
helicase Sub2, Prp5, was absent from our purified complexes. Prp5 and hydrolysis of ATP are required for stable binding of the U2 snRNP with the pre-mRNA in the presence of Cus2 which is thought to be the first ATP-dependent step in the splicing cycle (Liao, Colot et al. 1992); (Ruby, Chang et al. 1993);(Perriman, Barta et al. 2003). The reason for the absence of Prp5 in our CC preparations is that we used a thermo sensitive mutant of Prp5 (prp5-1), which is heat-inactivated and lost, thus blocking spliceosome assembly at the stage of CC2. However, Prp5 was never detected with high peptide numbers in our spliceosomes due to the fact that Prp5 acts at the stage of the pre-spliceosomal A complex prior to the formation of the $\mathrm{B}$ complex. We also could not detect the U2 snRNP associated protein Cus2 in our CC2. Cus2 belongs to the members of the RNA recognition motif (RRM) family of RNA binding proteins and it was suggested to mediate a functional interaction between the U2 snRNA and/or the U2 associated SF3a complex protein Prp11 and Prp5 (Yan, Perriman et al. 1998). The work by Perriman and Ares suggested a model for the interplay between Cus2, Prp5 and the U2 snRNP in which Prp5 might be needed for the ATP-dependent removal of Cus2 from the U2 snRNP leading to subsequent stable integration of the U2 snRNP into the spliceosome (Perriman, Barta et al. 2003). The absence of Cus 2 in our complexes could be explained by the absence of U2 snRNPs in our CC2 preparations. It might be that Cus2 is recruited together with U2 to the spliceosome to stabilize the binding of the U2 snRNA/snRNP until its stable integration into the spliceosome. To promote this, the Prp5-mediated removal of Cus2 is needed (Perriman, Barta et al. 2003). Our isolated CC2 could be used in the future for in vitro reconstitution of A complexes upon addition of purified U2 snRNPs and recombinant Prp5. In addition it would be interesting to investigate how the Prp5mediated hydrolysis of ATP promotes the stable association of the U2 snRNP in the pre-spliceosome

\subsection{Evolutionary conservation of yeast spliceosomes}

The large number of proteins found associated with human spliceosomal complexes are due to the higher amount of regulated splicing in the metazoan system whereas, as mentioned above, alternative splicing is nearly completely absent in yeast. However, most of the identified splicing factors found in our purified complexes have a human 
homolog and thus, are evolutionarily conserved in humans. Remarkably, more than $85 \%$ of the yeast splicing factors listed in Table 3.1 have a clear evolutionarily conserved counterpart (Fig. 4.1). The comparison of the proteome of metazoan and yeast spliceosomes revealed an evolutionarily conserved core design of the splicing machinery. In Fig 4.1 are shown the protein factors which associates with human spliceosomes without an obvious conserved counterpart in yeast. There are $\sim 80$ proteins without a yeast homolog, known to play a role in regulating alternative splicing, i.e. among others SR and hnRNP proteins (Wahl, Will et al. (2009). A set of about ten SR and hnRNP proteins and several U2-related proteins are present in early human spliceosomes but essentially absent from yeast (Fig. 4.1). We expected that one or more yeast SR-like or hnRNP proteins would be found in early yeast spliceosomal complexes (e.g. A complex). Indeed we found the yeast SR-like protein Npl3 associated with our early pre-spliceosomal CC2 (Table 3.1). Indeed, Npl3 was also recently shown to promote the recruitment of the U1 snRNP to the pre-mRNA (Kress, Krogan et al. 2008). The human splicing machinery contains many regulatory proteins needed for alternative splicing. The majority of these regulatory protein factors are only required in certain situations and are loosely associated with the human spliceosome. Obvious counterparts for many of these proteins are not present in yeast. For example, the members of the PPIase family (peptidyl-prolyl cis/trans isomerase) are represented with seven proteins in the human spliceosomes, but only one PPIase, NY-CO-10, shows $28 \%$ identity (45\% similarity) with the yeast Cwc27, which harbors a PPIase domain. This lead us to conclude that the yeast splicing machinery is less complex than that of metazoan due to the limited amount of regulated splicing. 


\section{Discussion}

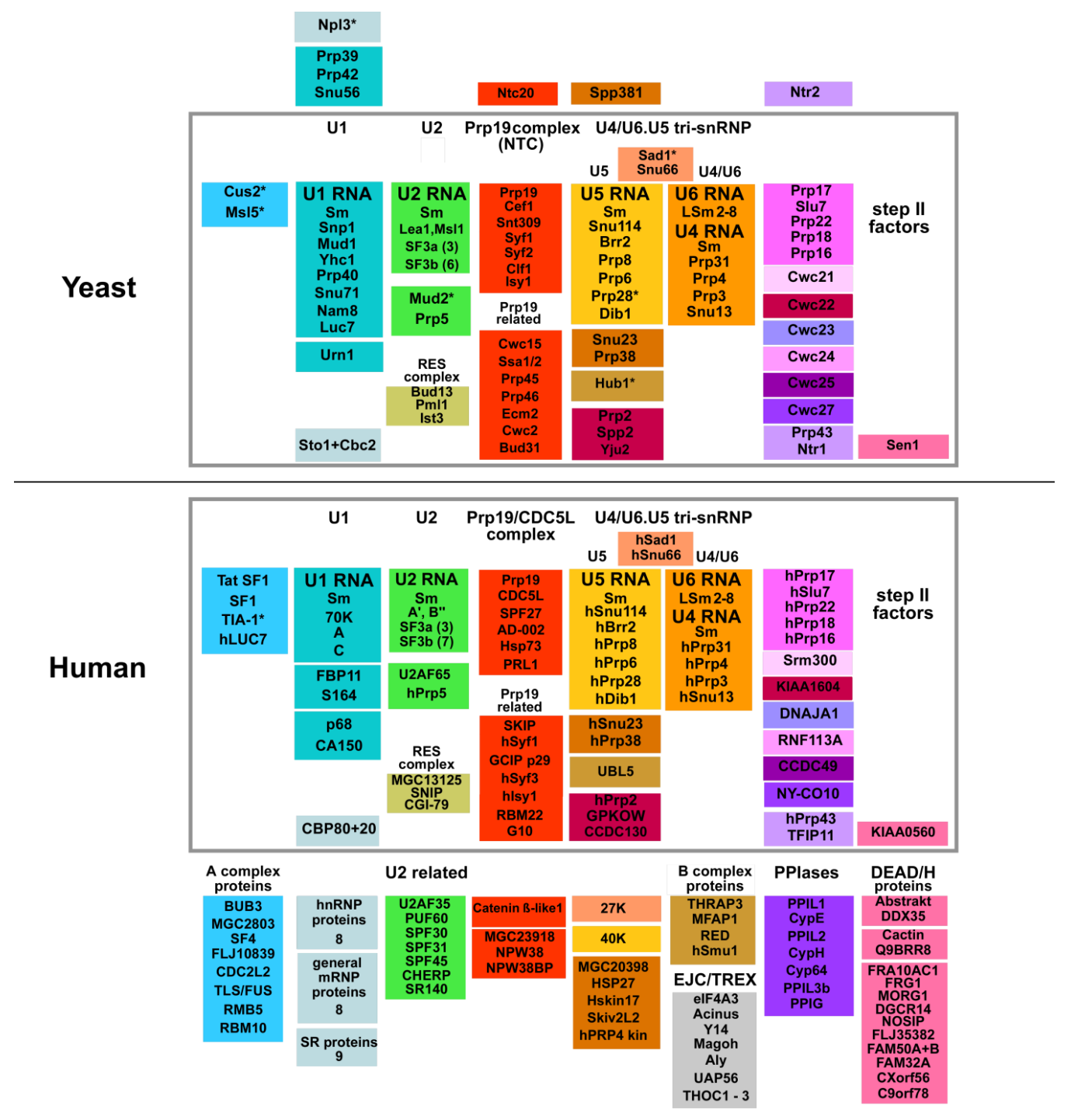

Figure 4.1: The yeast splicing machinery is less complex than that of humans

Upper rectangle: Yeast proteins (yeast nomenclature) evolutionarily conserved between yeast and man, associated with purified yeast B, Bact, and C complexes, are placed inside of the rectangle. Proteins above the rectangle do not have a human counterpart. Lower rectangle: Human proteins (human nomenclature) evolutionarily conserved between yeast and man, associated with purified human $\mathrm{A}, \mathrm{B}$, and $\mathrm{C}$ complexes, are placed inside of the rectangle. Proteins below the rectangle were found associated with purified human spliceosomal complexes, but the majority of them do not have a yeast counterpart (Behzadnia, Golas et al. 2007); (Bessonov, Anokhina et al. 2008). Numbers indicate the total number of individual proteins in a particular group. (Asterisks) Proteins that do have homologs in yeast or human but were not found or found loosely associated with purified spliceosomal complexes; yeast Ms15, Npl3, Mud2, and Hub1 were found with low peptide numbers in the 20S-25S peak shown in the results section for the B complex and Msl5, $\mathrm{Npl} 3$ and Mud2 were found in the commitment complex. Cus2, Prp28, and Sad1 were not detected by MS and are included for completeness, as well as human TIA-1, which is the homolog of yeast Nam8. Proteins are grouped according to snRNP association, function, presence in a stable heteromeric complex, or association with a particular spliceosomal complex, as indicated (Fabrizio, Dannenberg et al. 2009). 


\subsection{Spliceosomal dynamics during catalytic activation}

Comparative proteomics of human and Drosophila spliceosomal complexes showed a dramatic exchange of proteins during the transition from $\mathrm{B}$ to $\mathrm{C}$ complexes. More than 60 proteins are exchanged during catalytic activation of the metazoan splicing machinery (Bessonov, Anokhina et al. (2008); (Herold, Will et al. 2009). Our studies show that the yeast spliceosome is also in a highly dynamic state during its assembly and step 1 catalysis. The most dramatic compositional change in the yeast spliceosome occurred during the transition from the pre-catalytic B complex to the activated Bact complex. During the step of activation, the entire U1 snRNP is released, whereas the tri-snRNP undergoes massive remodeling, This entails dramatic structural rearrangements that at the RNA level involve unwinding of the U4/U6 duplex and the formation of U2/U6 base-pairing, a reorganization that is exceptional among RNP machines (Wahl, Will et al. (2009). Concomitant with the unwinding of the U4/U6 duplex, all U4 and U6 snRNP associated proteins are released from the spliceosome as well, together with factors that link the U5 snRNP to the U4/U6 disnRNP (Fig. 4.2)(Hacker, Sander et al. 2008). As a consequence, our B ${ }^{\text {act }}$ complexes lack all U4/U6 snRNP specific proteins and several U5 snRNP proteins, except Brr2, Prp8 and Snu114 which are present throughout the whole splicing cycle (Fig.4.2). In total $\sim 35$ proteins are lost during the transition from the $\mathrm{B}$ to the $\mathrm{B}^{\text {act }}$ complex. Subsequently after the disruption of the U4/U6 duplex and the loss of pre-catalytic binding partners, new partners have to be provided to stabilize the U6 snRNA interaction with pre-mRNA and the U2 snRNA. The factors which are recruited during the formation of the U2/U6/pre-mRNA base-pairing interaction were unclear at the start of this work, as well as the precise time at which such proteins are recruited. Here, we could demonstrate that 12 known splicing factors were recruited at the time of spliceosomal activation and that the eight proteins of the NTC-complex become more stably bound (Fig. 4.2, $\mathrm{B}^{\text {act }}$, and compare with $\mathrm{B}$ complex). As a result of this reproducible observation we regard these factors as characteristic for the yeast spliceosomal Bact complex and named them NTC-related proteins. 
Discussion
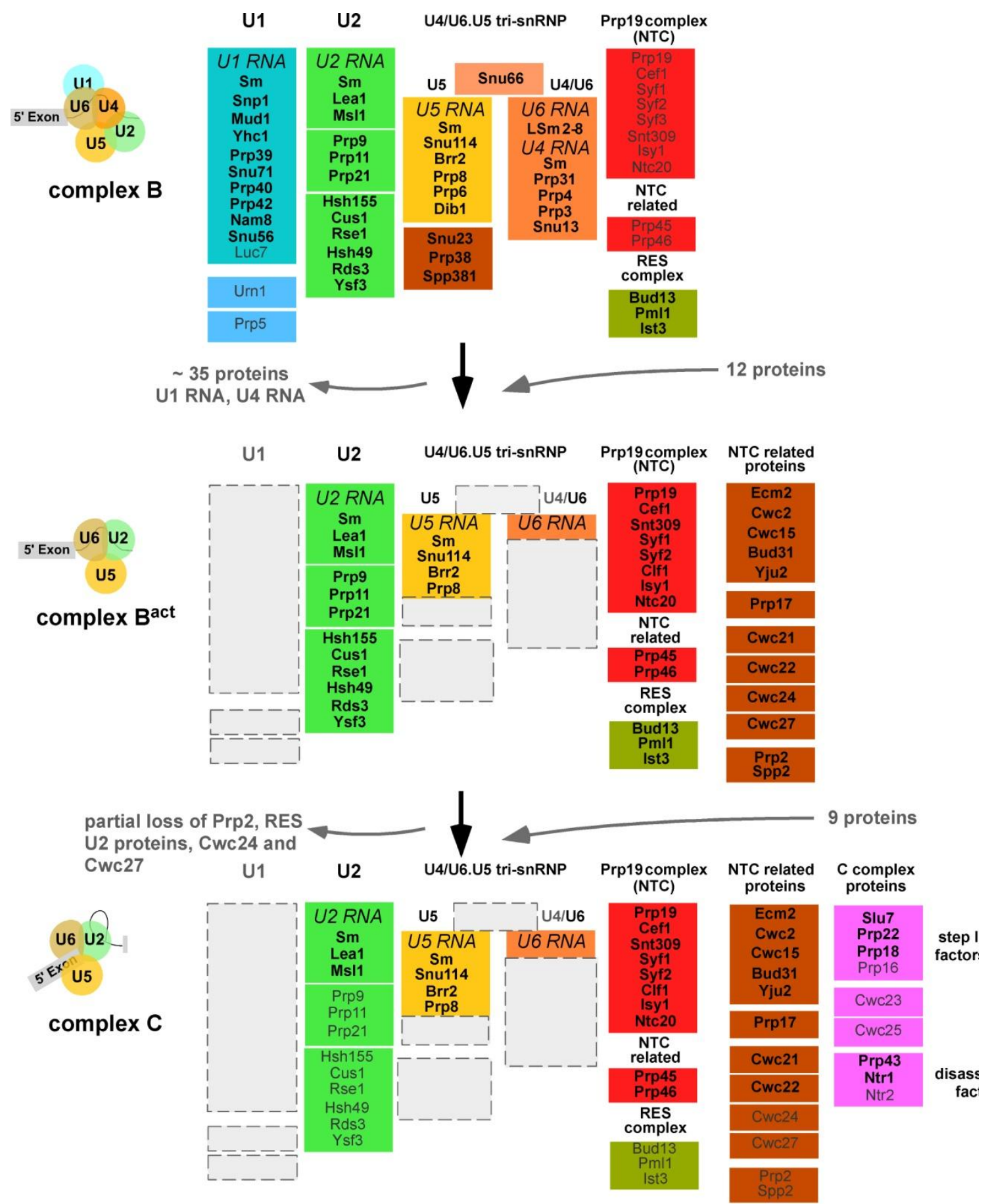

Figure 4.2: Compositional dynamics during catalytic activation

The protein composition of the yeast $\mathrm{B}, \mathrm{B}^{\text {act }}$, and $\mathrm{C}$ complexes was determined by MS. Proteins (yeast nomenclature) are grouped as described in the legend of Figure 4.1. The relative abundance of proteins is indicated by light (substoichiometric amounts) or dark (stoichiometric amounts) lettering and is based on the relative number of peptides sequenced (Table 3.1) (Fabrizio, Dannenberg et al. 2009) 
The proteins recruited to the Bact complex can be divided into two classes: (i) those most probably required to establish and/or stabilize the U2/U6 base-pairing interaction (e.g Cwc24, Ecm2 and $\mathrm{Cwc} 2$ a protein that contains a RNA recognition motif [RRM] (Hogg, McGrail et al.) and (ii) those more directly required to promote step 1, such as Prp2, Spp2, and Yju2. U6 snRNA not only engages in novel base pairing interactions with $\mathrm{U} 2$ and the pre-mRNA but also new protein-RNA interactions are established (Wahl, Will et al. 2009). It was postulated that members of the NTC complex and NTC-related proteins play an important role in restructuring the U6 and U2 snRNAs, and it was previously shown by Chan et al. (2003) that proteins of the NTC play a critical role in tethering and stabilizing the U6 and U5 snRNAs at the time of activation (Chan, Kao et al. 2003) NTC-dependent stabilization of U6 is mediated through remodeling of U6 snRNP, which includes the stabilization of U6/5'SS base pairing interaction, and destabilization of Lsm proteins from U6 (Chan, Kao et al. 2003). Additional rearrangements are required to shape and juxtapose evolutionarily conserved sequences of U6 snRNA (e.g. the internal stemloop structure (ISL) with the pre-mRNA 5'SS for catalysis of the first step. One of the proteins that influence the catalytic conformation of the RNA network in the spliceosome is Cwc2 which interacts physically with Prp19 (Hogg, McGrail et al.). Recent data from our laboratory indicate that $\mathrm{Cwc} 2$ interacts with the catalytically important ISL of U6 snRNA and the pre-mRNA substrate in $\mathrm{B}^{\text {act }}, \mathrm{B}^{*}$ and $\mathrm{C}$ complexes (Rasche, Dybkov et al. 2012). Thus, it might play a crucial role in positioning the catalytic site into an active structure. The U2 snRNP is also substantially remodelled during splicing, with an apparent destabilization of SF3a and $\mathrm{SF} 3 \mathrm{~b}$ proteins prior to formation of the $\mathrm{C}$ complex, which suggested that they are not required after step 1 (Bessonov, Anokhina et al. 2008); (Fabrizio, Dannenberg et al. 2009). Thus, a large number of structural and compositional rearrangements accompany the assembly and catalytic process of the spliceosome. As mentioned above, the activation of the spliceosome and splicing catalysis requires formation of an active catalytic centre. In this context, the Prp2 DEAH-box ATPase is known to act subsequently of the U4/U6 unwinding by the helicase Brr2 but just prior to step 1 of splicing catalysis. It was suggested that Prp2 is released from the spliceosome upon ATP hydrolysis. We could show that Prp2 is recruited very stably to the spliceosome at the stage of the Bact complex, and it remains stably bound to this pre-catalytic 
complex, as determined by the high peptide numbers analyzed by MS. This suggested that Prp2 cannot hydrolyze ATP in this specific spliceosomal "snapshot", otherwise it would dissociate from it. This observation led us to conclude that the Bact complex is not yet catalytically activated. This is further confirmed by the high $S$ value of our $\mathrm{B}^{\text {act }}$ complex (45S) and is consistent with previous studies that showed that, prior to ATP hydrolysis, the spliceosome has a higher $\mathrm{S}$ value than it has after ATP hydrolysis by Prp2 (Kim and Lin (1996). Despite the fact that we used a concentration of 2.0 $\mathrm{mM}$ ATP during the assembly of our $\mathrm{B}^{\text {act }}$ complexes, Prp2 is "trapped" in Bact. This is because our $\mathrm{B}^{\text {act }}$ complexes were assembled on the truncated M3-Act $\Delta 6$ pre-mRNA substrate and were able to undergo pre-catalytic activation in the presence of high ATP but not to proceed to catalytic activation and step 1 catalysis. As step 1 catalysis occurs in our complex $\mathrm{C}$ when we used the M3-Act $\Delta 31$ pre-mRNA, which is only 25 nucleotides longer downstream of the BPS, this led us to speculate that a longer RNA stretch downstream of the BPS may be required - either directly or as a proteinbinding site - to stimulate ATP hydrolysis and/or support the structural rearrangements that occurs during Prp2-mediated ATP hydrolysis and release. This assumption was in line with previous studies which postulated the importance of the length of the intron downstream of the BPS for step 1 catalysis (Rymond, Torrey et al. (1987), Cheng (1994), Fabrizio, Dannenberg et al. (2009). In addition, cross-linking experiments demonstrated contacts of the essential Prp2 DEAH-box ATPase with this intron region (Teigelkamp, McGarvey et al. (1994). Thus, $B^{\text {act }}$ represents a spliceosome prior to the final catalytic step mediated by Prp2. Therefore we suggest that one or more factors present in our purified spliceosomal $\mathrm{C}$ complex may be required for promoting step 1 (i.e. Cwc25) (Fabrizio, Dannenberg 2009).

The proteomic analysis of $\mathrm{C}$ complexes showed that at least nine proteins are recruited at the time of $\mathrm{C}$ complex formation and step 1 catalysis, these factors are named the C complex proteins (Figure 4.2). One of them is Cwc25, an essential spliceosomal factor that was recently shown to promote the first step of splicing and suggested to bind at or near the branch site of the pre-mRNA after Prp2 action (Warkocki, Odenwalder et al. (2009), (Tseng, Liu et al. 2011). We found Cwc25 only with low peptide numbers in the C complex (Table 3.1), indicating that Cwc25 had already acted (i.e. by promoting step 1 catalysis) and additional factors required for its 
dissociation (i.e. Prp16, Slu7 and Prp18, see below) have already entered (Ohrt, Odenwälder et al., manuscript submitted).

If one compares our purified pre-catalytic, but activated $\mathrm{B}^{\text {act }}$ complex with the first step spliceosome $\mathrm{C}$ complex, it is obvious that this transition also entails a dramatic remodeling. Our first step spliceosome showed a lower $S$ value $(40 \mathrm{~S})$ than did the $\mathrm{B}^{\text {act }}$ complex. This remodeling was also accompanied by a destabilization of Prp2 and its co-factor Spp2 as determined by the decrease of peptide numbers analyzed by MS (Table 3.1). Additionally we observed a decreased number of peptides for proteins belonging to the $\mathrm{U} 2$ associated SF3a and SF3b complexes. The SF3a/b proteins are required at early stages in the splicing cycle, but it is not yet clear whether they are required after step 1. We will discuss further the importance of the destabilization of the $\mathrm{U} 2 \mathrm{SF} 3 \mathrm{a} / \mathrm{b}$ proteins during the transition from complex $\mathrm{B}^{\text {act }}$ to $\mathrm{C}$ below, together with our dcFCCS data.

The proteomic analysis of $\mathrm{C}$ complexes showed also a recruitment of spliceosomal factors which are known to act at later stages of the splicing reaction and include also the so-called "second step factors" that comprise Prp16, Slu7, Prp18 and Prp22 (Umen and Guthrie (1995). Prp17 is also a second step factor but it is already present at the time of $\mathrm{B}^{\text {act }}$ complex formation, which is consistent with recent observation that Prp17 plays a role in step 1 of the splicing reaction (Sapra, Khandelia et al. 2008). Thus, Prp17 can be considered as a bona fide step 1 factor. Surprisingly, we also detected all members of the trimeric disassembly NTR complex (Ntr1, Ntr2 and Prp43) in our C complex preparations. The NTR plays a role at a later stage of the splicing cycle, during the disassembly of the spliceosome after completion of splicing. One explanation for the unexpected association of the NTR with the spliceosome is that the splicing machinery might initiate turnover of the stalled spliceosomes due to the mutation or the lack of the 3'SS in our pre-mRNA substrate (Pandit, Lynn et al. 2006).

In summary, the proteins present in complex C likely comprise the complete list of proteins required to maintain a functional RNP machine in which step 1 is catalyzed (Fig. 4.2) As the complete set of known step 2 factors is present in complex C, this indicates that also step 2 could occur under certain conditions and on a wild-type pre- 
mRNA substrate. The limited number of proteins recruited during the $\mathrm{B}^{\text {act }}$ to $\mathrm{C}$ transition revealed by this work has already offered the possibility of investigating step 1 and 2 catalysis in vitro using purified components of known composition (Warkocki, Odenwalder et al. 2009) and also gave us the opportunity of learning more about protein dynamics during catalytic activation and step 1 catalysis as revealed by dcFCCS in the second part of this work (Ohrt, Prior et al. 2012).

\subsection{Compositional dynamics correlate with structural changes}

Our EM analyses showed that the $\mathrm{B}, \mathrm{B}^{\text {act }}$ and $\mathrm{C}$ complexes exhibit distinct typical shapes (Figure 4). Complex B images have triangular/rhombic shapes which are very similar to corresponding images obtained for human and Drosophila B complexes (Deckert, Hartmuth et al. 2006), (Herold, Will et al. 2009). In addition, structural features which were first described for the human complex (Boehringer, Makarov et al. 2004), like head, neck, stump and foot, are also discernible in the yeast B complex. This suggests that higher order interactions and the general spatial organization of spliceosomal subunits are also conserved among metazoans and yeast. The most evident difference between B complexes from yeast and man lies in the size of the head region, which is substantially smaller in yeast. The structural heterogeneity observed for complex B's head domain in other organisms (Boehringer, Makarov et al. 2004);(Deckert, Hartmuth et al. 2006), is also seen in the yeast complex, but here the degree of heterogeneity is less pronounced. $\mathrm{B}$ and $\mathrm{B}^{\text {act }}$ are structurally very different, in agreement with substantial differences in protein/RNA composition and the profound compositional remodeling during the $\mathrm{B}$ to $\mathrm{B}^{\text {act }}$ transition. Remodeling also leads to a change in sedimentation behavior - from 40 to $45 \mathrm{~S}$ - during this activation step.

Our EM studies indicated that there are profound structural differences also between the $2 \mathrm{D}$ class averages of Bact and $\mathrm{C}$. This is also reflected in the $\mathrm{S}$ value which drops from $45 \mathrm{~S}$ to $40 \mathrm{~S}$ for the less compact appearing $\mathrm{C}$ complex. The reason for the observed structural differences were found only in later studies (Warkocki, Odenwalder et al. 2009) and result from remodeling event occurring concomitant with the transformation of the $\mathrm{B}^{\text {act }}$ complex into the $\mathrm{B}^{*}$ complex which is a pre-requisite 
for 5'SS cleavage in complex C. Thus, consistent with mechanistic differences between $\mathrm{B}^{\text {act }}$ and $\mathrm{C}$, their $2 \mathrm{D}$ structures suggest differences in their spatial organization. EM immunolabeling of spliceosomal components and 3D reconstructions may allow a more precise determination of the structural differences between $\mathrm{B}^{\text {act }}$ and $\mathrm{C}$ spliceosomes.

\subsection{Suitability of dual color Fluorescens Cross Correlation Spectroscopy (dcFCCS) for investigating spliceosomal protein dynamics}

With the experiments done in this work we demonstrated that dcFCCs is, in combination with the established in vitro reconstitution system of functional spliceosomes, a powerful approach to investigate dynamics of purified spliceosomes. For dcFCCS measurements, yeast spliceosomes were stalled before step 1 by using the temperature-sensitive mutant prp2-1 yielding a $\mathrm{B}^{\text {act } \Delta \operatorname{Prp} 2}$ spliceosome. It was shown by the work of Warkocki et al (2009) that highly purified $B^{\text {act } \Delta \operatorname{Prp} 2}$ can be catalytically activated to form B* when supplemented with recombinant Prp2 and Spp2 splicing factors (Warkocki, Odenwalder et al. 2009). Purified $B^{\text {act } \Delta \operatorname{Prp} 2}$ complexes assembled on actin pre-mRNA labeled at its 5' end with the red fluorescent dye Atto647N were used. Proteins were labeled in vivo by fusing the protein of interest with a fluorescent protein EGFP (enhanced green fluorescent protein) by genetic modification. As in any study involving the introduction of bulky labels, there was a risk of label-induced impaired behavior. In the system described here, neither the label on the pre-mRNA nor those on the various proteins impaired the activity of the spliceosomes examined. The resulting doubly fluorescent-labeled and purified spliceosomal complexes were analyzed before and after catalytic activation by $\operatorname{Prp} 2$ and were found to be stable under our dcFCCS conditions as demonstrated for Snu114-EGFP. Snu114 is known to bind to the spliceosome throughout the splicing cycle (Fabrizio, Laggerbauer et al. 1997) (Fabrizio, Dannenberg et al. 2009) and was therefore used as a "positive control" in our experiments. The dcFCCS results of our complexes were sufficiently reproducible and allowed the investigation of the binding and release of the proteins of interest. 


\subsection{Prp2-mediated transformation of the $B^{\text {act }}$ into the $B^{*}$ complex substantially alters the binding affinity of several proteins at the cataly tic core of the spliceosome}

Although the essential role of Prp2 in the catalytic activation of the spliceosome was established earlier, its mechanism of action has remained enigmatic (Kim and Lin (1996). The structural change the spliceosome undergoes upon Prp2-mediated, ATPdependent activation must be profound, given the substantial change in $\mathrm{S}$ value seen between the precursor $\mathrm{B}^{\text {act } \Delta \operatorname{Prp} 2}$ complex $(45 \mathrm{~S})$ and the catalytically activated spliceosome B* (40S) (Kim and Lin (1996); Warkocki, Odenwalder et al. (2009). We expanded our MS data by dcFCCS showing that the binding affinity of at least seven proteins, i.e., the $\mathrm{U} 2 \mathrm{SF} 3 \mathrm{a} / \mathrm{b}$ proteins Prp11 and Cus1, the RES complex protein Bud13, Cwc24, Cwc27, Yju2, and Cwc25, is quantitatively and qualitatively altered by Prp2-mediated catalytic activation of the spliceosome. Due to their characteristics in their binding behavior, these proteins can be divided into three groups. The first group comprises Cwc24, Cwc27, and Bud13, which are tightly bound to the $\mathrm{B}^{\text {act } \Delta \operatorname{Prp} 2}$ spliceosome and which dissociate almost completely (Cwc24 and Cwc27) or partly (Bud13), even under near-physiological conditions upon Prp2-mediated activation and conversion to the $\mathrm{B}^{*}$ complex. The second group includes the SF3a/b proteins Prp11 and Cus1, whose binding to the spliceosome is weakened by the catalytic activation thus becoming salt-sensitive, such that they dissociate from the $\mathrm{B}^{*}$ complex at higher salt concentrations, while staying associated with the $\mathrm{B}^{*}$ spliceosome at non-stringent conditions (Fig. 3.18). The third group contains proteins whose binding to the spliceosome is enhanced during the $\mathrm{B}^{\text {act }}$ to $\mathrm{B}^{*}$ transition and includes $\mathrm{Yju} 2$ (which is recruited at the stage of the $\mathrm{B}^{\text {act }}$ complex and which is more weakly bound prior to catalytic activation) and Cwc25 (which before the transition was not bound at all and is thus recruited to $\left.\mathrm{B}^{*}\right)$. Both proteins are known to be required for the first catalytic step that is catalyzed by complex $\mathrm{B}^{*}$. 


\subsection{Cwc24 functions in the generation of an active spliceosome but is not required for splicing catalysis per se}

There is little known about the function of Cwc24 and Cwc27 in splicing. Cwc27 contains a peptidylprolyl isomerase and also has an evolutionarily conserved counterpart in the human spliceosome, NYCO-10 (Ohi, Link et al. (2002); Fabrizio, Dannenberg et al. (2009), but nevertheless, Cwc27 is not essential for the growth of $S$. cerevisiae under standard conditions (Winzeler, Shoemaker et al. (1999), Giaever, Chu et al. (2002). In contrast, Cwc24 is known to be essential for yeast growth, and it is needed for the splicing of the U3 snoRNA precursor in vivo (Goldfeder and Oliveira (2008). Our results that Cwc24 and Cwc27 dissociate almost quantitatively from the spliceosome during or after the Prp2-mediated catalytic activation of the spliceosome (Fig. 3.15) was the first indication that they are not required for catalysis of the splicing reaction per se. This fact led us to investigate the role of $\mathrm{Cwc} 24$ in splicing in more detail. The depletion and reconstitution experiments, done in our laboratory, confirmed that the presence of Cwc24 is necessary for splicing to proceed through the first catalytic step in vitro (Ohrt, Prior et al. 2012). Surprisingly, they also showed that Cwc24 is not required during the actual catalysis; catalytically activated $\mathrm{B}^{*}$ complexes that had lost all of their Cwc24 were still able to perform the first catalytic step of splicing efficiently when complemented with the step 1 factor Cwc25 (Fig. 3.14B). Thus, the function of Cwc24 must be to assist in the assembly or the maturation of the activated spliceosome $\mathrm{B}^{\text {act }}$. Consequently, we regard Cwc24 as an assembly factor for the $\mathrm{B}^{\text {act }}$ complex that is probably involved in generating the correct structure or conformation of the $\mathrm{B}^{\text {act }}$ complex. Therefore it will be interesting to find out which proteins of the $\mathrm{B}^{\text {act }}$ complex are direct interaction partners of Cwc24 and whether it also binds to spliceosomal RNAs or the pre-mRNA.

Earlier in this work, we showed that the proteins of the RES complex are recruited to the spliceosome at the time of the B complex and that it is stoichiometrically present in $\mathrm{B}^{\text {act }}$ (Table 3.1 and Figure 4.2). Our dcFCCS results demonstrate that the RES protein Bud13 loses its affinity for the B* complex. Previous studies showed that the RES complex is not essential for yeast viability, but is required for efficient splicing in vitro and in vivo. The work by Dziembowski et al. (2004) demonstrated that the inactivation of these proteins causes leakage of unspliced pre-mRNA from the 
nucleus (Dziembowski, Ventura et al. (2004). Our present results are consistent with the idea that the RES proteins remain associated with the spliceosome until Prp2mediated catalytic activation of the spliceosome and first step of catalysis to prevent the premature nuclear release of unspliced pre-mRNA.

\subsection{0 $\mathrm{Sf3a} / \mathrm{b}$ proteins remain bound to the $\mathrm{B} *$ spliceosome under near- physiological conditions, but their binding is reduced at high salt}

Our dcFCCS data revealed clearly that Prp2-mediated ATP hydrolysis affects the binding affinity of the SF3a/b complexes (Fig. 3.18). We demonstrated that representative proteins of the Sf3a/b complex, Prp11 and Cus1, remained bound to the spliceosome under physiological salt conditions (i.e. $75 \mathrm{mM} \mathrm{KCl}$ ). However, a destabilization of their interaction with the $\mathrm{B}^{*}$ complex could be analyzed by the loss of their binding affinity at higher salt conditions. In human $\mathrm{B} / \mathrm{B}^{\text {act }}$ complex, several $\mathrm{SF} 3 \mathrm{a} / \mathrm{b}$ proteins bind to the pre-mRNA on both sides of the BS (Gozani, Potashkin et al. (1998), and a similar function may likely be ascribed to their counterparts in yeast. Indeed, Hsp155, the yeast homolog of human SF3b155, cross-links to pre-mRNA close to the BPS (McPheeters and Muhlenkamp (2003). Thus, the destabilization of proteins, losing their binding affinity upon Prp2-mediated ATP hydrolysis, could expose the BPS adenosine for nucleophile attack at the 5'SS phosphodiester bond, due to rearrangement of the spliceosome near the BPS.

There are somewhat conflicting reports regarding the fate of the U2-associated SF3a/b proteins during catalytic activation. Our MS data showed that the U2 SF3a/b proteins were represented in similar quantities in $\mathrm{B}$ and $\mathrm{B}^{\text {act }}$, nevertheless, in the $\mathrm{C}$ complex their presence was reduced to $20 \%-30 \%$. In the $\mathrm{B} *$ and $\mathrm{C}$ complexes, prepared from $\mathrm{B}^{\text {act } \Delta \operatorname{Prp} 2}$ by complementation in vitro, the same $\mathrm{U} 2$ proteins were found by MS to be similarly abundant in the $\mathrm{B}^{\text {act } \Delta \operatorname{Prp} 2}, \mathrm{~B}^{*}$, and $\mathrm{C}$ complexes (Warkocki, Odenwalder et al. (2009). In a recent paper (Lardelli et al. 2010), it was reported that endogenous yeast C complexes arrested in vivo by the effect of a cold-sensitive Prp16 mutant and subsequently purified from whole yeast extracts contained virtually no U2 proteins. In the present work, we found that, under dcFCCS conditions (i.e., spliceosomes reconstituted in vitro under near-physiological conditions and at $\sim 1 \mathrm{nM}$ 
concentration), the U2 proteins Prp11 and Cus1 are not released either from complex $\mathrm{B}^{*}$ or from complex $\mathrm{C}$. We believe that the results shown here correspond most closely to physiological reality because dcFCCS allows spliceosomes to be investigated directly in solution and in equilibrium without requiring biochemical/physical perturbation of the sample. The differences described above could be due simply to the $\mathrm{U} 2$ proteins having an intermediate binding affinity after catalytic activation of the spliceosome so that their continued presence in $\mathrm{B}^{*}$ and/or $\mathrm{C}$ complexes is sensitive to small changes in the spliceosome's physical environment. Since in all cases, either truncated pre-mRNAs or mutated RNA helicases were used to arrest the spliceosome at the desired stage, it is also possible that, in extract, discard mechanisms are responsible for the removal of the U2 proteins from dead-end spliceosomal complexes. Very recently it was shown in our laboratory that the U2 $\mathrm{SF} 3 \mathrm{a} / \mathrm{b}$ proteins remain bound to the spliceosome during the entire spliceosomal cycle and the U2 snRNP is released during disassembly of the spliceosome as an intact particle (Fourmann, Schmitzova et al. 2013).

\subsection{Prp2 action creates high-affinity binding sites for the step 1 factors Yju2 and Cwc25 in the catalytically activated spliceosome}

Yju2 is one of the factors which needs the ATP-dependent Prp2-mediated activation of the spliceosome for stable integration. Of all the proteins studied here by dcFCCS, Yju2 has the lowest affinity for the $\mathrm{B}^{\text {act } \Delta \mathrm{Prp} 2}$ spliceosome and can be completely removed from it at $300 \mathrm{mM}$ salt. After Prp2-mediated catalytic activation, the spliceosome's binding affinity for Yju2 is strongly enhanced, and its association becomes largely salt-resistant. These results evidenced that Prp2 has to function before Yju2 to create a high-affinity binding site for stable integration. Thus, it is possible to conclude that the stable integration of Yju2 is Prp2-dependent. Additionally we demonstrated that the first step factor Cwc25 is recruited after Prp2 has acted. No peptides were found for Cwc25 in our Bact complex preparations as revealed by MS analysis. However, via dcFCCS we clearly showed that after catalytic activation a strong binding site is created in the $\mathrm{B}^{*}$ spliceosome for the step 1 factor Cwc25. 


\subsection{Substantial Prp2-mediated remodeling during catalytic activation of the spliceosome}

The ability to isolate and to purify spliceosomal complexes stalled at distinct stages of the splicing cycle and to characterize their proteome was a milestone towards the understanding of the ongoing processes at the core of the splicing machinery during its activation. We showed a dramatic change in the protein composition during the transition from the $\mathrm{B}^{\text {act }}$ to $\mathrm{C}$ complex, including the destabilization of the $\mathrm{U} 2$ proteins and RES complex as revealed by MS. Thus, to expand our MS data, we measured the effect of the catalytic activation on the binding strength of at least seven proteins in this first application of dcFCCS to functional spliceosomes. Of theses, Bud13, Prp11 and Cus1, all belong to multiprotein complexes containing additional proteins. Bud13 is a member of the RES complex, which comprises two additional proteins, Prp11 and Cus1 belong to the U2 snRNP associated multiprotein complexes SF3a/b which consist of two (SF3a) or six additional proteins (SF3b) (see Figure 4.2). The dcFCCS results from this work are in line with our MS data. Thus, we imply that the interaction of at least 17 proteins with the spliceosome is affected by the Prp2mediated catalytic activation of the spliceosome (Fig. 4.3).

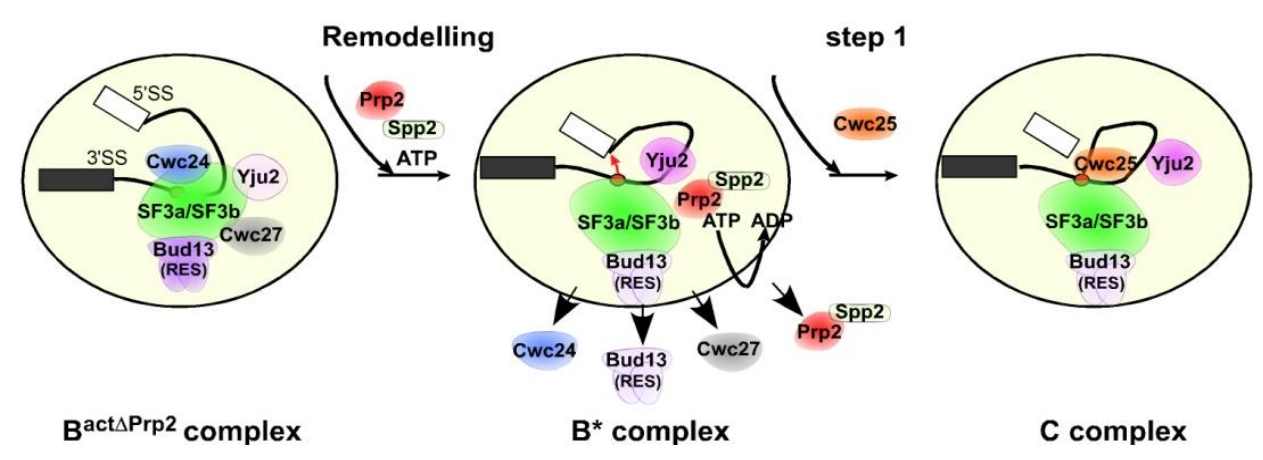

Figure 4.3: Schematic representations of the substantial remodelling the $B^{\text {act }}$ spliceosome undergoes during the Prp2/ATP-mediated catalytic activation.

Cwc24, Cwc27, the RES protein Bud13, Prp2 and Spp2 are released while the U2 SF3a/b proteins are destabilized by Prp2/ATP such that the BS adenosine becomes available for a nucleophile attack at the 5' SS phosphodiester bond. At the same time high affinity binding sites are created for Yju2 and Cwc25, which are required to promote the first step of splicing (adapted from (Ohrt, Prior et al. 2012)). 
Based on our data we addressed the question whether Prp2 is the only ATPase/helicase responsible for these dramatic rearrangements at the catalytic core of the spliceosome. The MS analysis of $\mathrm{B}^{\text {act } \Delta \operatorname{Prp} 2}$ complexes from the work of Warkocki et al. (2009) showed a complete absence of the other helicases Prp5, Sub2 and Prp28, which are required for earlier steps of spliceosome assembly. The only spliceosomal helicase that is stoichiometrically present in the $\mathrm{B}^{\text {act }}$ complex is Brr2, which is known to trigger together with the GTPase Snu114 the precatalytic activation of the spliceosome by disrupting U4/U6 interaction (Bartels, Klatt et al. 2002); (Small, Leggett et al. 2006).

It was recently shown that the obligate ATPase Brr2, together with Prp43, functions in the dissociation of the post-splicing complexes that contain the intron lariat (Arenas and Abelson 1997); (Small, Leggett et al. 2006), suggesting that Brr2 could also be involved in catalytic activation, together with Prp2. However, we demonstrated earlier that the Prp2-dependent shift in $S$ value from $\sim 45 \mathrm{~S}$ to $\sim 40 \mathrm{~S}$ during catalytic activation takes place in the presence of all rNTPs (not only ATP) (Warkocki, Odenwalder et al. 2009). In this work we showed that, upon Prp2-mediated catalytic activation, the dissociation of individual proteins, such as Cwc24-EGFP, occurs in the presence of UTP with efficiency equal to that in the presence of ATP (Fig. 3.15). Based on our results we can exclude the possibility that Brr2 contributes to spliceosome remodeling during catalytic activation due to the fact that yeast Brr2 hydrolyzes only ATP and no other rNTP, while Prp2 is rNTP unspecific (Kim, Smith et al. 1992). This would imply that Prp2 alone is responsible for the many changes in molecular interactions that take place during the transformation of $\mathrm{B}^{\text {act }}$ into the $\mathrm{B}^{*}$ spliceosome.

The assumption that Prp2 is alone responsible for the ongoing processes at the time of catalytic activation at the spliceosome's core suggests a cascade of remodeling steps during the $\mathrm{B}^{\text {act }}$ to $\mathrm{B}^{*}$ complex transition. One possible consideration for such a substantial remodeling model would be that Prp2 has only a single substrate and that only one protein is displaced from the network of intermolecular interactions in the $\mathrm{B}^{\text {act }}$ complex and that this process triggers all subsequent rearrangements. A possible Prp2 target could be Cwc24, as it is very stably bound in the $\mathrm{B}^{\text {act }}$ complex but loses its binding affinity during the transition to the $\mathrm{B}^{*}$ complex (Fig. 3.15). In this context, 
the recent demonstration of a direct interaction between Cwc24 and Cef1 is of interest (Goldfeder and Oliveira 2008). Cef1 is a core protein of the NTC complex, which acts as a major assembly platform, integrating and coordinating many molecular interactions in $\mathrm{B}^{\text {act }}$ and $\mathrm{B}^{*}$ complexes (Tsai, Chow et al. 1999); (Hogg, McGrail et al.). An alternative primary target of Prp2 could be one of the U2 SF3a/b proteins, which are known to interact with the pre-mRNA near the BPS. We cannot entirely exclude, however, that Prp2 may act on a number of targets, altering in succession the binding affinities of various proteins. This question could potentially be answered by performing a time-resolved analysis of the dissociation of various proteins and by determining the number of ATP molecules that are hydrolyzed during the transformation of a $\mathrm{B}^{\text {act } \Delta \operatorname{Prp} 2}$ to a $\mathrm{C}$ complex.

It is also unclear which RNA structure(s) in the spliceosome is/are the primary target(s) of Prp2/ATPase activity or whether Prp2 affects protein-protein interactions directly. Prp2 has been cross-linked to the region between the BPS and the 3'SS (Teigelkamp, McGarvey et al. 1994), raising the possibility that Prp2 modulates interactions between the BPS region and the U2 proteins. Alternatively, contact with this stretch of RNA might merely be required to stimulate Prp2/ATPase activity. It is also possible that Prp2/ATPase activity modulates the U2 RNA conformation during catalytic activation (Hilliker, Mefford et al. 2007); (Perriman and Ares 2007), which, in turn, could lead to the rearrangement of protein-RNA and protein-protein interaction at the catalytic core. Clearly, more information is needed about the direct contact sites of Prp2 on the $\mathrm{B}^{\text {act }}$ spliceosome and about the timing of the Prp2mediated structural changes of the spliceosome to understand this important and profound structural reorganization step. In conclusion, the studies described in this work show that our isolated and purified complexes are well suited for structural and biochemical investigations and that dcFCCS can contribute significantly to these sophisticated investigations using reconstituted, highly purified spliceosomes. 


\section{Future perspectives}

Our recently established affinity-based methods allowed us to isolate and characterize yeast spliceosomal complexes at defined functional stages (Dannenberg et al, 2012). In addition, it gave us the opportunity to carry out an investigation of the poorly understood conformational rearrangements in the spliceosome's catalytic core that occur prior to and during/after step 1 catalysis, using several approaches described in detail in this work. For example, by applying fluorescence-spectroscopic methods such as dcFCCS (in collaboration with Prof. J. Enderlein, Univ. of Göttingen) coupled with an in vitro reconstitution system (Warkocki, Odenwalder et al. 2009), we investigated the dynamics of the spliceosome's protein composition during catalytic activation by the RNA helicase/ATPase Prp2. We show that the binding affinity of a surprisingly high number of proteins is significantly changed during catalytic activation, suggesting remarkable Prp2-mediated structural rearrangements in the spliceosome's catalytic core (Ohrt, Prior et al. 2012). We have already expanded our studies and followed structural changes and the kinetics of protein recruitment/release during step 2 catalysis by dcFCCS. Our data show that the step 2 factors Slu 7 and Prp18 are needed to displace the step 1 factor $\mathrm{Cwc} 25$ from the spliceosome and that this displacement occurs immediately before step 2 catalysis and, in addition another RNA helicase/ATPase, Prp16, is involved (Ohrt et al., submitted). Thus, these studies have already paved the way for a deeper understanding of the action of Prp16, a crucial RNA helicase essential for step 2 catalysis. Additional studies including essential RNA helicases/ATPases required after step 2 catalysis, as for example Prp22 and Prp43, will also be undertaken in the future, to follow structural changes and the kinetics of protein recruitment/release during their action by dcFCCS and FRET (with Prof. J. Enderlein).

Additional main goals will also be to investigate molecular details of the transformation of the yeast Commitment complex to A complex and the pre-catalytic $\mathrm{B}$ to $\mathrm{B}^{\text {act }}$ complex, both of which involve dramatic structural rearrangements. For example, the latter rearrangement includes the displacement of all U4/U6 proteins and the stable integration of about 20 new proteins [i.e. the Prp19 (NTC) complex and the NTC-related proteins] into the newly formed $\mathrm{B}^{\text {act }}$ complex (Fabrizio et al., 2009). This will be performed by complementing purified $\mathrm{B}$ complexes with recombinantly 
expressed NTC and NTC-related proteins (in collaboration with Dr. Vlad Pena). With this system we will dissect the requirements for the Brr2-mediated dissociation of the U4/U6 base pairing which initiates activation and the role of proteins in restructuring the U6 and U2 snRNAs and in assembling the catalytic core RNP domain. Additionally, our isolated $\mathrm{CC} 2$ could be used for in vitro reconstitution of A complexes upon addition of purified U2 snRNPs and recombinant Prp5.

In collaboration with Prof. H. Stark's group, we have obtained a 3D Cryo-EM structure of the yeast $\mathrm{B}^{\text {act }}$ complex at $20-25 \AA$ resolution. To learn more about the structural organisation of individual snRNPs, we will localise important proteins and RNA regions within the $\mathrm{B}^{\text {act }}$ complex by immunoelectron microscopy. Using genetically tagged proteins, it would now be possible to map the position of selected proteins (e.g., Cwc2, Prp2 and Prp19) in purified yeast $\mathrm{B}^{\text {act }}$ complexes, providing initial insight into the location of the spliceosome's catalytic centre. A second major focus will be to determine the spliceosome's 3D structure at higher resolution, which we will pursue mainly by a combination of single-particle electron cryomicroscopy (with Prof. H. Stark). Our EM studies will be conducted mainly on reconstituted and purified yeast spliceosomes - with the hope of isolating sufficient quantities of all of the interesting intermediates formed during spliceosome activation and catalysis with the goal of obtaining cryo-EM structures with 10-15 A resolution or even higher. In collaboration with Prof. H. Stark, our laboratory is currently testing a variety of methods, including the optimization of buffer and $\mathrm{pH}$ conditions and mild crosslinking procedures, to optimize stabilization and thus reduce conformational heterogeneity of spliceosomes. At the same time, we will extend our EM studies to locate specific proteins and RNA regions to other spliceosomal complexes (i.e. B and C). The topographical data obtained in this way, in combination with biochemical and cross linking data on the spatial organisation of RNAs and proteins, will be of great value for the interpretation of the 3D cryo-EM structures. With the availability of $3 \mathrm{D}$ cryo-EM maps of yeast spliceosomes at higher resolution in the near future, crystal structures of individual spliceosomal proteins can be fit into the 3D EM maps, and should thus greatly facilitate our understanding of the organisation of the spliceosome. 


\section{References}

Abovich, N., P. Legrain, et al. (1990). "The yeast PRP6 gene encodes a U4/U6 small nuclear ribonucleoprotein particle (snRNP) protein, and the PRP9 gene encodes a protein required for U2 snRNP binding." Mol. Cell Biol. 10(12): 6417-6425.

Abu Dayyeh, B. K., T. K. Quan, et al. (2002). "Probing interactions between the U2 small nuclear ribonucleoprotein and the DEAD-box protein, Prp5." J Biol Chem 277(23): 20221-20233.

Arenas, J. E. and J. N. Abelson (1997). "Prp43: An RNA helicase-like factor involved in spliceosome disassembly." Proc. Natl. Acad. Sci. USA 94(22): 1179811802.

Bach, M. and R. Lührmann (1991). "Protein-RNA interactions in 20S U5 snRNPs." Biochim. Biophys. Acta 1088(1): 139-143.

Bach, M., G. Winkelmann, et al. (1989). "20S small nuclear ribonucleoprotein U5 shows a surprisingly complex protein composition." Proc. Natl. Acad. Sci. USA 86(16): 6038-6042.

Bartels, C., C. Klatt, et al. (2002). "The ribosomal translocase homologue Snu114p is involved in unwinding U4/U6 RNA during activation of the spliceosome." EMBO Reports 3(9): 875-880.

Bartels, C., H. Urlaub, et al. (2003). "Mutagenesis Suggests Several Roles of Snu114p in Pre-mRNA Splicing." J Biol Chem 278(30): 28324-28334.

Behzadnia, N., M. M. Golas, et al. (2007). "Composition and three-dimensional EM structure of double affinity-purified, human prespliceosomal A complexes." Embo J 26(6): 1737-1748.

Bessonov, S., M. Anokhina, et al. (2010). "Characterization of purified human Bact spliceosomal complexes reveals compositional and morphological changes

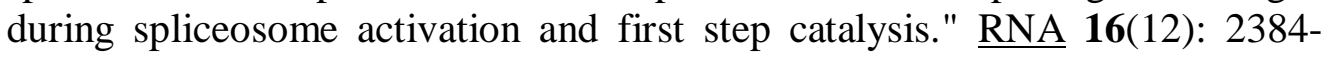
2403.

Bessonov, S., M. Anokhina, et al. (2008). "Isolation of an active step I spliceosome and composition of its RNP core." Nature 452(7189): 846-850.

Blum (1987). "Improved silver staining of plant proteins, RNA and DNA in polyacrylamide gels." Electrophoresis.

Boehringer, D., E. M. Makarov, et al. (2004). "Three-dimensional structure of a precatalytic human spliceosomal complex B." Nat Struct Mol Biol 11(5): 463468.

Boon, K. L., T. Auchynnikava, et al. (2006). "Yeast ntr1/spp382 mediates prp43 function in postspliceosomes." Mol Cell Biol 26(16): 6016-6023.

Brow, D. A. (2002). "Allosteric cascade of spliceosome activation." Annu. Rev. Genet. 36: 333-360.

Brow, D. A. and C. Guthrie (1988). "Spliceosomal RNA U6 is remarkably conserved from yeast to mammals." Nature 334(6179): 213-218.

Caspary, F. and B. Séraphin (1998). "The yeast U2A'/U2B complex is required for pre-spliceosome formation." EMBO J. 17(21): 6348-6358.

Chan, S. P., D. I. Kao, et al. (2003). "The Prp19p-associated complex in spliceosome activation." Science 302(5643): 279-282.

Chanfreau, G., S. A. Elela, et al. (1997). "Alternative 3'-end processing of U5 snRNA by RNase III." Genes Dev 11(20): 2741-2751. 
Cheng, S. C. (1994). "Formation of the yeast splicing complex A1 and association of the splicing factor PRP19 with the pre-mRNA are independent of the 3 ' region of the intron." Nucleic Acids Res. 22(9): 1548-1554.

Company, M., J. Arenas, et al. (1991). "Requirement of the RNA helicase-like protein PRP22 for release of messenger RNA from spliceosomes [see comments]." Nature (London) 349(6309): 487-493.

Cordin, O., D. Hahn, et al. (2012). "Structure, function and regulation of spliceosomal RNA helicases." Curr Opin Cell Biol 24(3): 431-438.

Dalbadie-McFarland, G. and J. Abelson (1990). "PRP5: a helicase-like protein required for mRNA splicing in yeast." Proc. Natl. Acad. Sci. USA 87(11): 4236-4240.

Dannenberg, J., P. Fabrizio, et al. (2012). Affinity purification of spliceosomal and small nuclear ribonucleoprotein complexes. Handbook of RNA biochemistry; Weinheim: Wiley-VCH. 2.Ed., (in Press).

Das, R., Z. Zhou, et al. (2000). "Functional association of U2 snRNP with the ATPindependent spliceosomal complex E." Mol. Cell 5(5): 779-787.

Deckert, J., K. Hartmuth, et al. (2006). "Protein composition and electron microscopy structure of affinity-purified human spliceosomal B complexes isolated under physiological conditions." Mol Cell Biol 26(14): 5528-5543.

Dreyfuss, G., V. N. Kim, et al. (2002). "Messenger-RNA-binding proteins and the messages they carry." Nat Rev Mol Cell Biol 3(3): 195-205.

Dziembowski, A., A. P. Ventura, et al. (2004). "Proteomic analysis identifies a new complex required for nuclear pre-mRNA retention and splicing." EMBO J 23(24): 4847-4856.

Fabrizio, P. and J. Abelson (1990). "Two domains of yeast U6 small nuclear RNA required for both steps of nuclear precursor messenger RNA splicing." Science 250(4979): 404-409.

Fabrizio, P., J. Dannenberg, et al. (2009). "The evolutionarily conserved core design of the catalytic activation step of the yeast spliceosome." Mol Cell 36(4): 593608.

Fabrizio, P., B. Laggerbauer, et al. (1997). "An evolutionarily conserved U5 snRNPspecific protein is a GTP-binding factor closely related to the ribosomal translocase EF-2." EMBO J. 16(13): 4092-4106.

Fabrizio, P., D. S. McPheeters, et al. (1989). "In vitro assembly of yeast U6 snRNP: a functional assay." Genes Dev 3(12B): 2137-2150.

Fenn, J. B., M. Mann, et al. (1989). "Electrospray ionization for mass spectrometry of large biomolecules." Science 246(4926): 64-71.

Földes-Papp, Z. (2005). "How the molecule number is correctly quantified in twocolor fluorescence cross-correlation spectroscopy: corrections for cross-talk and quenching in experiments." Curr Pharm Biotechnol 6(6): 437-444.

Foldes-Papp, Z. and R. Rigler (2001). "Quantitative two-color fluorescence crosscorrelation spectroscopy in the analysis of polymerase chain reaction." Biol Chem 382(3): 473-478.

Fourmann, J. B., J. Schmitzova, et al. (2013). "Dissection of the factor requirements for spliceosome disassembly and the elucidation of its dissociation products using a purified splicing system." Genes Dev 27(4): 413-428.

Frank, D. N., H. Roiha, et al. (1994). "Architecture of the U5 small nuclear RNA." Mol Cell Biol 14(3): 2180-2190. 
Giaever, G., A. M. Chu, et al. (2002). "Functional profiling of the Saccharomyces cerevisiae genome." Nature 418(6896): 387-391.

Golas, M. M., B. Sander, et al. (2003). "Molecular Architecture of the Multiprotein Splicing Factor SF3b." Science 300(5621): 980-984.

Goldfeder, M. B. and C. C. Oliveira (2008). "Cwc24p, a novel Saccharomyces cerevisiae nuclear ring finger protein, affects pre-snoRNA U3 splicing." J Biol Chem 283(5): 2644-2653.

Gottschalk, A., G. Neubauer, et al. (1999). "Identification by mass spectrometry and functional analysis of novel proteins of the yeast [U4/U6.U5] tri-snRNP." Embo J 18(16): 4535-4548.

Gottschalk, A., G. Neubauer, et al. (1999). "Identification by mass spectrometry and functional analysis of novel proteins of the yeast [U4/U6.U5] tri-snRNP." EMBO J. 18(16): 4535-4548.

Gottschalk, A., J. Tang, et al. (1998). "A comprehensive biochemical and genetic analysis of the yeast U1 snRNP reveals five novel proteins." RNA 4(4): 374393.

Gozani, O., J. Potashkin, et al. (1998). "A potential role for U2AF-SAP 155 interactions in recruiting U2 snRNP to the branch site." Mol. Cell Biol. 18(8): 4752-4760.

Hacker, I., B. Sander, et al. (2008). "Localization of Prp8, Brr2, Snu114 and U4/U6 proteins in the yeast tri-snRNP by electron microscopy." Nat Struct Mol Biol 15(11): 1206-1212.

Hartmuth, K., H. Urlaub, et al. (2002). "Protein composition of human prespliceosomes isolated by a tobramycin affinity-selection method." Proc Natl Acad Sci U S A 99(26): 16719-16724.

Haustein, E. and P. Schwille (2007). "Fluorescence correlation spectroscopy: novel variations of an established technique." Annu Rev Biophys Biomol Struct 36: 151-169.

Herold, N., C. L. Will, et al. (2009). "Conservation of the protein composition and electron microscopy structure of Drosophila melanogaster and human spliceosomal complexes." Mol Cell Biol 29(1): 281-301.

Hilliker, A. K., M. A. Mefford, et al. (2007). "U2 toggles iteratively between the stem IIa and stem IIc conformations to promote pre-mRNA splicing." Genes Dev 21(7): 821-834.

Hogg, R., J. C. McGrail, et al. "The function of the NineTeen Complex (NTC) in regulating spliceosome conformations and fidelity during pre-mRNA splicing." Biochem Soc Trans 38(4): 1110-1115.

Jurica, M. S., L. J. Licklider, et al. (2002). "Purification and characterization of native spliceosomes suitable for three-dimensional structural analysis." RNA 8(4): 426-439.

Jurica, M. S. and M. J. Moore (2002). "Capturing splicing complexes to study structure and mechanism." Methods 28(3): 336-345.

Kastner, B., N. Fischer, et al. (2008). "GraFix: sample preparation for single-particle electron cryomicroscopy." Nat Methods 5(1): 53-55.

Kettling, U., A. Koltermann, et al. (1998). "Real-time enzyme kinetics monitored by dual-color fluorescence cross-correlation spectroscopy." Proc Natl Acad Sci U S A 95(4): 1416-1420. 
Kim, S. H. and R. J. Lin (1996). "Spliceosome activation by PRP2 ATPase prior to the first transesterification reaction of pre-mRNA splicing." Mol Cell Biol 16(12): 6810-6819.

Kim, S. H., J. Smith, et al. (1992). "The purified yeast pre-mRNA splicing factor PRP2 is an RNA-dependent NTPase." EMBO J 11(6): 2319-2326.

Kiss, T. and B. E. Jady (2004). "Functional characterization of 2'-O-methylation and pseudouridylation guide RNAs." Methods Mol Biol 265: 393-408.

Kistler, A. L. and C. Guthrie (2001). "Deletion of MUD2, the yeast homolog of U2AF65, can bypass the requirement for sub2, an essential spliceosomal ATPase." Genes Dev 15(1): 42-49.

Konarska, M. M., J. Vilardell, et al. (2006). "Repositioning of the reaction intermediate within the catalytic center of the spliceosome." Mol Cell 21(4): 543-553.

Kosowski, T. R., H. R. Keys, et al. (2009). "DExD/H-box Prp5 protein is in the spliceosome during most of the splicing cycle." RNA 15(7): 1345-1362.

Kress, T. L., N. J. Krogan, et al. (2008). "A single SR-like protein, Np13, promotes pre-mRNA splicing in budding yeast." Mol Cell 32(5): 727-734.

Kretzner, L., A. Krol, et al. (1990). "Saccharomyces cerevisiae U1 small nuclear RNA secondary structure contains both universal and yeast-specific domains." Proc Natl Acad Sci U S A 87(2): 851-855.

Laemmli, U. K. (1970). "Cleavage of structural proteins during the assembly of the head of bacteriophage T4." Nature 227(5259): 680-685.

Lardelli, R. M., J. X. Thompson, et al. "Release of SF3 from the intron branchpoint activates the first step of pre-mRNA splicing." RNA 16(3): 516-528.

Lesser, C. F. and C. Guthrie (1993). "Mutations in U6 snRNA that alter splice site specificity: implications for the active site." Science 262(5142): 1982-1988.

Liao, X. C., H. V. Colot, et al. (1992). "Requirements for U2 snRNP addition to yeast pre-mRNA." Nucleic Acids Res. 20(16): 4237-4245.

Liu, Y. C., H. C. Chen, et al. (2007). "A novel splicing factor, Yju2, is associated with NTC and acts after Prp2 in promoting the first catalytic reaction of pre-mRNA splicing." Mol Cell Biol 27(15): 5403-5413.

Long, J. C. and J. F. Caceres (2009). "The SR protein family of splicing factors: master regulators of gene expression." Biochem J 417(1): 15-27.

Lopez, P. J. and B. Seraphin (1999). "Genomic-scale quantitative analysis of yeast pre-mRNA splicing: implications for splice-site recognition." Rna 5(9): 11351137.

Makarov, E. M., O. V. Makarova, et al. (2002). "Small Nuclear Ribonucleoprotein Remodeling During Catalytic Activation of the Spliceosome." $\underline{\text { Science }}$ 298(5601): 2205-2208.

Makarova, O. V., E. M. Makarov, et al. (2002). "Protein 61K, encoded by a gene (PRPF31) linked to autosomal dominant retinitis pigmentosa, is required for U4/U6*U5 tri-snRNP formation and pre-mRNA splicing." EMBO J 21(5): 1148-1157.

Makarova, O. V., E. M. Makarov, et al. (2004). "A subset of human 35S U5 proteins, including Prp19, function prior to catalytic step 1 of splicing." EMBO J 23(12): 2381-2391.

Manley, J. L. and A. R. Krainer (2010). "A rational nomenclature for serine/argininerich protein splicing factors (SR proteins)." Genes Dev 24(11): 1073-1074. 
Mann, M., R. C. Hendrickson, et al. (2001). "Analysis of proteins and proteomes by mass spectrometry." Annu Rev Biochem 70: 437-473.

McPheeters, D. S. and P. Muhlenkamp (2003). "Spatial organization of protein-RNA interactions in the branch site-3' splice site region during pre-mRNA splicing in yeast." Mol Cell Biol 23(12): 4174-4186.

Merril, C. R., D. Goldman, et al. (1981). "Ultrasensitive stain for proteins in polyacrylamide gels shows regional variation in cerebrospinal fluid proteins." Science 211(4489): 1437-1438.

Moehle, E. A., C. J. Ryan, et al. (2012). "The yeast SR-like protein Npl3 links chromatin modification to mRNA processing." PLoS Genet 8(11): e1003101.

Moore, M. J., C. C. Query, et al. (1993). Splicing of precursors to mRNA by the spliceosome. RNA World. A. Gesteland. Cold Spring Harbor, New York, Cold Spring Harbor Labratory Press: 303-357.

Moore, M. J. and P. A. Sharp (1993). "Evidence for two active sites in the spliceosome provided by stereochemistry of pre-mRNA splicing." Nature (London) 365(6444): 364-368.

Mouaikel, J., C. Verheggen, et al. (2002). "Hypermethylation of the cap structure of both yeast snRNAs and snoRNAs requires a conserved methyltransferase that is localized to the nucleolus." Mol Cell 9(4): 891-901.

Mütze, J., T. Ohrt, et al. (2011). "Fluorescence correlation spectroscopy in vivo." Laser \& Photonics Reviews 5(1): 52-67.

Neubauer, G., A. Gottschalk, et al. (1997). "Identification of the proteins of the yeast U1 small nuclear ribonucleoprotein complex by mass spectrometry." Proc. Natl. Acad. Sci. USA 94(2): 385-390.

Newman, A. J. (1997). "The role of U5 snRNP in pre-mRNA splicing." EMBO J 16(19): 5797-5800.

Nilsen, T. W. (1998). RNA-RNA interactions in nuclear pre-mRNA splicing. RNA Structure and Function. R. W. S. a. M.Grundber-Manago. Cold Spring Harbor, New York., Cold Spring Harbor Laboratory Press: 279-307.

O'Day, C. L., G. Dalbadie-McFarland, et al. (1996). "The Saccharomyces cerevisiae Prp5 protein has RNA-dependent ATPase activity with specificity for U2 small nuclear RNA." J. Biol. Chem. 271(52): 33261-33267.

Ohi, M. D. and K. L. Gould (2002). "Characterization of interactions among the Cef1p-Prp19p-associated splicing complex." RNA 8(6): 798-815.

Ohi, M. D., A. J. Link, et al. (2002). "Proteomics analysis reveals stable multiprotein complexes in both fission and budding yeasts containing Myb-related Cdc5p/Cef1p, novel pre-mRNA splicing factors, and snRNAs." Mol Cell Biol 22(7): 2011-2024.

Ohrt, T., M. Prior, et al. (2012). "Prp2-mediated protein rearrangements at the catalytic core of the spliceosome as revealed by dcFCCS." RNA 18(6): 12441256.

Ohrt, T., W. Staroske, et al. "Fluorescence cross-correlation spectroscopy reveals mechanistic insights into the effect of 2'-O-methyl modified siRNAs in living cells." Biophys J 100(12): 2981-2990.

Pandit, S., B. Lynn, et al. (2006). "Inhibition of a spliceosome turnover pathway suppresses splicing defects." Proc Natl Acad Sci U S A 103(37): 1370013705. 
Perriman, R., I. Barta, et al. (2003). "ATP requirement for Prp5p function is determined by Cus2p and the structure of U2 small nuclear RNA." Proc Nat1 Acad Sci U S A 100(24): 13857-13862.

Perriman, R. J. and M. Ares, Jr. (2007). "Rearrangement of competing U2 RNA helices within the spliceosome promotes multiple steps in splicing." Genes Dev 21(7): 811-820.

Query, C. C., M. J. Moore, et al. (1994). "Branch nucleophile selection in pre-mRNA splicing: evidence for the bulged duplex model." Genes Dev 8(5): 587-597.

Rasche, N., O. Dybkov, et al. (2012). "Cwc2 and its human homologue RBM22 promote an active conformation of the spliceosome catalytic centre." EMBO J 31(6): 1591-1604.

Ricka, J. and T. Binkert (1989). "Direct measurement of a distinct correlationfunction by fluorescence cross-correlation." Physical Review A 39(5): 26462652.

Rosbash, M. and B. Séraphin (1991). "Who's on first? The U1 snRNP-5' splice site interaction and splicing." Trends Biochem. Sci. 16(5): 187-190.

Ruby, S. W., T. H. Chang, et al. (1993). "Four yeast spliceosomal proteins (PRP5, PRP9, PRP11, and PRP21) interact to promote U2 snRNP binding to premRNA." Genes Dev 7(10): 1909-1925.

Rymond, B. C. and M. Rosbash (1985). "Cleavage of 5' splice site and lariat formation are independent of 3 ' splice site in yeast mRNA splicing." Nature (London) 317(6039): 735-737.

Rymond, B. C., D. D. Torrey, et al. (1987). "A novel role for the 3' region of introns in pre-mRNA splicing of Saccharomyces cerevisiae." Genes Dev 1(3): 238246.

Sambrook, J., D. W. Russell, et al. (1989). "Molecular Cloning: A Laboratory Manual." Cold Spring Harbor, NY: Cold Spring Harbor Laboratory Press.

Sapra, A. K., P. Khandelia, et al. (2008). "The splicing factor Prp17 interacts with the U2, U5 and U6 snRNPs and associates with the spliceosome pre- and postcatalysis." Biochem J 416(3): 365-374.

Schwer, B. and C. H. Gross (1998). "Prp22, a DExH-box RNA helicase, plays two distinct roles in yeast pre-mRNA splicing." EMBO J 17(7): 2086-2094.

Schwille, P., F. J. Meyer-Almes, et al. (1997). "Dual-color fluorescence crosscorrelation spectroscopy for multicomponent diffusional analysis in solution." Biophys J 72(4): 1878-1886.

Shevchenko, A., M. Wilm, et al. (1996). "Mass spectrometric sequencing of proteins silver-stained polyacrylamide gels." Anal. Chem. 68(5): 850-858.

Shevchenko, A., M. Wilm, et al. (1996). "Mass spectrometric sequencing of proteins silver-stained polyacrylamide gels." Anal Chem 68(5): 850-858.

Shuster, E. O. and C. Guthrie (1988). "Two conserved domains of yeast U2 snRNA are separated by 945 nonessential nucleotides." Cell 55(1): 41-48.

Singh, R. and R. Reddy (1989). "Gamma-monomethyl phosphate: a cap structure in spliceosomal U6 small nuclear RNA." Proc Natl Acad Sci U S A 86(21): 8280-8283.

Singh, R. and J. Valcarcel (2005). "Building specificity with nonspecific RNAbinding proteins." Nat Struct Mol Biol 12(8): 645-653.

Small, E. C., S. R. Leggett, et al. (2006). "The EF-G-like GTPase Snu114p regulates spliceosome dynamics mediated by Brr2p, a DExD/H box ATPase." $\underline{\text { Mol Cell }}$ 23(3): 389-399. 
Sontheimer, E. J. (2001). "The spliceosome shows its metal." Nat Struct Biol 8(1): 11-13.

Spingola, M., L. Grate, et al. (1999). "Genome-wide bioinformatic and molecular analysis of introns in Saccharomyces cerevisiae." RNA 5(2): 221-234.

Staley, J. P. and C. Guthrie (1998). "Mechanical devices of the spliceosome: motors, clocks, springs, and things." Cell 92(3): 315-326.

Stevens, S. W., I. Barta, et al. (2001). "Biochemical and genetic analyses of the U5, U6, and U4/U6 x U5 small nuclear ribonucleoproteins from Saccharomyces cerevisiae." RNA 7(11): 1543-1553.

Stevens, S. W., D. E. Ryan, et al. (2002). "Composition and Functional Characterization of the Yeast Spliceosomal Penta-snRNP." Mol. Cell 9(1): 3144.

Studier, F. W. (2005). "Protein production by auto-induction in high density shaking cultures." Protein Expr Purif 41(1): 207-234.

Tanaka, N., A. Aronova, et al. (2007). "Ntr1 activates the Prp43 helicase to trigger release of lariat-intron from the spliceosome." Genes Dev 21(18): 2312-2325.

Tarn, W. Y., K. R. Lee, et al. (1993). "Yeast precursor mRNA processing protein PRP19 associates with the spliceosome concomitant with or just after dissociation of U4 small nuclear RNA." PNAS 90(22): 10821-10825.

Teigelkamp, S., M. McGarvey, et al. (1994). "The splicing factor PRP2, a putative RNA helicase, interacts directly with pre-mRNA." EMBO J. 13(4): 888-897.

Tsai, R. T., R. H. Fu, et al. (2005). "Spliceosome disassembly catalyzed by Prp43 and its associated components Ntr1 and Ntr2." Genes Dev 19(24): 2991-3003.

Tsai, R. T., C. K. Tseng, et al. (2007). "Dynamic interactions of Ntr1-Ntr2 with Prp43 and with U5 govern the recruitment of Prp43 to mediate spliceosome disassembly." Mol Cell Biol 27(23): 8027-8037.

Tsai, W. Y., Y. T. Chow, et al. (1999). "Cef1p is a component of the Prp19passociated complex and essential for pre-mRNA splicing." J. Biol. Chem. 274(14): 9455-9462.

Tseng, C. K., H. L. Liu, et al. (2011). "DEAH-box ATPase Prp16 has dual roles in remodeling of the spliceosome in catalytic steps." RNA 17(1): 145-154.

Umen, J. G. and C. Guthrie (1995). "Prp16p, Slu7p, and Prp8p interact with the 3' splice site in two distinct stages during the second catalytic step of pre-mRNA splicing." RNA 1(6): 584-597.

Valadkhan, S. and Y. Jaladat (2010). "The spliceosomal proteome: at the heart of the largest cellular ribonucleoprotein machine." Proteomics 10(22): 4128-4141.

Valadkhan, S. and Y. Jaladat (2011). "The spliceosomal proteome: at the heart of the largest cellular ribonucleoprotein machine." Proteomics 10(22): 4128-4141.

Vijayraghavan, U., R. Parker, et al. (1986). "Mutations in conserved intron sequences affect multiple steps in the yeast splicing pathway, particularly assembly of the spliceosome." EMBO J. 5(7): 1683-1695.

Wahl, M. C., C. L. Will, et al. (2009). "The spliceosome: design principles of a dynamic RNP machine." Cell 136(4): 701-718.

Wang, Q. and B. C. Rymond (2003). "Rds3p is required for stable U2 snRNP recruitment to the splicing apparatus." Mol Cell Biol 23(20): 7339-7349.

Warkocki, Z., P. Odenwalder, et al. (2009). "Reconstitution of both steps of Saccharomyces cerevisiae splicing with purified spliceosomal components." Nat Struct Mol Biol 16(12): 1237-1243. 
Wiest, D. K., C. L. O'Day, et al. (1996). "In vitro studies of the Prp9.Prp11.Prp21 complex indicate a pathway for $\mathrm{U} 2$ small nuclear ribonucleoprotein activation." J. Biol. Chem. 271(52): 33268-33276.

Will, C. L. and R. Luhrmann (2011). "Spliceosome structure and function." Cold Spring Harb Perspect Biol 3(7).

Will, C. L. and R. Lührmann (2001). "Spliceosomal UsnRNP biogenesis, structure and function." Curr. Opin. Cell. Biol. 13(3): 290-301.

Will, C. L. and R. Lührmann (2006). "Spliceosome Structure and Function." The RNA World.

Winzeler, E. A., D. D. Shoemaker, et al. (1999). "Functional characterization of the S. cerevisiae genome by gene deletion and parallel analysis." Science 285(5429): 901-906.

$\mathrm{Xu}$, Y. Z. and C. C. Query (2007). "Competition between the ATPase Prp5 and Branch Region-U2 snRNA Pairing Modulates the Fidelity of Spliceosome Assembly." Mol Cell 28(5): 838-849.

Yan, D., R. Perriman, et al. (1998). "CUS2, a yeast homolog of human Tat-SF1, rescues function of misfolded U2 through an unusual RNA recognition motif." Mol. Cell Biol. 18(9): 5000-5009.

Yean, S. L. and R. J. Lin (1991). "U4 small nuclear RNA dissociates from a yeast spliceosome and does not participate in the subsequent splicing reaction." Mol. Cell Biol. 11(11): 5571-5577.

Yean, S. L., G. Wuenschell, et al. (2000). "Metal-ion coordination by U6 small nuclear RNA contributes to catalysis in the spliceosome." Nature 408(6814): 881-884.

Zhang, D. and M. Rosbash (1999). "Identification of eight proteins that cross-link to pre-mRNA in the yeast commitment complex." Genes Dev 13(5): 581-592.

Zhou, Z., L. J. Licklider, et al. (2002). "Comprehensive proteomic analysis of the human spliceosome." Nature 419(6903): 182-185. 


\section{Apendix}

\subsection{List of abbreviations}

3'SS

$3^{6}$ splice site

5'SS

5' splice site

${ }^{\circ} \mathrm{C}$

degree celsius

A

adenosine

ADP

adenosine-5'-diphosphate

AMP-PCP

5-adenylyl methylenediphosphonate

APS

ammonium peroxy sulfate

ATP

adenosine-5'-triphosphate

bp

basepair

BPS

branch point sequence

C

cytosine

$\mathrm{CC}$

Commitment complex

$\mathrm{Ci}$

Curie

CV

column volumes

$\mathrm{Da}$

Dalton

dcFCCS

dual-color Fluorescence cross correlation spectroscopy

DNA

deoxyribonucleic acid

dNTPs

deoxynucleotide-5 5 -triphosphates

DTT

1,4- dithiothreitol

EDTA

ethylendiamine- $\mathrm{N}, \mathrm{N}, \mathrm{N}^{\star}, \mathrm{N}^{\star}$-tetraacetic acid

EM

Electron microscopy

fmol

femtomole

G

guanosine

G-75/150

gradient buffer containing $75 \mathrm{mM}$ or $150 \mathrm{mM} \mathrm{KCl}$

GDP

guanosine-5'-diphosphate

GTP

gunosine-5'-triphosphate

$\mathrm{h}$

hour(s)

$\mathrm{kDa}$

kilo-Dalton

1

liter 


\begin{tabular}{|c|c|}
\hline Lsm & Like-Sm \\
\hline$\mu$ & micro \\
\hline$\mu l$ & microliter \\
\hline$\mu \mathrm{m}$ & micrometer \\
\hline$\mu \mathrm{M}$ & micromolar \\
\hline M & molar \\
\hline $\min$ & minute \\
\hline $\mathrm{ml}$ & milliliter \\
\hline $\mathrm{mM}$ & milimolar \\
\hline mRNA & messenger RNA \\
\hline MS & mass spectrometry \\
\hline $\mathrm{n}$ & nano \\
\hline $\mathrm{nM}$ & nanomolar \\
\hline nmol & nmol \\
\hline NP-40 & Nonidet P-40 \\
\hline $\mathrm{nt}$ & nucleotide \\
\hline NTPs & nucleotide-5'-triphosphates \\
\hline OD & optical density \\
\hline PAA & poly-acrylamide \\
\hline PAGE & poly-acrylamide gel electrophoresis \\
\hline PCI & phenol-chloroform-isoamylalcohol \\
\hline PCR & polymerase chain reaction \\
\hline PEG & polyethylene glycol \\
\hline pmol & picomole \\
\hline pre-mRNA & pre-messenger RNA \\
\hline Prp & pre-mRNA processing \\
\hline RNA & ribonucleic acid \\
\hline RNP & ribonucleoprotein \\
\hline RT & room temperature \\
\hline S & Svedberg \\
\hline S. cerevisiae & Saccharomyces cerevisiae \\
\hline SDS & sodium dodecylsulfate \\
\hline Sm & "Smith", patient in which Sm proteins were first discovered \\
\hline
\end{tabular}


snRNA

snRNP

$\mathrm{T}$

TBE

TE

TEMED

Ts

$\mathrm{U}$

U snRNA

U snRNP

UV

YPD small nuclear ribonucleic acid

small nuclear ribonucleoprotein

thymidine

tris-borate-EDTA buffer

Tris-EDTA buffer

$\mathrm{N}, \mathrm{N}, \mathrm{N}$ ', N'-tetramethylethylendiamine

temperature-sensitive

uridine

uridine rich small nuclear ribonucleic acid

uridine rich small nuclear ribonucleoprotein

ultraviolet

yeast extract, peptone 


\subsection{Curriculum vitae}

Julia Dannenberg

Geburtsdatum: 27. August 1982

Geburtsort: Braunschweig

Staatsangehörigkeit: deutsch

\section{Schulbildung}

1989 bis 1995

Grundschule, Hermannshagen (Hann.Münden)

1995 bis 2002

Grotefend-Gymnasium Hann.Münden

Abitur Juni 2002

\section{Studium}

10/2002 bis 03/2008 Studium an der Georg-August-Universität Göttingen im

\section{Diplomstudiengang Biologie}

Hauptfach: Botanik

1. Nebenfach: Immunologie

2. Nebenfach: Physik

Mündliche Prüfungen im Mai 2007

Diplomarbeit März 2007 bis Februar 2008

Titel der Arbeit : , Isolierung und Charakterisierung der

Proteinzusammensetzung von Spleißosomen aus der Hefe

S.cerevisiae"

angefertigt am MaxPlanck-Institut für biophsykalische Chemie

Göttingen, in der Abteilung für Zelluläre Biochemie

Betreuer: $\quad$ Prof. Reinhard Lührmann

Korreferent: $\quad$ Prof. Ralf Ficner

\section{Promotion}

09/2008 bis 03/2013 Promotion bei Prof. Dr. Reinhard Lührmann, Abteilung Zelluläre Biochemie, Max-Planck-Institut für biophysikalische Chemie, Göttingen 
Titel der Arbeit: "Biochemical and structural characterization of spliceosomes purified at defined stages of assembly from the yeast S. cerevisiae"

\subsection{List of publications}

Fabrizio P, Dannenberg J, Dube P, Kastner B, Stark H, Urlaub H, Lührmann R. „The evolutionarily conserved core design of the catalytic activation step of the yeast spliceosome.“ (Mol Cell. 2009 Nov 25)

Ohrt T, Prior M, Dannenberg J, Odenwalder P, Dybkov O, Rasche N, Schmitzova J, Gregor I, Fabrizio P, Enderlein J, Luhrmann R. "Prp2-mediated protein rearrangements at the catalytic core of the spliceosome as revealed by dcFCCS". (RNA 2012)

Dannenberg, J., Fabrizio, P., Will, C., \& Lührmann, R. (2012). „Affinity purification of spliceosomal and small nuclear ribonucleoprotein complexes”. In R.K. Hartmann, A.Bindereif, \& A. Schön (Eds.), Handbook of RNA biochemistry (2.ed.(in press). Weinheim: Wiley-VCH.

Ohrt, T., Odenwälder, P., Dannenberg, J., Prior, M., Warkocki, Z., Schmitzová, J., Karaduman, R., Gregor, I., Enderlein, J., Fabrizio, P. and Lührmann, R. "Molecular dissection of step 2 catalysis of yeast pre-mRNA splicing investigated in a purified system" (in press (2013)).

\subsection{Conferences}

"Meeting of the European Associated Laboratory (LEA) on pre-mRNA splicing", 2009, Göttingen

Präsentation eines Posters mit dem Titel: "Isolation and characterization of early spliceosomal complexes and mRNP from the yeast S.cerevisiae”. 
“5 $5^{\text {th }}$ International $\mathrm{PhD}$ student symposium Horizons in Molecular Biology", 2008, Göttingen Präsentation eines Posters mit dem Titel: "The evolutionarily conserved core design of the catalytic activation step of the yeast spliceosome."

“7 $7^{\text {th }}$ International $\mathrm{PhD}$ student symposium Horizons in Molecular Biology”, 2010, Göttingen Präsentation eines Posters mit dem Titel: "Characterization and reconstitution of early spliceosomal complexes isolated from the yeast $S$. cerevisiae"

\subsection{Acknowledgments}

An dieser Stelle möchte ich mich von Herzen bei all denen bedanken, die mich während meiner Doktorarbeit unterstützt und motiviert haben.

Reinhard Lührmann danke ich in erster Linie für die großartige Möglichkeit der Promotion über ein tolles, spannendes Projekt in seiner Abteilung. Ein ganz besonderer Dank gilt ihm aber für seine Großzügigkeit, sein Vertrauen und seine Unterstützung, die er mir in den letzten Jahren entgegengebracht hat und die mir bei der Verwirklichung meines Traumes des Medizinstudiums sehr geholfen und es erst möglich gemacht haben. Vielen Dank dafür, Reinhard;)

Mein ganz besonderer und größter Dank gilt Patrizia Fabrizio „for being the ultrabest supervisor ever „; () !!! Während meiner Arbeit hatte ich die beste Betreuung, die man sich vorstellen und wünschen kann. Ich bedanke mich für die großartige Hilfe und Unterstützung, für die Antworten auf all meine Fragen, die zahlreichen Gespräche und Diskussionen, für das Miteinander-Lachen, für die guten und die schlechten Zeiten und alles was sie mir in dieser Zeit gegeben hat. Vielen Dank für die tolle Zeit, du bist großartig (:)!

Bei Thomas Ohrt bedanke ich mich für die tolle Zusammenarbeit, für seine unbeschreibliche Hilfe und Unterstützung und dafür, dass ich so viel von ihm lernen durfte. Vielen Dank für diese tolle, unvergessliche Zeit und dafür dass du nicht nur ein super Postdoc sondern auch ein toller Freund warst bzw. bist $\odot$ !! 
Ein herzliches Dankeschön geht an die weiteren Mitglieder meines Prüfungsausschusses: Prof. Ralf Ficner, Prof. Jörg Enderlein, Prof. Heike Krebber, Prof. Holger Stark, Prof. Jürgen Wienands

Ein ganz großer Dank geht natürlich an meine Kollegen und Freunde Carsten, Carli, Cornelius, Irina, Nicolas, Norbert, Olex, Peter O., Ramazan und Thomas O. (in alphabetischer Reihenfolge(-))!!! Ohne sie wäre die Zeit nur halb so schön gewesen. Danke für die tolle Zeit, die zahlreichen Gespräche und Diskussionen und den riesen Spass, den wir zusammen hatten und dafür, dass ihr immer ein offenes Ohr für mich hattet:-).

Mira Prior danke ich für ihre ausgezeichnete Arbeit, die tolle und witzige Zeit während unserer gemeinsamen Messzeit (an dieser Stelle auch lieben Dank an Flip (:)) und dafür, dass sie mich in die Geheimnisse der Biophysik eingeweiht hat :).

Thomas Conrad danke ich für den ,just in time delivery service“ gesunder, glücklicher Hefe-Zellen in Kilogramm -Mengen und für die netten Gespräche in der Küche, wenn's dann doch mal wieder länger gedauert hat $;$.

Elke Penka danke ich für die zahlreichen Klonierungen und für ihre große Hilfsbereitschaft, Wiebke Behrens für die Vorbereitung frischer, aktiver und hochmotivierter Hefe-Extrakte:-).

Holger Stark und seiner Abteilung sowie Berthold Kastner danke ich für die tolle Zusammenarbeit und für die Durchführung der EM-Untersuchungen

Monika Raabe, Johanna Lehne, Uwe Pleßmann danke ich für die Durchführung der MS-Analysen.

Henning Urlaub, dem Süßigkeiten-Räuber, danke ich für die zahlreichen lustigen Momente und seine Unterstützung. 
Reinhard Rauhaut danke ich für seine großartige Hilfe in allen Lebenslagen und für die netten Gespräche $(;$

Jana Schmitzova und Vlad Pena für die Hilfe mit rekombinanten Proteinen und eine tolle Zusammenarbeit.

Gabi, Uschi, Gertrud, Claudia, Juliane, Irene, Kami und all den anderen helfenden Händen der Abteilung danke ich für ihre Unterstützung.

Danke Klaus, für die vielen interessanten und witzigen Gespräche und Diskussionen (:)

Ein großes Dankeschön auch an all die anderen Mitglieder der Abteilung für eine tolle Atmosphäre und eine gute Zeit.

Daniel danke ich dafür, dass er immer für mich da war, auch in stressigen Zeiten, und immer ein offenes Ohr für mich hatte.

Und als letztes noch ein riesen Dankeschön an meine Mädels@:! 
Apendix

\subsection{Erklärung}

Hiermit versichere ich, dass die Dissertation mit dem Titel "Biochemical and structural characterization of spliceosomes purified at defined stages of assembly from the yeast S. cerevisiae" von mir selbstständig und ohne unerlaubte Hilfe angefertigt worden ist.

Göttingen, den 05.03.2013

Julia Dannenberg 